University of South Florida

DIGITAL COMMONS

Digital Commons @ University of

@ UNIVERSITY OF SOUTH FLORIDA

South Florida

School of Geosciences Faculty and Staff

Publications

School of Geosciences

2020

\title{
Agua Para el Futuro: Estrategia de Seguridad Hídrica para América Latina y el Caribe
}

\author{
Fernando Bretas \\ Guillermo Casanova \\ Thomas L. Crisman \\ University of South Florida, tcrisman@usf.edu \\ Antonio Embid \\ Liber Martin
}

See next page for additional authors

Follow this and additional works at: https://digitalcommons.usf.edu/geo_facpub

Part of the Earth Sciences Commons

\section{Scholar Commons Citation}

Bretas, Fernando; Casanova, Guillermo; Crisman, Thomas L.; Embid, Antonio; Martin, Liber; and Miralles, Fernando, "Agua Para el Futuro: Estrategia de Seguridad Hídrica para América Latina y el Caribe" (2020). School of Geosciences Faculty and Staff Publications. 2241.

https://digitalcommons.usf.edu/geo_facpub/2241

This Technical Report is brought to you for free and open access by the School of Geosciences at Digital Commons @ University of South Florida. It has been accepted for inclusion in School of Geosciences Faculty and Staff Publications by an authorized administrator of Digital Commons @ University of South Florida. For more information, please contact digitalcommons@usf.edu. 
Authors

Fernando Bretas, Guillermo Casanova, Thomas L. Crisman, Antonio Embid, Liber Martin, and Fernando Miralles 


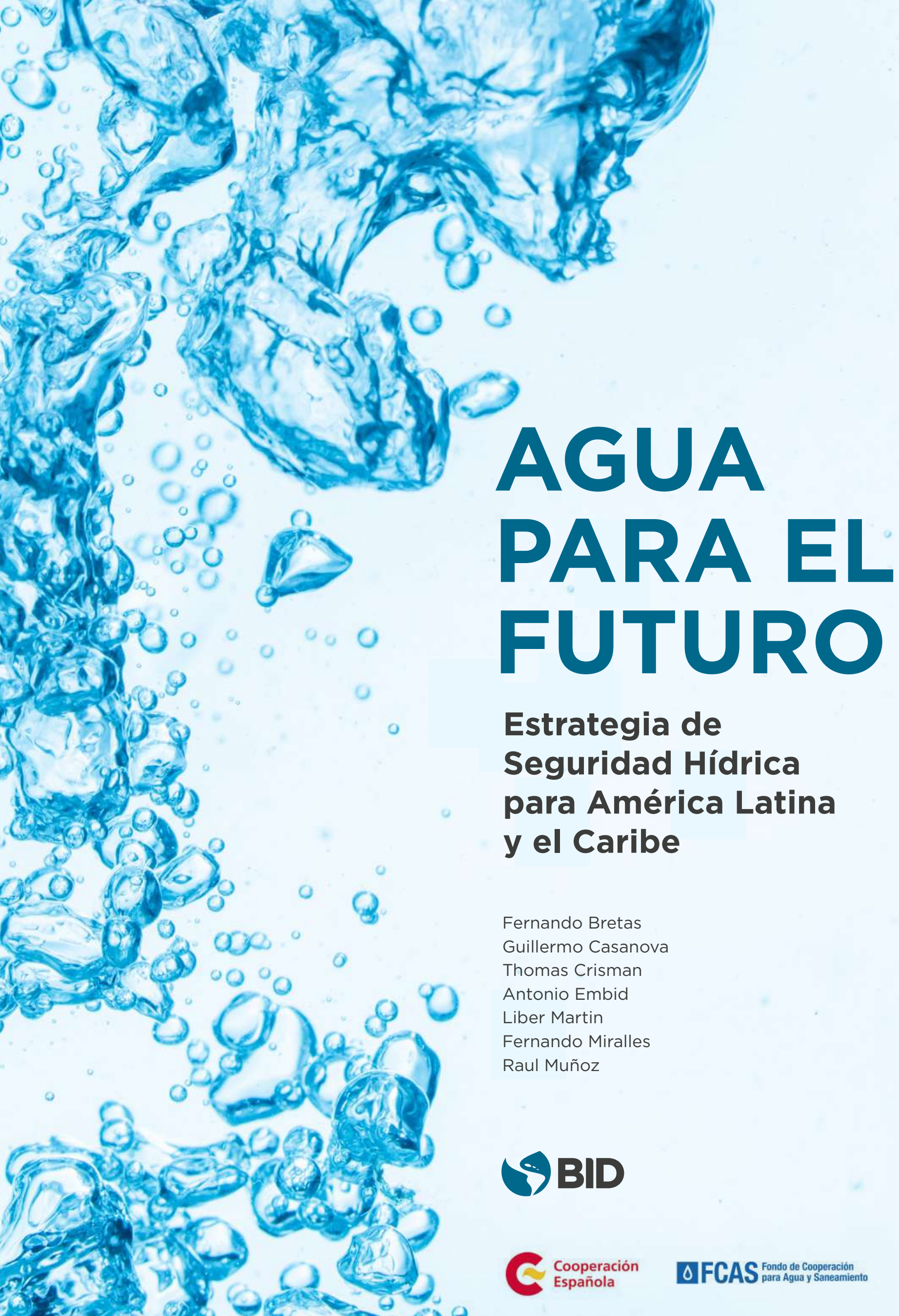




\section{SBID}

\section{AGUA PARA EL FUTURO}

\section{Estrategia de Seguridad Hídrica para América Latina y el Caribe}

\section{Volumen 1: Informe Principal \\ Junio 2019}

Fernando Bretas

Guillermo Casanova

Thomas Crisman

Antonio Embid

Liber Martin

Fernando Miralles

Raul Muñoz (coordinador)

Giulia Carcasci (soporte)

\section{https://www.iadb.org/}

Copyright (c) 2020 Banco Interamericano de Desarrollo. Esta obra se encuentra sujeta a una licencia Creative Commons IGO 3.0 Reconocimiento-NoComercial-SinObrasDerivadas (CC-IGO 3.0 BY-NCND) (https://creativecommons.org/licenses/by-nc-nd/3.0/igo/legalcode) y puede ser reproducida para cualquier uso no-comercial otorgando el reconocimiento respectivoal BID. No se permiten obras derivadas.

Cualquier disputa relacionada con el uso de las obras del BID que no pueda resolverse amistosamente se someterá a arbitraje de conformidad con las reglas de la CNUDMI (UNCITRAL). EI uso del nombre del BID para cualquier fin distinto al reconocimiento respectivo y el uso del logotipo del BID, no están autorizados por esta licencia CC-IGO y requieren de un acuerdo de licencia adicional.

Note que el enlace URL incluye términos y condiciones adicionales de esta licencia.

Las opiniones expresadas en esta publicación son de los autores y no necesariamente reflejan el punto de vista del Banco Interamericano de Desarrollo, de su Directorio Ejecutivo, de la Unión Europea, de la AECID ni de los países que representa.

Diseño y diagramación: Alejandro Scaff Herrera

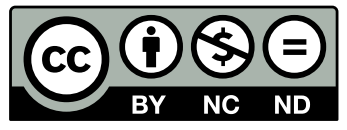




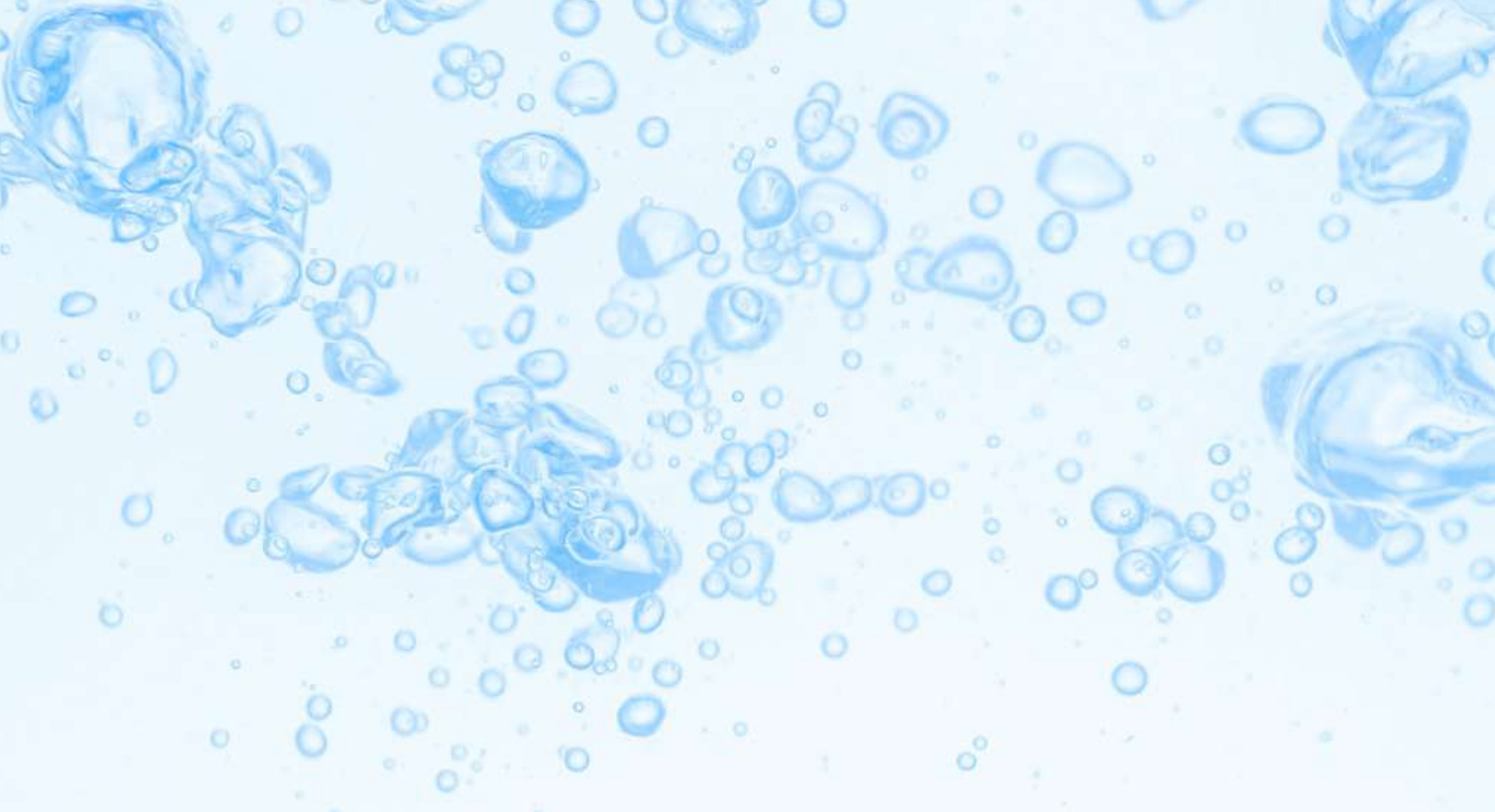

\section{Agradecimientos}

El equipo agradece los comentarios y retroalimentación recibidos durante el desarrollo del documento por Alfred Grunwaldt, Kleber Machado, Mauro Nalesso, y Hector Valdes. Los autores también desean agradecer a todos los colegas del BID que han participado en los talleres de socialización de la Estrategia, y que han enriquecido el valor de este producto: Melissa Barandiaran, Pedro Coli, Maricarmen Esquivel, Lucio Javier Garcia, Francisco Gonzalez, Sergio Lacambra, Maria Alejandra Perroni, Lina Salazar, Keisuke Sasaki, Adrien Vogt-Schilb, David Wilk, y Patricio Zambrano.

Los recursos para elaborar estos estudios proceden de la Facilidad de Inversiones para América Latina (LAIF) de la Unión Europea. En el marco de este instrumento de financiamiento, la Unión Europea firmó un acuerdo con la Agencia Española de Cooperación Internacional para el Desarrollo (AECID) para la gestión del proyecto regional "Promover la adaptación al cambio climático y la gestión integral de los recursos hídricos en el sector de agua y saneamiento en América Latina en el marco del Fondo de Cooperación para Agua y Saneamiento (FCAS)", el cual establece que las actividades relacionadas con asistencias técnicas serán ejecutadas a través del BID. El presente documento hace parte de la Cooperación Técnica "Estrategia de Seguridad Hídrica para América Latina y el Caribe”. 
Índice de Contenido

I. Introducción 5

II. Situación Actual de la Seguridad Hídrica en América Latina y el Caribe $\quad 13$

II.1 Disponibilidad Hídrica 17

II.2 Calidad de Agua, Ambiente y Ecosistemas $\quad 30$

II.3 Aspectos Normativos y de Gobernanza $\quad 47$

II.4 Estado de la Infraestructura Hídrica 54

III. Seguridad Hídrica y la Experiencia del BID 62

III.1 Inventario de Proyectos de Referencia en el BID 65

III.2 Lecciones Aprendidas $\quad 73$

IV. Oportunidades de Innovación en Seguridad Hídrica 84

IV.1 Cambio Climático y Planificación Multisectorial (Nexo) 89

IV.2Infraestructura Hídrica y Soluciones Basadas en la Naturaleza 94

IV.3 Marco Institucional para la Seguridad Hídrica 113

IV.4 Avances en Ciencia y Tecnología 130

V. Estrategia de Seguridad Hídrica para América Latina y el Caribe - 142 Cuencas Sostenibles

$\begin{array}{ll}\text { V.1 Misión y Visión } & 144\end{array}$

$\begin{array}{ll}\text { V.2 Objetivos Estratégicos } & 147\end{array}$

VI. Agua para el Futuro - Plan de Trabajo 2020-2030 166

VI.1 Programas Integrados de Inversión: Políticas e Infraestructura 170

$\begin{array}{ll}\text { VI.2 Programas de Conocimiento } & 179\end{array}$

VI.3 Algunas Consideraciones para Implementación 186

VII. Referencias Bibliográficas 196

$\begin{array}{ll}\text { ANEXOS } & 216\end{array}$ 


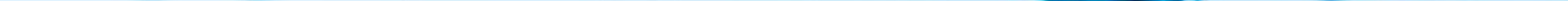




\section{Introducción}

Los países de América Latina se encuentran en un constante estado de cambio socioeconómico y ambiental (fenomenos migratorios, concentración urbana, sequias, inundaiones, disminución del área de glaciares, y progresiva desaparecimiento de ecosistemas...).

Estas situaciones representan una amenaza para la seguridad hídrica (SH) en toda la región.

La seguridad hídrica se refiere a la posibilidad de acceso a cantidades de agua suficientes para satisfacer la diversidad de usos del agua, la preservación de la calidad de los recursos hídricos y la debida consideración del cambio climático.

La Seguridad Hídrica es un reto desde el punto de vista social, político y económico y se ha convertido en uno de los principales desafíos a enfrentar para el desarrollo sostenible.

\section{La región de ALC se caracteriza por la} abundancia de agua, aunque existen grandes heterogeneidades espaciales y temporales en su distribución. Además, la dependencia crítica del sector agrícola y de diversos sectores energéticos en crecimiento, aumentan la presión sobre la SH.

Los principales retos que deben enfrentar las estrategias de SH en la región pasan por la compleja interacción entre todos los sectores que usan el recurso, la alta vulnerabilidad de la región a los desastres naturales de origen hídrico, el deficiente acceso al agua y a los servicios de saneamiento, la debilidad institucional y la deficiente infraestructura hídrica.

\section{Este informe presenta un análisis detallado de} la situación de la seguridad hídrica en América Latina y el Caribe y, partiendo de este análisis, proporciona un plan de trabajo exhaustivo con un conjunto integrado de programas para garantizar la SH.

Este documento ha sido elaborado para una amplia audiencia, tanto dentro como fuera del BID. os países de la región de América Latina y el Caribe (ALC) se encuentran en un estado de cambio constante. Desde hace varias décadas, la población está migrando hacia las principales ciudades, recurriendo, a menudo, a vivir en desarrollos irregulares con disponibilidad y calidad limitada de agua. Muchas de estas ciudades se encuentran en la costa y dependen de pequeñas cuencas costeras o de montañas distantes para abastecerse de recursos hídricos. Las cabeceras de las cuencas están sujetas a la deforestación y a la conversión de tierras a la agricultura. Los eventos de sequía meteorológica prolongadas (falta de lluvia) están afectando los flujos superficiales, haciendo cada vez más frecuentes las sequías hidrológicas e interrumpiendo el suministro de agua a las ciudades. Por otro lado, fuentes de agua dulce como los glaciares tropicales, se están retrayendo rápidamente: en las próximas dos décadas, se espera que desaparezcan la mayor parte de los que se encuentran por debajo de los 5.000 metros sobre el nivel del mar (msnm). De igual forma, los ecosistemas montañosos, como los páramos han ido desapareciendo o viendo disminuida su capacidad natural de almacenamiento y regulación. El cambio climático junto a los cambios en el uso del suelo, producto de una rápida y no sostenible expansión de la frontera agrícola, está afectando la disponibilidad y la calidad de los recursos hídricos, a corto y a largo plazo, tanto en áreas rurales como urbanas. Esta situación representa un peligro crítico para la seguridad hídrica en toda la región, y sitúa a las zonas altamente pobladas con un clima árido o semiárido en una situación particular de vulnerabilidad.

\section{¿Qué es a Seguridad Hídrica (SH)?}

Seguridad Hídrica (SH) es la capacidad de una población para salvaguardar el acceso sostenible a cantidades adecuadas de agua de calidad aceptable para el sostenimiento de los medios de vida, el bienestar humano y el desarrollo socioeconómico; para garantizar la protección contra la contaminación transmitida por el agua y los desastres relacionados con el agua, y para la conservación de los ecosistemas en un clima de paz y estabilidad política (ONU Agua, 2013). En este contexto, la seguridad hídrica se refiere a la posibilidad de acceso a cantidades de agua suficientes para satisfacer 
LA SH se ha convertido, progresivamente, en uno de los principales desafíos para el desarrollo sostenible la diversidad de usos del agua, la preservación de la calidad de los recursos hídricos y la debida consideración del cambio climático en: (i) la planificación de la infraestructura hídrica, (ii) la regulación de caudales, (iii) el manejo, la preservación y la valoración económica de los servicios ecosistémicos alrededor del agua y (iv) la gestión de inundaciones y riesgos de desastres naturales.

Desde un punto de vista teórico, la SH es una evolución de otros conceptos para la gestión del agua que se han desarrollado en décadas recientes. Quizás el más destacable de estos esfuerzos es la Gestión Integrada de Recursos Hídricos (GIRH), definido como "un proceso que promueve la gestión y el desarrollo coordinado del agua, la tierra y los recursos relacionados, con el fin de maximizar el bienestar social y económico resultante, pero de manera equitativa y sin comprometer la sostenibilidad de los ecosistemas" (Asociación Mundial para el Agua). En este sentido, los conceptos de SH y GIRH tienen aspectos y objetivos comunes.

En un sentido práctico, sin embargo, vale la pena destacar algunas diferencias importantes entre la SH y la GIRH. En primer lugar, la SH es una meta que procesos como la GIRH (Gestion integrada de recursos hidricos) se esfuerzan en alcanzar. Por ello, en la práctica, la GIRH se ha traducido hacia un enfoque en el proceso (de hecho, existen manuales para la GIRH con instrucciones detalladas de dicho proceso), mientras que la $\mathrm{SH}$ se enfoca fundamentalmente en la meta en sí, sin especificar necesariamente el proceso para alcanzarla. Esto supone, de alguna manera, un reconocimiento a las múltiples formas de implementar procesos para lograr la $\mathrm{SH}$, dependiendo de la problemática específica, la geografía, la climatología, los esquemas institucionales, las leyes y reglamentaciones existentes y otros factores. En otras palabras, la SH es menos prescriptiva en cuanto al proceso que la GIRH. Por último, y esto es un aspecto en el que este informe hace especial hincapié, la SH se enfoca en la gestión del ciclo del agua, es decir, en la gestión integral de la oferta y la demanda; mientras que la GIRH se enfoca en la gestión de recursos (agua y tierra principalmente), lo que en la práctica significa poner el acento en la gestión de la oferta y la demanda hídrica de manera fragmentada. Por todo ello, podemos considerar a la SH como un complemento o una modernización de conceptos y procesos como la GIRH y otros similares.

\section{Un importante desafío social, político y económico}

LA SH se ha convertido, progresivamente, en uno de los principales desafíos para el desarrollo sostenible. El recurso hídrico es el canal principal a través del cual se sentirán los impactos del cambio climático sobre los principales motores del crecimiento de la economía mundial: la agricultura, la energía, la industria y el sector urbano. Por ejemplo, en el sector agrícola, el cambio de los patrones de precipitación y temperatura están ya alterando significativamente la productividad agronómica, el potencial de riego y la ventaja 
comparativa de algunas naciones. En las regiones con fuentes de abastecimiento de agua menos confiables, la infraestructura y los servicios en las ciudades en crecimiento podrían exacerbar la escasez subyacente, lo que a su vez limitaría los patrones de crecimiento urbano. En el sector energético, los planes para reducir las emisiones de gases de efecto invernadero suelen basarse en las presunciones, a menudo optimistas, sobre la disponibilidad suficiente de agua para una expansión masiva de la capacidad de generación de energía hidroeléctrica y de biocombustibles: el agua también es necesaria para el enfriamiento de los combustibles fósiles y otras formas de generación de energía. Otras consecuencias del cambio climático relacionadas con la $\mathrm{SH}$ incluyen los posibles efectos sobre la salud humana y los cambios en los hábitats naturales, las cuencas hidrográficas y la biodiversidad. De hecho, el aumento en la temperatura produce cambios no solo en los patrones hidrológicos, como hemos mencionado anteriormente, sino que también afecta a la calidad del recurso. El cambio climático, junto a los fenómenos de eutrofización, producto de aguas sobreenriquecidas con nutrientes, están contribuyendo a la proliferación de brotes de cianobacterias (bacterias eucariotas extremadamente peligrosas para la salud humana, con una gran adaptabilidad a mayores temperaturas).

La SH es también un problema social, económico y político. La sostenibilidad a largo plazo de los recursos hídricos debe enmarcarse dentro de la adaptación a las condiciones variables del clima, el uso de la tierra y la demografía cambiante de la población. La SH es tema de preocupación creciente debido a la disponibilidad de este recurso vital y cómo gestionarlo para responder a los desafíos planteados por la demanda humana en diversos sectores, así como por consideraciones ambientales, socioeconómicas y relacionadas con el cambio climático. Los recursos hídricos se encuentran con frecuencia en situación de estrés por el sector de la agricultura, responsable de, aproximadamente, el $70 \%$ del total de las extracciones de agua dulce en el mundo (FAO, 2011a). La variabilidad y el cambio climático determinan oscilaciones espaciales y temporales de la disponibilidad de agua, con una intensificación de las fluctuaciones del ciclo hidrológico, que provocan el aumento de los eventos de inundaciones y sequía. Esto podría incrementar la competencia por el agua entre los diferentes sectores y usos, como la agricultura, pero también la generación de energía, el abastecimiento de agua potable y el medio ambiente. En la región de América Latina y el Caribe, la población y el ingreso per cápita siguen aumentando, lo que a su vez incrementa la demanda de agua, especialmente en los países en rápido crecimiento. En este contexto, resulta cada vez más evidente que las restricciones en SH pueden afectar a otros sectores (p. ej. producción alimentaria y generación de energía), con consecuencias cuantificables para el bienestar general social (Bazilian et al., 2011; Miralles-Wilhelm, 2016; Perrone y Hornberger, 2014; Miralles-Wilhelm y Muñoz-Castillo, 2018). 
La región se caracteriza por la abundancia de agua en su conjunto, aunque con grandes heterogeneidades espaciales y temporales

\section{¿Cuál es la situación en América Latina y el Caribe?}

En términos comparativos, la región se caracteriza por la abundancia de agua en su conjunto, aunque con grandes heterogeneidades espaciales y temporales, así como con una dependencia crítica de la producción agrícola y sectores energéticos diversos y en crecimiento, que aumentan la presión sobre la SH. Según estimaciones de la Organización para la Agricultura y la Alimentación (FAO), el 32\% de los recursos hídricos renovables mundiales pueden encontrarse en la región de ALC. Sin embargo, la gran variabilidad espacial en la distribución de estos recursos se traduce en contrastes sorprendentes, como el patrón de lluvias de la Cuenca Amazónica frente a las condiciones de clima árido o semiárido del norte de Chile, el norte y centro de México y el noreste de Brasil. La dimensión temporal se refiere a la variabilidad natural del clima de la región, con fuertes anomalías en las precipitaciones que son moduladas dentro de un rango de escalas temporales (Grimm y Saboia, 2015; Grimm y Zilli, 2009 y Mo y Schemm, 2008). La prospectiva del cambio climático con los cambios en el ciclo hidrológico y las crecientes demandas de agua impulsadas por el crecimiento demográfico y el crecimiento económico imponen desafíos importantes para el futuro de las estrategias de $\mathrm{SH}$ en la región de ALC.

En este contexto, la SH ha sido reconocida como un reto de naturaleza crítica para el crecimiento sostenible y la estabilidad social en la región. Dada la compleja interacción entre los diferentes sectores implicados (agua y saneamiento, agricultura, energía...) es imperativo pasar de los enfoques tradicionales de gestión sectorial, en los que la toma de decisiones y la planificación de inversiones se llevan a cabo como si estos fuesen independientes uno del otro, hacia un enfoque integrado (p. ej. el enfoque de nexo Agua-Energía-Alimentos) para la planificación del desarrollo de los recursos hídricos y su uso. Además de para promover la eficiencia económica y de recursos, este marco de planificación integrada es importante para evitar consecuencias no deseadas y posibles conflictos relativos a la $\mathrm{SH}$ en las próximas décadas en la región (Da Silva et al. 2018; Miralles-Wilhelm y Muñoz-Castillo, 2018).

\section{Estamos mejorando, pero aún queda mucho camino por recorrer}

En lo que se refiere a la gestión de los recursos hídricos, están empezando a aparecer mejores prácticas relacionadas con la SH, generalmente enfocadas en una aplicación más pragmática de la GIRH y centradas en aspectos como: (i) la planificación integrada de obras de drenaje urbano; (ii) la incorporación de los cuerpos de agua en la gestión del ambiente urbano; y (iii) el manejo adecuado de los desechos sólidos que, más allá de su impacto sobre la salud y el medio ambiente, a menudo pueden comprometer el funcionamiento del sistema de aguas pluviales y alcantarillado sanitario. A pesar de estos avances, aún quedan muchos retos pendientes para lograr niveles de $\mathrm{SH}$ aceptables en la región. Entre los más importantes, su alta vulnerabilidad a los desastres naturales, especialmente de los segmentos más pobres de la población, 
quienes han sido históricamente los más afectados. La urbanización rápida y no planificada en áreas vulnerables al riesgo, la degradación ambiental y las fallas de gobernanza son factores asociados al aumento del impacto de los desastres naturales de origen hídrico, como inundaciones y sequías.

Algunos otros retos relacionados con la SH en la región vienen de lejos. Es el caso, por ejemplo, del acceso al recurso y a los servicios de saneamiento, las fallas y deficiencias institucionales y la dotación de infraestructura hídrica. La infraestructura construida (infraestructura gris) carece de la capacidad de recuperación para seguir el ritmo del cambiante estado de la SH en ALC. A diferencia de esta, las soluciones basadas en la naturaleza (SBN) (o infraestructura "verde") no tienen una esperanza de vida limitada y pueden respaldar la sostenibilidad a largo plazo de la SH siempre que los enfoques de gestión adaptativa y la eficiencia de su operación y mantenimiento estén integrados en el diseño del sistema. Aunque las SBN a menudo pueden servir como soluciones independientes, cada vez más se incluyen en la infraestructura gris para obtener soluciones híbridas. En los últimos tiempos se está prestando mayor atención al uso de SBN para el almacenamiento y la regulación de agua (tanto para el suministro como para el control de inundaciones), su tratamiento, reutilización y los proyectos multipropósito que promueven la $\mathrm{SH}$, la seguridad alimentaria y la seguridad energética en áreas de rápida urbanización de ALC. Las tendencias apuntan hacia un mayor énfasis en soluciones descentralizadas a pequeña escala, situadas cerca de la fuente de problemas individuales, de las cuales puedan adueñarse las comunidades locales que participen en los proyectos, desde la conceptualización hasta la implementación y operación.

\section{¿Qué?}

El objetivo principal de este documento es presentar un análisis de la $\mathrm{SH}$ en la región de ALC, que aborda el asunto a través de cinco perspectivas complementarias: una de diagnóstico de la situación actual en la región (Capítulo II); una histórica, desde el punto de vista de la actividad del Banco Interamericano de Desarrollo (BID) en materia de SH (Capítulo III); una prospectiva que analiza oportunidades de innovación en este tema de vital importancia para el BID y sus clientes (Capítulo IV); una estratégica, que establece objetivos prioritarios para la región en materia de SH (Capítulo V); y una propositiva, que esboza un plan de trabajo para avanzar en materia de $\mathrm{SH}$ en la región durante la próxima década, a través de programas de inversión en políticas, infraestructura y conocimiento (Capítulo VI). El documento ha sido preparado en consulta con diversos actores, dentro y fuera del BID, y con los diversos sectores relacionados con la seguridad hídrica en los países de la región. La lógica del esquema para desarrollar estas perspectivas de SH en ALC se ilustra en la Figura 1.1. 


\section{¿Para quién?}

Este documento ha sido escrito para una amplia audiencia. Así, dentro del BID, puede servir como guía para propósitos de planificación y puede usarse para elaborar las estrategias de los países y notas sectoriales del Banco. También puede ser útil como referencia a divisiones operativas del BID, como la División de Agua y Saneamiento (WSA), y a otras divisiones y departamentos con intereses en temas de SH. Para el lector ajeno al Banco, proveniente de otros sectores, instituciones y organizaciones, este documento constituye un análisis exhaustivo de los retos y oportunidades que plantea la $\mathrm{SH}$ en la región de ALC, considerado desde la perspectiva particular de propuestas de programas de inversión por parte del BID y sus clientes.

Figura 1.1. Esquema de desarrollo de este informe, mostrando la síntesis de las perspectivas de diagnóstico (Capítulo II), histórica (Capítulo III), prospectiva (Capítulo IV), estratégica (Capítulo V) y propositiva (Capítulo VI) para SH en la región de ALC.

Diagnóstico

(Capítulo II)

- Disponibilidad Hídrica y Cambio Climático

- Calidad de Agua, Ambiente y Ecosistemas

- Aspectos Normativos y de Gobernanza

- Estado de la Infraestructura Hídrica
Introducción

(Capítulo I)

- Definición

- Motivación

- Objetivos

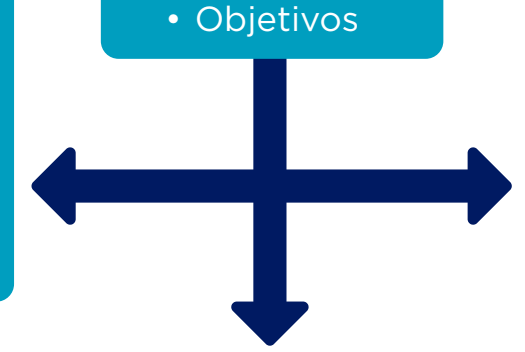

Experiencia

(Capítulo III)

- Inventario de

Proyectos

- Lecciones Aprendidas

Innovación

(Capítulo IV)

- Cambio Climático y Planificación Multi-sectorial (Nexo)

- Infraestructura Hídrica y SBN

- Marco Institucional para la SH

- Avances en Ciencia y Tecnología

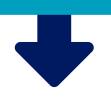

Estrategia de SH para LAC - Cuencas Seguras

(Capítulo V)

- Misión y Visión

- Objetivos Estratégicos

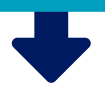

Cuencas Seguras - Plan de Trabajo 2020-2030 (Capítulo VI)

- Programas de Inversión en Infraestructura y Políticas

- Programas de Conocimiento y Creación de Capacidades

- Consideraciones para Implementación 


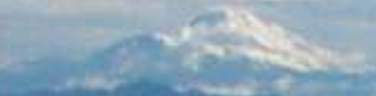

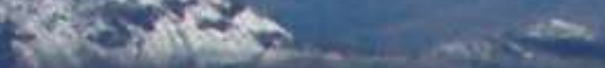

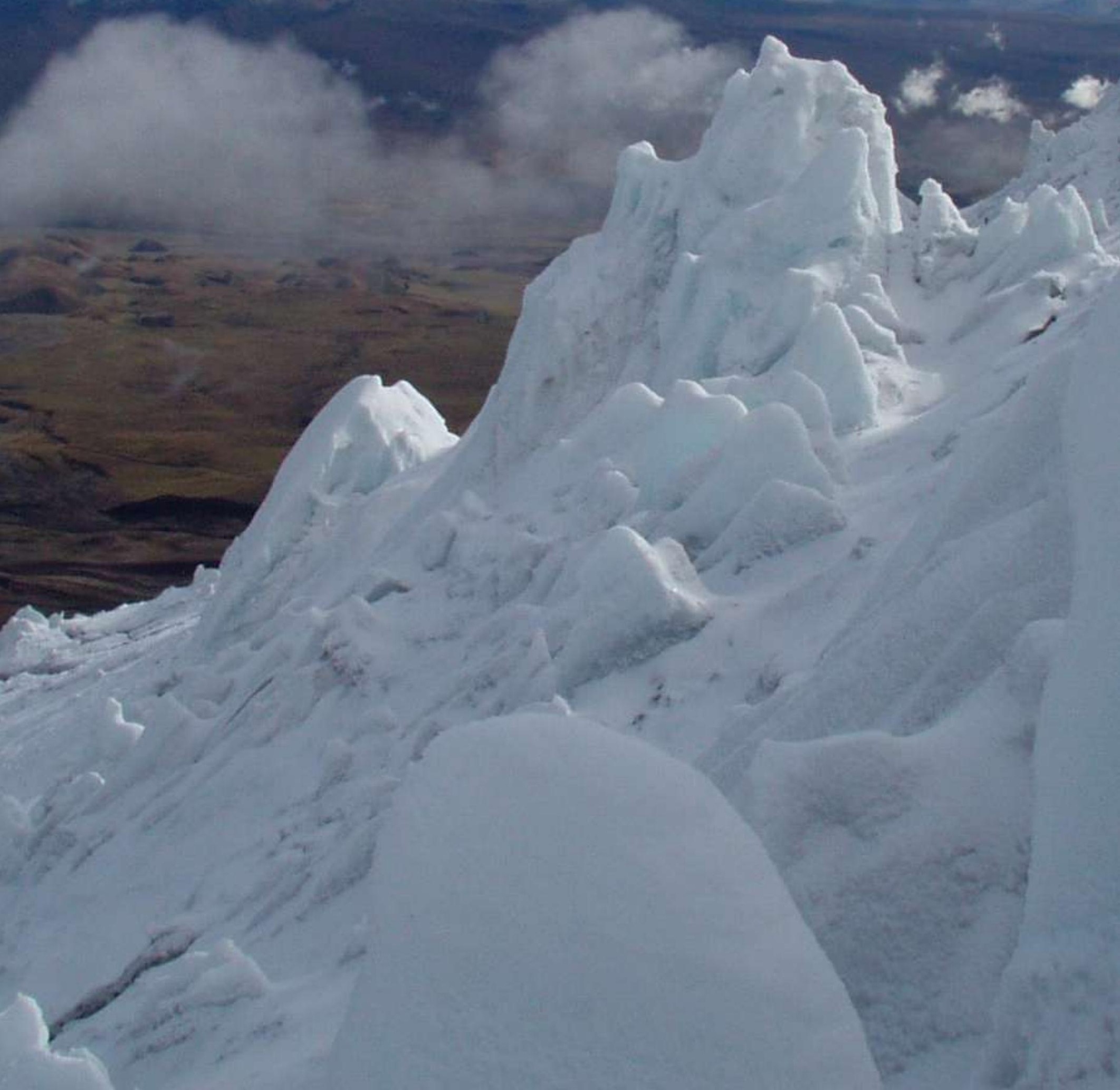




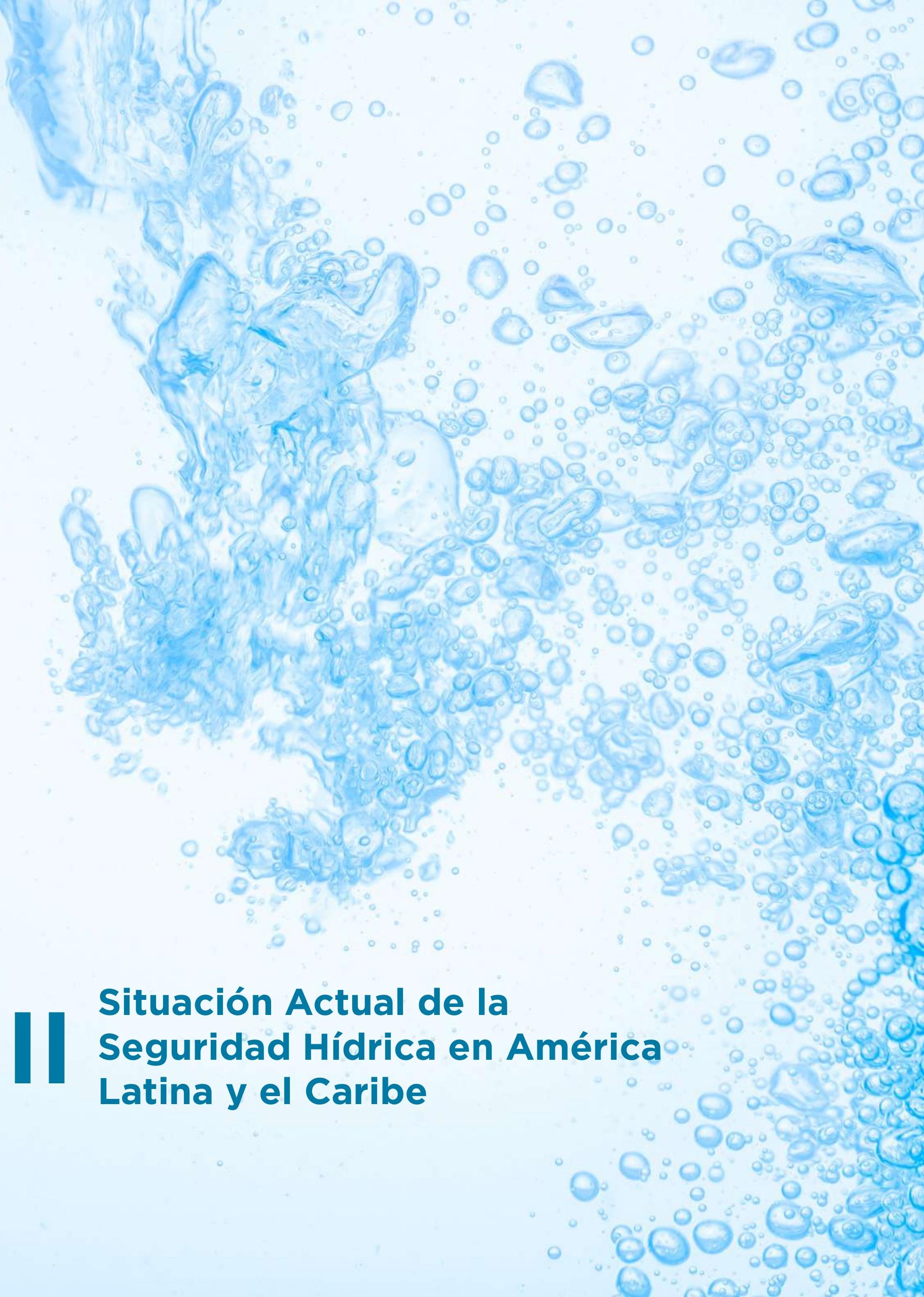


Hasta el momento se han identificado cuatro grandes tipos de problemas relacionados con la SH: (i) el balance hídrico, representado por la disponibilidad de los recursos hídricos y sus limitaciones debido al cambio climático; (ii) la calidad de agua y su incidencia en el medio ambiente y en los ecosistemas en un contexto de cambio climático; (iii) la institucionalización de la protección y el uso del agua, representada por la gestión del agua a través de mejoras en los mecanismos normativos y de gobernanza para facilitar la implementación de acciones efectivas de adaptación y mitigación y (iv) inversiones en infraestructura hídrica, que mejoren el acceso al agua para diversos usos y actividades productivas, y reduzcan los riesgos relacionados con el exceso o el déficit del agua.

Con respecto al balance hídrico, la región de ALC es una de las áreas del planeta con mayor abundancia de recursos hídricos aunque la capacidad de almacenamiento de sus cuencas y acuíferos está disminuyendo progresivamente como consecuencia del cambio climático. La región presenta una enorme heterogeneidad en la distribución espacial y temporal de sus recursos hídricos y muchas fuentes de agua de la región se encuentran amenazadas debido, fundamentalmente a una gestión ineficiente de los recursos. La incidencia y circunstancias relacionadas con los eventos hídricos extremos (sequías e inundaciones) también varian a lo largo de la región.

La calidad del agua limita la disponibilidad de los recursos hídricos en la región. La contaminación de fuentes de agua derivada de las actividades humanas (principalmente la disposición de aguas residuales -con niveles de tratamiento variables-, la producción de alimentos, las actividades extractivas e industriales y la generación eléctrica), es un problema que se ha ido extendiendo en la mayor parte de los países de la región.

Con respecto a los marcos normativos e institucionales, existen deficiencias relacionadas fundamentalmente con la insuficiencia de los marcos normativos, la falta de capacidad para aplicarlos, la debilidad de las autoridades nacionales de aguas, la debilidad de los organismos de cuenca y la fragmentación del poder decisorio.

Sobre la infraestructura hídrica, las mejoras deben concentrarse aquellas relacionadas con el agua para abastecimiento humano y redes de saneamiento, el agua para riego y producción de alimentos; el agua para producir energía y la infraestructura para combatir los eventos extremos (sequías e inundaciones). Todas ellas presentan deficiencias y potencial de mejora.

\section{Situación Actual de la Seguridad Hídrica en América Latina y el Caribe}

Recuadro 2.1. Los grandes desafíos de la $\mathrm{SH}$ en América Latina y el Caribe

El avance de esfuerzos para lograr mejoras en la disponibilidad y calidad de los recursos hídricos a escala global ha empezado a traducirse recientemente en marcos de referencia desarrollados por diversos organismos (ONU Agua, 2013; OCDE, 2013; Asociación Mundial para el Agua, 2013) para gestionar y lograr mejoras en la SH en América Latina y Caribe.

Por ejemplo, en un análisis de CEPAL (Peña, 2016) se identifican los siguientes desafíos generales de la SH en ALC:

- El acceso de la población a niveles adecuados de agua potable y saneamiento.

- La disponibilidad de agua para garantizar un desarrollo productivo sostenible y reducir la conflictividad asociada a la competencia por el agua entre sectores.

- La conservación de los cuerpos de agua en un estado compatible con la protección de la salud pública y el medio ambiente.

- La reducción de los riesgos relacionados con el exceso de agua, en especial en las zonas urbanas y en las afectadas por huracanes, tormentas tropicales y otras perturbaciones fuertes.

El informe concluye que para atender estos desafíos es necesario que la región haga un esfuerzo para incrementar y mejorar su dotación de infraestructura, tema en el que, en las últimas décadas, se ha registrado un descenso de los esfuerzos llevados a cabo por los gobiernos, así 
como en mejorar los sistemas institucionales. Estos últimos muestran graves déficits, que tienden a acentuarse debido al mayor desarrollo y complejidad de las sociedades actuales y a la intensificación en el uso de los recursos naturales. Los déficits observados en las estructuras institucionales del sector responden básicamente a las inconsistencias en su diseño, a la incapacidad de los Estados para implementar la normativa de forma efectiva, a las debilidades de la intervención de la sociedad civil y a las fallas en la operación de los mercados.

Otro estudio, realizado por el BID (BID, 2012), identifica los siguientes retos para la SH en la región, prestando mayor atención a los impactos del cambio climático:

- Deficiente suministro, distribución y sostenibilidad de fuentes de agua: la mayoría de los países en el Caribe enfrenta escasez de agua y/o un acceso restringido, en el que el suministro es menor que la demanda que continúa aumentando debido al crecimiento de la población y su desarrollo. Una situación parecida se encuentra en muchas áreas de países más grandes como México, Brasil, Chile y Perú. Incluso en países con amplios recursos hídricos para abastecer a su población, la distribución del agua se lleva a cabo de una manera insostenible e inconsistente en la mayoría de los casos, resultando en una mayor amenaza a las fuentes de agua y a sus ecosistemas asociados, debido a los impactos del cambio climático.

- Contaminación y degradación de la calidad del agua: mientras los problemas del suministro de agua afectan a un subconjunto de países en regiones áridas y semiáridas, los problemas con la baja calidad del agua perjudican a todos los países de la región. La degradación progresiva de la calidad del agua socava la integridad ecológica y los mismos ecosistemas de los que depende la población de la región. Es el caso de la Cuenca del Amazonas y una gran parte de los países de la región que poseen zonas costeras en el Atlántico y el Pacífico. Algunos ejemplos son la contaminación causada por los sistemas de disposición de aguas residuales; la contaminación de aguas superficiales y subterráneas ocasionada por prácticas agrícolas e industriales, y la salinización de los acuíferos cercanos a las costas. Dado que el aumento de la temperatura, ocasionado por el cambio climático, se convierte en un multiplicador de los impactos causados por la contaminación ambiental sobre la calidad de las fuentes de agua, este se convierte en un tema especialmente crítico que se demuestra, por ejemplo, en el aumento de la frecuencia del número de casos de brotes de cianobacterias en los cuerpos de agua durante el verano. 
- Infraestructura para la gestión de los recursos hídricos deteriorada o inadecuada: desde el deterioro de los sistemas de drenaje y tratamiento hasta el inadecuado mantenimiento y operación de estos, pasando por el diseño, la planificación y la construcción de nuevas instalaciones. En esta área los problemas afectan a toda la región. Cada año, fuertes inundaciones causan daños cuantiosos e impiden el desarrollo. Aquí también los problemas predominan en regiones pobres con alta densidad poblacional (Río de Janeiro, Nicaragua y Haití). La infraestructura inadecuada afecta a las zonas rurales menos desarrolladas, más vulnerables a los desastres naturales y al cambio climático.

- Débil gobernanza y fortalecimiento Institucional: En la región de ALC, las instituciones administrativas de recursos hídricos (ministerios, autoridades nacionales y locales) están, por lo general, gestionadas inadecuadamente y muestran debilidades constantes en su administración. Aunque muchos países han progresado en materia de fortalecimiento institucional (Brasil, México, Perú), es necesario desarrollar acciones proactivas que faciliten e incentiven un proceso de adaptación al cambio climático, tanto a nivel nacional como subnacional.

Tomados en su conjunto, los marcos de referencia que se han desarrollado hasta el momento, a escala global y para el caso específico de los países de ALC, se enfocan en cuatro grandes tipos de problemas relacionados con la SH: (i) el balance hídrico, representado por la disponibilidad de los recursos hídricos y sus limitaciones debido al cambio climático; (ii) la calidad de agua y su incidencia en el medio ambiente y los ecosistemas en un contexto de cambio climático; (iii) la institucionalización de la protección y el uso del agua, representada por la gestión del agua a través de mejoras en los mecanismos normativos y de gobernanza para facilitar la implementación de acciones efectivas de adaptación y mitigación y (iv) inversiones en infraestructura hídrica que mejoren el acceso al agua para diversos usos y actividades productivas y reduzcan los riesgos relacionados con el exceso o el déficit del agua.

Este capítulo analiza detalladamente estos cuatro grupos de problemas como elementos del diagnóstico de la situación actual de la SH en la región. 


\section{II.1 Disponibilidad Hídrica}

Abundancia de recursos...

En un contexto global, la región de ALC es una de las áreas del planeta con más abundancia de recursos hídricos. De hecho, la región tiene una precip-

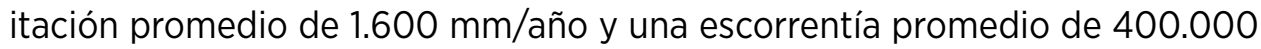
$\mathrm{m}^{3} /$ año, lo que representa más del $30 \%$ de los recursos hídricos en el mundo. Sin embargo, su población es equivalente al $6 \%$ y su superficie terrestre es 13\% del total mundial. Esto significa que su disponibilidad media per cápita alcanza aproximadamente los $22.000 \mathrm{~m}^{3}$ /persona/año, casi cuatro veces más que la disponibilidad media a escala global, que es de $6.100 \mathrm{~m}^{3} /$ persona/año. Estos valores son aún más destacables cuando se comparan con los de continentes como Asia que, con un promedio de precipitaciones de $650 \mathrm{~mm} / \mathrm{año}$, tiene una dotación de $2.500 \mathrm{~m}^{3} /$ persona/año (Willaarts et al., 2014). A pesar de estos valores tan favorables, la región está aún lejos de haber solucionado los problemas de $\mathrm{SH}$. En este sentido, resulta útil revisar algunos de los principales aspectos relacionados con la disponibilidad hídrica, los efectos del cambio climático y cómo estos interactúan y plantean retos para el desarrollo de los países de la región.

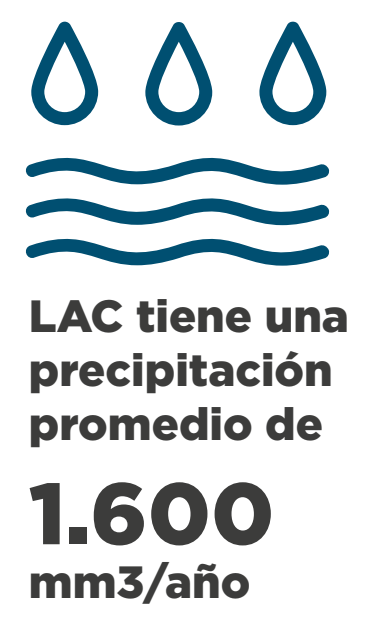

$\rightarrow$ Representan de los recursos hídricos mundiales
Las cuencas en la región de ALC producen mayor caudal de agua por área terrestre que cualquier otro continente
Las cuencas en la región de ALC producen mayor caudal de agua por área terrestre que cualquier otro continente. La cordillera Andina es el mayor contribuyente a este caudal (Harden, 2006). Los pastizales y humedales de alta montaña situados por encima de los 3.000 metros, los páramos y los bofedales, tienen una alta capacidad de retención y regulación de agua debido a sus suelos altamente orgánicos (Harden, 2006; Buytaert et al., 2006). Sin embargo, su capacidad de almacenamiento, históricamente elevada, se está reduciendo rápidamente como resultado combinado de dos factores. Por un lado, el calentamiento antropogénico continuo y progresivo, que no 
solo impacta la disponibilidad de agua proveniente de los glaciares tropicales (Vergara et al., 2007), sino que también afecta a la calidad de los servicios ecosistémicos que prestan los ecosistemas de alta montaña. Por el otro, la intensificación de los impactos humanos del pastoreo, el riego y la minería (Rodell et al., 2018). Por ejemplo, la reducción en los caudales fluviales junto con los períodos de sequía intensa, han llevado a la reciente escasez de agua en La Paz (Martínez, 2017), Lima (http://water.nature.org/waterblueprint/ city/lima) y Sao Paulo (http://water.nature.org/waterblueprint/city/sao paulo). Al igual que con las grandes áreas metropolitanas, también el Pantanal, el humedal más grande del mundo, que exhibe un pulso de inundación anual predecible como resultado de vastas cantidades de agua que salen de la sabana hacia el norte (Junk y da Cunha, 2018), ha experimentado una reducción de los caudales de agua asociado con el cambio en el uso de la tierra para ampliar la producción agrícola.

La disponibilidad de agua subterránea en los acuíferos de la región ha sido menos estudiada, pero análisis recientes indican una tendencia a la disminución progresiva de la cantidad de agua almacenada y de los caudales en estos acuíferos (Rodell et al., 2018; Lo et al., 2016).

\section{...desigualmente distribuidos}

Por otra parte, la región presenta una gran heterogeneidad en la distribución espacial de sus recursos hídricos. Así, alberga el desierto más árido del mundo en Atacama (Chile), con sectores de lluvias prácticamente inexistentes, y áreas con un hiperrégimen de agua (superiores a 2.500 mm/año). Un 36\% de la superficie de ALC corresponde a zonas clasificadas genéricamente como áridas, muchas de las cuales presentan escasez de agua para satisfacer las demandas (UNESCO, 2010). Además, el 53\% de la escorrentía en la región se concentra en un solo río, el Amazonas. Las cuencas del golfo de México, el Atlántico Sur y el río de la Plata, con el $40 \%$ de la población de la región, contienen el $10 \%$ de los recursos hídricos disponibles y, en el caso de Perú, el $65 \%$ de la población se concentra en áreas que tienen un $2 \%$ de su agua (WWC, 2000).

\section{...en disminución}

Muchas fuentes de agua en toda la región se encuentran amenazadas
Muchas fuentes de agua en toda la región se encuentran amenazadas. Es el caso de la mayoría de los países del Caribe, que se enfrentan a la escasez de agua y/o a la falta de acceso al recurso, debido a la ineficiencia en la gestión de los recursos hídricos (combinado con situaciones donde las demandas generalmente igualan o superan los suministros y existe una demanda en aumento impulsada por el crecimiento de la población y el desarrollo), que exacerba los problemas. Algunos países de la región (por ejemplo, Surinam y Venezuela) siguen funcionando sin ninguna separación real entre la au- 
toridad de recursos de agua y la empresa proveedora de los servicios, lo que implica que los derechos de agua y/o permisos de uso están dados por la misma institución que solicita los recursos. Tampoco existe información suficiente ni actualizada de las cuencas hidrográficas y los acuíferos, lo que limita el proceso de toma de decisiones en el uso de los recursos hídricos. Situaciones similares se viven en muchos sectores en países más grandes como México, Brasil, Chile y Perú.

\section{...y mal gestionados}

Incluso en los países con abundantes recursos hídricos para abastecer a su población, la distribución del agua se lleva a cabo de una manera insostenible en la mayoría de los casos, con los impactos del cambio climático amenazando las fuentes aún más. Esto demandará el diseño de estructuras adaptativas de gobernanza del agua. Las controversias entre los usos, aguas arriba y aguas abajo, se distribuyen por toda la región, lo que da a entender, en algunos casos, una falta de entendimiento y de diálogo entre los usuarios. Es el caso de las cuencas peruanas en Santa, Piura y Tacna. En Brasil, la sequía de São Paulo de 2013-15 llevó a discutir una antigua idea de revertir parte del río Paraiba do Sul para abastecer a la megalópolis. Este río suministra la mayoría del agua a la ciudad de Río de Janeiro y los suburbios aguas abajo, por lo que, en caso de que la reversión se haga efectiva, es bastante probable que se produzca un conflicto entre ambas megalópolis.

Proyectando el futuro del agua en ALC: ¿qué escenario queremos ver? En lo que se refiere a la relación entre la $\mathrm{SH}$ y el cambio climático en ALC, el BID desarrolló recientemente un informe (Miralles-Wilhelm y Muñoz-Castillo, 2018) del que hemos extraído la Figura 2.1. Esta muestra las estimaciones del volumen de disponibilidad hídrica total anual (suma de escorrentía superficial y agua subterránea) con tres modelos de simulación hidroclimáticos, bajo los escenarios de cambio climático RCP4.5 (moderado) y RCP6.0 (severo). Esta se puede suponer como la disponibilidad hídrica total para las cuencas y acuíferos de toda la región bajo dos posibles escenarios futuros.

Hay dos resultados claves que se pueden discernir de esta figura:

- El volumen de disponibilidad hídrica total en la región para el escenario climático RCP4.5 (moderado) es sensiblemente mayor (en el orden del 25-30 por ciento, en general) que aquel para el RCP6.0 (severo). Este resultado es consistente con la idea de disminución de la disponibilidad hídrica media con un aumento de la intensidad del cambio climático, lo cual está ampliamente documentado en la literatura para el caso mundial, y resumido en el Quinto Informe de Evaluación del Grupo Intergubernamental de Expertos para el Cambio Climático de las Naciones Unidas (IPCC) (Grupo de Trabajo II; Jiménez Cisneros et al., 2014; Magrin et al., 2014 y sus referencias). 
- Los distintos modelos hidroclimáticos producen estimaciones de disponibilidad hídrica similares (mismo orden de magnitud) para cada escenario climático, lo que sugiere la robustez de estas estimaciones a escala regional en $\mathrm{ALC}$.

Mientras el volumen de disponibilidad hídrica total regional podría no variar significativamente en las próximas décadas, la distribución espacial alrededor de la región muestra algunas variaciones importantes que es preciso destacar. En este sentido, la Figura $\mathbf{2 . 2}$ muestra el volumen de disponibilidad hídrica anual generado en toda la región, en un escenario climático RCP4.5 (moderado) para el año 2050. Debido a que el volumen de disponibilidad calculado por los modelos hidroclimáticos son similares, los resultados para el modelo GISS ${ }^{1}$ se muestran como representativos para fines de ilustración.

Los cambios en la disponibilidad de la región durante el período 20152050 se muestran en la Figura 2.3. Algunos efectos localizados son notables: menor disponibilidad hídrica en la cuenca del Amazonas, el norte de México, el noreste de Brasil, el Caribe y América Central. El derretimiento progresivo de los glaciares en los Andes mantiene de forma temporal la disponibilidad hídrica relativamente estable en las cuencas aguas abajo de la cordillera hasta mediados de siglo pero, a partir de este momento, tiende a disminuir (Miralles-Wilhelm y Muñoz-Castillo, 2018). Estas tendencias son esperables dada la combinación de cambios en la precipitación, temperatura y dinámicas de los diferentes ecosistemas en la región (áreas costeras, glaciares de alta montaña, glaciares, sabanas secas y otros).

Figura 2.1. Estimaciones de disponibilidad hídrica regional en ALC (suma de la escorrentía superficial y el agua subterránea renovable para todos los países) utilizando los modelos del sistema terrestre CCSM, FIO y GISS, para dos escenarios de cambio climático: RCP4.5 (moderado) y RCP6.0 (severo)

RCP 4.5 / Disponibilidad Hidrica Total para ALC ( $\left.\mathrm{km}^{3} / \mathrm{yr}\right)$

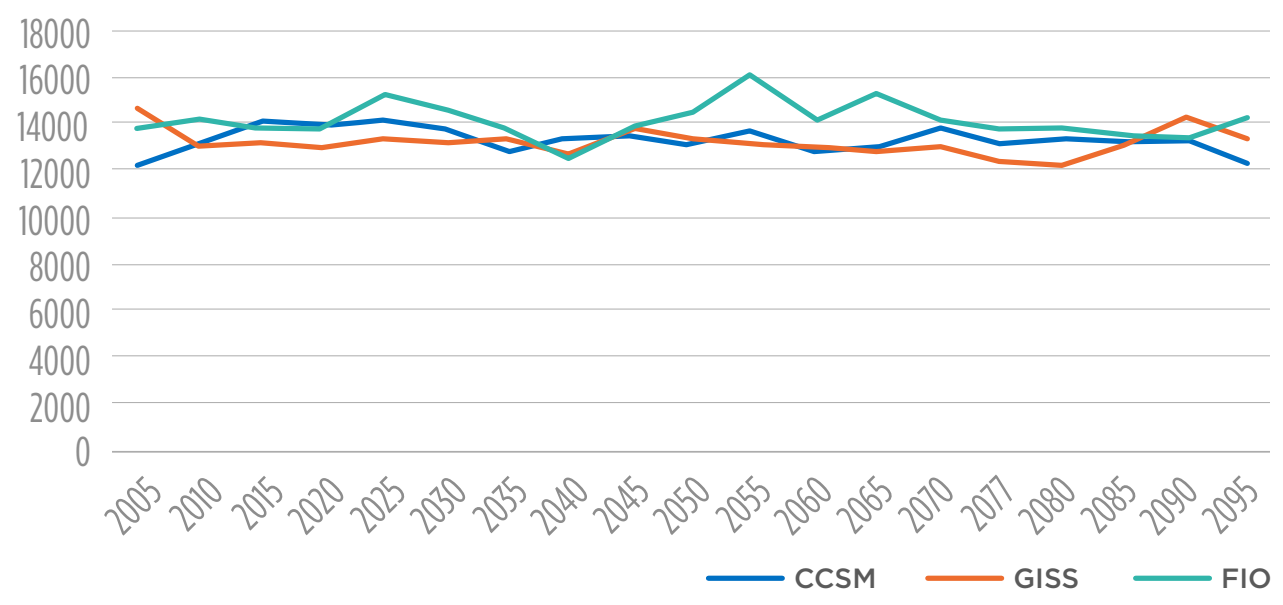

Fuente: Miralles-Wilhelm y Muñoz-Castillo, 2018.

1 Goddard Institute for Space Studies. 


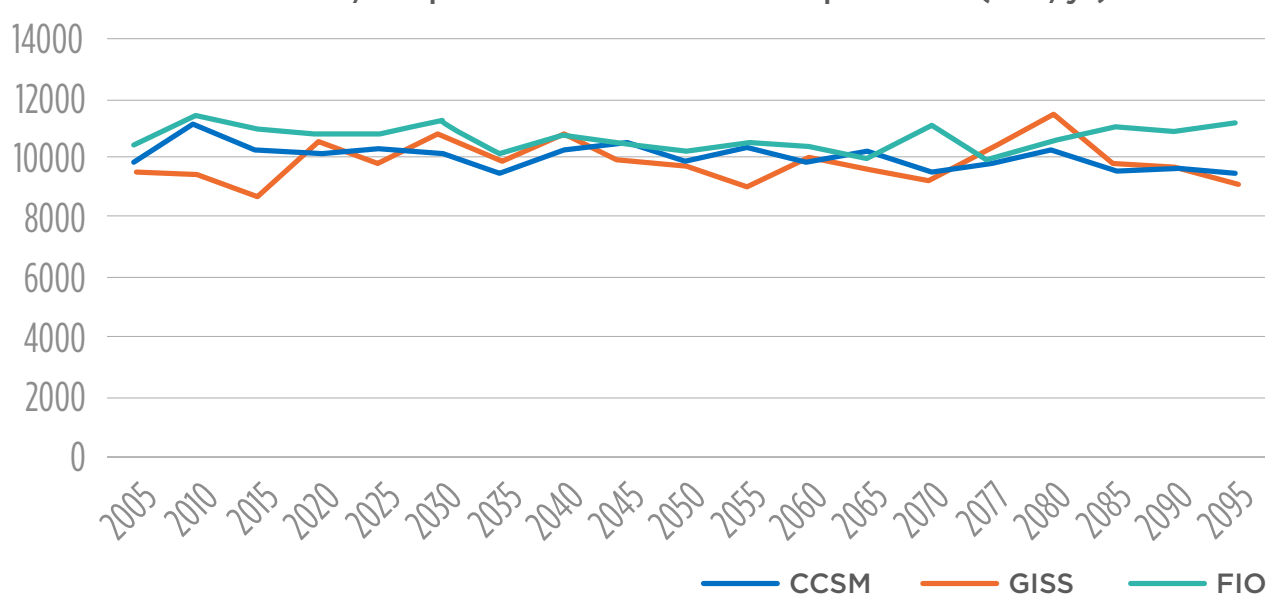

Fuente: Miralles-Wilhelm y Muñoz-Castillo, 2018.

Algunas de las tendencias que muestran estos resultados pueden resumirse como sigue. Se secan la cuenca del Amazonas, el norte de México, el noreste de Brasil y los países del Caribe y América Central, que parecen tener una tendencia hacia la reducción de la disponibilidad, una tendencia que es más pronunciada hacia la segunda mitad del siglo, particularmente en México. Durante la primera mitad del siglo, los países andinos mantienen relativamente estables sus niveles de disponibilidad hídrica debido al derretimiento glacial progresivo. A partir de 2050, muestra una predisposición a secarse. Así parece suceder en la costa del Pacífico peruana, que refleja una tendencia a secarse que se estabiliza hacia el final del siglo (debido al derretimiento de los glaciares drenando en dirección oeste a esa cuenca). Chile apunta una constante inclinación a la disminución de la escorrentía en todas las simulaciones. En general, la tendencia a la disminución de la disponibilidad hídrica se proyecta principalmente en el sur de México, Haití y la República Dominicana; en algunas partes de América Central y en grandes áreas de Brasil y Perú.

Recuadro 2.2. Cuando el agua deja huella

Es importante destacar que la demanda hídrica en ALC no solo es causada por los usos del agua en la región. La complejidad del uso del agua, debido al intercambio comercial de productos, es un tema que despierta cada vez más interés en el mundo por su impacto en la SH. En este sentido, el concepto de "huella hídrica" (Hoekstra y Mekonnen, 2011) ha sido introducido para cuantificar las cantidades de agua y sus diferentes tipos de uso, proporcionando una imagen más clara del consumo de recursos hídricos y su variación con la ubicación y a lo largo del tiempo. Esta referencia cuantifica geográficamente la huella hídrica (WF, por sus siglas en inglés) de la humanidad, con una alta resolución espacial, y especifica el uso del agua pluvial (WF verde), el agua superficial y subterránea (WF azul) y los volúmenes de agua contaminada (WF gris). 


\subsection{6}

\section{Mm3/ persona/año Huella hídrica de ALC}

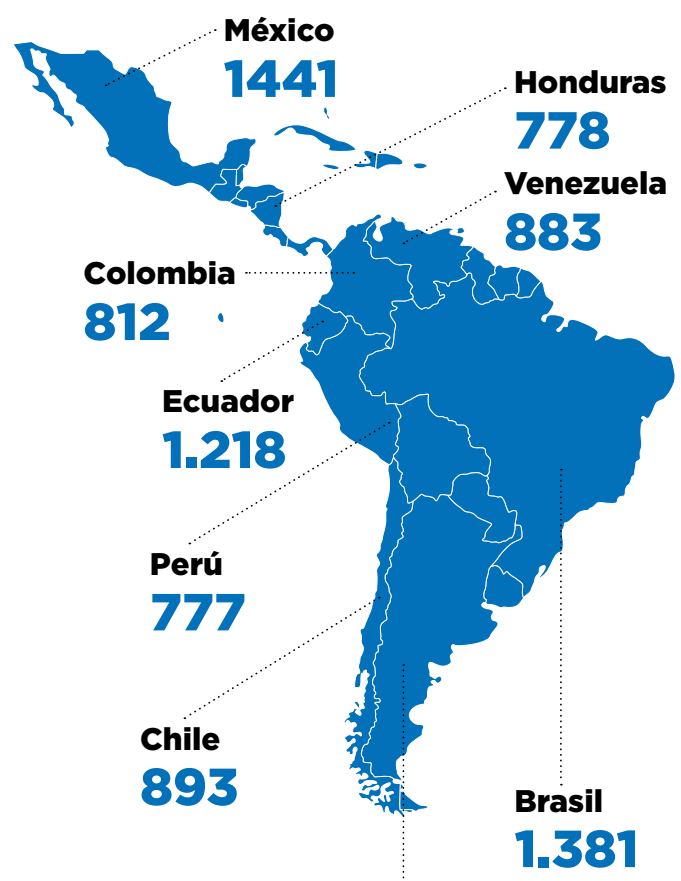

\section{Argentina 1.404}

Las huellas hídricas han sido estimadas para cada país, tanto desde la perspectiva de la producción como del uso. Los caudales de agua virtual internacional son estimados con base en el comercio de materias primas agrícolas e industriales. La WF promedio anual mundial en el período $1996-2005$ fue de $9.087 \mathrm{Gm} 3 / 2$ ño (74\% verde, $11 \%$ azul y $15 \%$ gris). La producción agrícola contribuye en un $92 \%$. Alrededor de una quinta parte de la WF global se relaciona con la producción para la exportación. El volumen total de los flujos de agua virtual internacional relacionado con el comercio de productos agrícolas e industriales fue de $2.320 \mathrm{Gm} 3 / 2$ ño (68\% verde, $13 \%$ azul y $19 \%$ gris). La WF del consumidor promedio global fue de $1.385 \mathrm{~m} 3 / 2$ ño. El consumidor promedio en Estados Unidos tiene una WF de $2.842 \mathrm{~m} 3 / 2 n ̃ o$, mientras que el promedio per cápita en China y la India es de 1.071 y 1.089 m³/año, respectivamente. La mayor contribución a la WF del consumidor medio es la del consumo de cereales (27\%), seguida de la carne (22\%) y de los productos lácteos (7\%). El volumen y las modalidades de consumo y la WF por tonelada de producto de los productos consumidos son los principales factores determinantes de la WF de cada consumidor. Estos resultados ilustran la dimensión global del consumo del agua, mostrando que varios países extranjeros dependen en gran medida de los recursos hídricos de otros e impactos significativos sobre el consumo de agua y la contaminación en otros lugares.

\subsection{0 Gm3/año}

promedio mundial relacionado con el comercio agricola e industriales

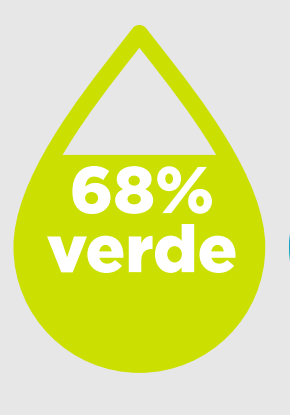

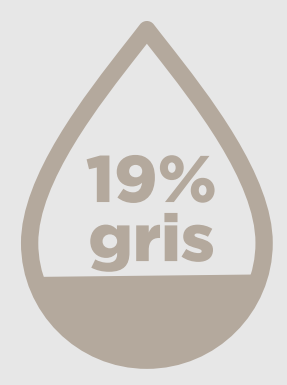

Aunque la región de ALC es un exportador neto de agua, la WF varía ampliamente entre países y existen importantes intercambios de agua dentro de la región. Por ejemplo, México es uno de los principales importadores de agua virtual del mundo con $91 \mathrm{Mm} 3 /$ año (Konar et al., 2011). La huella hídrica de ALC es de 1.136 m³/persona/año (Chapaign y Hoekstra, 2004) y para dar una idea de su variabilidad, las WF de Argentina, Brasil, Ecuador, Perú, México, Honduras, Chile, Colombia y Venezuela es de $1.404 \mathrm{~m}^{3} /$ persona/año, $1.381 \mathrm{~m}^{3} /$ persona/año, $1.218 \mathrm{~m}^{3}$ / persona/año, $777 \mathrm{~m}^{3} /$ persona/año, $1.441 \mathrm{~m}^{3} /$ persona/año, $778 \mathrm{~m}^{3} /$ persona/año, $803 \mathrm{~m}^{3}$ /persona/año, $812 \mathrm{~m}^{3} /$ persona/año y $883 \mathrm{~m}^{3} /$ persona/ año, respectivamente. 
Figura 2.2. Distribución de la disponibilidad hídrica en la región de ALC en 2050, en escenario de cambio climático RCP4.5 (moderado)

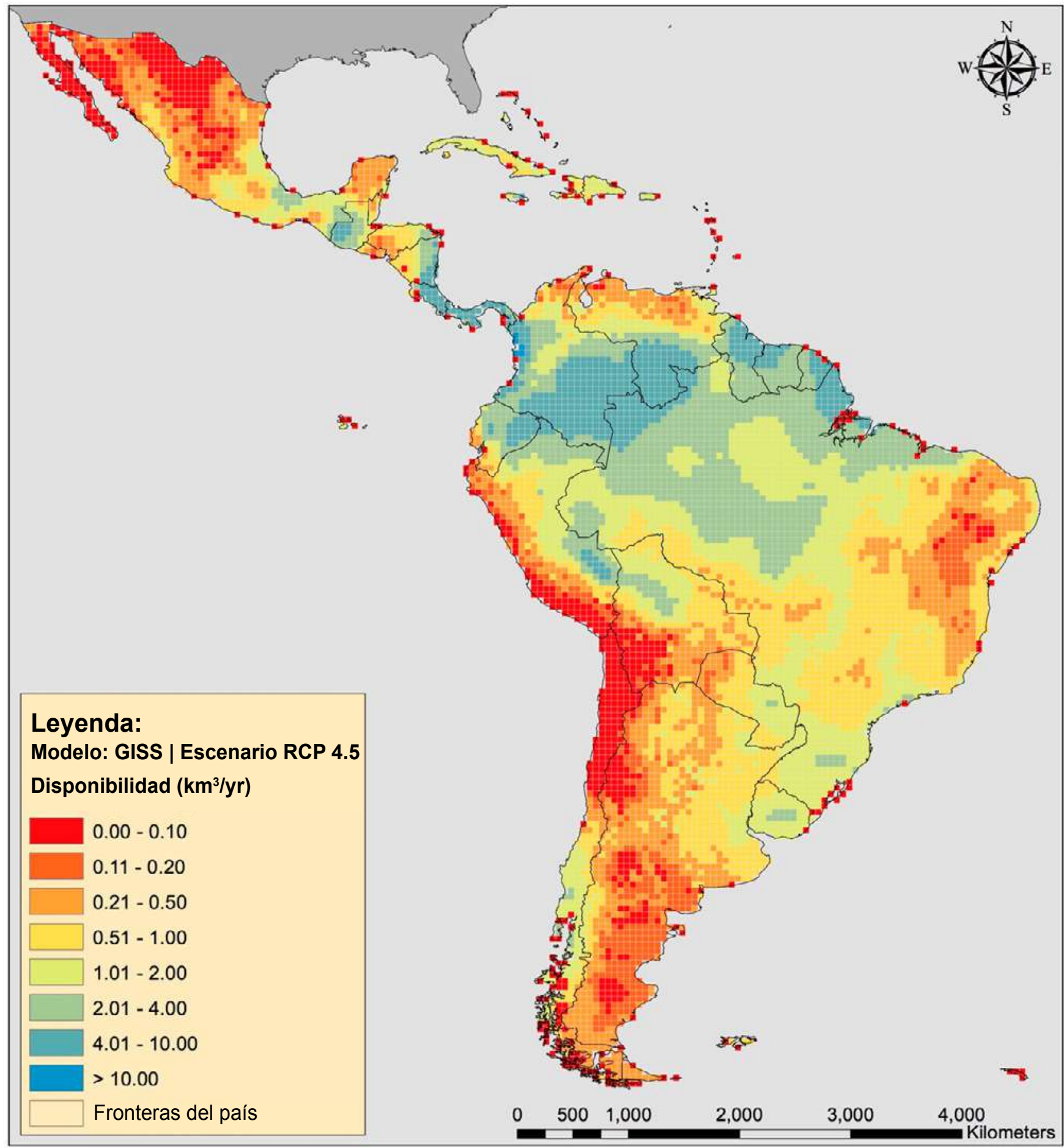

Fuente: Miralles-Wilhelm y Muñoz-Castillo, 2018. 
Figura 2.3. Cambios proyectados en la disponibilidad hídrica en la región de ALC para el período 20152050, proyectado utilizando el escenario climático RCP4.5 (moderado)

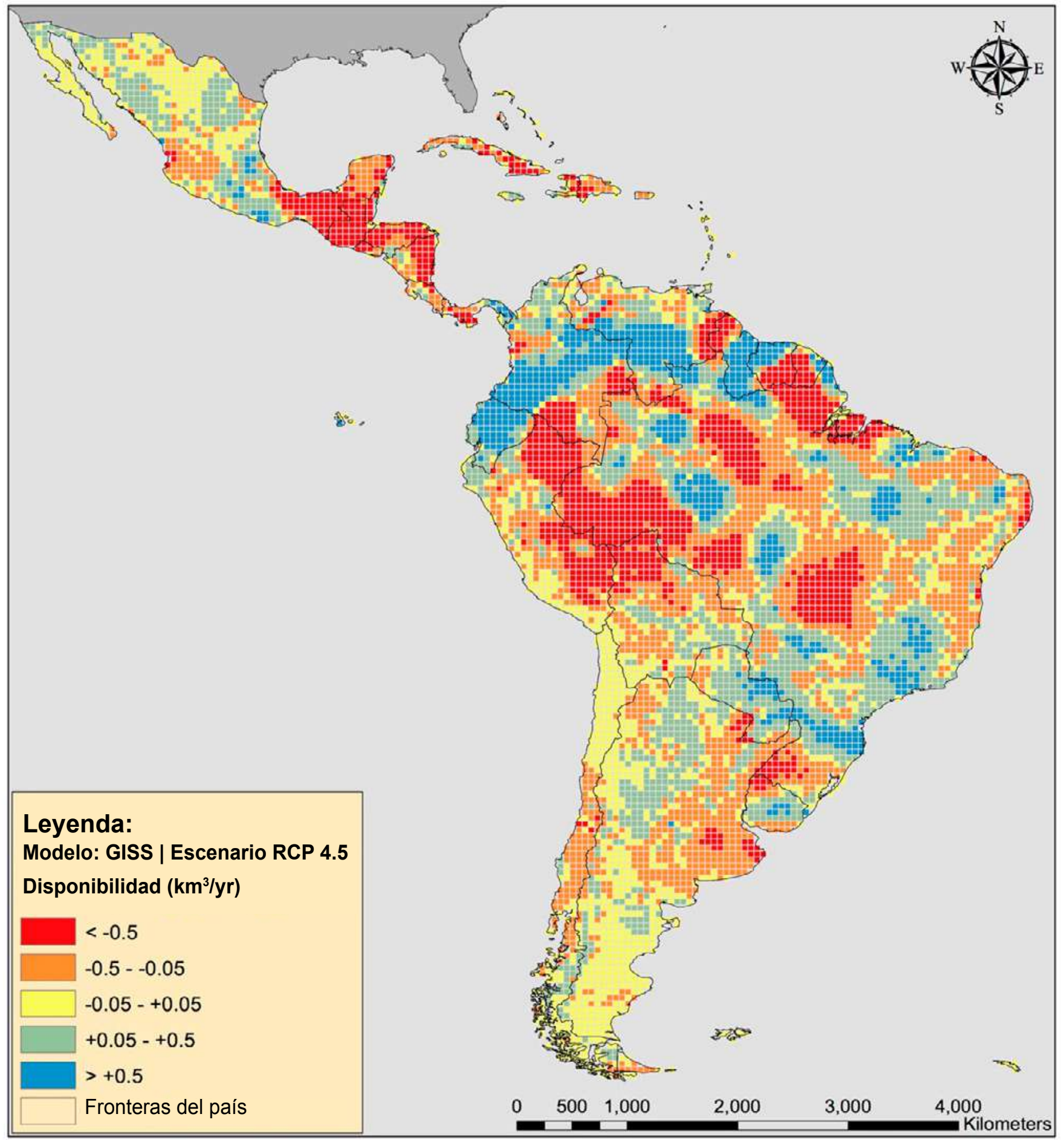

Fuente: Miralles-Wilhelm y Muñoz-Castillo, 2018. 


\section{Aguas subterráneas menos conocidas}

En el caso de las aguas subterráneas, existe un nivel menos avanzado del estado de conocimiento, en comparación con los recursos de agua superficial. En este sentido, se han desarrollado ejercicios conjuntos por parte de organismos nacionales, regionales y globales para hacer una caracterización de los acuíferos existentes en ALC, su extensión, disponibilidad hídrica y la calidad de sus aguas. Quizás la síntesis más completa de la situación de los recursos hídricos subterráneos se encuentre en la serie de estudios y mapas desarrollados por el Worldwide Hydrogeologic Mapping and Assessment Program (WHYMAP: http://whymap.org), un consorcio de organizaciones a escala global coauspiciado por la ONU, particularmente por su Programa Hidrológico Internacional (PHI).

El mapa que se muestra en la Figura 2.4. presenta la distribución geográfica de los recursos de agua subterránea en la región. Puede observarse una riqueza de recursos (colores oscuros) en la mayor parte del sur y América Central, con excepciones en Chile y el noroeste de Argentina y de Brasil. Existe una menor abundancia de recursos en el norte y el oeste de México. De acuerdo con los datos presentados en este mapa, existe sobreexplotación de acuíferos en zonas de escasa recarga del centro y el norte de México. Esto, unido a la relativa escasez de aguas superficiales en esta misma zona (ver mapa en la Figura 3), apunta a una escasa disponibilidad hídrica y, consecuentemente, mayores riesgos asociados a la $\mathrm{SH}$.

En lo que se refiere a la calidad del agua, una fracción significativa de los acuíferos en el norte y centro de Brasil, en Chile y el norte de Argentina y en México son de poca profundidad, lo que les hace más susceptibles a la contaminación motivada por recargas agrícolas o intercambios con fuentes de agua superficial contaminada. Adicionalmente, existen porciones del Acuífero Guaraní que se han salinizado, debido, posiblemente, a una combinación de sobreexplotación y contaminación proveniente de descargas de agua superficial. Sin embargo, es importante destacar que, aunque mapas como este sintetizan la información existente, al mismo tiempo adolecen de vacíos de información que pueden ser importantes: la extensión superficial y vertical de estos acuíferos necesita de mediciones más detalladas espacialmente y el intercambio con las aguas superficiales exige también una caracterización temporal de mayor resolución. Esta necesidad (que es al mismo tiempo una oportunidad de innovación) se presenta de forma más detallada en el Capítulo IV (Oportunidades de innovación en Seguridad Hídrica).

Sequías e inundaciones: un riesgo presente, aunque variable Otro aspecto importante en materia de SH que debe ser considerado desde el punto de vista físico es el de los riesgos relacionados con eventos hídricos extremos, tanto sequías como inundaciones. Estas se producen debido a una combinación de baja (sequía) o alta (inundaciones) disponibilidad hídrica (como sucede en muchas partes de la región -Figura 3-) y fallas o faltas 
de infraestructura para prevenir o mitigar sus efectos. Aunque el tema de la infraestructura se aborda en la Sección II.4, es importante analizar aquí las condiciones naturales de ocurrencia de estos eventos.

Las sequías se producen cuando concurren condiciones de humedad bajas en el suelo junto con bajas tasas de precipitación durante períodos prolongados. Estas condiciones hidrometeorológicas (humedad del suelo y tasa de precipitación) pueden resultar en una disponibilidad mucho menor al promedio histórico que usualmente se utiliza en la planificación hidrológica. Las inundaciones, por su parte, resultan de tasas de precipitación elevadas (mayores al promedio histórico) combinadas con condiciones topográficas locales: por ejemplo, elevaciones topográficas bajas como zonas costeras cuyas mareas altas contribuyen, junto con las lluvias, a elevar el riesgo de inundación; o pendientes pronunciadas que causan inundaciones en los valles debido al arrastre de escorrentía. Un tercer ejemplo de aumento del riesgo de inundaciones es el desbordamiento de los cauces de los ríos debido a mayores caudales causados por las altas precipitaciones. Estas condiciones locales varían a lo largo de la región, lo que resulta en diferentes niveles de riesgos tanto para sequías como para inundaciones. Las figuras 2.5 y 2.6 ilustran una síntesis de estas condiciones de riesgo, a través de una compilación de datos realizada por el World Resources Institute (WRI).

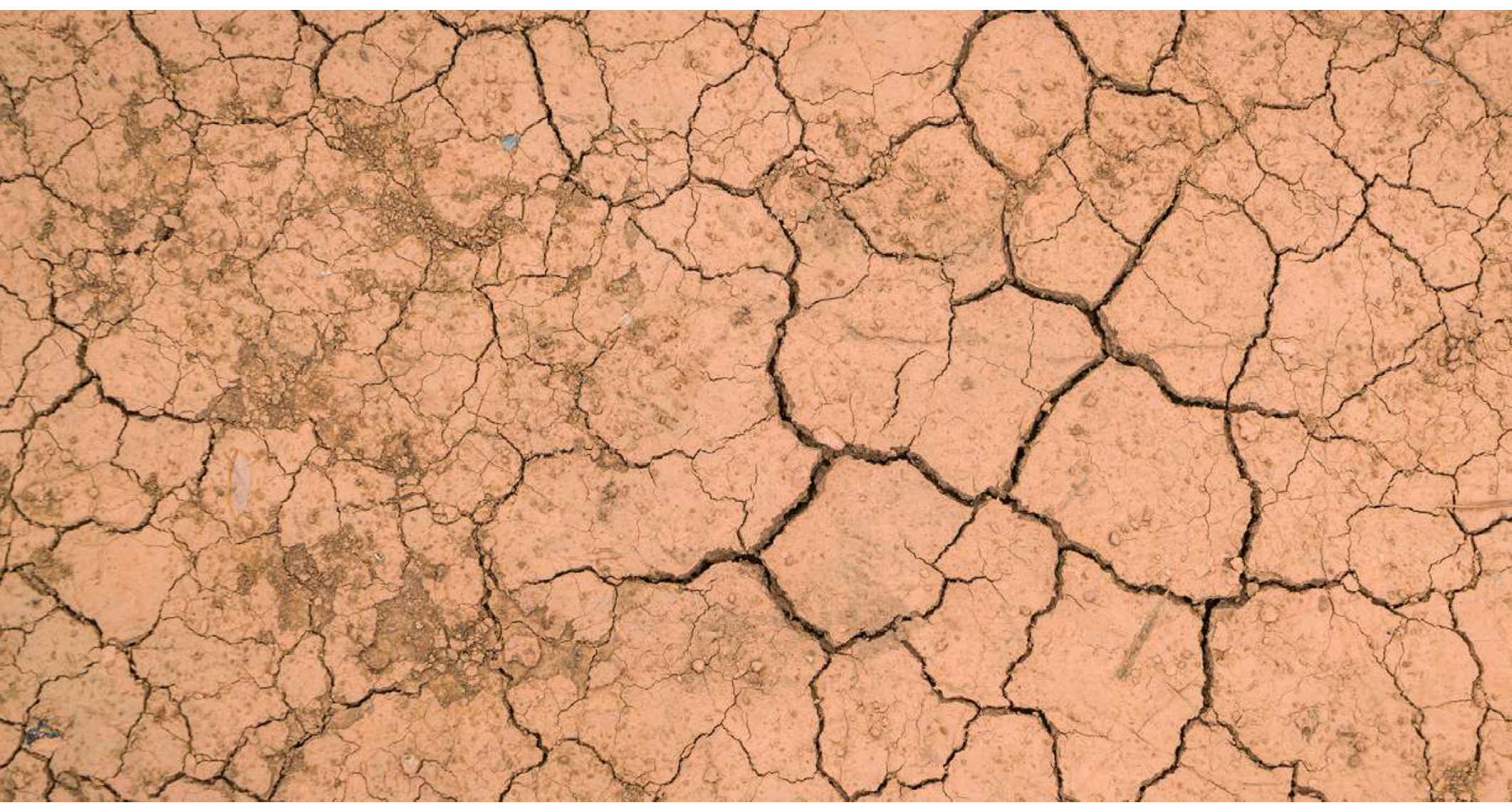


Figura 2.4. Mapa de recursos de aguas subterráneas en ALC.

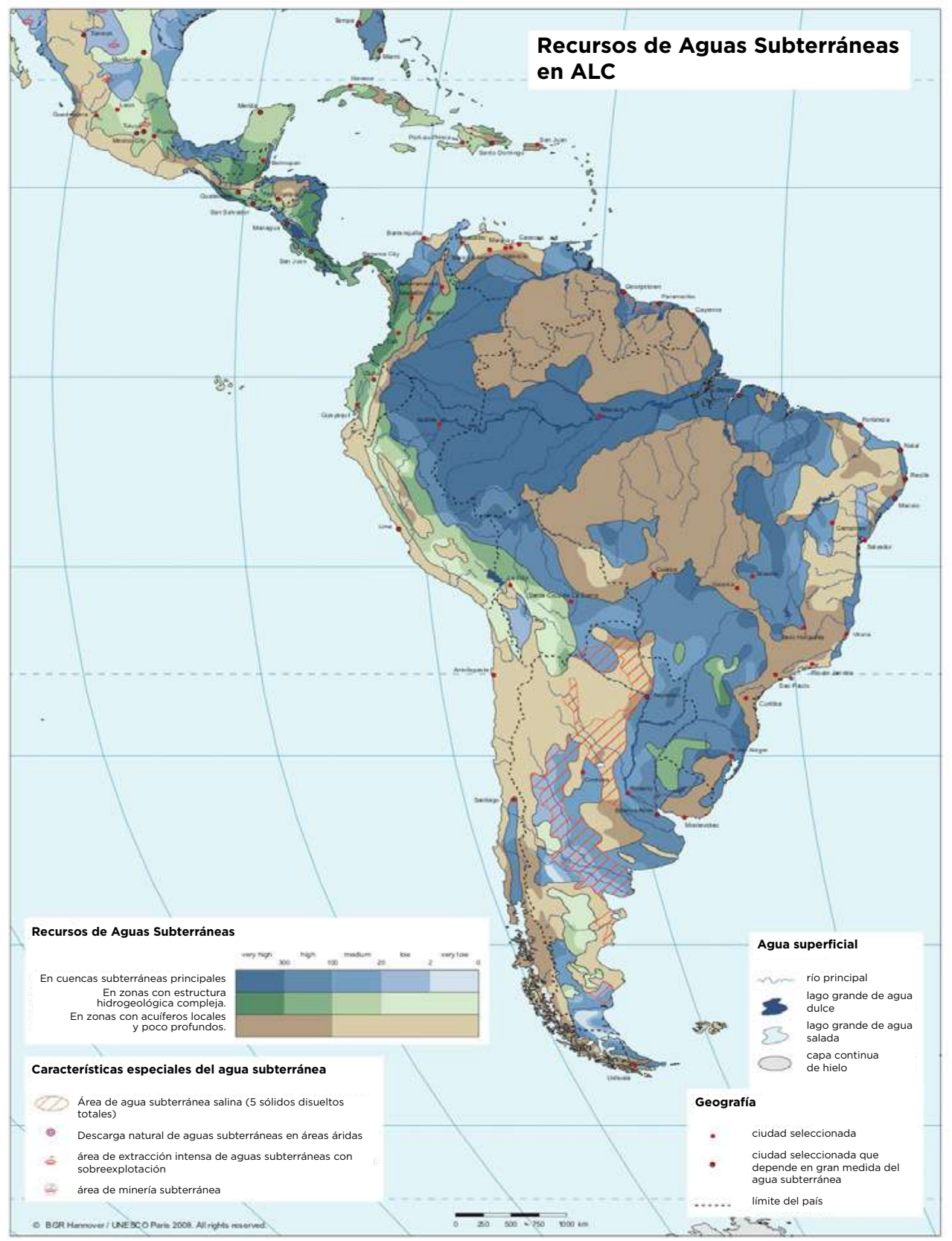

Fuente: WHYMAP, 2008. 
Figura 2.5. Mapa de riesgo de intensidad de sequías en la región de ALC

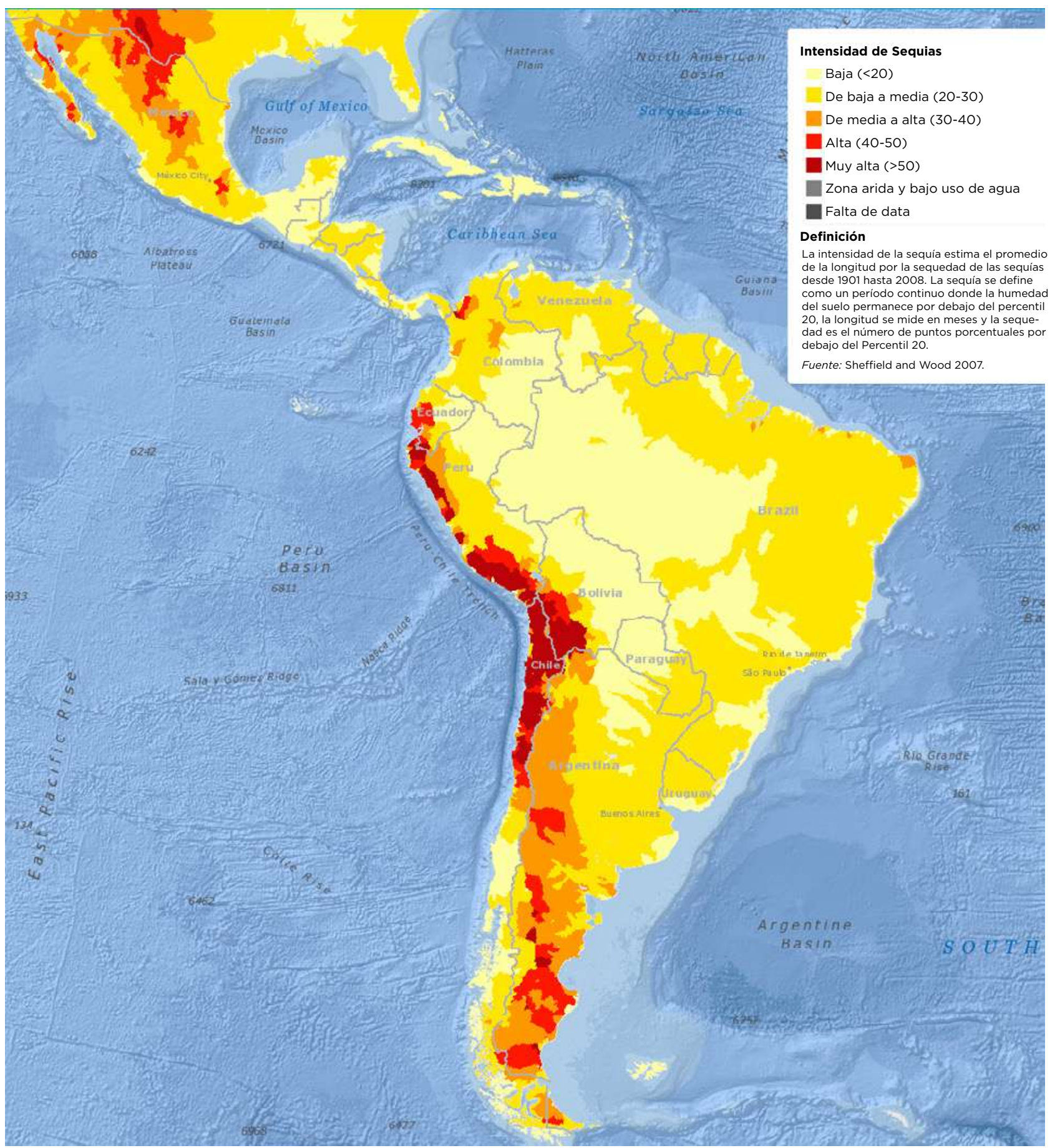

Fuente: Base de datos Aqueduct Water Risk Atlas del World Resources Institute. 
Figura 2.6. Mapa de riesgo de ocurrencia de inundaciones en la región de ALC

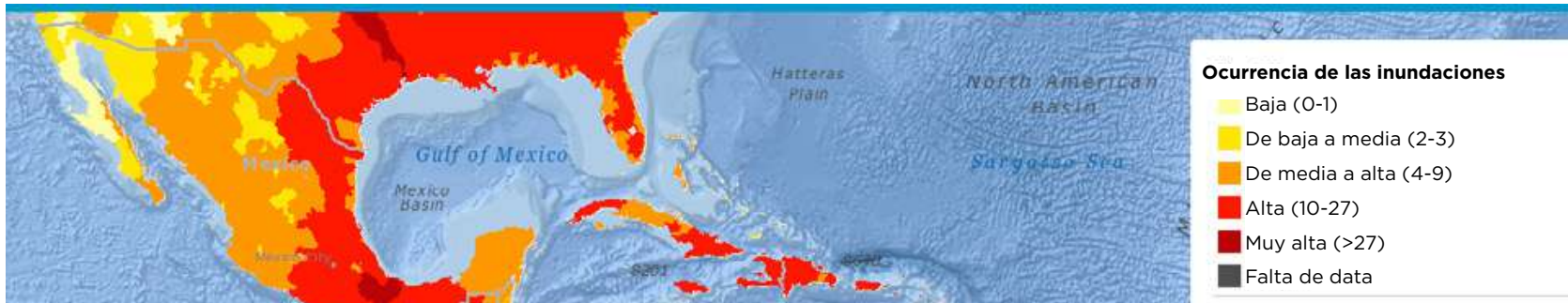

\section{Definición}

La ocurrencia de las inundaciones es un cuento del número de inundaciones registradas desde 1985 hasta 2011

Fuente: Brakenridge, Dartmouth Flood Observaroty 2011.

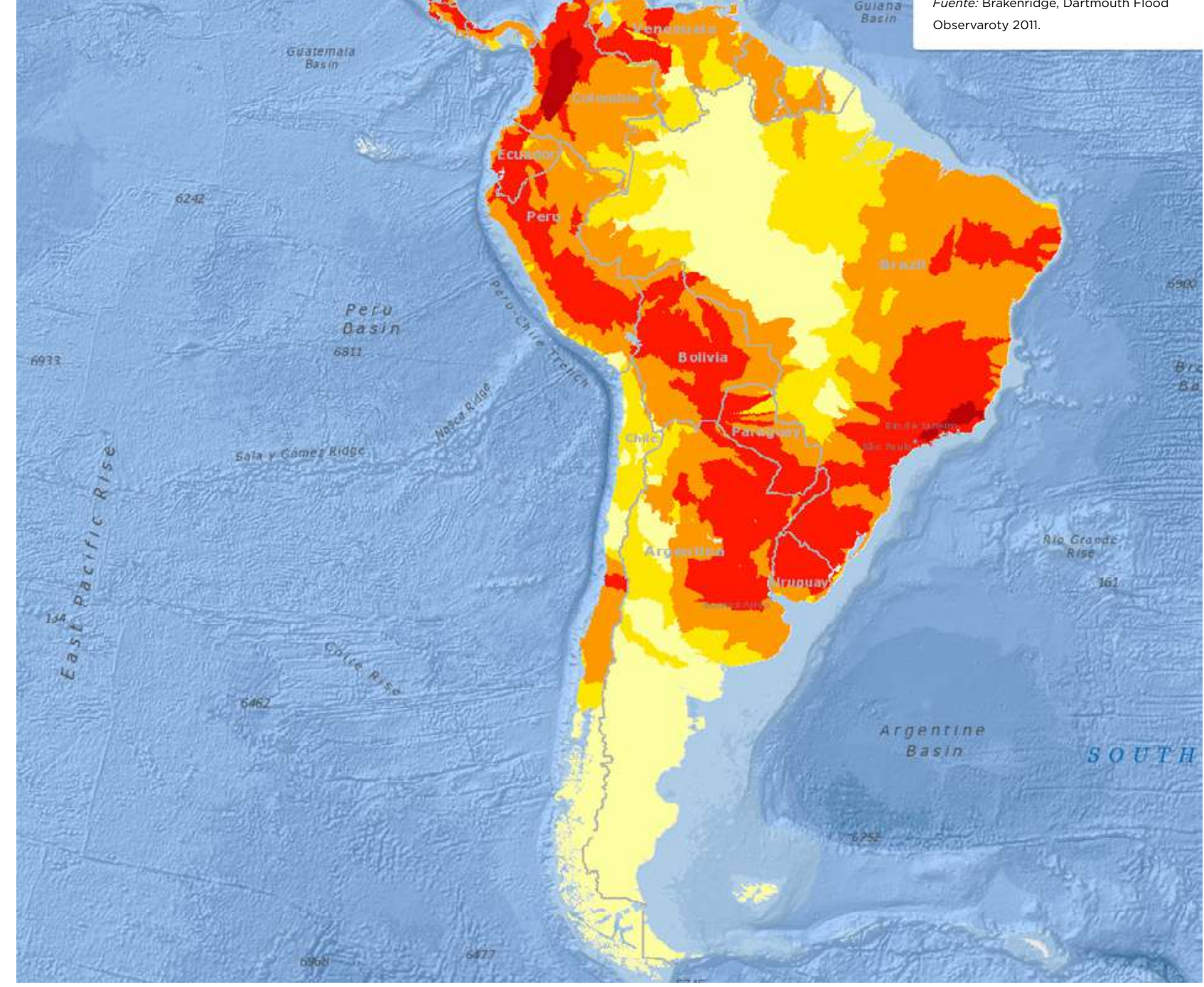

Fuente: Base de datos Aqueduct Water Risk Atlas del World Resources Institute. 


\section{II.2 Calidad del agua, ambiente y ecosistemas}

La calidad del agua es un factor adicional importante que limita la disponibilidad de los recursos hídricos en la región, especialmente en zonas áridas y semiáridas. Las fuentes naturales de agua tienen, a menudo, un importante contenido de sales y algunos elementos, como el arsénico y el boro (asociados a la actividad volcánica) y la presencia de evaporitas, que restringen su disponibilidad para determinados usos. El arsénico se encuentra presente en las fuentes naturales de las zonas áridas de México, América Central, Perú, Chile y Argentina, entre otros países (Pérez-Carrera y Fernández, 2010).

Además de esto, los ecosistemas de agua dulce (ríos, lagos y humedales) están influenciados por el área terrestre que drena en ellos, es decir, la cuenca hidrográfica. La cuenca, a su vez, es la unidad básica para determinar los presupuestos (balances) de agua (nutrientes y sedimentos que ingresan a cada ecosistema y que son retenidos por el ecosistema y exportados aguas abajo). El equilibrio entre estos tres componentes determina los impactos ambientales y las respuestas de los ecosistemas tanto en su estructura como en su función.

En las cuencas hidrográficas, los impactos ambientales son aditivos desde la parte superior de la cuenca hasta su descarga aguas abajo. Para los ríos, el ecosistema de agua dulce dominante en ALC, las corrientes se originan en los puntos más altos de la cuenca y contribuyen con el mayor número (aproximadamente el 95\%) y longitud (73\%) a las corrientes totales en una cuenca (Leopold et al., 1994 , Nadeau y Lluvias, 2007). La estructura y la función de estas corrientes de agua están influenciadas por la entrada de materia orgánica de la vegetación que bordea el canal y las concentraciones globales de nutrientes y sedimentos son característicamente bajas. A medida que la corriente baja, la pendiente se ensancha y se vuelve más rica en nutrientes y sedimentos, conforme aumenta el volumen total de agua que ingresa al canal como resultado del aumento progresivo del área de la cuenca que desemboca en la corriente. Los tramos medios e inferiores de los ríos más grandes de ALC (p. ej. Amazonas y Orinoco) han desarrollado interacciones

La contaminación de fuentes de agua derivadas de las actividades humanas es un problema que se ha ido extendiendo en la mayor parte de los países de la región importantes con sus llanuras de inundación, durante los períodos de inundaciones estacionales, que son críticos para los ciclos de vida de las especies de peces comercialmente importantes y la dinámica de la red alimentaria. En general, cuanto más pequeña es la cuenca y más pronunciado es el gradiente de elevación a lo largo de la corriente, más sensible es el sistema a las perturbaciones humanas y al cambio climático. Esto es particularmente cierto para las cuencas hidrográficas que drenan en las pequeñas montañas del Caribe y las de los bosques costeros de Mata Atlántica en la costa de Brasil.

La contaminación de fuentes de agua derivada de las actividades humanas (principalmente la disposición de aguas residuales -con niveles de tratamiento variables-, la producción de alimentos, las actividades extractivas e indus- 
triales y la generación eléctrica), es un problema que se ha ido extendiendo en la mayor parte de los países de la región. Estas actividades antropogénicas merecen una atención especial dado que, históricamente, han ido en aumento a medida que ha crecido la población, incrementándose la urbanización (mayor al 75\% de la población de ALC, desde el 2010) y, con ello, la presión de la demanda sobre los recursos hídricos que ha resultado en el empobrecimiento acelerado de la calidad del agua.

\section{Disposición de aguas residuales}

Según Naciones Unidas (ONU, 2018), las aguas residuales del 26\% de hogares en el mundo no reciben tratamiento. La región de América Latina y el Caribe, con un $22 \%$, solo está ligeramente retrasada con respecto a la media mundial. En los últimos veinte años se ha producido un avance sustancial en el tratamiento de aguas residuales urbanas que ha duplicado la cobertura de tratamiento. Las grandes municipalidades pueden acometer los costos de inversión y de mantenimiento, pero para que el proceso sea sostenible, estos costos deben estar incorporados a las tarifas. Recientemente entró en servicio la Planta de Tratamiento de Aguas Residuales de Atotonilco (México), la mayor del mundo, para tratar más de $30 \mathrm{~m}^{3} / \mathrm{s}$.

Mientras que, aproximadamente, el $91 \%$ y el $79 \%$ de la población de ALC recibe agua potable y alcantarillado (Noyala et al., 2012), la mayoría de los países de la región están tratando actualmente el 10\%-15\% de las aguas residuales (Reynolds, 2002; Noyala et al., 2012; Wilk y Altafin, 2018). Los porcentajes de tratamiento varían ampliamente desde aproximadamente el 5\% en Colombia y la mayor parte de América Central y el Caribe hasta el $100 \%$ en Chile (WSP, 2008; Wilk y Altafin 2018).

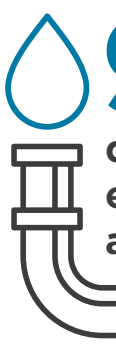

\section{$10-15 \%$ de las aguas se stán tratando}

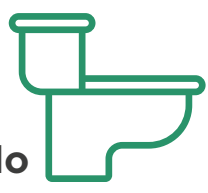

de la población

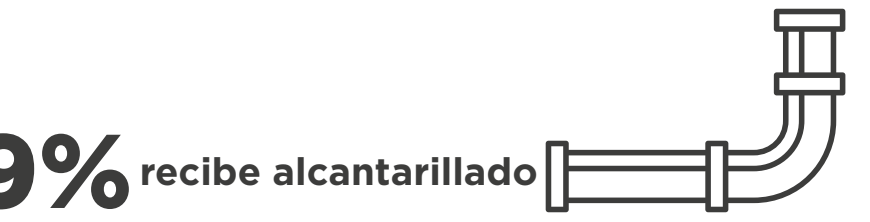

Adicionalmente, el aumento gradual en la temperatura promedio y extrema, producto del cambio climático, junto con el sobreenriquecimiento de nutrientes en el agua, incrementa el riesgo de aparición de brotes de cianobacterias en los cuerpos de agua. En este sentido el cambio climático es un elemento catalítico muy potente para la expansión de esta bacteria y en un futuro más caliente, estos organismos tendrán una ventaja sobre otros presentes durante los eventos de eutroficación. Es por tanto necesario monitorear y controlar la cantidad de escorrentía superficial rica en nitrógeno y fósforo que se arroja sin ningún tipo de tratamiento a los ríos, que van a dar a lagunas y reservorios de agua importantes para el abastecimiento de las grandes urbes. 


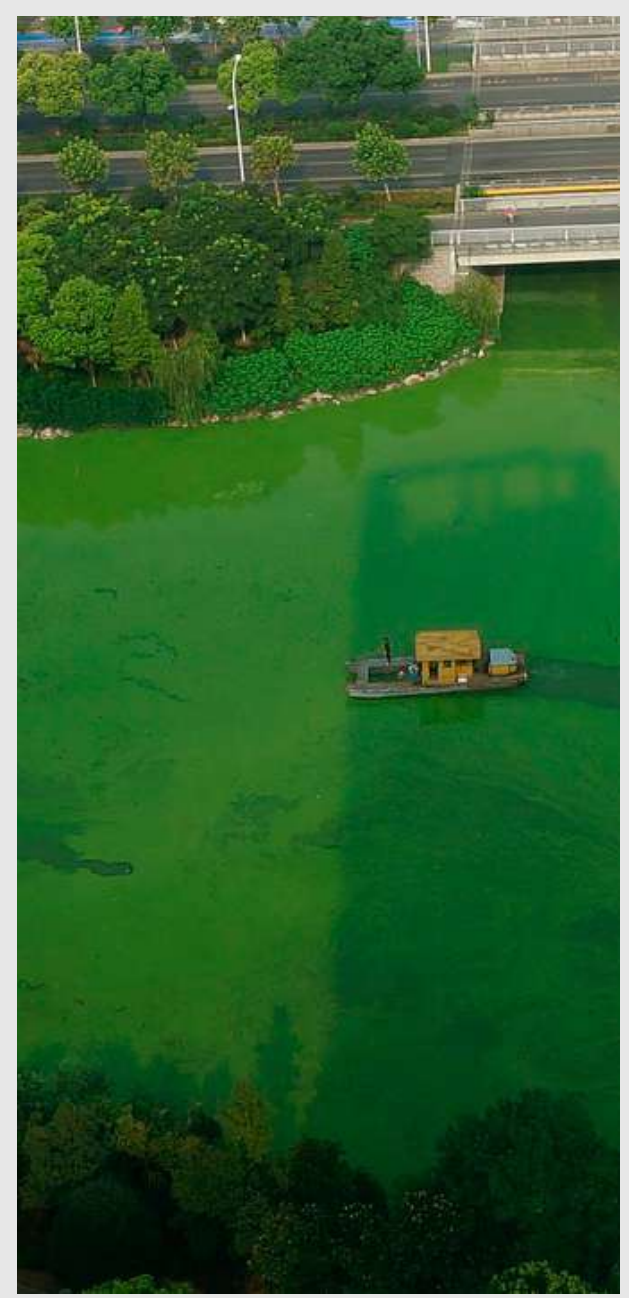

\section{Recuadro 2.3. Cianobacterias invasoras}

Las cianobacterias, también conocidas como algas verde-azules, son organismos eucariotas con una alta resistencia a las altas temperaturas y especialmente "amantes" de las aguas calientes. Su afloramiento en los cuerpos de agua amenaza la salud de los ecosistemas anexos y de las comunidades que dependen de estas fuentes (Paerl et al., 2008). El calentamiento global parece estar detrás del incremento masivo de este tipo de organismos en todas las aguas del planeta. La región de América Latina y el Caribe no es una excepción.

Es el caso, por ejemplo, de la laguna de Guarapiranga, responsable del abastecimiento de agua a aproximadamente 3,8 millones de personas, en la zona metropolitana de Sao Paulo, y en la que se han producido varios eventos de afloramiento de cianobacterias durante la época más caliente y lluviosa del verano (Oliver et al., 2016). Debido a que con cambio climático se espera un mayor número de días calientes en el verano, así como un aumento en el número de precipitaciones para esta zona, es muy factible que, si no se hacen inversiones para remover el exceso de nitrógeno y fosforo en el agua, se incremente la frecuencia de aparición de episodios de cianobacterias. Argentina ha vivido también un incremento en el número de episodios de cianobacterias, principalmente en la zona central del país (Aguilera et al., 2018). Es de esperar que esta situación se agrave con el cambio climático y teniendo en cuenta los bajos niveles de tratamiento (en particular remoción de nitrógeno y fosforo) de las aguas residuales que van a dar a los cuerpos de agua de los que la población se suple.

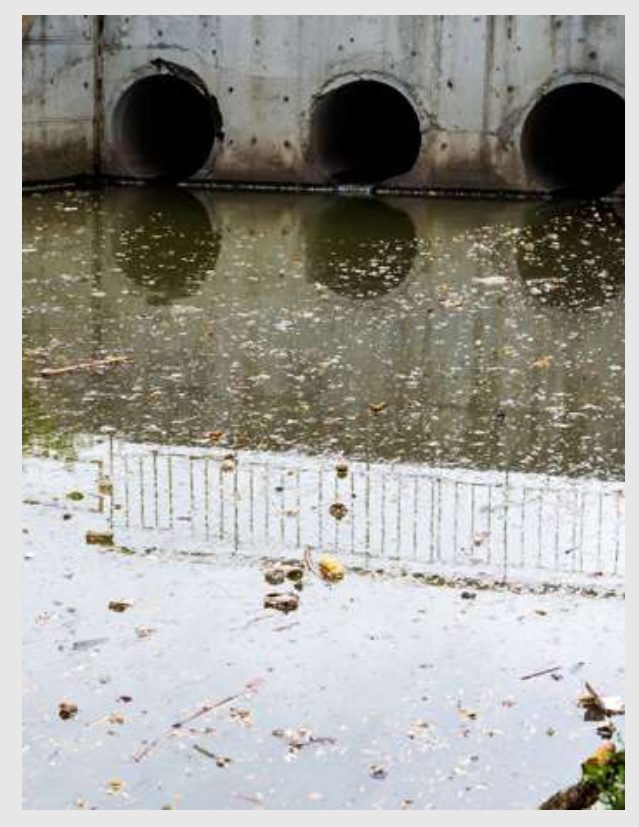

Recuerdo 2.4. La paradoja del alcantarillado

Los avances que se están produciendo en el alcantarillado, como uno de los Objetivos de Desarrollo Sostenible, están produciendo un fenómeno ciertamente paradójico. Y es que, si no se actúa en el tratamiento de las aguas residuales, lo que se hace es facilitar la llegada de más contaminación urbana a los ríos, otros cuerpos de agua y ecosistemas receptores.

Por otro lado, las poblaciones rurales, ampliamente dispersas en toda la región de ALC, han separado durante mucho tiempo las aguas residuales de las aguas grises (las que provienen de usos domésticos como el lavado de ropa o de utensilios de cocina). Estas últimas se descargan directamente al medio ambiente. Con la rápida urbanización de las poblaciones, los desechos domésticos se combinan en una sola descarga (aguas grises y aguas residuales), abrumando las plantas de tratamiento existentes, incluso para el tratamiento de aguas residuales más básico. 
Recuerdo 2.5. La descontaminación por vía judicial

A la hora de acometer el tratamiento de aguas residuales urbanas, existen en la región dos casos destacables y paradigmáticos por su judicialización. El primero es el del río Bogotá, fuertemente contaminado al existir, en su parte alta, industrias de curtidos de piel (curtiembres) que vertían metales (cromo y sulfuros) y sangre y demás desechos de los mataderos. A esto se añadían los vertidos sin tratar de las poblaciones aledañas (incluidos los habitantes de Bogotá) y otros vertidos industriales, minería extractiva y escombros. En 2004 se produjo una sentencia del Tribunal Administrativo de Cundinamarca (Sentencia 479 de 2004) que declaraba responsables del estado del río a instituciones públicas y particulares. Esta sentencia dio pie a una acción decidida sobre el conjunto de la cuenca para tratar de enfocar el problema globalmente.

El segundo caso reseñable es el de la cuenca del río Matanza- Riachuelo en Argentina, por el que las autoridades fueron sentenciadas a limpiar el río, lo que condujo al diseño de un plan integral para la recuperación ambiental de la cuenca.

Ambos casos abren una ventana de oportunidad para superar las grandes dificultades que supone emprender el tratamiento de las aguas residuales urbanas con el objetivo último de alcanzar un estado saludable de los ecosistemas fluviales (ríos, principalmente, y, en su caso, lagos y/o zonas húmedas).

Las dos cuencas mencionadas en el Recuadro 2.5. (Bogotá y Matanza-Riachuelo) forman parte del subconjunto de las cuatro cuencas más contaminadas en la región, a las que se añaden las de río Tieté (que atraviesa la ciudad de San Paulo, en Brasil) y la del lago Ypacarai en Paraguay. En México están identificadas las de los ríos Lerma, Rio Bravo y Suchiate; en Argentina, las cuencas del Reconquista, el Suquía, el Caracaña, el Río de la Plata, el Curaco, el Colorado y el Negro; en Chile, las de los ríos Maipo, Biobío, Elqui y Loa; en Colombia, las cuencas del Cauca y el Magdalena; en Brasil, los ríos Doce y Paraiba do Sul ; en Paraguay, los ríos Paraná y Paraguay; en Venezuela, los ríos Guaire y Murillo; en Perú, el río Ucayali y, finalmente, en Costa Rica, las cuencas de los ríos Tarcoles y Virilla.

La contaminación procede, en general, de todas las fuentes concebibles: abastecimiento urbano, basuras, vertidos industriales y mineros y vertidos agrarios. La única forma de avanzar hacia el éxito es actuar en todos los frentes simultáneamente. Sólo abordando de manera integral el problema, a nivel de cuenca se estaría en disposición de aspirar a la mejora de los ecosistemas fluviales. 
Los rebaños de alpacas se han expandido rápidamente y el sobrepastoreo esta produciendo una grave erosión a un 50-60\% de los Andes

Los rebaños de alpacas se han expandido rápidamente y el sobrepastoreo esta produciendo una grave erosión a un 50-60\% de los Andes

\section{Cambio en el uso del suelo para producir alimentos}

Las cabeceras de los ríos principales en ALC, incluyendo el Amazonas, están dominadas por pastizales intercalados con humedales de alta montaña, bofedales o páramos. Durante siglos, las actividades de pastoreo han resultado en la construcción de redes de canales para capturar la escorrentía estacional y dirigirla a los bofedales que sirven como un suministro de agua confiable (Verzijl y Quispe, 2013). Estos bofedales modificados por el hombre se han expandido con el tiempo y cumplen una función valiosa para almacenar agua en las montañas. Con un suministro de agua estable, los rebaños de alpacas se han expandido rápidamente y el sobrepastoreo es evidente en la mayoría de las áreas de elevaciones altas, lo que lleva a una grave erosión a un 50-60\% de los Andes (Millones, 1982). Esta situación se ha visto agravada por el redescubrimiento de la quinua que duplicó su producción en la primera década del siglo XXI, aumentando sus precios en un 300\%. Esto ha comprometiendo la SH del altiplano que se ha vuelto muy inestable a medida que más pastores han aumentado sus rebaños de alpacas con las ganancias de las ventas de quinua, incrementando así la presión sobre el agua almacenada en los bofedales. Además, el cambio climático ha provocado una reducción progresiva de los glaciares locales y en lugares como El Alto, en Bolivia, se planean presas adicionales multipropósito para recolectar agua de manera más efectiva y suplir a La Paz de agua potable.

Además de este ejemplo de los pastizales de alta montaña, los ecosistemas terrestres más amenazados por la conversión agrícola son la selva amazónica, los bosques secos y los pastizales subtropicales (Grau y Aide, 2008). Actualmente, solo subsiste el $20 \%$ del bioma original de la Amazonia y, con las tasas actuales de deforestación, para el 2030 se habrá perdido el $27 \%$ del bosque actual, especialmente en la Amazonia andina de Bolivia y Perú, aunque sus tasas de deforestación palidecen en comparación con las de Brasil2: la deforestación del Cerrado, las tierras de la sabana que bordean el este y sur de la Amazonía, han experimentado una rápida disminución, con una pérdida proyectada del 30\% de su extensión restante para el año 2050³. Mientras que la mayoría de las tierras despejadas en estos dos biomas se dedicaron históricamente la producción de ganado, la tendencia actual es destinarlas a la producción de soja. Hoy por hoy, Brasil es el principal productor mundial de soja, cuyo cultivo se ha cuadruplicado en los últimos 20 años para satisfacer, en parte, las crecientes demandas de China ${ }^{4}$. Esta expansión de la producción ha venido acompañada de problemas de erosión masiva y el envío de mayores cargas de sedimentos a los ríos del sistema del Amazonas que fluyen hacia el norte, así como a los que se dirigen al sur hacia el Pantanal.

El bosque seco del oeste de Costa Rica (Guanacaste) se ha utilizado tradicionalmente para el pastoreo de ganado. Durante la estación seca dependía

2 http://wwf.panda.org/our work/forests/deforestation in the amazon

3 https://www.worldwildlife.org/stories/saving-the-cerrado-Brasil-s-vital-sabana

4 https://www.producer.com/2018/05/brazil-could-take-soybean-production-crown-de nosotros/ 
Es necesario equilibrar la construcción de infraestructura con la producción de cultivos de alto valor en toda la región de los humedales para sostener rebaños, especialmente en la cuenca del río Tempisque. En 1980 se puso en marcha el Proyecto de riego Arenal-Tempisque (PRAT) con el objetivo de proporcionar agua durante todo el año y superar las restricciones impuestas por la precipitación estacional húmeda-seca y las sequías periódicas (Daniels y Cumming, 2008; De Szoeke et al., 2016). El agua fue transportada desde el lago Arenal, en las tierras altas, a través del Canal Oeste de siete metros de ancho, para fomentar la conversión de bosques secos en pastoreo de ganado y en la producción de cultivos. Las tierras recién regadas contribuyeron rápidamente con el $50 \%$ de la producción total de arroz y azúcar en Costa Rica. Si bien el canal original estaba revestido de concreto con pasos inferiores en los cruces de arroyos, en la década de los noventa se construyeron, apresuradamente, 20 kilómetros de canales más para dar cuenta del aumento de la demanda de producción. Estos nuevos canales estaban forrados de sedimentos y carecían de alcantarillas para el paso del arroyo debajo del canal. El resultado ha sido una alteración completa de la hidrología de la corriente de flujo intermitente a flujo permanente de fugas del canal.

Estas acciones ilustran claramente las respuestas rápidas implementadas para enfrentar las tendencias cambiantes del mercado de productos agrícolas sin preocuparse por posibles impactos en la SH. Los humedales se transformaron en arrozales que, aunque tenían la capacidad funcional de humedal nativo, carecían de la estructura natural requerida por la vida silvestre, especialmente las aves migratorias. Esta situación todavía está evolucionando, ya que muchos agricultores están cambiando a la producción de azúcar para apoyar los mercados de biocombustibles. El azúcar requiere el drenaje de la tierra en lugar del riego, por lo que se ignora la infraestructura del canal de riego, que aún fluye sin cesar y se desperdicia. Existe una necesidad crítica de equilibrar la construcción de infraestructura con la producción de cultivos de alto valor en toda la región (Ringler et al., 2000).

\section{Actividades extractivas}

La minería en ALC comenzó hace 500 años centrándose en metales preciosos de depósitos aluviales en Brasil y en minas de pozos en los Andes (Machado y Figueiroa, 2001). Las operaciones de extracción de pozos se han trasladado progresivamente a áreas muy remotas y más altas en los Andes. Muchas de estas minas han llegado al final de su factibilidad económica, dejando depósitos de desechos mineros ricos en metales pesados que se están lixiviando en diversos grados hacia los arroyos locales. Las concentraciones de muchos metales pesados (incluido el zinc, el cobre y el arsénico) superan los estándares de consumo seguro (Oyarzun et al., 2003; y Oyarzun et al., 2006), tanto en el agua como en los sedimentos. Esto último es especialmente preocupante debido a la lixiviación a largo plazo y al movimiento físico aguas abajo. Es importante tener en cuenta que muchos ríos tienen concentraciones elevadas de metales pesados naturalmente, a partir de la 
lixiviación del lecho de roca; pero los impactos de la minería pueden superar estos valores en órdenes de magnitud. También se desconoce el impacto de la recarga en la calidad de las aguas subterráneas dado que no se monitorean en la mayor parte de los casos.

Las operaciones mineras activas en los Andes tienen una alta demanda de agua que es atendida cada vez más por los arroyos, a medida que desaparecen las fuentes tradicionales de los glaciares. El resultado ha sido el acaparamiento de agua por parte de las empresas mineras que privan de agua a las comunidades aguas abajo para satisfacer sus necesidades básicas de agua potable y riego (Bebbington y Williams, 2008; Sosa y Zwarteveen, 2012). Además, los cambios en los patrones de precipitación y la alta variabilidad del ciclo hidrológico anual, exacerbado por el cambio climático, hacen que estas prácticas de uso del agua para producción minera sean poco sostenibles y se conviertan en un riesgo para el bienestar y la salud de las comunidades más pobres. La descarga reducida también aumenta los temores de que el agua restante de los arroyos se concentre en gran medida en los metales pesados lixiviados de los desechos de las minas. Finalmente, existe una creciente preocupación por que las comunidades privadas de agua en la costa oeste de América del Sur se vean obligadas a considerar la transferencia de agua entre las cuencas para satisfacer las necesidades domésticas, con la posibilidad inminente de que las corrientes contaminadas mineras se conviertan en parte del suministro de agua, exponiendo así a las poblaciones a riesgos de salud.

La extracción de depósitos aluviales para obtener oro, ópalos y uranio es una práctica común en todas las naciones de la cuenca del Amazonas y el este de Brasil (Minas Gerais). Hay tres tipos de operaciones en curso: corporativas y artesanales, que se centran en los depósitos terrestres a lo largo de los ríos, y el dragado comercial de los sedimentos de los canales fluviales. El uranio de los depósitos de desechos mineros se está lixiviando en arroyos y embalses en Minas Gerais (Rodgher et al., 2012), pero se ha logrado cierto éxito en disminuir el impacto de la minería artesanal para los ópalos mediante acuerdos cooperativos (Milanez et al., 2013). 
Figura 2.7. Mapa de riesgo de ocurrencia de impactos a la calidad del agua en la región de LAC

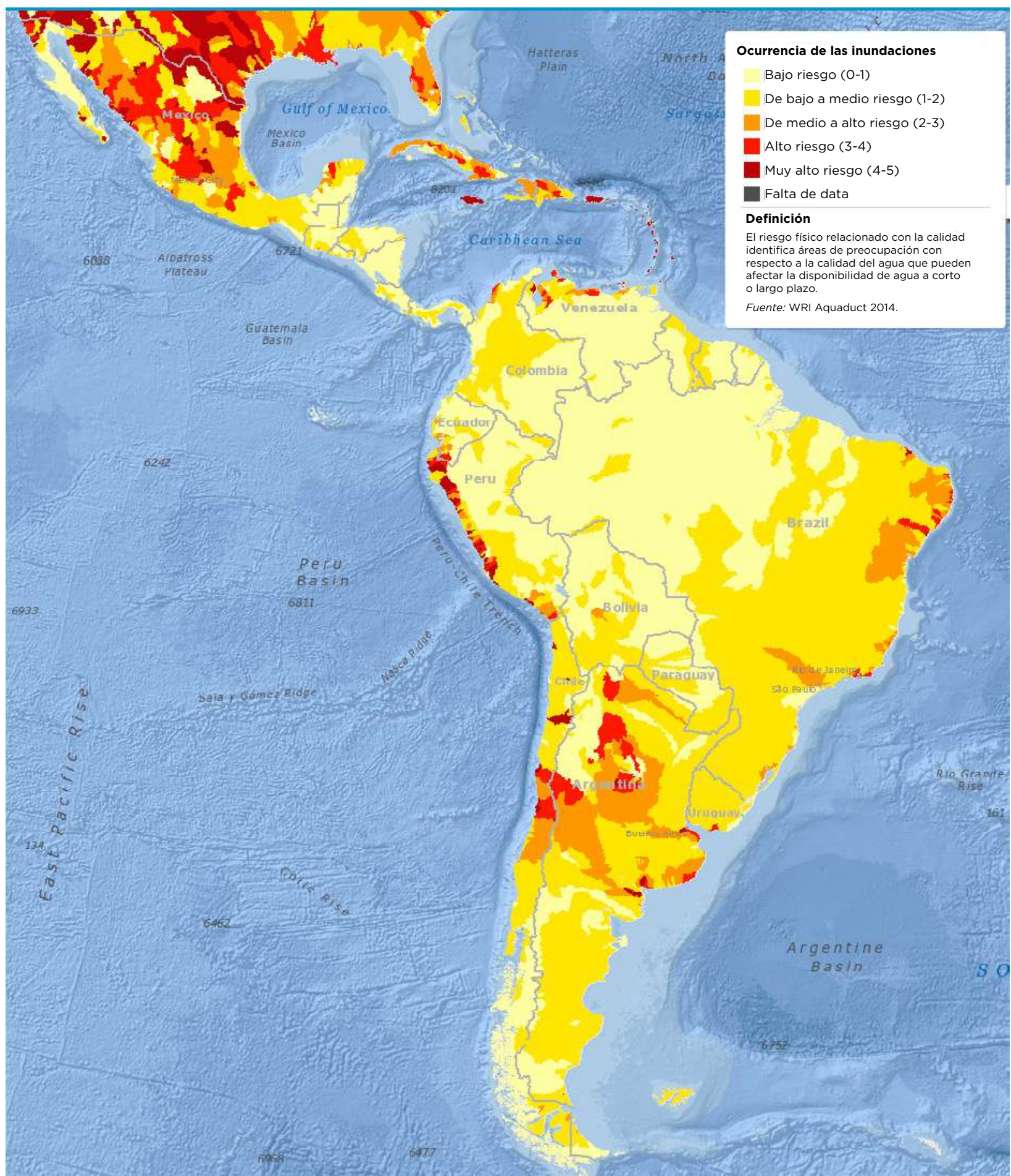

Fuente: Base de datos Aqueduct Water Risk Atlas del World Resources Institute. 
Cuadro 2.1. Caracterización cualitativa de desafíos de $\mathrm{SH}$ relacionados con la disponibilidad hídrica (bajo un rango de escenarios de cambio climático) y calidad de agua.

DH=Disponibilidad Hídrica; AS=Agua Subterránea; $C A=C a l i d a d$ de Agua; $\mathrm{SE}=$ Riesgo de Sequías; IN=Riesgo de Inundaciones. Se utiliza el color verde para condiciones satisfactorias (o favorables), amarillo para condiciones intermedias, y rojo para condiciones desfavorables (o insatisfactorias).

\begin{tabular}{|c|c|c|c|c|c|c|}
\hline País & DH & AS & CA & SE & IN & Comentarios \\
\hline Argentina & & & & & & $\begin{array}{l}\text { DH: la DH media es razonable (>20 mil m³/cap/año), pero con marcadas } \\
\text { diferencias regionales. } \\
\text { AS: El acuífero Guaraní (transfronterizo) sirve como fuente de agua, pero existe } \\
\text { un gran número de fuentes subterráneas que necesitan caracterización más } \\
\text { detallada. } \\
\text { CA: Fuentes de agua tanto superficiales como subterráneas a lo largo del país } \\
\text { en riesgo por prácticas agrícolas, deforestación, uso de agroquímicos y cambios } \\
\text { en el uso del suelo, particularmente en la cuenca del Río de La Plata (RLP). } \\
\text { Las cuencas Matanza-Riacheulo, Reconquista, Suquía, Caracaña, RLP, Curaco, } \\
\text { Colorado y Negro también destacan por problemas de contaminación debido a la } \\
\text { disposición de aguas residuales. } \\
\left.\text { SE: un } 75 \text { porciento del territorio es árido (con disponibilidad < } 1000 \mathrm{~m}^{3} / \mathrm{cap} / a n ̃ o\right) \\
\text { y dado a sequías acentuadas por fenómenos como El Niño. } \\
\text { IN: La mayor incidencia de inundaciones es en el noreste del país alrededor de la } \\
\text { cuenca del RLP y sus afluentes (Bermejo, Paraguay, Uruguay y Paraná). }\end{array}$ \\
\hline Bahamas & & & & & & $\begin{array}{l}\text { DH: El país tiene una DH relativamente baja (aprox. } 3000 \mathrm{~m}^{3} / \mathrm{cap} / \mathrm{año} \text { ), lo cual } \\
\text { resulta en una situación de estrés hídrico frecuente. } \\
\text { AS: Existe una delineación de los acuíferos a nivel de las islas que forman el país, } \\
\text { pero una buena parte requiere de una caracterización adecuada. } \\
\text { CA: Existen problemas pronunciados de contaminación por salinización de los } \\
\text { acuíferos. } \\
\text { SE: Existe poca información relacionada al riesgo de sequías, pero el país es } \\
\text { afectado por los eventos regionales en la cuenca del Caribe. } \\
\text { IN: El país está sujeto a un riesgo de inundaciones moderado debido a eventos } \\
\text { extremos y a la cercanía de la población a las costas. }\end{array}$ \\
\hline Barbados & & & & & & $\begin{array}{l}\text { DH: El país tiene la menor DH de la región, alrededor de } 280 \mathrm{~m}^{3} / \mathrm{cap} / a n ̃ o . \\
\text { AS: Existe una delineación de los acuíferos a nivel nacional, pero se requiere de } \\
\text { una caracterización adecuada. } \\
\text { CA: Las fuentes de contaminación son diversas (desechos sólidos, descargas } \\
\text { urbanas, actividades agrícolas e industriales). } \\
\text { SE: Existe poca información relacionada al riesgo de sequías, pero el país es } \\
\text { afectado por los eventos regionales en la cuenca del Caribe. } \\
\text { IN: El riesgo de inundaciones es moderado debido a la baja tasa de precipitación. }\end{array}$ \\
\hline Belice & & & & & & $\begin{array}{l}\left.\text { DH: La DH en el país es alta ( }>60000 \mathrm{~m}^{3} / \mathrm{cap} / a n ̃ o\right), \text { por lo que el estrés hídrico es } \\
\text { insignificante. } \\
\text { AS: Existe una delineación de los acuíferos en el país, pero hace falta realizar } \\
\text { estudios detallados de caracterización de los mismos. } \\
\text { CA: La contaminación del agua se debe a fuentes puntuales (aguas residuales } \\
\text { domésticas, industriales y agroindustriales) y no puntuales (erosión del suelo con } \\
\text { agroquímicos). } \\
\text { SE: El riesgo de sequías es bajo, debido principalmente a la alta DH. } \\
\text { IN: Se ha realizado un inventario de inundaciones e identificado su frecuencia de } \\
\text { ocurrencia. }\end{array}$ \\
\hline
\end{tabular}




\begin{tabular}{|c|c|c|c|c|c|c|}
\hline País & DH & AS & $\mathbf{C A}$ & SE & IN & Comentarios \\
\hline Bolivia & & & & & & $\begin{array}{l}\text { DH: la DH es relativamente alta (aprox. } 75000 \text { m³/cap/año) pero distribuida } \\
\text { desigualmente entre las cuenca del Amazonas, La Plata y la cuenca Cerrada } \\
\text { (lacustre o endorreica). } \\
\text { AS: Los acuíferos del Altiplano (La Paz y El Alto) y del Valle Central } \\
\text { (Cochabamba) están en explotación, pero sin caracterización hidrogeológica } \\
\text { detallada. } \\
\text { CA: Problemas generalizados de falta de alcantarillado sanitario y descargas } \\
\text { directas de industrias extractivas a cuerpos de agua. } \\
\text { SE: La cuenca Cerrada sufre sequías frecuentes y se han empezado a extender } \\
\text { hacia la zona urbana de La Paz. } \\
\text { IN: Las inundaciones son frecuentes a lo largo del país, con cuantiosas pérdidas } \\
\text { humanas y materiales. }\end{array}$ \\
\hline
\end{tabular}

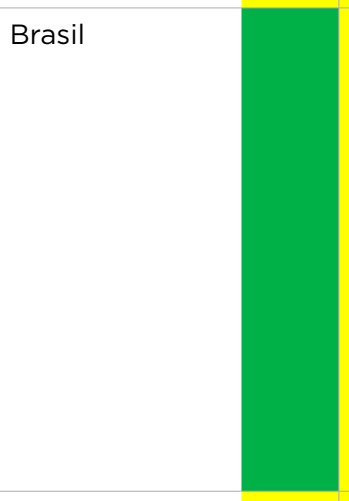

Chile

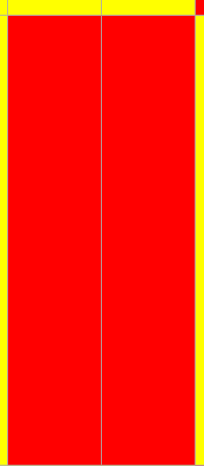

Colombia

Costa Rica
DH: la DH en el país es alta (>48000 m³/cap/año), con disponibilidades menores en los estados del noreste.

AS: Existe una delineación de los acuíferos a nivel nacional distribuidos en regiones hidrogeológicas, pero una buena parte requiere de una caracterización adecuada.

CA: Debido a los altos caudales, la calidad de agua se mantiene relativamente bien en la mayor parte de las cuencas del país, con problemas puntuales debido a las industrias extractivas. Es de notar la cuenca del Río Tiete, que atraviesa la ciudad de Sao Paolo, y las cuencas de los ríos Negro y San Francisco son de notar por problemas de contaminación vía disposición de aguas residuales.

SE: Hay estados de sequía frecuentes en el noreste del país particularmente y en las áreas costeras de manera general.

IN: Las inundaciones tienen una alta frecuencia en una buena parte del territorio, particularmente en las zonas urbanas del este y sureste del país.

DH: La DH a nivel nacional es alta (>60000 m³/cap/año), pero con un gradiente latitudinal significativo de condiciones desérticas (norte) a mayor (sur) disponibilidad. ${ }^{13}$

AS: Existe una serie de acuíferos a lo largo del país, pero son utilizados mayormente en la región norte para abastecimiento de actividades agrícolas y extractivas. ${ }^{123}$

CA: Existe incidencia extensa de contaminación por efluentes mineros y residuos industriales líquidos y contaminación agrícola y difusa de las aguas subterráneas.1 2 Las cuencas de Maipo, Biobío, Elqui, Loa son de notar por problemas de contaminación vía disposición de aguas residuales.

SE: Hay una incidencia fuerte de sequías en la zona centro y norte del país.

IN: El perfil de precipitaciones extremas hacia el sur del país resulta en inundaciones y eventos extremos de flujos de escombros.

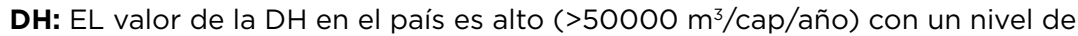
acceso al recurso que no da muestras de escasez hídrica.Sin embargo, la zona norte de Colombia (departamento de la Guajira) es una zona seca y semiárida que pasa por eventos de sequia frecuentes. Es tambien el departamento con los índices más altos de pobreza del país.

AS: Debido a la abundancia de recursos superficiales, los acuíferos no han sido estudiados ni explotados extensivamente.

CA: La carga contaminante a los cuerpos de agua es diversa (aguas residuales domésticas e industriales, extractivas y agrícolas, además de lixiviados de rellenos sanitarios. Las cuencas de los ríos Cauca y Magdalena son de notar por problemas de contaminación vía disposición de aguas residuales.

SE: La sequías en el país constituyen un problema relativamente menor con una incidencia moderada en las zonas costeras.

IN: Debido a la alta precipitación, una buena parte del país está expuesta a inundaciones crónicas.

DH: El país tiene una DH alta (>30000 $\mathrm{m}^{3} / \mathrm{cap} / \mathrm{año}$ ) con un nivel de acceso al recurso que no da muestras de escasez hídrica.

AS: Se ha realizado un esfuerzo de caracterización geológica de los acuíferos en el país con un grado de conocimiento intermedio de su potential como fuente de agua y calidad de la misma.

CA: La fuente principal de contaminación es la descarga directa de vertidos residenciales, industriales y agrícolas en los cuerpos de agua.1 3 Las cuencas de los ríos Tarcoles y Virilla son de notar por problemas de contaminación vía disposición de aguas residuales.

SE: El riesgo de sequías es relativamente menor e incrementa levemente hacia la costa atlántica.

IN: EL riesgo de inundaciones es elevado, debido principalmente a eventos extremos de precipitación. 


\begin{tabular}{|c|c|c|c|c|c|c|}
\hline País & DH & AS & CA & SE & IN & Comentarios \\
\hline Ecuador & & & & & & $\begin{array}{l}\text { DH: La DH media para el país es alta ( } 30000 \mathrm{~m}^{3} / \mathrm{cap} / \mathrm{año} \text { ), pero con deficiencias } \\
\text { mayores en la costa pacífica del país (casi cero). } \\
\text { AS: Se ha incrementado el esfuerzo para hacer una caracterización de los } \\
\text { acuíferos a nivel nacional, pero el conocimiento es incipiente. } \\
\text { CA: La calidad de agua se ve afectada por diversas fuentes (minería y petróleo, } \\
\text { agroquímicos), con mayor incidencia de contaminación en la zona costera (golfo } \\
\text { de Guayaquil). } \\
\text { SE: La aridez de la costa pacífica resulta en mayor riesgo de sequías en el país. } \\
\text { IN: El país sufre de condiciones de riesgo de inundaciones crónicas. }\end{array}$ \\
\hline El Salvador & & & & & & $\begin{array}{l}\left.\text { DH: EL país tiene una DH media moderada ( }>4000 \mathrm{~m}^{3} / \mathrm{cap} / a n ̃ o\right) \\
\text { AS: Existe información sobre delineación de acuíferos, pero hace falta una } \\
\text { caracterización meas detallada. } \\
\text { CA: La problemas de calidad se originan debido a la disposición de desechos } \\
\text { líquidos y sólidos a los cuerpos de agua sin tratamiento. } \\
\text { SE: El riesgo de sequías es bastante moderado debido a la alta tasa de } \\
\text { precipitación. } \\
\text { IN: Alto riesgo de inundaciones debido a la alta tasa de precipitación e } \\
\text { infraestructura escasa. }\end{array}$ \\
\hline
\end{tabular}

DH: La DH del país es moderada-alta (10000 m³/cap/año), y exhibe un nivel relativamente bajo de estrés hídrico.

AS: Los acuíferos contribuyen en menor medida a las aguas superficiales como fuentes de abastecimiento, y se han caracterizado escasamente.

CA: La contaminación del agua se debe a fuentes puntuales (aguas residuales domésticas, industriales y agroindustriales) y no puntuales (erosión del suelo con agroquímicos).

SE: Se han realizado estudios preliminares de riesgos de sequías y mapas de amenaza.

IN: Se ha realizado un inventario de inundaciones e identificado su frecuencia de ocurrencia.

Guyana

DH: La DH del país es la más alta de la región ( $>300000 \mathrm{~m}^{3} / \mathrm{cap} / \mathrm{año}$ ), con estrés hídrico insignificante.

AS: Se utiliza como fuente de agua potable debido a su alta pureza, y se ha realizado una caracterización preliminar de los acuíferos del país.

CA: Contaminación debida a disposición de desechos sólidos y líquidos y de agroquímicos, los cuales afectan fuentes de agua superficial y subterránea. SE: Existe poca información relacionada al riesgo de sequías, pero el país es afectado por los eventos regionales en la cuenca del Caribe.

IN: Debido al gran caudal fluvial y faltas de infraestructura, el país es vulnerable a las inundaciones.

DH: El país tiene una DH baja (aprox. $1000 \mathrm{~m}^{3} / \mathrm{cap} / \mathrm{año}$ ), lo cual resulta en situación de estrés hídrico crónica, particularmente en la zona norte del país). AS: Las aguas subterráneas se encuentran en estado de explotación, pero con una caracterización de los acuíferos que es insuficiente.

CA: La calidad de agua es pobre debido a la deforestación y otras prácticas agrícolas, y fuentes de contaminación diversas (desechos sólidos, descargas urbanas).

SE: El riesgo de sequías es relativamente bajo, pero sujeto a tendencias regionales del clima en el Caribe.

IN: El riesgo de inundaciones es relativamente alto debido a faltas de infraestructura.

Honduras

DH: La DH en el país es alta ( $\left.>15000 \mathrm{~m}^{3} / \mathrm{cap} / a n ̃ o\right)$ con poca incidencia de estrés hídrico.

AS: Los acuíferos se utilizan extensamente, y se han realizado estudios de caracterización detallada de los mismos.

CA: El deterioro de la calidad se debe a la descarga de desechos orgánicos de los centros poblados en el paso de los ríos, y por el arrastre de agroquímicos de los suelos y los desechos industriales.

SE: El país está sujeto a riesgo de sequía moderado, con poca capacidad de prevención y respuesta.

IN: El país está sujeto a inundaciones considerables debido a eventos extremos y falta de infraestructura. 


\begin{tabular}{|c|c|c|c|c|c|c|}
\hline País & DH & AS & CA & SE & IN & Comentarios \\
\hline Jamaica & & & & & & $\begin{array}{l}\left.\text { DH: El país tiene una DH relativamente baja ( }<3000 \mathrm{~m}^{3} / \mathrm{cap} / a n ̃ o\right) \text {, lo cual resulta } \\
\text { en una situación de estrés hídrico crónica. } \\
\text { AS: Se ha realizado una caracterización preliminar de los acuíferos del país, pero } \\
\text { no hay estudios detallados de explotación de los mismos. } \\
\text { CA: Las fuentes de contaminación son diversas (desechos sólidos, descargas } \\
\text { urbanas, actividades agrícolas). } \\
\text { SE: El riesgo de sequías es relativamente bajo, pero sujeto a tendencias } \\
\text { regionales del clima en el Caribe. } \\
\text { IN: El riesgo de inundaciones es relativamente alto debido a faltas de } \\
\text { infraestructura. }\end{array}$ \\
\hline
\end{tabular}

\section{México}

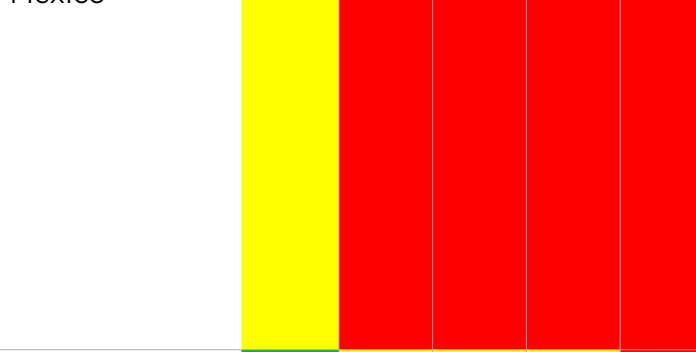

Nicaragua

Panamá

Paraguay
DH: La DH en el país es relativamente baja $\left(<5000 \mathrm{~m}^{3} / \mathrm{cap} / a n ̃ o\right)$ y distribuida desigualmente en un gradiente norte (menor) a sur (mayor).

AS: El agua subterránea se sobre-explota extensamente para usos diversos (satisfaciendo casi 40 porciento de la demanda total).

CA: La calidad de agua se ve afectada en la mayor parte de las cuencas del país por una combinación de fuentes puntuales (descargas) y difusas (agrícolas). Las cuencas de los ríos Lerma, Suchiate y Bravo son de notar por problemas de contaminación vía disposición de aguas residuales.

SE: El alto riesgo a sequías es notorio, particularmente en la zona centro y norte del país.

IN: Una buena parte del territorio del país está sujeto a inundaciones crónicas.

DH: La DH en el país es relativamente alta (40000 m³/cap/año), con poca señal de estrés hídrico.

AS: El recurso subterráneo se explota, pero con escasa caracterización de los acuíferos.

CA: Las fuentes de contaminación son variadas (descargas puntuales domésticas, prácticas agrícolas y extractivas).

SE: Se han realizado ejercicios de delineación de zonas susceptibles a las sequías.

IN: El país está sujeto a inundaciones crónicas por una combinación de eventos extremos y fallas de infraestructura.

DH: El país tiene una DH alta (>50000 m³/cap/año), lo cual resulta en un estrés hídrico insignificante.

AS: Se ha elaborado un mapa hidrogeológico del país, pero no existe una caracterización de los acuíferos para efectos de planificación y uso de los recursos.

CA: Las fuentes de contaminación notables son los desechos sólidos, los plaguicidas, la extracción de piedras y arena de los cauces de ríos, y la falta de sistemas de saneamiento adecuados.

SE: Debido a su alta $\mathrm{DH}$, el riesgo a las sequías es relativamente bajo.

IN: El país tiene riesgo de inundaciones relativamente bajo, excepto en áreas urbanas, donde el riesgo es moderado a alto.

DH: EL país tiene una DH alta ( $>60000 \mathrm{~m}^{3} / \mathrm{cap} / \mathrm{año}$ ), lo cual resulta en un estrés hídrico insignificante.

AS: Se han delineado y caracterizado los acuíferos principales, y se explotan con sofisticación relativa al resto de la región.

CA: Existe poco monitoreo e información sobre la calidad de agua excepto en algunas cuencas urbanas en Asunción. Las cuencas de los ríos Paraná y Paraguay, y el lago Ypacaraí son de notar por problemas de contaminación vía disposición de aguas residuales.

SE: El nivel de riesgo a sequías es moderado en la zona norte del país, el cual tiene menos precipitaciones.

IN: El riesgo a las inundaciones es alto en todo el país debido a escasa infraestructura.

DH: El país tiene una DH promedio muy alta (>70000 $\mathrm{m}^{3} / \mathrm{cap} / \mathrm{año}$ ), pero con una distribución muy desigual hacia la costa del pacífico.

AS: Los acuíferos se explotan particularmente en la zona costera del pacífico, y se encuentran medianamente caracterizados.

CA: Las actividades agrícolas, construcción de infraestructura, usos industriales, mineros, municipales y pastoreo tienen un impacto significativo en la calidad de agua en buena parte del territorio del país. La cuenca del río Ucayali es de notar por problemas de contaminación vía disposición de aguas residuales.

SE: Por sus condiciones de clima árido, la costa del pacífico presenta altos riesgos de sequías extremas.

IN: El riesgo de inundaciones a nivel nacional es alto debido principalmente al gradiente de precipitaciones entre la Amazonia y la costa pacífica. 


\begin{tabular}{|c|c|c|c|c|c|c|}
\hline País & DH & AS & CA & SE & IN & Comentarios \\
\hline $\begin{array}{l}\text { República } \\
\text { Dominicana }\end{array}$ & & & & & & $\begin{array}{l}\text { DH: El país tiene una DH relativamente baja }\left(<3000 \mathrm{~m}^{3} / \mathrm{cap} / \mathrm{año}\right) \text {, lo cual resulta } \\
\text { en una situación de estrés hídrico frecuente. } \\
\text { AS: Existe un mapa hidrogeológico nacional y varios acuíferos del país se } \\
\text { encuentran caracterizados. } \\
\text { CA: Existen problemas pronunciados de contaminación por actividades agrícolas } \\
\text { y salinización de los acuíferos. } \\
\text { SE: El riesgo de sequías es relativamente bajo, pero sujeto a tendencias } \\
\text { regionales del clima en el Caribe. } \\
\text { IN: El riesgo de inundaciones es relativamente alto debido a faltas de } \\
\text { infraestructura. }\end{array}$ \\
\hline Surinam & & & & & & $\begin{array}{l}\text { DH: El país tiene una DH muy alta (aprox. } 200000 \mathrm{~m}^{3} / \mathrm{cap} / \mathrm{año} \text { ), lo que se refleja } \\
\text { en una ausencia de estrés hídrico. } \\
\text { AS: Los acuíferos del país se han delineado, pero se necesitan estudios detallados } \\
\text { de su potencial de explotación. } \\
\text { CA: Las fuentes de contaminación son diversas (desechos sólidos, descargas } \\
\text { urbanas, actividades agrícolas y extractivas). } \\
\text { SE: El riesgo de sequías en el país es moderado y causado por eventos } \\
\text { hidroclimatológicos. } \\
\text { IN: El riesgo de inundaciones es moderado debido a la alta tasa de precipitación } \\
\text { y necesidades de infraestructura. }\end{array}$ \\
\hline $\begin{array}{l}\text { Trinidad y } \\
\text { Tobago }\end{array}$ & & & & & & $\begin{array}{l}\text { DH: El valor de la DH en el país es mediano-bajo (aprox } 3000 \mathrm{~m}^{3} / \mathrm{cap} / \mathrm{año} \text { ), lo } \\
\text { que resulta en un nivel de estrés hídrico mediano. } \\
\text { AS: Los acuíferos del país se han delineado, pero se necesitan estudios detallados } \\
\text { de su potencial de explotación. } \\
\text { CA: Las fuentes de contaminación son diversas (desechos sólidos, descargas } \\
\text { urbanas, actividades agrícolas y extractivas). } \\
\text { SE: La vulnerabilidad a sequías es relativamente baja excepto durante eventos } \\
\text { extremos (como la sequía regional del } 2009-10 \text { ). } \\
\text { IN: La vulnerabilidad a inundaciones es relativamente alta debido a eventos } \\
\text { extremos de lluvia y a falta de infraestructura. }\end{array}$ \\
\hline Uruguay & & & & & & $\begin{array}{l}\text { DH: La DH en Uruguay es relativamente alta ( }>50000 \mathrm{~m}^{3} / \mathrm{cap} / \mathrm{año} \text { ), y esto se } \\
\text { refleja en un estrés hídrico bajo. } \\
\text { AS: Los principales acuíferos del país se han delineado pero su caracterización } \\
\text { necesita mejoras. } \\
\text { CA: Existen problemas de contaminación importantes en varias de las cuencas } \\
\text { abastecedoras, debido principalmente a prácticas agrícolas y ganaderas. } \\
\text { SE: El riesgo de sequías en el país es moderado y causado por eventos } \\
\text { hidroclimatológicos. } \\
\text { IN: El riesgo de inundaciones es relativamente alto debido a la abundante DH y } \\
\text { falta de infraestructura de drenaje. }\end{array}$ \\
\hline Venezuela & & & & & & $\begin{array}{l}\left.\text { DH: El país tiene un DH alta (>50000 } \mathrm{m}^{3} / \mathrm{cap} / a n ̃ o\right) \text {, lo que se traduce en un estrés } \\
\text { hídrico bajo excepto en la zonas costeras densamente pobladas. } \\
\text { AS: Las aguas subterráneas se encuentran en estado de explotación, pero con } \\
\text { una caracterización de los acuíferos que es insuficiente. } \\
\text { CA: Las fuentes de contaminación son diversas (desechos sólidos, descargas } \\
\text { urbanas, actividades agrícolas y mineras). Las cuencas de los ríos Guaire y } \\
\text { Murillo son de notar por problemas de contaminación vía disposición de aguas } \\
\text { residuales. } \\
\text { SE: Los riesgos de sequía son moderados debidos a la abundante DH. } \\
\text { IN: El país sufre de inundaciones crónicas y extensas ocasionadas por una } \\
\text { combinación de condiciones físicas y deficiencias de infraestructura. }\end{array}$ \\
\hline
\end{tabular}

Fuente: Diagnóstico de los Recursos Hídricos en América Latina (2013), Editorial Pearson; Base de datos Aqueduct, World Resources Institute, www.wri.org; Water Resources Assessment of the Bahamas (2004), US Army Corps of Engineers; Groundwater Monitoring in Latin America, (2013), International Groundwater Resouces Assesment Centre (IGRAC); Water and Sanitation Belize, (2013), IDB Technical Note IDB-TN-609; Diagnóstico del agua en las Américas, (2012). Red Interamericana de Academias de Ciencias y Foro Consultivo y Tecnológico AC, ISBN 978-607-9217-04-4; Adamson, James K. and Jean-Baptiste, Gérald and Miner, W. Javan, (2016). Summary of Groundwater Resources in Haiti, (2016), Geological Society of America; Water Resources Assessment of Jamaica, (2001). US Army Corps of Engineers; Miralles-Wilhelm et al. (2017). Physical Impacts of Climate Change on Water Resources. Banco Mundial; Base de datos AQUASTAT (FAO). 


\section{$300 \%$} aumentará la generación eléctrica en el Amazonas ccon la construcción de más de 150 presas
Impactos ambientales de presas para generar electricidad y para usos múltiples

Aunque las estimaciones varían, las naciones montañosas de ALC satisfacen una parte importante de sus necesidades energéticas a través de la generación hidroeléctrica: Costa Rica (cerca del 100\%), seguida por Ecuador, Perú y Colombia (más del 70\% de la demanda). Brasil, a menor altitud, se encuentra actualmente en un $80 \%$ hidroeléctrico (Tundisi et al., 2014). Perú tiene el mayor número de presas en la actualidad y, junto con Bolivia, la mayoría son pequeñas y altas en las montañas (Anderson et al., 2018). Las presas más antiguas de Brasil se construyeron en el este y sureste del país, pero como se ocuparon todos los sitios favorables para la construcción de presas, la construcción comenzó a moverse hacia la cuenca del Amazonas (Da Silva Soito et al., 2011 y Tundisi et al 2014).

Si bien hay un número cada vez mayor de pequeñas presas en los Andes, la tendencia actual de construir nuevos embalses hidroeléctricos se centra en los sitios más bajos en la Amazonia andina y los afluentes de las tierras bajas del río Amazonas. Los pequeños embalses en los Andes tienen un potencial limitado de energía hidroeléctrica debido a su pequeño tamaño y profundidad, pero son críticos para el riego de áreas de pastoreo de alpacas, quinua y como suministro de agua para grandes ciudades como La Paz, Lima y Quito (Chevallier et al., 2011). Los recursos hídricos que alimentan estos embalses son suministrados por el agua de deshielo glacial (Guido et al., 2016), y los glaciares se han venido derritiendo progresivamente durante los últimos 50 años (Rabatel et al., 2013).

Para aprovechar la alta precipitación y las diferencias topográficas, actualmente se planifican o construyen más de 150 grandes presas en seis de los ocho principales afluentes del Amazonas con el objetivo de aumentar en un $300 \%$ la generación de electricidad en los próximos 20 años (Finer y Jenkins, 2012; Anderson et al., 2018). La mayoría están ubicadas en la ecorregión de los Andes altos del Amazonas y son más grandes que cualquier instalación actual en cualquiera de las naciones andinas. Perú ubicará el mayor número de presas planificadas. Los Andes contribuyen con el 50\% del caudal del río Amazonas, el 93\% de su carga de sedimentos y la mayor parte del nitrógeno y el fósforo para impulsar la productividad fluvial (Anderson et al. 2018). Existe una gran preocupación por que estas estas nuevas presas andinas interrumpan la conectividad de los Andes con las tierras bajas del Amazonas, atrapen el $100 \%$ del sedimento necesario para los diversos tipos morfológicos del canal, así como una parte significativa de nitrógeno y fósforo y aisle las áreas de conservación más altas en las montañas del río inferior (Tundisi et al., 2014; Finer y Jenkins, 2012; Anderson et al. 2018).

Como la mayoría de los sitios favorables para las presas se han ocupado en 
Además de atrapar sedimentos y nutrientes, las presas pueden tener un gran impacto en la SH a través de su huella hídrica azul el este y sureste de Brasil, la cuenca del Amazonas se ve como la "nueva frontera hidroeléctrica", donde ya hay 100 presas operativas y se planean 137 adicionales (Tundisi et al., 2014; Da Silva Soito y Freitas, 2011). Debido al bajo relieve general, las presas en la cuenca del Amazonas tienden a ser amplias y no tan altas, lo que da como resultado que grandes áreas de bosques se inunden como parte de los embalses hidroeléctricos, que atrapan grandes cantidades de sedimentos cargados de ríos que son críticos para las llanuras y los canales aluviales más bajos del Amazonas (Manyari y de Carvalho, 2007; Finer y Jenkins, 2014). Tales embalses de gran superficie tienden a volverse anóxicos (sin oxígeno disuelto) en grandes áreas (debido a la descomposición de la vegetación de la selva tropical que abandona allí durante la construcción); plantean problemas de calidad del agua por exceso de nutrientes, que promueven la proliferación de algas, y son importantes contribuyentes al azufre atmosférico durante las fases de baja agua (Tundisi et al. 1998, Rosa et al. 2003).

Además de atrapar sedimentos y nutrientes, las presas pueden tener un gran impacto en la SH a través de su huella hídrica azul, es decir al transformar escorrentía fluvial en pérdidas de agua por evaporación de su superficie. Cuanto mayor sea el área del embalse y mayor sea la temperatura, mayor será la liberación de vapor a la atmósfera (Hogeboom et al., 2018). Debido a la topografía que exige la necesidad de grandes superficies de embalses, Brasil tiene la huella de agua azul más grande de todas las naciones del mundo, cuestionando los beneficios positivos de la energía hidroeléctrica.

Las presas también pueden tener impactos ecológicos y sociales significativos (Finer y Jenkins, 2012). Los ríos evolucionan en su estructura y función desde las aguas de cabecera hasta su descarga de una manera predicha (Stream Continuum) que, si es interrumpida por una presa (discontinuidad en serie), puede tener serios impactos en los movimientos ascendentes de especies de peces comercialmente importantes y en peligro de extinción (Ward y Stanford, 1983). Tundisi et al. (2014) recomendaron espaciar las posiciones de las presas a lo largo de la longitud del río para permitir una distancia suficiente para que el río se recupere antes de encontrarse con otro embalse. Además de esto, las presas comúnmente generan conflictos sociales por necesidades de reasentamiento de poblaciones y sus actividades productivas, entre otros factores.

Quizás el impacto más significativo de las presas se refiere a la reducción de la conectividad ecológica y a la interrupción de los caudales ambientales. Lo primero hace referencia a la capacidad de conexión entre ecosistemas similares. El caudal ambiental es "la cantidad, el tiempo y la calidad de los flujos de agua requeridos para sostener los ecosistemas de agua dulce y estuarinos y los medios de vida y el bienestar humanos que dependen de estos ecosistemas" 5 . Para mitigar estos impactos, además de mantener un caudal mínimo en los canales fluviales, se deben desarrollar especificaciones para 
caudales medios mensuales y para la frecuencia de pulsos de caudal alto e inundaciones de las planicies fluviales (Richter et al, 2006). Las inundaciones anuales de las planicies fluviales son especialmente críticas para la productividad de los bosques y la cría de especies de peces de importancia comercial en la cuenca del Amazonas (Tundisi et al., 2014).

Para tener mayor relevancia en el manejo sostenible de agua dulce, los caudales ambientales deben cambiar su enfoque de restauración hacia la adaptación al cambio climático y cambios en el uso de la tierra; expandirse desde sitios únicos a cuencas hidrográficas completas e incluir la sostenibilidad socioecológica en todos los escenarios de gestión del agua (Poff y Matthews, 2013). Es muy importante que los caudales ambientales reconozcan las diferencias en la estructura y la función fluvial dictadas por los procesos fundamentales que operan en los ecosistemas e incorporen un manejo adaptativo que considere cambios a corto y largo plazo en la extensión de biomas individuales a lo largo de la región.

En lo que se refiere a las inundaciones, la tendencia actual es a utilizar soluciones de infraestructura verde, por sí solas o combinadas con las tradicionales soluciones de infraestructura gris. Todas estas medidas deben ser recogidas en los planes de gestión del riego de inundación (PGRI).

Recuadro 2.6. Infraestructura verde para la esperanza

En estos momentos, tanto en ALC como en el mundo en general, se prefieren soluciones de infraestructura verde o Soluciones Basadas en la Naturaleza (SBN) frente a, o en combinación con, las tradicionales soluciones infraestructurales (presas, encauzamientos, etc.). Las SBN utilizan los ecosistemas naturales y los servicios que estos proveen para responder a desafíos como el cambio climático, la seguridad alimentaria o los desastres naturales. Por ejemplo, la reforestación para estabilizar el cauce de un río y prevenir desbordamientos o la creación de humedales para mejorar y depurar la calidad del agua.

El reto para las SBN estriba en mostrar su eficiencia y viabilidad antes de emprender los programas de inversiones a mayor escala. Por ejemplo, en Colombia (a través del Fondo de Agua de Bogotá -Agua Somos-) se están comprando tierras para implantar en ellas infraestructura verde, que puede ir desde la reforestación de extensos territorios (páramos, en ese caso) a acciones más específicas en el curso de los ríos para devolverles su naturalidad y la recuperación de sus áreas naturales de inundación.

Al igual que ha ocurrido con la estrategia sobre el cambio climático, sería deseable contar con fondos para acometer experiencias piloto sobre la eficiencia y costoefectividad de las infraestructuras verdes en la lucha contra los fenómenos extremos como las inundaciones y sequías. 


\section{II.3Aspectos normativos y de gobernanza}

\section{Normativa escasa o poco pertinente}

El origen de la normativa en materia de aguas en ALC es muy antigua. Al margen de antecedentes regulatorios no basados en la existencia de una ley sino en otro tipo de instrumentos, incluyendo los propios de las poblaciones indígenas originarias, está basada en reproducciones, más o menos literales, de la Ley de Aguas española de 1879, de gran prestigio en su momento por su calidad normativa.

Durante la última década se ha observado gran interés por crear nuevas normativas en materia de aguas en distintos países

Es necesario superar la brecha del informalismo y la falta de eficacia de las normativas en materia de aguas.
Durante la última década se ha observado gran interés por crear nuevas normativas en materia de aguas en distintos países, lo que ha mejorado sus aspectos formales de forma clara, con independencia de su grado de aplicación real (Embid et al., 2017). Este fenómeno también ha sido captado por otros autores (Peña, 2016) que destacan los avances que se han experimentado en los últimos años en la región, en materia de agua y medio ambiente, aunque resalta lo mucho que aún falta por recorrer.

Esa apelación al camino que falta por recorrer unido a ciertas críticas sobre la situación existente es también preocupación de algunos estudios que señalan la insuficiencia de los marcos normativos, la falta de capacidad para aplicarlos, la debilidad de las autoridades nacionales de aguas, la debilidad de los organismos de cuenca, la fragmentación del poder decisorio y la escasa participación de las comunidades implicadas (Altomonte y Sánchez, 2016). Como prueba de las deficiencias detectadas se menciona la ausencia de capacidad para resolver conflictos, específicamente en el ámbito de los conflictos entre los diversos usos del agua.

Es evidente que es necesario superar la brecha del informalismo y la falta de eficacia de las normativas en materia de aguas, incluso para remediar los casos, todavía variados, de países que no cuentan con leyes de aguas (p. ej., Colombia, El Salvador, Guatemala) o aquellos cuyas normas son tan antiguas que sus prescripciones están completamente desconectadas de las preocupaciones fundamentales de la sociedad del siglo XXI (Panamá, con un decreto de 1966). También existen casos de países que, aunque cuentan con leyes recientes, les falta el adecuado desarrollo reglamentario sin el cual la novedad normativa no es implementable en la práctica (Paraguay).

Sí pueden mostrarse algunos ejemplos de avance en esta materia como, por ejemplo, la incorporación del derecho humano al agua a diversas constituciones en ALC, en correspondencia con una Observación de 2002 del Comité de Derechos Económicos, Sociales y Culturales de Naciones Unidas y la posterior proclamación del mismo, en 2010, por su Asamblea General. Sin embargo, muchos de estos esfuerzos adolecen de falta de contenidos con- 
cretos y dejan de lado la evidente necesidad de que la normativa ordinaria haga posible la implementación de estas leyes en la práctica.

Pero, además, se han dado una serie de leyes en los últimos años, probablemente conectadas con la Agenda ONU (Objetivos del Milenio 2005-2015) que se discuten en detalle en Embid et al. (2017). También existen otros proyectos de reforma normativa que no se han acabado de concretar todavía en una ley aprobada y en vigor (p. ej., Costa Rica, Guatemala, El Salvador, México o República Dominicana). Estas leyes se resumen en el Cuadro 2.2.

Cuadro 2.2. Leyes de aguas (reformadas o en vías de reforma) por país (en negrita se destacan las leyes sancionadas en este siglo).

El presente cuadro contempla sólo leyes de aguas y no la legislación complementaria (legislación civil, ambiental, de servicio público de agua, ordenamiento territorial, etc.), aunque esta haga parte sustancial del régimen jurídico del agua y algunos países, que carecen de leyes de aguas, se rijan incluso exclusivamente por ella.

\begin{tabular}{|c|c|c|c|}
\hline País & Ley / № & Año & Estado \\
\hline Argentina & $\begin{array}{l}\text { Ley de Aguas de Santa Fe № } \\
13740 \\
\text { Ciudad Autónoma de Buenos } \\
\text { Aires N } 3265 \\
\text { La Pampa N²581 } \\
\text { Provincia de Buenos Aires } \\
\text { NN}^{\circ} 2257 \\
\text { Chubut N } 4148 \\
\text { Córdoba N } 5589 \text { (reformada } \\
\text { en 2006) } \\
\text { Mendoza (con legislación } \\
\text { complementaria) }\end{array}$ & $\begin{array}{l}2018 \\
2010 \\
2010 \\
1999 \\
1996 \\
1974 \\
1884\end{array}$ & $\begin{array}{l}\text { Intento de reforma } \\
\text { en varias de las } \\
24 \text { provincias } \\
\text { argentinas }\end{array}$ \\
\hline Bolivia & $\begin{array}{l}\text { La Ley de Dominio y } \\
\text { Aprovechamiento de Aguas } \\
\text { ha sido derogada en varias } \\
\text { partes existiendo una variedad } \\
\text { de normas que a veces } \\
\text { se superponen regulando } \\
\text { sectores concretos }\end{array}$ & 1906 & $\begin{array}{l}\text { Varios proyectos e } \\
\text { intentos de reforma }\end{array}$ \\
\hline Brasil & $\begin{array}{l}\text { Ley de las Aguas № 9433/97 } \\
\text { A partir de su sanción cada } \\
\text { uno de los } 27 \text { estados del } \\
\text { Brasil ha promulgado su } \\
\text { propia ley de aguas }\end{array}$ & 1997 & Vigente \\
\hline Chile & $\begin{array}{l}\text { Código de Aguas. Reforma } \\
\text { parcial } 2005 .\end{array}$ & 1981 & $\begin{array}{l}\text { Intento de reforma } \\
\text { parcial } 2014 / 2015 . \\
\text { Creo que hay una } \\
\text { reforma parcial de } \\
2018 \text { o } 2019\end{array}$ \\
\hline Colombia & $\begin{array}{l}\text { Código Nacional de Recursos } \\
\text { Naturales Renovables y de } \\
\text { Protección al Medio Ambiente }\end{array}$ & 1974 & $\begin{array}{l}\text { Intento de dictar } \\
\text { una ley de aguas }\end{array}$ \\
\hline
\end{tabular}




\begin{tabular}{|c|c|c|c|}
\hline País & Ley / No & Año & Estado \\
\hline Costa Rica & Ley de aguas № 276 & 1942 & $\begin{array}{l}\text { Sucesivos intentos } \\
\text { de reforma }\end{array}$ \\
\hline Cuba & $\begin{array}{l}\text { Ley de Aguas Terrestres No. } \\
124 \text { y Decreto reglamentario } \\
\text { No. } 337 \text { del } 2017\end{array}$ & 2017 & \\
\hline $\begin{array}{l}\text { República } \\
\text { Dominicana }\end{array}$ & Ley de Aguas № 5852 & 1962 & $\begin{array}{l}\text { Sucesivos intentos } \\
\text { de reforma }\end{array}$ \\
\hline Ecuador & $\begin{array}{l}\text { Ley Orgánica de } \\
\text { Recursos Hídricos, Usos y } \\
\text { Aprovechamiento del Agua }\end{array}$ & 2014 & $\begin{array}{l}\text { Reglamento de } \\
2015 \text { modificado } \\
\text { parcialmente en } \\
2017 .\end{array}$ \\
\hline El Salvador & $\begin{array}{l}\text { Ley sobre gestión integrada } \\
\text { de los recursos hídricos }\end{array}$ & 1981 & $\begin{array}{l}\text { Se encuentra en } \\
\text { debate la Ley } \\
\text { General de Aguas }\end{array}$ \\
\hline Guatemala & $\begin{array}{l}\text { No cuenta con ley de } \\
\text { aguas específica ni con una } \\
\text { autoridad en la materia. El } \\
\text { régimen legal de las aguas } \\
\text { se encuentra disperso en } \\
\text { diferentes normas de distinto } \\
\text { rango. }\end{array}$ & & $\begin{array}{l}\text { Intento reiterado } \\
\text { de dictar una ley de } \\
\text { aguas }\end{array}$ \\
\hline Haití & $\begin{array}{l}\text { El país no cuenta con ley de } \\
\text { agua específica. }\end{array}$ & & \\
\hline Honduras & Ley General de Aguas & 2009 & \\
\hline México & $\begin{array}{l}\text { Ley de Aguas Nacionales } 1992 \\
\text { (reformada parcialmente en } \\
\text { 2004/2008/2013) }\end{array}$ & 1992 & $\begin{array}{l}\text { Intento de reforma } \\
2014 / 2015\end{array}$ \\
\hline Nicaragua & $\begin{array}{l}\text { La ley General de Aguas } \\
\text { Nacionales № } 620\end{array}$ & 2007 & $\begin{array}{l}\text { Reglamento de } \\
2010\end{array}$ \\
\hline Panamá & $\begin{array}{l}\text { Ley de Aguas Decreto Ley } \\
35 \text { de } 22 \text { de septiembre } \\
\text { sobre el uso del agua con } \\
\text { algunas reformas y leyes } \\
\text { complementarias }\end{array}$ & 1966 & $\begin{array}{l}\text { Sin intento de } \\
\text { reforma } \\
\text { Proyecto de Ley } 573 \\
\text { de } 2013 \text { de creación } \\
\text { de la Autoridad } \\
\text { Nacional del Agua }\end{array}$ \\
\hline Paraguay & $\begin{array}{l}\text { Ley 3239/07 de Recursos } \\
\text { Hídricos }\end{array}$ & 2007 & $\begin{array}{l}\text { En vías de } \\
\text { reglamentación }\end{array}$ \\
\hline Perú & $\begin{array}{l}\text { Ley de Recursos Hídricos-Ley } \\
\text { № } 29338\end{array}$ & 2009 & $\begin{array}{l}\text { Modificada en } 2017 . \\
\text { Reglamento de } \\
2010 \text { modificado en } \\
2014 .\end{array}$ \\
\hline Puerto Rico & Ley de Aguas № 136 & 1976 & Intento de reforma \\
\hline Uruguay & $\begin{array}{l}\text { Código de Aguas, decreto } \\
\text { № } 14859 \text {. Reforma de } \\
\text { Constitución en } 2004 \text { (art. } \\
\text { 47). Ley } 18.610 \text { de } 2009 \\
\text { sobre Principios de la Política } \\
\text { Nacional de Aguas. }\end{array}$ & 1978 & \\
\hline Venezuela & Ley de Aguas & 2007 & \\
\hline
\end{tabular}


¿Cómo es la normativa de aguas en ALC?

Una vez enumeradas las normativas más recientes sobre aguas en ALC, se puede realizar una caracterización y diagnóstico desde la perspectiva de la $\mathrm{SH}$.

La normativa en materia de aguas existe en la mayor parte de los casos, pero no siempre recoge los temas o principios que requiere la situación actual de SH. En este caso, no sólo es crucial contar con una normativa relativa a las aguas "moderna" y adecuada a la problemática de los tiempos actuales (Embid et al., 2018b); también, dependiendo del caso, otros ámbitos de normatividad, como los relativos al ordenamiento y la planificación territorial, urbanística o ambiental, o la política de residuos, pueden resultar igualmente importantes. Sin embargo, se advierten grandes dificultades en el momento de asegurar su efectividad y cumplimiento. Se debe reiterar que la informalidad es la característica general en la mayor parte de los casos. A continuación, se resumen algunas de estas dificultades.

- Falta información. En muchos supuestos, se desconocen cuestiones básicas o no hay instrumentos para conocerlas y facilitar, de esa forma, la gestión del agua y con ello la SH. El ejemplo de la ausencia de registros o catastros, o su actualización, es evidente. Sin el conocimiento fehaciente de los usos de las aguas, los volúmenes utilizados, su procedencia, su destino, su titular o su calidad, entre otros factores, se hace imposible la generación de permisos de uso y de vertido, la gestión efectiva de las aguas y el grado de $\mathrm{SH}$ existente.

- Administración hídrica deficiente. La administración hídrica presenta distintas deficiencias: (i) no siempre está basada en la cuenca hidrográfica; (ii) tiene escasos medios personales y económicos; (iii) el grado de formación del personal suele no ser suficiente; (iv) está, en ocasiones, muy politizada (formas de acceso a la función pública); y (v) está fragmentada. Excepto la primera característica, el resto son aplicables también a las entidades administrativas relativas al ordenamiento territorial o al urbanístico, de mucha importancia para una gestión adecuada de las aguas, como ya se ha indicado. Lo anterior es aplicable a los estados, pero en el caso de los estados federales, también se aplica a estados federados (es el caso de las Provincias argentinas, por ejemplo). En relación a esta última circunstancia ${ }^{6}$, existen múltiples órganos administrativos con competencias en materias fuertemente relacionadas con el agua como lo son la agricultura, la energía, la industria, el territorio o el medio ambiente. Allí también es advertible la fragmentación y falta de coordinación de políticas (Embid et al. 2018b).

- Planificación hidrológica poco desarrollada. En la mayor parte de los casos, la planificación hidrológica es aún incipiente. Aunque muchos doc-

6 En el informe CEPAL 2018 b, pp. 99 y ss. se dedica mucho espacio a los avances en el tema de mecanismos de coordinación en la institucionalidad relacionada con la implantación de la Agenda 2030 para el desarrollo sostenible. Se traen ejemplos de muchos países, de creación de nuevos órganos en algunos casos o, en otros, encargado funciones ya existentes para la implementación de la Agenda 2030 


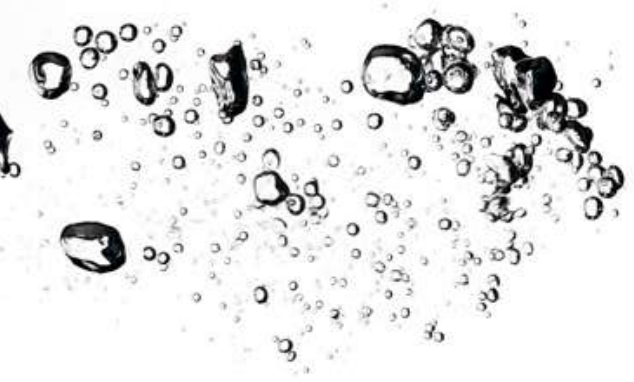

umentos se llamen "Planes", existen pocos con un enfoque en $\mathrm{SH}$ (es el caso del Plan de Panamá de 2016 que utiliza esa denominación). Otro tanto ocurre en el caso del ordenamiento territorial. No existen planes de ordenamiento del territorio que respondan al concepto de plan. Tampoco existen planes especiales de gestión de sequías o de riesgo de inundación; ni determinación de la línea de ribera (concepto argentino que sirve para delimitar el cauce -dominio público- de las tierras circundantes) ni delimitación de las vías de evacuación. En caso de existir, el nivel de coordinación entre planificaciones sectoriales implicadas en la SH (la energética, la agraria o la propiamente hidrológica) suele ser muy bajo o, incluso, nulo (Embid et al., 2018b).

- La interrelación equilibrada entre usos no siempre está bien concebida ni definida. En particular, debe señalarse la relación conflictiva entre minería y agua (problemática que se intensifica cuando se trata de minería ilegal -Benavides Vanegas y Ruiz López, 2016-), con el agua para las ciudades y el agua para la agricultura (Bustos Niño et al., 2016) y también entre energía y agua (Embid et al., 2017). Un ejemplo claro de este ámbito de conflictividad de usos es la aplicación de la técnica del fracking (fractura hidráulica) para la búsqueda de recursos energéticos no convencionales de petróleo y gas natural (Embid y Embid, 2017; Arroyo y Perdiel, 2015). Cuando existe regulación sobre el particular (p. ej. la provincia argentina de Mendoza, con normativa aparecida en el primer semestre de 2018), se suele prever la evaluación de impacto ambiental para los proyectos que pretenden usar esa técnica, pero sería necesario dar un paso más y prever una evaluación de riesgos completa, que incluya aquellos relacionados con el cambio climático sobre la disponibilidad de agua.

- El régimen económico-financiero del agua suele ser deficiente por distintas causas. La autofinanciación de las políticas hídricas no está asegurada con las cantidades que pagan los usuarios (cuando están establecidas y las pagan efectivamente), lo que quiere decir que no se sigue el siempre recomendado principio de recuperación de costos de los servicios prestados con el agua (o se sigue de manera deficiente). Todo ello es comprensible en un marco general en el que hemos notado la ausencia de registros o catastros fiables o actualizados porque en esos casos: ¿a quién cobrar y en qué cantidad? Por otra parte, en el contexto actual, fiar todo a la financiación presupuestaria no parece recomendable ni posible ya que, además, ésta, si cabe, suele ser inferior a la necesaria.

- Los mecanismos de resolución de conflictos son lentos. Lo es la práctica de los jueces y tribunales, donde se denota también muchas veces la ausencia de especialización de sus componentes (Martín y Justo, 2015). En ocasiones, además, la independencia de los órganos del poder judicial no está garantizada. Esto genera una desconfianza que, entre otras razones, ha conducido a la regulación de mecanismos de arbitraje en los 
La autofinanciación de las políticas hídricas no está asegurada con las cantidades que pagan los usuarios llamados Tratados de Protección de Inversiones. A su vez, estos mecanismos de arbitraje suelen primar los derechos de los inversores frente a los intentos de las autoridades locales de realizar políticas defensoras de los intereses generales. Esto conduce al llamado "enfriamiento regulatorio" (Bohoslavsky, 2010; Solanes, 2015).

- Herramientas de evaluación y diagnóstico débiles e inapropiadas. En caso de existir, las herramientas de evaluación y diagnóstico previo a la toma de decisiones suelen ser muy débiles, inapropiadas o mal aplicadas. La mayoría de los países cuenta con procedimientos obligados de evaluación de impacto ambiental (e incluso, a veces, de evaluación estratégica de impacto ambiental) con diferente nivel de desempeño; pero no cuentan con evaluaciones de riesgo, imprescindibles desde el enfoque de SH (como se ha señalado anteriormente con el ejemplo concreto de la técnica del fracking). Tampoco son habituales las evaluaciones rigurosas de tipo económico y social sobre el beneficio real de los proyectos, presupuestos, capacidad de pago de los usuarios, etc., a menudo sobrevaloradas para su justificación.

- Es necesario poner un mayor énfasis en el "ciclo del agua", es decir, en los sistemas, tanto grandes como pequeños, de abastecimiento de agua potable y de tratamiento (y, si es posible, reutilización) de las aguas residuales urbanas. Las grandes inversiones deberían centrarse en ambas esferas (facilitando como primera medida la inversión privada, pues la pública en las condiciones actuales no será suficiente) y los esfuerzos organizativos e institucionales (proceder a las reformas necesarias de la actual estructura administrativa). Esto debe venir acompañado de la consecución de economías de escala en el abastecimiento y en el saneamiento. Eso está muy relacionado con la insuficiencia o incapacidad, muchas veces, del nivel territorial municipal para la prestación de estos servicios por lo que sería conveniente buscar unidades de gestión más amplias, propiciando asociaciones de municipios (mancomunidades, consorcios) u otras fórmulas semejantes.

Por otra parte, en el caso en el que existe un mercado de aguas (Chile) está bien claro que se produce sin conocimiento real de las aguas existentes, de su estado de calidad ni de los titulares de los derechos de aprovechamiento. Tampoco las transacciones están rodeadas de la suficiente publicidad y, desde luego, las preocupaciones ambientales en el funcionamiento del mercado son prácticamente nulas en su planteamiento y, consiguientemente, en sus resultados prácticos. Tal mercado, además, no garantiza el abastecimiento de aguas a las zonas rurales, ámbito en el que actualmente se pueden observar grandes deficiencias (más de un millón de chilenos que viven en el espacio rural son abastecidos actualmente a través de camiones y no a través de infraestructura hídrica de abastecimiento). No cabe duda de que deberían ser reforzados los poderes y medios (personales y económicos) de la Dirección General del Agua, pues los presupuestos del mercado (la publicidad y la 
La situación de abastecimiento humano es muy variable, según el país y la subregión

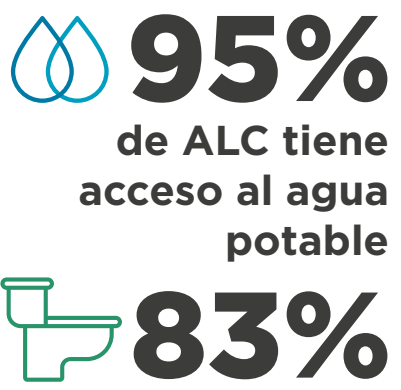

a saneamiento mejorado transparencia) no se cumplen y es condición imprescindible del mercado la existencia de un regulador con poderes efectivos.

Hay que dedicar especial atención a las políticas relativas a los fenómenos extremos como pueden ser las sequías y las inundaciones. Las características de buena parte de la región (sobre todo Centroamérica) y los avances en el conocimiento de los impactos del cambio climático muestran tendencias a propiciar un aumento de estos fenómenos extremos. Por ello es muy necesario que se implementen políticas de prevención del riesgo de sequía y de inundación, con los ejemplos ya conocidos en la Unión Europea de los Planes de Gestión del Riesgo de Sequía y de Gestión del Riesgo de Inundación. Ello debería llevar, en una segunda fase, a la introducción en las normativas sectoriales existentes ( $p$. ej., de aguas, de energía, de agricultura) de consideraciones relativas a los impactos del cambio climático.

\section{II.4 Estado de la infraestructura hídrica}

Los esfuerzos regionales y nacionales para mejorar las condiciones de la infraestructura hídrica se han concentrado en diferentes usos y propósitos que podemos clasificar en: (i) agua para abastecimiento humano; (ii) agua para riego y producción de alimentos; (iii) agua para producir energía; y (iv) infraestructura para combatir los eventos extremos (sequías e inundaciones).

\section{Infraestructura para abastecimiento humano}

En particular, las inversiones en infraestructura hídrica en ALC han sido objeto de énfasis debido al rol que cumplen, dentro de un marco de $\mathrm{SH}$, en el aseguramiento del suministro de agua para el abastecimiento humano con calidad aceptable para la salud. Asociado a este abastecimiento, se encuentra la recogida de las aguas domésticas usadas a través de una red de saneamiento, que mejora la higiene de las familias y, consecuentemente, su nivel sanitario. Como es previsible, la situación es muy variable, según el país y la subregión.

La información más completa y actualizada sobre los niveles de acceso a estos servicios, corresponde a la reportada por la OMS y UNICEF en 2015 que presenta la Figura 2.8. De ella se deduce que el conjunto de los países de ALC presenta un nivel de acceso al agua potable del $95 \%$ y a saneamiento mejorado del $83 \%$, con una gran variabilidad entre países. El país que muestra mayores deficiencias es Haití, en el que la cobertura de agua segura es tan sólo del $58 \%$, en tanto que la cobertura de saneamiento es tan sólo del $28 \%$. Los que más alto grado de cobertura en agua segura han alcanzado son: Barbados, Belice y Uruguay, con el 100\%. Y por encima del 95\% se encuentran Argentina, Bahamas, Brasil, Chile, Costa Rica, Guyana, México, Panamá, Paraguay y Trinidad y Tobago. En saneamiento, estarían primero Argentina, Barbados, Chile, Costa Rica y Uruguay, con porcentajes superiores al 95\%. Los mismos desequilibrios que se producen entre los países, tienen lugar 
dentro de estos. Como ejemplo en México, los estados de Chiapas, Guerrero y Oaxaca tienen coberturas cercanas al $74 \%$, mientras que a nivel nacional los porcentajes son del $96 \%$ y del $85 \%$ en saneamiento.

Figura 2.8. Porcentajes de cobertura de agua y saneamiento, global para la región de ALC y por países.

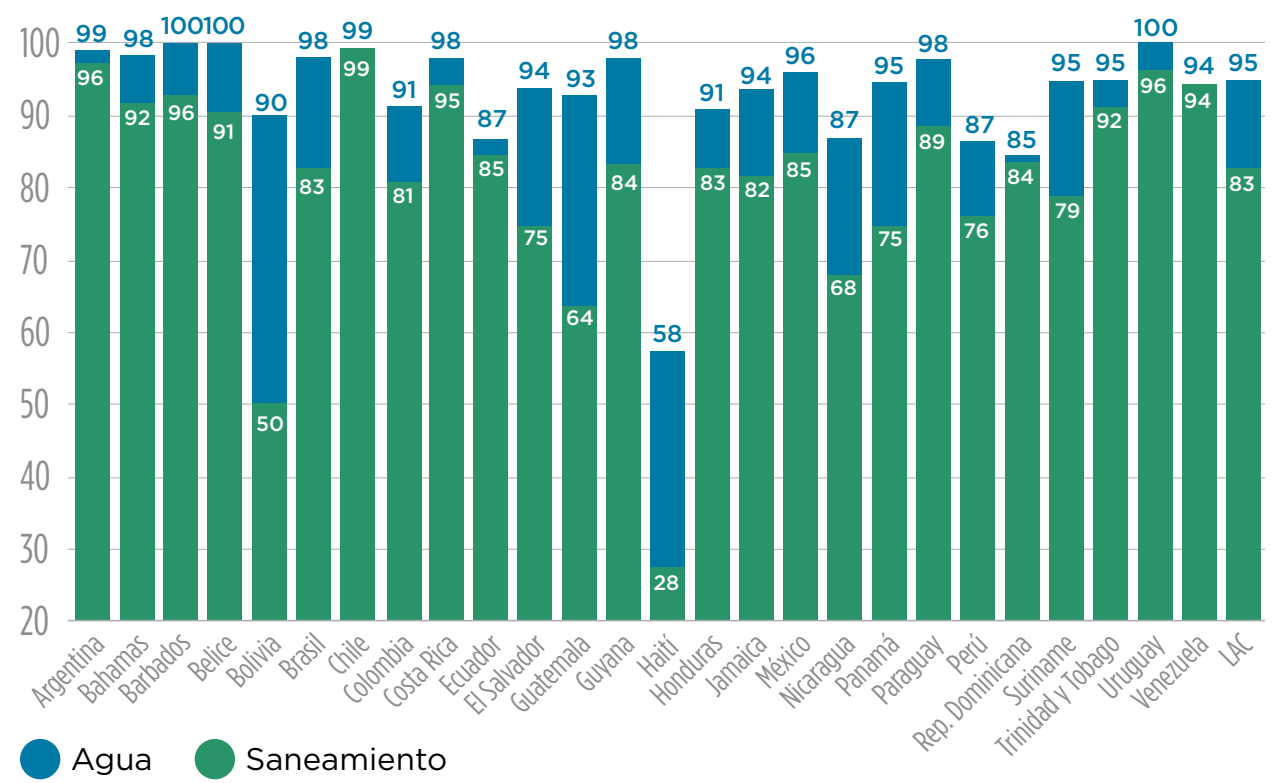

Fuente: Documento de Marco Sectorial de Agua y Saneamiento. BID, diciembre 2017.

A ello se añade que la calidad del servicio no es plenamente satisfactoria, ni siquiera en las zonas con una razonable cobertura de redes. Los principales problemas detectados, muy generalizados en la región, son: (i) falta de potabilidad, por presencia de materia fecal y contaminantes químicos; (ii) falta de suficiente presión para asegurar la llegada de agua a pisos superiores; (iii) falta de continuidad en el servicio, con amplios períodos de cortes de agua. Se reportan porcentajes del $60 \%$ de sistemas de agua que no aseguran el servicio las 24 horas durante los siete días de la semana, con el riesgo de roturas al restituir el servicio por los golpes de ariete que provoca el aire que haya entrado en los conductos; (iv) déficits en las conexiones intradomiciliarias.

El suministro con aguas subterráneas presenta también falta de potabilidad por la presencia de nitratos, arsénico, boro y otros contaminantes. En zonas costeras, y de manera muy especial en las islas del Caribe, la sobreexplotación de los acuíferos favorece la intrusión salina, lo que inhabilita esta agua para el abastecimiento urbano al convertirlas en aguas salobres, con alto contenido salino. Los efectos del cambio climático todavía agudizarán más estos problemas, de forma que, o bien se identifican fuentes de recursos potables dentro de las islas o habrá que contemplar la tecnología de desalinización. Por otro lado, la pérdida de estas reservas subterráneas, en tanto que reservas estratégicas, añaden dificultad para afrontar los episodios de sequía. 
Con las reservas propias de los análisis llevados a cabo para el presente trabajo, las conclusiones alcanzadas son las siguientes a nivel regional:

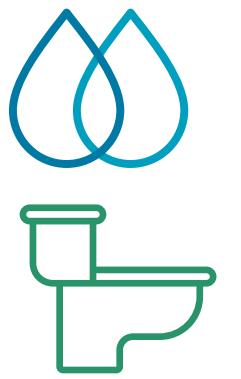

- Cobertura agua (promedio):

$95 \%$

- Cobertura agua segura (promedio):

$68 \%$

- Objetivo agenda 2030:

$100 \%$

- Cobertura saneamiento promedio:

$68 \%$

- Cobertura saneamiento real:

$22 \%$

- Objetivo agenda 2030:

$100 \%$

- Población sin cobertura de agua segura: 198 millones

- Población sin cobertura de saneamiento real: 457 millones

El Joint Monitoring Programme (un programa conjunto de monitoreo de la OMS y UNICEF ), que menciona el Marco Sectorial de WSA, estima que, a nivel regional, la cobertura de hogares con aguas residuales tratadas está alrededor del $22 \%$ en promedio, con una variación muy alta entre países (en Chile supera el $80 \%$, seguido por Uruguay, con el 45\%; México, con un 37\%; Brasil, con un 27\%; Perú, con un 23\%; en países como Ecuador, Bolivia, Colombia y Trinidad y Tobago estos valores varían entre el $10 \%$ y el $20 \%$ ). Los datos se presentan en la Figura 2.9. La línea roja marca el nivel promedio para ALC que, como se ha indicado, es del $22 \%$.

Figura 2.9. Porcentajes de cobertura de hogares cuyas aguas residuales son tratadas.

90

80

80

70

60

50

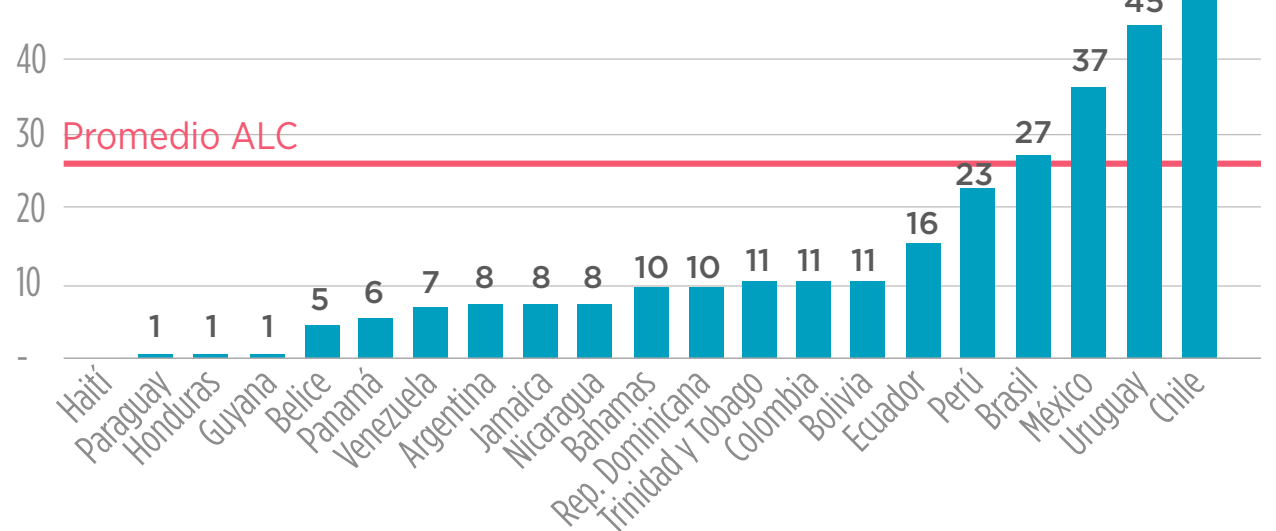

Fuente: Documento de Marco Sectorial de Agua y Saneamiento. BID. Diciembre 2017. 


\section{ALC ha alcanzado un desarrollo en sistemas de riego muy modesto en su conjunto}

\section{Infraestructura para riego y producción de alimentos}

En cuanto a agua para riego, de acuerdo con la FAO (2016), en el año 2010, en el conjunto de la región el consumo alcanzó la cifra de $236 \mathrm{~km}^{3}$, de los cuales unos $50 \mathrm{~km}^{3}$ se obtienen de aguas subterráneas. Los mayores consumidores del recurso son México, la región Andina, Brasil y el resto de países de América del Sur. La región de Centroamérica, así como el Caribe y Guyana quedan muy por detrás.

Resulta interesante tener una aproximación a la dotación bruta media por hectárea. Para ello se ha utilizado el consumo en el año 2010 con la superficie en riego del 2013. La cifra resultante es solo un estimado, pero suficiente para hacer una aproximación razonable: (i) en la región de ALC en su conjunto, la dotación bruta media es de $9.477 \mathrm{~m}^{3} / \mathrm{ha}$, valor moderadamente alto dentro del rango en otras regiones del mundo, lo que indica que se podría aspirar a su reducción mediante proyectos de modernización, ii) dentro de las regiones con máxima expansión del regadío, la región Andina es la que tiene un menor consumo de agua por hectárea, con $6.954 \mathrm{~m}^{3} / \mathrm{ha} / \mathrm{año}$, lo que revela que, en conjunto, es la que cuenta con instalaciones más modernas y tecnificadas; iii) Brasil está por debajo de la media de la región, con $8.315 \mathrm{~m}^{3} /$ ha/año, pero casi un $20 \%$ por encima que la región andina; iv) destacan, por sus fuertes dotaciones, otros países de América del Sur, con $16.421 \mathrm{~m}^{3} / \mathrm{ha} /$ año, cifra que tiene su relevancia desde el punto de vista de presión sobre los recursos por cuanto que cuentan en 2013 con una extensión del regadío de 3,8 millones de hectáreas y, v) es reseñable el gran consumo en Caribe Grandes Antillas, $12.000 \mathrm{~m}^{3} /$ ha-año, también importante por la presión que ejerce sobre los recursos de la región ya que tiene una superficie en riego de un millón de hectáreas.

En ALC, el porcentaje de superficie regada sobre el total de superficie cultivada (que incluye secano y regadío) ha pasado desde un 9,7\%, en 1973 , hasta el 12,7\% en 2013 (FAO, 2016). Según la misma fuente, en el mundo, el porcentaje medio de superficie regada frente a la superficie total cultivada es del 20,6\%. En Asia se dan los mayores porcentajes (40,9\%). En Europa, el porcentaje medio es moderado (7,3\%), pero destaca la Europa Mediterránea con un porcentaje del 31,4\%. El marco descrito acerca de diversas regiones del mundo, permite afirmar que ALC ha alcanzado un desarrollo en sistemas de riego muy modesto en su conjunto, lo cual le da ventajas comparativas en cuanto a sus posibilidades de expansión por razones económicas, pero con consecuencias negativas para la SH.

Por su carácter de gran consumidor del recurso, el riego tiene un claro protagonismo en la contaminación. Por lo general, las aguas de riego contienen nutrientes, sedimentos y otras sustancias provenientes de productos agroquímicos que contaminan sus descargas a lagos, embalses, zonas costeras o acuíferos. En este sentido, la solución que se atisba más viable es la de 


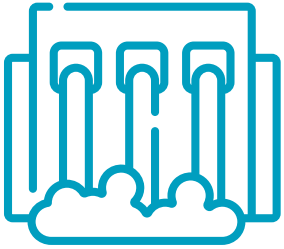 \\ $71,6 \%$ \\ de la enegía de América del Sur se genera de hidroeléctricas}

\subsection{Mw}

es el potencial

hidroeléctrico de LAC, sólo se aprovecha

el $22,6 \%$ prestarle el apoyo necesario, técnico, legal, financiero y de todo tipo, para establecer medidas que atenúen los impactos negativos: tecnificación del riego, asesoramiento y formación del agricultor y aplicación de lo que podría denominarse "código de buenas prácticas agrarias".

\section{Infraestructura para producir energía}

En cuanto a infraestructura hídrica para acceso a la energía, según el BID ${ }^{7}$, la población de ALC accede preferentemente al consumo de energía mediante la generación eléctrica. En este sentido, entre 2000 y 2016, el porcentaje de cobertura ha pasado del 87 al 97 por ciento, acercándose a la meta de servicio universal prevista para 2030. La competencia se establece especialmente entre la energía hidroeléctrica y la proveniente del carbón y derivados del petróleo. En América del Sur la energía hidroeléctrica es mayoritaria, con un porcentaje del $71,6 \%$, en tanto que las térmicas quedan en un $10,3 \%$. La energía nuclear ocupa un puesto secundario, con el 2,2\%.

Por su importancia en la generación de electricidad en la región, es preciso mencionar las grandes centrales hidroeléctricas. Brasil cuenta con 26 grandes centrales que, considerando la central de Itaupú, compartida con Paraguay, suponen una potencia total instalada de $62.234 \mathrm{Mw}$, y una producción estimada de 337 Gwh. A su vez, Argentina cuenta con nueve grandes centrales que, contemplando Yacyretá, compartida con Paraguay, suponen otros 15.235 Mw y una producción de $41 \mathrm{Gwh}$. Venezuela, cuenta con cuatro grandes centrales con una potencia total de $23.664 \mathrm{Mw}$; Colombia dispone de otras cuatro, con una potencia total de 5.829 Mw. Perú y México cuentan con solo una gran central, Mantaro y Malpaso, respectivamente, con potencias respectivas de $1.156 \mathrm{Mw}$ y $1.080 \mathrm{Mw}$. Considerados en su conjunto, la potencia instalada en grandes centrales se eleva a $109.198 \mathrm{Mw}$ que suponen casi el $70 \%$ de los 156.850 Mw hidroeléctricos implantados en la región.

Las posibilidades de crecimiento de la energía hidroeléctrica en ALC son factibles por la oportunidad que ofrece la mitigación del cambio climático a través de actividades que permitan la reducción de emisiones de gases de efecto invernadero, priorizando las energías renovables, tanto convencionales (la hidroeléctrica) como las no convencionales (eólica y solar). En estos términos, el potencial hidroeléctrico de ALC se ha estimado en $693.505 \mathrm{Mw}$ (Olano, 2011), lo que significa que, actualmente, sólo se está aprovechado el $22,6 \%$ de este potencial. En este valor habría que factorizar igualmente el impacto del cambio climático sobre los ciclos hidrológicos, lo que se traduciría en una reducción en los caudales turbinables en algunas zonas de la región. El potencial final instalable dependerá de consideraciones económicas, ambientales, climáticas y de la demanda eléctrica. En el Capítulo IV se presentan resultados de proyecciones futuras de la matriz energética de ALC y su impacto sobre la SH.

7 Documento de Marco Sectorial de Energía. BID Junio 2018. 
Un estudio de investigación reciente del BID (2017) analizó proyecciones de demanda hídrica bajo diferentes escenarios socioeconómicos y de cambio climático en la región. Los resultados de la demanda hídrica proyectada al 2025 y 2050 se compararon con la capacidad de almacenamiento de agua existente actualmente en cada país de la región, para determinar déficits de infraestructura hídrica de almacenamiento (capacidad de presas). Los resultados de este análisis se muestran en la Tabla 2.1. En estos resultados, puede verse que ya durante el año 2015 (datos reales, no proyecciones), existieron déficits de infraestructura de almacenamiento de agua en una buena parte de los países de la región, incluyendo países con déficits cuantiosos como Chile, Ecuador y Perú.

Tabla 2.1. Comparación entre la capacidad de almacenamiento de la infraestructura existente (presas) y la demanda hídrica en los países de la región de ALC.

\begin{tabular}{|c|c|c|c|c|c|c|c|}
\hline País & $\begin{array}{c}\text { Capacidad de } \\
\text { Embalses }(R ; \mathrm{km} 3)\end{array}$ & $\begin{array}{l}\text { D (km3) } \\
2015\end{array}$ & $\begin{array}{l}(R-D) k m \\
2015\end{array}$ & $\begin{array}{c}D(\mathrm{~km} 3) \\
2025\end{array}$ & $\begin{array}{l}\text { (R-D) } \mathrm{km}^{3} \\
2025\end{array}$ & $\begin{array}{c}\text { D }(\mathrm{km} 3) \\
2050\end{array}$ & $\begin{array}{c}\text { (R-D) } \mathrm{km}^{3} \\
2050\end{array}$ \\
\hline Argentina & 131,60 & 48,27 & 83,33 & 57,59 & 74,01 & 73,87 & 57,73 \\
\hline Belice & 0,12 & 0,23 & $-0,110,25$ & $-0,13$ & 0,36 & $-0,24$ & \\
\hline Bolivia & 0,60 & 3,63 & $-3,03$ & 4,88 & $-4,28$ & 7,27 & $-6,67$ \\
\hline Brasil & 700,40 & 103,14 & 597,26 & 119,51 & 580,89 & 152,60 & 547,80 \\
\hline Chile & 14,44 & 65,06 & $-50,62$ & 78,47 & $-64,03$ & 108,12 & $-93,68$ \\
\hline Colombia & 11,28 & 13,68 & $-2,40$ & 17,71 & $-6,43$ & 25,60 & $-14,32$ \\
\hline Costa Rica & 2,00 & 2,73 & $-0,73$ & 2,91 & $-0,91$ & 4,02 & $-2,02$ \\
\hline Rep. Dom. & 2,30 & 6,72 & $-4,42$ & 7,13 & $-4,83$ & 9,83 & $-7,53$ \\
\hline Ecuador & 7,70 & 18,59 & $-10,89$ & 22,74 & $-15,04$ & 32,86 & $-25,16$ \\
\hline Guatemala & 0,46 & 5,04 & $-4,58$ & 5,42 & $-4,96$ & 7,65 & $-7,19$ \\
\hline Guyana & 0,81 & 2,94 & $-2,133,58$ & $-2,77$ & 4,78 & $-3,97$ & \\
\hline Honduras & 5,80 & 2,34 & $3,462,51$ & 3,29 & 3,55 & 2,25 & \\
\hline Haití & 0,30 & 2,04 & $-1,742,19$ & $-1,89$ & 3,08 & $-2,78$ & \\
\hline Jamaica & 0,01 & 1,70 & $-1,69$ & 1,84 & $-1,84$ & 2,65 & $-2,65$ \\
\hline México & 150,00 & 107,35 & 42,65 & 122,68 & 27,32 & 168,56 & $-18,56$ \\
\hline Nicaragua & 32,00 & 2,22 & 29,78 & 2,38 & 29,62 & 3,34 & 28,66 \\
\hline Panama & 9,14 & 0,71 & $8,430,77$ & 8,37 & 1,08 & 8,06 & \\
\hline Perú & 5,77 & 21,39 & $-15,62$ & 27,51 & $-21,74$ & 39,17 & $-33,40$ \\
\hline Paraguay & 33,53 & 2,73 & 30,80 & 3,50 & 30,03 & 5,15 & 28,38 \\
\hline El Salvador & 3,88 & 3,25 & $0,633,49$ & 0,39 & 4,91 & $-1,03$ & \\
\hline Surinam & 20,00 & 1,17 & 18,83 & 1,41 & 18,59 & 1,89 & 18,11 \\
\hline Uruguay & 17,20 & 7,29 & $9,919,19$ & 8,01 & 13,90 & 3,30 & \\
\hline Venezuela & 157,60 & 38,02 & 119,58 & 43,53 & 114,07 & 58,37 & 99,23 \\
\hline Total & 1306,94 & 460,26 & 846,67 & 541,19 & 765,74 & 732,62 & 574,32 \\
\hline
\end{tabular}

Fuente: BID (2017). 


\section{Infraestructura para combatir eventos extremos}

En los últimos 20 años la región de ALC ha soportado diversos episodios de sequía (como las del Caribe en 2009- 2010, Argentina en 2012 o México en 2011-2012) y, más recientemente, en Chile, São Paulo (Brasil) o Bolivia en los años 2016-2017. El impacto económico de estos eventos extremos puede ser significativo: se han citado cifras de $2,5 \%$ del PIB, en el caso de Argentina y más de 3.000 millones de dólares en el caso de la sequía en México. Algunos de estos eventos se asocian con el fenómeno del Niño, lo que los vincula a la variabilidad y al cambio climático. Estos episodios han planteado la necesidad de fomentar un uso racional y eficiente del recurso, circunstancia potenciada por los efectos del cambio climático. Sin embargo, todavía no se han impulsado suficientemente planes de sequía que contribuyan a aumentar la resiliencia de los sistemas frente a este fenómeno adverso.

\section{Recuadro 2.7. Seguía en Bolivia}

Como ejemplo reciente de creación de infraestructura para combatir eventos extremos se puede resaltar la sequía de 2016-2017 en Bolivia, con repercusión en las ciudades capitales de La Paz, El Alto, Sucre, Oruro y Potosí. En un informe redactado por el Ministerio de Medio Ambiente y Agua boliviano se describen todos los hechos relacionados con esta:

i) Origen del problema: una reducción importante de precipitaciones y su consecuencia inmediata de reducción de aportaciones a los ríos.

ii) Efectos producidos: con reducción en el suministro en importantes ciudades del país, resultando en restricciones en La Paz, Sucre, Cochabamba, Potosí y Oruro. En diciembre de 2016, el 51\% de los municipios del país fueron afectados por la sequía y siete de las diez principales ciudades sufrieron de déficit hídrico.

Como consecuencia de ello, el Gobierno de Bolivia adoptó dos tipos de medidas: unas de tipo infraestructural, como la creación del Programa Nacional de Perforación de Pozos de Agua Subterráneas "Nuestro Pozo", con la finalidad de garantizar la disponibilidad de agua para la seguridad alimentaria; y otras de gobernanza, como la promulgación de 13 decretos supremos destinados a mejorar la producción agrícola y enfrentar la sequía.

También, ALC sufre crónicamente de inundaciones, que generan pérdidas económicas cuantiosas. Los valores estimados de pérdidas son variables, dependiendo de las áreas afectadas por las inundaciones. En julio de 2018, UNICEF informó sobre las fuertes inundaciones provocadas por el paso de la tormenta tropical Noel por México, República Dominicana, Haití, Honduras y 
Nicaragua: miles de personas perdieron sus hogares y necesitaron suministros básicos de emergencia, refugio y asistencia sanitaria, La tormenta generó pérdidas económicas que se cifran en miles de millones de dólares. Este es un tipo de desastre de una especial intensidad que suele afectar a grandes extensiones de territorio y a diferentes cuencas hidrográficas.

Para trabajar en su prevención, hace falta una respuesta específica desde los sistemas hidrológico-hidráulico (sistemas de las cuencas) que se podría concretar en Planes de Gestión del Riesgo de Inundación (PGRI), como los que se están implantando en Europa a raíz de la Directiva 2007/60/CE y que en España fueron aprobados en 2016 (véase en el Anexo A los detalles de estos PGRI). En ALC no se han implementado planes de esta naturaleza, aunque existe una potencial demanda para ello. 
Inxeses
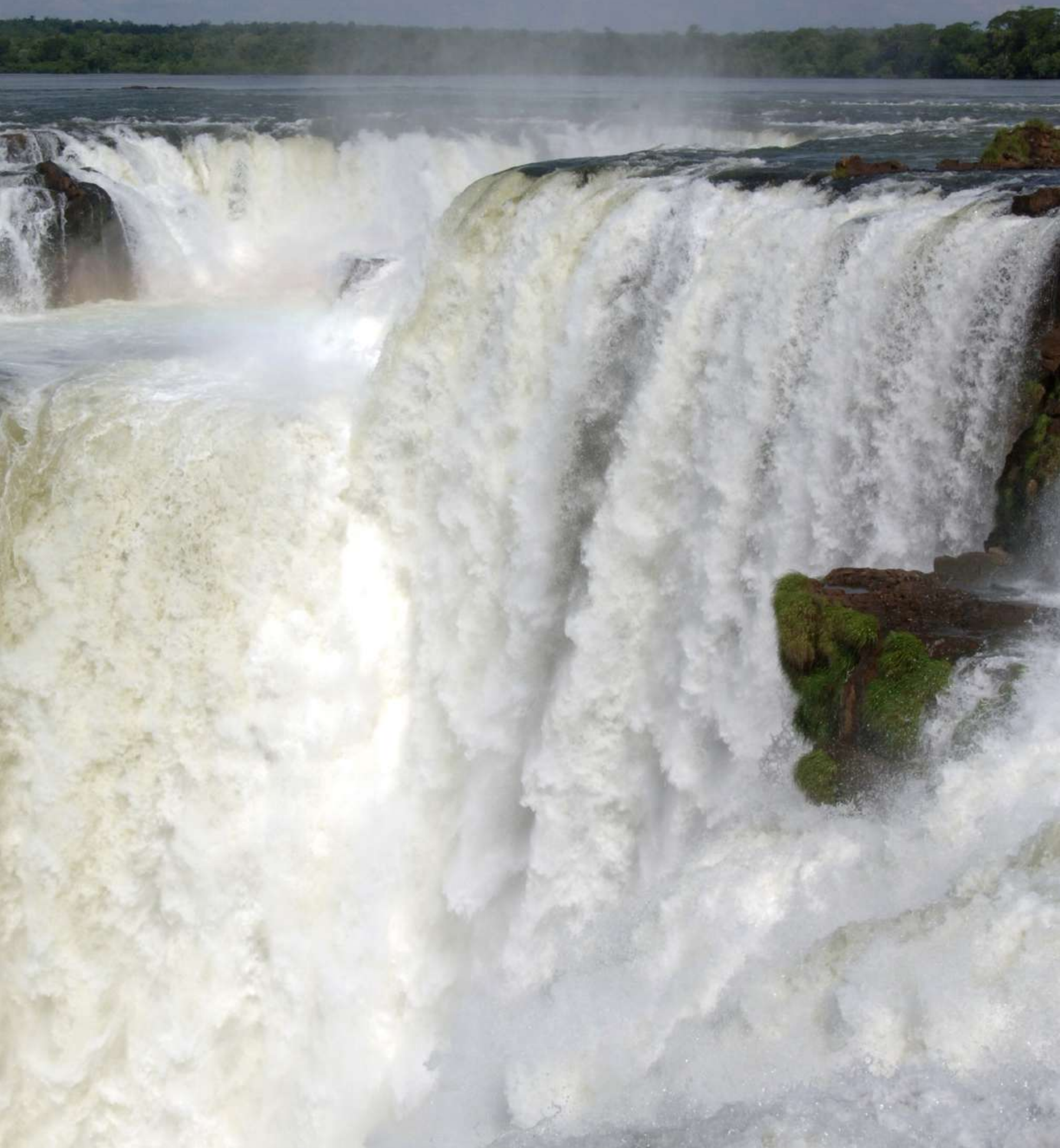

Este análisis pretende identificar experiencias positivas transformadoras financiadas por el BID y saber cuál ha sido la mejor escala y forma de actuación de cara a proponer estrategias que apoyarán el logro de la SH en la región durante la próxima década.

Del análisis de los documentos de Marcos Sectoriales (MS) y de los proyectos incluidos en la cartera del Banco se desprende una amplia acción en recursos hídricos, cambio climático, medio ambiente y recursos naturales. También puede percibirse que el BID ha tenido una participación importante en la puesta en marcha de una nueva percepción de la importancia del recurso del agua.

(1) Para extraer lecciones aprendidas que puedan ser aplicadas a un marco general de actuación en el ámbito de la SH, es necesario entender lo que funcionó y qué se puede cosechar como reproducible, a qué escala y con qué metodología. En este sentido, algunas de las experiencias más exitosas durante la primera década del 2000 se dieron en Ecuador, Brasil y Perú.

De este análisis de la cartera del Banco sobresalen dos acciones futuras fundamentales y básicas para la SH: continuar con la preparación de planes nacionales dentro del contexto ampliado de SH y expandir el alcance de SBN con el objetivo de seleccionar y establecer la gobernanza de conservación de reservas estratégicas de agua en todos los países.

Del análisis de la amplísima acción del BID en la región puede concluirse que el Banco tiene la experiencia y los recursos para apoyar a los países en pro de la SH. La mayoría de las acciones que conducen a este objetivo ya se han adoptado o están en proceso.

De la experiencia del BID pueden extraerse lecciones útiles sobre los siguientes elementos:

- Las cuencas hidrográficas, sus puntos positivos (constituyen el nivel de gestión más adecuado) y limitaciones (su implantación lleva tiempo y requiere seguimiento).

- Los Fondos de Agua, son un instrumento innovador de protección de las cuencas hidrográficas con un enorme potencial en SH.

\section{Seguridad hídrica y la experiencia del BID}

E ste capítulo presenta una revisión de la acción del Banco relacionada con la SH. Aunque hasta el momento, el Banco no ha tenido una cartera específicamente denominada de Seguridad Hídrica, sí cuenta con una amplia trayectoria en temas relacionados con servicios de agua y saneamiento, gestión de recursos hídricos (incluyendo la GIRH), adaptación al cambio climático, respuesta a eventos extremos y otros temas relacionados que vale la pena destacar para establecer el contexto de acciones innovadoras en $\mathrm{SH}$ de cara al futuro.

Un apoyo importante para la conceptualización y el desarrollo de la estrategia

Tanto los programas del Fondo Español de Cooperación para Agua y Saneamiento en América Latina y el Caribe (FECASALC) - 580 MUSD de donación que han conformado una cartera de 1.592 MUSD, como las cooperaciones técnicas financiadas a través de la Facilidad de Inversión para América Latina (LAIF) de la Unión Europea, han servido para prestar apoyo a los países de la región en materia de seguridad hídrica; especialmente en lo referente a áreas de planificación, gestión de sequías y gestión de inundaciones, así como a desafíos derivados de la falta de calidad del recurso por medio de intervenciones en saneamiento ambiental. De manera específica se ha apoyado también el desarrollo de planes de seguridad hídrica a nivel nacional, de cuenca y municipal que pilotarán las directrices de trabajo de esta estrategia.

\section{Foco de la revisión}

Para definir el período y foco de esta revisión se impone un análisis crítico de los hitos que han marcado la trayectoria del Banco en el amplio ámbito de la gestión de los recursos hídricos. Igualmente, es necesario definir qué categoría de proyectos impactan la presente revisión. En una región que no cuenta con cobertura universal de agua y saneamiento ${ }^{8}$, es importante definir, qué acciones se diseñan para garantizar la $\mathrm{SH}$ en contextos de escasez o exceso de recursos hídricos y de impacto del cambio climático. Alcanzar la cobertura

8 En el 2015 el acceso a agua segura alcanzaba 94,6\% y al saneamiento mejorado de $83,1 \%$; otros estimados indican que el $70 \%$ de las aguas servidas no reciben tratamiento alguno antes de verterse en ríos, lagos o el mar (Jouravlev, 2014) 
- Las empresas de agua y saneamiento, que deberán ser más proactivas en las tareas de protección y conservación de las cuencas hidrográficas.

- La recuperación urbana y el control de la contaminación, que deberán ser repensados como intervenciones integrales a nivel de cuenca urbana.

- Los Planes Nacionales de Recursos Hídricos (PNRH), que deberán estar amparados por la legislación y contar con recursos de financiación.

- Las Cuentas Económicas Ambientales del Agua, que pueden llegar a ser una herramienta clave para la planificación hidrológica.

EI BID deberá integrar una visión integral y de conjunto, minimizar los conflictos por el uso del recurso, crear la demanda de proyectos, ejercer un papel instrumentador y capacitador y buscar modelos de inversión y formas innovadoras de financiación. universal en agua y saneamiento es una deuda pendiente de los países de ALC con su población y, por tanto, esta es la dirección hacia la que deben dirigirse los esfuerzos sectoriales. Garantizar la cobertura universal a través del manejo sostenible de la disponibilidad y de la calidad de los recursos hídricos, en situaciones rutinarias o de estrés, bajo un clima cada vez más variable, son acciones alineadas con el concepto básico de SH.

En este sentido, esta revisión de la experiencia del BID se concentró en la identificación de acciones financiadas por el Banco, planeadas para i) conocer la disponibilidad de recursos hídricos; ii) garantizar el abastecimiento para usos actuales y futuros a través de obras de infraestructura o recuperación y manejo de servicios ambientales en áreas de recarga de aguas superficiales y subterráneas (infraestructura verde); iii) mejoras de eficiencia de producción y de uso del agua en ambientes urbanos; iv) recuperación de la calidad del agua de fuentes superficiales y acuíferos estratégicos y v) reúso y apoyo a la creación de mecanismos de gobernanza específica para la $\mathrm{SH}$.

Escala temporal y espacial de la actuación del Banco

Para elaborar una estrategia efectiva de SH para el Banco y sus clientes es importante analizar la escala temporal y espacial de actuación. En el sector público, las divisiones del Banco tienen contrapartes específicas que pueden ser compañías de agua y saneamiento, autoridades de agua o de medio ambiente, ministerios y gobiernos nacionales y/o subnacionales, así como contrapartes de otros sectores como el de agricultura y el de energía.

Recuadro 3.1. Los "pequeños” mucipios de Brasil

Algunos países, por ejemplo, Brasil, limitan el monto total de los préstamos y el nivel de actuación del Banco (difícilmente el país autoriza préstamos directos a pequeños municipios). Por su parte, el Banco tiene limitaciones para apoyar a un número grande de beneficiarios. Brasil tiene alrededor de 5.565 municipios, 5.153 de los cuales tienen menos de 50.000 habitantes (32\% de la población del país ${ }^{9}$ ), y quedan, por lo tanto, prácticamente fuera del alcance del Banco. En agua y saneamiento, el Banco atiende a algunos de los grandes municipios (Sao Paulo, Rio de Janeiro, Salvador, Recife, Goiânia, Fortaleza, Porto Alegre, Joinville, Belém y Manaus), pero existe una demanda mayor por atender. La población de Joinville es de aproximadamente 500.000 habitantes; las demás ciudades son regiones metropolitanas con poblaciones superiores a un millón. 
Algunos proyectos y estudios pueden llegar a escala nacional (desarrollo institucional ambiental, planes nacionales de recursos hídricos, estrategias de mitigación y adaptación al cambio climático y/o desastres naturales, estrategias de biodiversidad y de desarrollo agrícola); otros a nivel de cuencas urbanas o rurales y, recientemente, se han empezado a definir acciones por ecosistemas debido a sus funciones ecológicas e impactos económicos (es el caso del Pantanal en el Brasil y la Puna en los Andes). El procedimiento seguido en este análisis busca identificar experiencias positivas transformadoras, financiadas por el Banco, y cuál ha sido la mejor escala y forma de actuación para proponer estrategias que apoyarán el logro de la SH en la región en la década siguiente.

Un recuento histórico detallado de la evolución del tema de $\mathrm{SH}$ en el Banco se presenta en el Anexo B.

\section{III.1 Inventario de proyectos de referencia en el BID}

En el 2018, la División de Agua y Saneamiento (WSA) del BID preparó un inventario de proyectos que incluía su propia cartera así como la de otras divisiones con impactos en recursos hídricos y en la SH. Para ello, utilizó una metodología que consideraba los siguientes criterios:

- Sistemas de apoyo a la toma de decisiones, que incluye herramientas de planificación de la gestión de los recursos hídricos entre usos competitivos, con enfoque multisectorial.

- Ambiental, que incluye planes de acciones contra la contaminación de la calidad del agua y la degradación de los ecosistemas de cuenca aumentando la resiliencia de los sistemas socioeconómicos y la infraestructura frente al cambio climático.

- Gobernanza para la gestión de recursos hídricos, con iniciativas de elaboración de políticas públicas, fortalecimiento institucional y mecanismos de gobernanza.

- Drenaje y control de las inundaciones, para la mejora de las obras de drenaje pluvial y sistemas de control de las inundaciones.

Los resultados del inventario indican que, entre 2010 y 2018, WSA aprobó 336 proyectos entre préstamos, cooperaciones técnicas y estudios con una inversión acumulada total de US\$9,7 billones, que representan el 7,5\% del total de proyectos aprobados en el mismo periodo por el Banco y alcanzan el $10,5 \%$ de las inversiones realizadas. Aplicando los criterios mencionados, fueron seleccionados 71 proyectos con relevancia para el sector de recursos hídricos (19 préstamos de inversión, 51 cooperaciones técnicas y 1 estudio). Según el eje temático fueron identificados 17 proyectos relacionados a sistema de apoyo para toma de decisiones, 24 con el tema ambiental, 8 con gobernanza y 22 con drenaje y control de inundaciones. Un inventario 
similar de proyectos fue realizado consultando las carteras de las divisiones: Desarrollo Urbano y Vivienda, Cambio Climático y Sostenibilidad y Recursos Naturales y Desarrollo Sostenible.

Del análisis de los documentos de Marcos Sectoriales (MS) y de los proyectos incluidos en la cartera del Banco, principalmente a partir del 2007, se desprende una amplia acción en recursos hídricos, cambio climático, medio ambiente y recursos naturales. Operativamente, las acciones propuestas en los MS contribuyen y al mismo tiempo dependen de la SH (Cuadro 3.1.).

En el marco de esta revisión, es necesario entender lo que funcionó y qué se puede cosechar como reproducible, a qué escala y con qué metodología. Con este objetivo, se hizo una selección de proyectos y/o programas exitosos para un análisis más detallado en el marco de esta revisión de cartera. El análisis de proyectos de la cartera que incluyen el tema de recursos hídricos desde 1990, demuestra que el Banco ha tenido una participación importante en la puesta en marcha de una "nueva" percepción de la importancia de este recurso natural renovable. No obstante, a partir de 2006 se inicia una acción más amplia que se intensifica a partir del 2010 para atender los mandatos de la Novena Reposición de Capital del BID.

Cuadro 3.1. Correlación de los objetivos de los marcos sectoriales del Banco con la SH

\section{Energía}

Medio ambiente y biodiversidad

Acceso universal y servicios de alta calidad

Carteras de energía diversificadas

Suficiente infraestructura e integración de redes

Fortalecimiento institucional

\section{Agua y saneamiento}

Acceso universal y calidad del servicio

Fortalecimiento de la gobernanza del sector

Gestión de los servicios innovadora y sostenible

Proyectos que incorporan $\mathrm{CC}$, gestión de riesgo y SH

\section{Cambio climático}

Inclusión de CC en los sectores

Fortalecimiento de la gobernanza e instituciones con CC

Mejor acceso a financiamiento climático

\section{Agricultura y gestión de los recursos naturales}

Alto nivel de productividad agrícola

Aprovechamiento sustentable

Gestión de riesgos de CC y desastres en la agricultura

Ingresos de familias rurales aumentan

\section{Desarrollo urbano y vivienda}

Mayor capacidad de gestión de áreas urbanas Infraestructura y servicios urbanos de calidad y menos vulnerables

Acceso a servicios sociales básicos

Mejor uso del espacio urbano 
Durante los años 90, el objetivo más importante era apoyar a los países en el proceso de construcción y/o fortalecimiento de su institucionalidad para la gestión ambiental, el tema del momento. La mayor preocupación era el impacto ambiental y, aunque los recursos hídricos eran de los más impactados por descargas de aguas servidas domésticas, agrícolas e industriales sin tratamiento, la inquietud con la cantidad de agua de buena calidad para abastecer una economía en expansión era prioritaria para las compañías de agua y saneamiento. Por otro lado, salvo excepciones ${ }^{10}$, las compañías de agua aún no habían internalizado que la protección de fuentes y ecosistemas de cabecera que usaban era parte de su negocio.

Recuadro 3.2. Experiencias exitosas de la cartera del BID

\section{Ecuador: Ecuador: un exitoso Plan de Gestión de Recursos Hídricos}

Entre el 2000 y el 2006, se dieron algunos intentos infructuosos de incluir el manejo de las cuencas productoras de agua en los proyectos de agua y saneamiento financiados por el BID en la región Andina y en el Caribe. El proyecto para implantar un plan de gestión de recursos hídricos en la Hoya de Quito, ejecutado por FONAG (Fondo para la Protección del Agua), es una de las excepciones. Este proyecto estaba conectado con el préstamo Programa de Saneamiento Ambiental para el Distrito Metropolitano de Quito (1424/OC-EC). Hay que resaltar que FONAG, operativo en el 2006, ya había trabajado en la Hoya de Quito. El apoyo del Banco fue para dar continuidad a sus acciones y el valor agregado fue el desarrollo del Plan de Gestión de los Recursos Hídricos de la Hoya de Quito.

Manaus: implicando a la población en un proyecto que cambió la ciudad En el 2005 se aprueba el Programa de Saneamiento Ambiental de Manaus (PROSAMIM) para encontrar soluciones para el problema ambiental, urbanístico y social que afectaba a la ciudad de brasileña de Manaus y, en particular, a los moradores de la cuenca urbana conocida como Educandos-Quarenta en dicha ciudad. Estos cursos de agua eran anualmente represados por el río Negro (uno de los formadores del río Amazonas), inundando un área ocupada por habitaciones precarias conocidas como palafitas. EI PROSAMIM no solo resolvió el problema de drenaje de estos cursos de agua sino que también transformó el paisaje de la ciudad y la vida de sus habitantes"1, reasentándoles en viviendas dignas con todos los servicios. EI PROSAMIM Ilegó a la III fase y su ejecución cambió totalmente el centro de Manaus. El éxito del PROSAMIM se debió al proceso innovador de implicar a la población en el proyecto desde el comienzo $y$ al arreglo ejecutivo que involucraba una unidad ejecutora del proyecto con acceso directo al gobierno del estado.

10 La Compañía de Saneamiento de Minas Gerais-COPASA, Brasil, protege varias de sus nacientes desde antes de los 90.

11 Los locales antes inundables fueron transformados en parques y áreas de esparcimiento. 


\section{Perú: modernizando la gestión de recursos hídricos}

Otra experiencia exitosa del BID en la promoción de temas de recursos hídricos ha sido el esfuerzo de modernización de la gestión de recursos hídricos en el Perú, lo cual representa un apoyo conjunto BID-Banco Mundial empezado en la década de los 90. El BID respaldó el sector en Perú con varias cooperaciones técnicas que impulsaron temas puntuales como el apoyo a la gestión de cuenca binacional Puyanbo-Tumbes (frontera con Ecuador); apoyo para preparar el Plan Nacional de Recursos Hídricos; apoyo para regularizar derechos de acceso al agua para pequeñas comunidades y apoyo para determinar el valor económico del agua. Pronto fue aprobado un préstamo programático de políticas en tres fases, que impulsó la modernización del sector de recursos hídricos, incluyendo la aprobación en el 2009 de la nueva Ley de Recursos Hídricos, que contiene explícitamente la GIRH. El proceso culminó con la aprobación, también en el 2009, del proyecto de modernización de la gestión de los recursos hídricos, que impulsó la creación de la Autoridad Nacional del Agua, su fortalecimiento institucional, la descentralización de la gestión y la preparación de planes de gestión para tres cuencas críticas del país.

\section{¿Qué hemos aprendido?}

De este análisis de la cartera del Banco sobresalen dos acciones futuras fundamentales y básicas para la SH: continuar con la preparación de planes nacionales dentro del contexto ampliado de SH y expandir el alcance de SBN con el objetivo de seleccionar y establecer la gobernanza de conservación de reservas estratégicas de agua en todos los países.

En relación con los planes nacionales de recursos hídricos, es importante identificar una metodología de preparación y un formato de presentación para transformarlo en un documento vivo, más objetivo y de fácil manejo por parte del usuario. Estos planes nacionales y otras acciones concernientes a la SH, como se resalta en el Marco Sectorial de cambio climático, deben ser incluidos en la programación de los países al más alto nivel. La muestra de proyectos presentada en el Cuadro 3.2. es representativa de la amplitud de acciones que el Banco ha realizado para apoyar a los países en la gestión de sus recursos hídricos. Algunos proyectos, como las cuentas ambientales, están en estado inicial de desarrollo en el marco de la actuación del BID, pero fueron seleccionadas porque representan una buena oportunidad de insertar el tema de $\mathrm{SH}$ en la planificación nacional. 
Cuadro 3.2. Algunos ejemplos de proyectos de la cartera del BID en temas relacionados a la SH.

\begin{tabular}{|c|c|c|c|c|c|}
\hline Ámbito & Proyectos & $\begin{array}{l}\text { Estado de } \\
\text { ejecución }\end{array}$ & Acciones & País & Observaciones \\
\hline & $\begin{array}{l}\text { Programa de } \\
\text { Saneamiento } \\
\text { Ambiental de la } \\
\text { Cuenca Del Río } \\
\text { Ipojuca }\end{array}$ & En ejecución & $\begin{array}{l}\text { Fortalecimiento de la gestión de } \\
\text { recursos hídricos, red de alcantarillado, } \\
\text { abastecimiento de agua, muestreo } \\
\text { de calidad del agua, recuperación de } \\
\text { riberas, pago por servicios ambientales, }\end{array}$ & Brasil & $\begin{array}{l}\text { La cuenca del Río } \\
\text { Ipojuca Incluye } \\
\text { áreas urbanas y no } \\
\text { urbanas. }\end{array}$ \\
\hline
\end{tabular}

(2012-Actual)

Programa de
Saneamiento
Ambiental de
la Cuenca del
Río Reconquista
(2014-actual)

En ejecución

cobro por el uso del agua, sistema de gestión ambiental en empresa de Ays, recuperación de la calidad del manantial.

\section{Concepto integral de gestión}

de cuencas, planes de gestión utilizando visión compartida, redes de alcantarillado, redes de agua potable, comunicación estratégica, sistema de información de RRHH, control de la contaminación industrial, gestión de residuos sólidos y apoyo al ordenamiento territorial.

Programa de
Modernización de los
Recursos Hídricos

\section{CUENCAS}

Ejecutado

(2009-2015)

\author{
Fondos de Agua \\ apoyados por la \\ Latin American \\ Water Funds \\ Partnership
}

En ejecución

Fortalecimiento de la Autoridad Nacional del Agua, descentralización de la gestión de RRHH, planes de gestión para tres cuencas claves, sistema de información de RRHH, sistema de monitoreo de $\mathrm{RRHH}$ (calidad y cantidad).

Mecanismo de financiamiento para protección de cuencas hidrográficas y provisión de pago por servicios ambientales a largo plazo. Facilita la gestión de los recursos hídricos, promueve resolución de conflictos, apoya la conservación y/o preservación de la infraestructura verde.

\section{Programa}

Multipropósito de

agua potable y riego

para los municipios

de Batallas,

Pucarani y El Alto

(2015-actual)

\section{En Ejecución}

Construcción de nuevos sistemas de riego y recuperación de sistemas existentes, construcción de sistemas de abastecimiento de agua potable para comunidades, implementación de planes de manejo de cuencas con visión de cambio climático, desarrollo de estructura comunitaria para la gobernanza de los recursos hídricos en las cuencas intervenidas.

\begin{tabular}{|c|c|c|c|c|c|}
\hline $\begin{array}{l}\text { EMPRESA } \\
\text { DE AyS }\end{array}$ & $\begin{array}{l}\text { Programa de } \\
\text { Saneamiento } \\
\text { Ambiental } \\
\text { para el Distrito } \\
\text { Metropolitano de } \\
\text { Quito-Fases I y II } \\
\text { (2002-2015) }\end{array}$ & Ejecutado & $\begin{array}{l}\text { Control de ocupación de laderas para } \\
\text { protección de infraestructura de drenaje, } \\
\text { redes de agua y alcantarillado, control de } \\
\text { agua no contabilizada, manejo de áreas } \\
\text { de protección ecológica, obras de regu- } \\
\text { lación hídrica, estabilización de taludes, } \\
\text { reparación de colectores, reasentamien- } \\
\text { to y desarrollo comunitario. }\end{array}$ & Ecuador & $\begin{array}{l}\text { El apoyo a la } \\
\text { empresa de AyS de } \\
\text { Quito ya entra en su } \\
\text { sexta fase. }\end{array}$ \\
\hline \multirow{2}{*}{$\begin{array}{l}\text { MUNICIPALI- } \\
\text { DAD-ESTADO }\end{array}$} & $\begin{array}{l}\text { Programa social } \\
\text { y ambiental para } \\
\text { los Igarapés de } \\
\text { Manaus- Fases I-III } \\
\text { (2005-Actual) }\end{array}$ & En ejecución & $\begin{array}{l}\text { Control de áreas inundables, creación } \\
\text { de parques lineales, reasentamiento, } \\
\text { red de alcantarillado y tratamiento de } \\
\text { aguas servidas, plan director de drenaje, } \\
\text { planificación urbana. }\end{array}$ & Brasil & $\begin{array}{l}\text { Programa en su } \\
\text { tercera fase. }\end{array}$ \\
\hline & $\begin{array}{l}\text { Programa de } \\
\text { recuperación } \\
\text { ambiental de Belo } \\
\text { Horizonte-Drenurbs } \\
(2004-2012)\end{array}$ & Ejecutado & $\begin{array}{l}\text { Controle de inundación, drenaje urbano, } \\
\text { protección de arroyos urbanos, creación } \\
\text { de área de protección de arroyos } \\
\text { urbanos y parques temáticos. }\end{array}$ & Brasil & \\
\hline
\end{tabular}




\begin{tabular}{|c|c|c|}
\hline Ámbito & Proyectos & $\begin{array}{l}\text { Estado de } \\
\text { ejecución }\end{array}$ \\
\hline \multirow{2}{*}{ PLANES } & $\begin{array}{l}\text { Planes Nacionales de } \\
\text { Recursos Hídricos o } \\
\text { de Seguridad Hídrica }\end{array}$ & Preparados \\
\hline & $\begin{array}{l}\text { Sistemas de Cuentas } \\
\text { Ambientales para } \\
\text { el Agua (System } \\
\text { of Environmental- } \\
\text { Economic } \\
\text { Accounting for } \\
\text { Water-SEEA-Water) } \\
\text { basado en el System } \\
\text { of environmental- } \\
\text { economic } \\
\text { accounting }\end{array}$ & En desarrollo \\
\hline
\end{tabular}

HERRAMIEN-

TAS Y ESTUDIOS

\begin{tabular}{|c|c|c|}
\hline HyDROBID & $\begin{array}{l}\text { En imple- } \\
\text { mentación }\end{array}$ & $\begin{array}{l}\text { Simulación de la disponibilidad de } \\
\text { recursos hídricos considerando distintos } \\
\text { escenarios, contribución a la gestión } \\
\text { de recursos hídricos y fortalecimiento } \\
\text { de las instituciones responsables. } \\
\text { lgualmente incluye un modulo que } \\
\text { permite incluir datos de modelos de } \\
\text { cambio climático con respecto a la } \\
\text { precipitación. }\end{array}$ \\
\hline
\end{tabular}

NEXO AGUACOMIDA-ENERGIA
Instrumento de planificación y de política de recursos hídricos, evaluación de la demanda y disponibilidad de $\mathrm{RRHH}$, proyecciones, identificación de temas críticos, líneas de acción, monitoreo y evaluación de la implementación.

Incorporación de información hidrometeorológica en las cuentas económicas nacionales y utilización de modelos de input- output (p. ej. modelos de balance hídrico) para evaluar escenarios de gestión de RRHH e impactos en la economía y viceversa.
País

Perú, Brasil,

Panamá,

Costa Rica,

Uruguay y

otros países

Brasil'13, Guatemala $^{14}$ Colombia, Costa Rica ${ }^{15}$, México

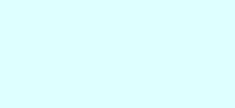

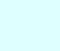




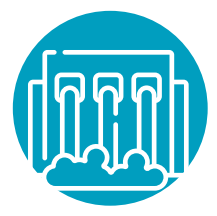

El análisis de las actividades de los proyectos y estudios financiados con recursos del BID expone la abundancia y extensión del trabajo realizado en la región. Esta visión se amplía aún más cuando se incorporan los objetivos y metas de los marcos sectoriales en el contexto de la Estrategia Institucional. No obstante, la dispersión de la información motivada por la sectorización interna al Banco, dificulta la construcción de acciones temáticamente más focalizadas, con mayor alcance e impacto regional o al nivel de país.

De este abanico histórico, se enumeran los esfuerzos relacionados con la $\mathrm{SH}$ que el Banco ha ejecutado hasta el momento para diferentes instituciones:

- Empresas de agua y saneamiento: mejora de la gobernanza, tarificación adecuada, reducción de agua no contabilizada, mejora de la eficiencia y productividad, sistema de gestión ambiental, protección de fuentes, gestión de cuencas, expansión de redes, tratamiento de agua y efluentes, reúso de efluentes tratados, disposición final de residuos, inclusión comunitaria en el negocio.

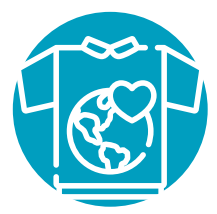

- Instituciones ambientales: fortalecimiento institucional, control de la contaminación del agua, aire y suelo; protección de la biodiversidad y de ecosistemas estratégicos, pagos por servicios ambientales, adaptación y mitigación de los efectos del cambio climático, prevención y mitigación de desastres naturales, gestión ambiental, sistema de información ambiental.

- Instituciones responsables del manejo de recursos hídricos: gestión integrada de recursos hídricos, catastro de usuarios, monitoreo hidrometereológico, modelos hidroclimatológicos y de cuencas, gestión de cuencas, planes nacionales de recursos hídricos, modelos de gestión de recursos hídricos, modelos de financiamiento de la gestión de recursos hídricos, sistemas de información.

- Instituciones agrícolas: garantía de agua para el riego, mejora de eficiencia de los sistemas de riego, descentralización de la gestión del agua en los distritos de riego, fortalecimiento de juntas de usuarios, operación y mantenimiento de los sistemas de riego, drenaje y manejo del agua de drenaje hacia los acuíferos subterráneos, tarifas de agua para riego, catastro de regantes, sistema de información, optimización del uso del agua, eficiencia energética.

- Instituciones del sector energético: estudios hidrológicos y diseño de presas, análisis de impacto ambiental, eficiencia energética de empresas de agua y saneamiento.

- Instituciones de planificación nacional: cuentas nacionales, objetivos nacionales de desarrollo, cuentas ambientales nacionales, eficiencia hídrica por actividad económica.

- Gobiernos municipales: control de inundaciones en ambientes urbanos, recuperación de riberas de ríos y arroyos urbanos con creación de áreas de esparcimiento, drenaje urbano, planes maestros de drenaje urbano, recuperación de la calidad de arroyos y ríos urbanos, adaptación y resiliencia frente al cambio climático y desastres naturales. 
Estas acciones, ya incorporadas a proyectos del Banco, son fundamentales para construir el apoyo que generará una estrategia y plan de acción en SH para sus clientes. Además, la literatura abunda en sugerencias y ejemplos aún más específicos de soluciones para lograr la SH en un tiempo no muy lejano. Por ejemplo, una síntesis de las conclusiones de la Semana Mundial del Agua del 2015 (Garzón y Sturzenegger, 2016) incluye los desafíos futuros de la región para lograr los objetivos de sostenibilidad en agua y saneamiento. Estos son:

- Alcanzar la universalización de los servicios.

- Desarrollar mecanismos innovadores para atraer capital.

- Mejorar la calidad de los servicios.

- Mejorar la eficiencia de la gestión empresarial.

- Asegurar la sostenibilidad de los servicios de pequeña escala.

- Expandir el tratamiento del agua residual en forma sostenible.

- Evaluar integralmente la disponibilidad hídrica.

- Monitorear los avances y mejorar la transparencia en la información recolectada.

- Mejorar la organización institucional y la gobernabilidad del sector.

Muchos de estos desafíos están presentes en el MS de Agua y Saneamiento del BID. Dicho documento presenta la justificación para cada desafío y sugiere acciones para atenderlos. Por ejemplo, el desafío "Evaluar integralmente la disponibilidad hídrica" vincula agua y saneamiento con:

- La necesidad de efectuar un trabajo coordinado e intersectorial para asegurar la disponibilidad de agua en las fuentes de abastecimiento.

- El reconocimiento del capital natural y los servicios ecosistémicos (SBN) que estos prestan, en particular, ante los impactos del cambio climático. Por otro lado, dichos servicios se verán igualmente afectados por el cambio climático, por lo que los sistemas de monitoreo son importantes.

- El compromiso de reducir o eliminar las cargas contaminantes sobre los cuerpos de agua. En este sentido, el aumento en la temperatura por la actividad antropogénica se convierte en un multiplicador de los efectos negativos de la contaminación ambiental.

Adicionalmente, el MS detalla cada desafío. En relación con Evaluar integralmente la disponibilidad hídrica, se reconoce que: "En materia de administración de los recursos hídricos en América Latina y el Caribe, los casos exitosos de gestión integral son limitados. Un mapeo institucional muestra la heterogeneidad de ministerios, instituciones y niveles de gobierno a cargo de esta labor, 
así como las superposiciones y vacíos de funciones; aunque, en general, la responsabilidad se mantiene en los niveles superiores de gobierno. También se observa una carencia de recursos presupuestarios suficientes y estables para desarrollar las actividades propias de esta labor en forma permanente.

El BID tiene la experiencia y los recursos para apoyar a los países en pro de la SH

Si agregamos los detalles presentados para los demás desafíos cubiertos en el marco sectorial, es posible corroborar la amplia acción del Banco en la región. Por lo tanto, se puede concluir que el Banco tiene la experiencia y los recursos para apoyar a los países en pro de la SH. La mayoría de las acciones que conducen a este objetivo ya se han adoptado o están en proceso. Falta entender cómo debe organizarse el Banco y qué tipo de proyectos, estudios o acciones tiene que desarrollar para ampliar el alcance y el impacto de las acciones futuras en cuanto a SH en la región; también cómo puede ayudar a los países a apalancar recursos adicionales que complementen las inversiones, a través de préstamos del sector.

\section{III.2 Lecciones aprendidas}

¿Cuáles son las principales lecciones que podemos sacar de la extraer de la cartera y la amplia experiencia del Banco?

\section{Manejo de cuencas}

La experiencia con la implantación de proyectos de manejo de cuencas con financiamiento del BID permitió entender los puntos positivos y las limitaciones de este concepto. Definitivamente, por sus características geomorfológicas, la unidad territorial denominada cuenca hidrográfica constituye el espacio ideal para implantar modelos de gestión de recursos hídricos. Dependiendo del tamaño, puede ser necesario dividir cuencas de mayores extensiones en subcuencas y establecer estructuras institucionales de manejo en dos niveles. Por ejemplo, la cuenca del río Reconquista, aunque no sea muy extensa (cerca de $1.670 \mathrm{Km} 2$ ), por sus características está dividida en cuenca alta, media y baja siendo la parte alta esencialmente rural y las demás, urbanas.

Independientemente, de sus características geomorfológicas y de la ocupación de su espacio físico, el proceso de implantación de gestión por cuencas toma tiempo.

Recuadro 3.3. Las gestión de recursos hídricos: lenta pero segura

El proyecto de Modernización de la Gestión de los Recursos Hídricos (PMGRH) en el Perú es una de las experiencias más exitosas del Banco en diseño e implantación de estructuras de gestión de recursos hídricos. Al final del proyecto, se habían elaborado planes de gestión para seis cuencas y todas ellas disponían de consejos de cuencas instalados y fun- 
cionando (tres cuencas con financiamiento BID y tres con financiamiento del Banco Mundial). No obstante, Perú empezó a solicitar apoyo, principalmente a través de cooperaciones técnicas, para manejar problemas específicos o conflictos por el uso del agua en una cuenca a partir del 2000. El primer tramo del Programa de Reformas de Recursos Hídricos (PE-L1024) fue aprobado en el 2007 y el tercero y último en el 2010. El PMGRH fue aprobado en el 2009 y el último desembolso se dio en el 2015. A pesar de los resultados positivos del proyecto, el camino es largo si se quiere implantar la GIRH en las 159 cuencas del país ${ }^{16}$. Además, el Banco financió con recursos no-reembolsables (PE-T1168) del Fondo SECCI (Fondo de Energía Sostenibles y Cambio Climático del BID) medidas de adaptación en las cuencas de los ríos Santa y Mayo (subcuenca del Quillcay, regiones de San Martin y Ancash). Los objetivos específicos de la Cooperación Técnica (CT) fueron: (i) priorizar medidas de adaptación al cambio climático identificadas en los estudios de Evaluación Local Integrada (ELI) realizada por el Programa de Fortalecimiento de Capacidades Nacionales para manejar el Impacto del Cambio Climático y la Contaminación del Aire (PROCLIM) y la Segunda Comunicación Nacional de Cambio Climático en las cuencas seleccionadas; (ii) fortalecer las capacidades de implementación de medidas del adaptación al cambio climático en las cuencas seleccionadas; (iii) promover la inclusión de las variables de cambio climático en las políticas, planes y estrategias de desarrollo de las regiones; (iv) generar nuevas capacidades en la formulación, conducción e implementación de proyectos de desarrollo regional con un enfoque de adaptación al cambio climático bajo la modalidad del sistema nacional de inversión pública.

En el proyecto del Reconquista en Argentina, la primera operación fue aprobada en 1993 y terminó su ejecución en el 2006. Con financiamiento de la primera operación se creó el Comité de Cuenca del Río Reconquista (COMIREC), a través de una ley que aún sigue sin reglamentación. La segunda operación fue aprobada en el 2014 y se encuentra en fase de ejecución, la cual se encuentra bastante retrasada comparada con el cronograma inicial. El plan de gestión integral de recursos hídricos, que debería ser la primera contratación del proyecto, fue licitado, pero aún no está contratado.

El ejemplo peruano descrito en el Recuadro 3.3. prueba que el tiempo que lleva implementar cambios en la manera de gestionar los recursos hídricos con los países es significativo y requiere de seguimiento continuo. Así ha sucedido en el caso de Perú y esta ha sido también la experiencia en el proceso de implantación de gestión de recursos hídricos, bien sea por cuencas o creación de áreas de protección y/o conservación (fondos de agua), reservas de agua (México) $)^{17}$ o productores de agua (Brasil) ${ }^{18}$.

16 Autoridad Nacional del Agua, "Política y Estrategia Nacional de Recursos Hídricos de Perú", 2012 
¿Por qué es tan costoso en términos de tiempo y esfuerzo implementar cambios en la gestión de recursos hídricos?

- El concepto de GIRH, concebido a partir de la década de los ochenta, requiere de una coordinación institucional en varios niveles (nacional, estatal y local) y la participación de los usuarios en la toma de decisiones. Hasta los ochenta, los sistemas de gestión del agua eran sectoriales con decisiones verticales, sin consulta a los usuarios o a los pares (aún hoy, muchos continúan así). Cada institución tenía su agenda y quienes la manejaban, por sus tradiciones, no entendían este nuevo concepto. Estas dificultades todavía persisten en muchos de nuestros países.

- Falta de recursos humanos capacitados en las instituciones de gestión de recursos hídricos por falta de oferta en las universidades o condiciones laborales poco atractivas.

- Falta de información confiable para la toma de decisiones. Este tema sigue pendiente según evaluaciones más recientes (Garzón López, 2017). Es necesario desarrollar sistemas de información de recursos hídricos (algunos países como Brasil, Perú y Colombia ya disponen de estos sistemas) e implantar y operar estaciones de monitoreo hidrometereológico y de calidad del agua. Curiosamente, no es difícil conseguir los recursos para implantar dichas estaciones, pero los recursos para su operación y mantenimiento son escasos y casi siempre provistos por los gobiernos, por lo que carecen de constancia. Normalmente no existe ningún catastro de los principales usuarios. Por ejemplo, no se sabe con certeza cuantas industrias están ubicadas en la cuenca del río Reconquista y Perú necesitó de préstamos del BID y del Banco Mundial para realizar un catastro de usuarios de los sistemas de riego del país.

- Falta de recursos financieros para financiar la gestión de recursos hídricos. En Perú las cuencas incluidas en el PMGRH actualmente cuentan con los planes de gestión de recursos hídricos, pero no disponen de los recursos para implementarlos. En algunos casos, la cuestión del cambio climático no había sido considerado en el diseño de dichos planes. El problema de la falta de recursos fue corregido en el proyecto Reconquista, en el que los recursos presupuestados incluyen las acciones que componen el plan de gestión de la cuenca; pero este aún no ha sido desarrollado y los recursos financieros están siendo consumidos en obras definidas con objetivos institucionales y no a partir de definiciones técnicas estratégicas y de un consenso entre representantes de los usuarios y del gobierno. El Programa de Saneamiento Ambiental de la Cuenca Del Río Ipojuca (Brasil) financia la implementación de parte de un plan de gestión de recursos hídricos, preparado con recursos del gobierno. Este es uno de los prob- 
lemas fundamentales para la sostenibilidad de la gestión de los recursos hídricos. La inexistencia de recursos financieros para financiar estos planes crea frustración entre los usuarios que a su vez genera descrédito en el sistema de gestión propuesto, generando un círculo vicioso.

- El cobro por el uso del agua no se ha adoptado y cuando se adopta no refleja la productividad hídrica por sector económico. Al final del PMGRH en el Perú, el valor recaudado por metro cúbico alcanzó solo S/.0,13, un valor muy bajo pero muy superior a la meta inicial del programa ${ }^{19}$. En Brasil se ha implementado en 45 cuencas, incluyendo todas las de los estados de Ceará, Rio de Janeiro y Paraíba, y algunas de São Paulo, Minas Gerais y Paraná20. El país está dividido en 12 regiones hidrográficas con una multitud de cuencas ${ }^{21}$. El desarrollo de las cuentas económicas ambientales del agua en Brasil, para el período 2013-2015, evidencia la gran dispersión de eficiencia en el uso de los recursos hídricos entre las actividades económicas. Por ejemplo, los índices medios para las industrias extractivas $\left(603,74 \mathrm{R} \$ / \mathrm{m}^{3}\right)$ son superiores a aquellos de las industrias de transformación( $R \$ 246,62)$ y del sector agrícola $(R \$ 10,81)^{22}$. Estas diferencias reflejan el alto valor agregado bruto y el bajo consumo de agua de las industrias extractivas en comparación con los demás sectores. En momentos de escasez, los sectores más eficientes son perjudicados si se adoptan los mismos criterios de restricción al uso. Por ejemplo, la Confederação Nacional das Industrias de Brasil, en su trabajo preparado para las elecciones del 2018, alega que, por estar adoptando medidas de conservación de agua, para el sector industrial, el costo marginal de reducir un $\mathrm{m}^{3}$ de captación de agua es muy superior al costo marginal de un usuario con $30 \%$ a $35 \%$ de perdidas.

La iniciativa de crear reservas estratégicas de agua en cada país como medidas preventivas o de adaptación a escenarios de escasez hídrica es fundamental

\section{Fondos de Agua}

La iniciativa de crear reservas estratégicas de agua en cada país como medidas preventivas o de adaptación a escenarios de escasez hídrica es fundamental también para atacar problemas de mayor envergadura, como el cambio climático. El uso sostenible de la infraestructura verde no solo preserva el potencial de fuentes. También garantiza su calidad con repercusiones en los costos de tratamiento de agua. Reconociendo el potencial de esta iniciativa, el BID, la Fundación Fomento Económico Mexicano S.A.B de C.V. (FEMSA), The Nature Conservancy (TNC) y el Global Environmental Facility (GEF) lanzaron la Alianza Latinoamericana de Fondos de Agua (ALFA). El objetivo de esta alianza es proveer asistencia técnica y financiera destinada a la creación y fortalecimiento de los Fondos de Agua, como un instrumento

19 Informe de Terminación de Programa (PCR), Programa de Modernización de la Gestión de los Recursos Hídricos, 2016.

20 Confederação Nacional das Indústrias-CNI, "Segurança Hídrica: Novo Risco Para a Competitividade", Para as eleições de 2018

21 Agência Nacional de Águas-ANA, "Atlas Brasil: Panorama Nacional-Volume 1, Abastecimento Urbano de Agua",2010.

22 Agência Nacional de Águas (ANA), Contas Econômicas Ambientais Da Água No Brasil, 2018 
El sector de agua potable y saneamiento debe asumir un papel más proactivo en las tareas de protección y conservación de las cuencas hidrográficas innovador de protección de cuencas hidrográficas. En 2017 se llevó a cabo una evaluación de cinco fondos financiados por la ALFA al final de cinco años de ejecución. Estos fondos fueron Espirito Santo, Palmas, and Camboriu (Brasil); Bogotá, Medellín y Santa Marta (Colombia); Santo Domingo y Yaque del Norte (República Dominicana); Monterrey (México) y Lima (Perú). La evaluación concluyó que el proceso fue satisfactorio e identificó varios aspectos que pueden ser perfeccionados (Garzón-López, 2017). Aquí recogemos aquellos relacionados al diseño y monitoreo. Con relación al diseño de los fondos, es recomendable la realización de una evaluación detallada de la cuenca hidrográfica; el reconocimiento de las limitaciones de los modelos utilizados (incluyendo los financieros) y trabajar las recomendaciones que el proceso genera para que sean prácticas y de fácil implantación. En lo que se refiere a monitoreo, recomienda la inclusión de indicadores robustos que reflejen las mejoras de la calidad y cantidad de agua debido a los esfuerzos de conservación y restauración. La revisión reconoce también que la conformación de fondos de agua es un proceso de largo plazo y que tiene incidencias positivas en la SH.

\section{Proyectos con Empresas de Agua y Saneamiento (EAS)}

El Banco tiene una vasta experiencia de trabajo con Empresas de Agua y Saneamiento. Algunos ejemplos destacables son: Empresa Pública Metropolitana de Agua Potable y Saneamiento-Quito-Ecuador, SABESP-Brasil, Empresas Públicas de Medellín-EPM, CAESB-Brasilia-Brasil y AySA-Argentina. Muchos de los proyectos con estas empresas acumulan ya varias fases y años de trabajo. WSA tiene un abanico de productos para estas empresas que incluyen: fortalecimiento de la empresa, incluyendo restructuración de la gobernanza corporativa; estudio de tarifas; reducción de agua no contabilizada; valoración de activos; monitoreo de redes de agua y alcantarillado; tratamiento de agua y efluentes y reúso y disposición final de efluentes tratados, entre otros. En algunos proyectos, el Banco ha apoyado el desarrollo de sistemas de gestión ambiental. El desafío del cambio climático y sus consecuencias abren nuevas áreas de actuación para las EAS, que tendrán que desarrollar sus planes de adaptación y estrategias de SH.

Entre las conclusiones de la Semana Mundial del Agua del 2015 fueron identificadas áreas en las que el sector de agua y saneamiento necesita ser más proactivo para garantizar la sostenibilidad de la disponibilidad de su insumo principal. En este sentido se afirmaba: “El sector de agua potable y saneamiento debe asumir un papel más proactivo en las tareas de protección y conservación de las cuencas hidrográficas, partiendo del reconocimiento de los beneficios económicos potenciales resultantes de un mejor control sobre los usos del suelo y de la preservación o restauración de ecosistemas naturales. Se deberán también considerar las posibilidades de: i) adquirir terrenos estratégicamente ubicados en las cuencas abastecedoras para evitar su degradación o acometer su restauración y/o conservación; ii) impulsar medi- 
das de regulación del uso del suelo; iii) proponer mecanismos de pago por servicios ambientales a los moradores de las cuencas que adopten prácticas productivas ambientalmente sostenibles, tales como mosaicos productivos agroforestales, e iv) incluir en las tarifas tasas ambientales dirigidas a la protección de las cuencas de interés"23.

Estas innovaciones requerirán que el BID empiece a analizar y proponer proyectos de agua y saneamiento siguiendo metodologías del campo de la ecología industrial (Industrial Ecology), haciendo un seguimiento al ciclo de vida de proyectos de control de la contaminación industrial, que incluyen todos los pasos de la producción, distribución, venta al consumidor, tratamiento y disposición final de los residuos generados. La EAS tendrá que ser vista como una industria del agua que obtiene su insumo de una cuenca que necesita de conservación y/o restauración, manejo y, en algunos casos, preservación con perspectivas de largo plazo. Procesado el insumo agua, los desperdicios tienen que ser minimizados para que el negocio sea rentable. Los efluentes generados deberán ser debidamente tratados y reutilizados en un nuevo proceso productivo o en procesos de recuperación y/o devolución al ambiente para que cumpla con sus funciones. En algunas ocasiones, la reglamentación a la que están sometidas las EAS limitan su efectividad y funcionamiento. Por ejemplo, el Servicio de Alcantarillado y Agua Potable de Lima (SEDAPAL) solo puede tratar efluentes domésticos, por ley. Por tanto, cuando diseña una planta de tratamiento de aguas residuales, únicamente puede considerar estos efluentes para dimensionar el tratamiento de la nueva planta y la inversión correspondiente. Sin embargo, el efluente real lleva descargas industriales y agrícolas no controladas aguas arriba, por lo que la nueva planta no será efectiva en términos de su objetivo de descontaminación.

\section{Recuperación urbana y control de la contaminación}

A este respecto, la experiencia con los proyectos PROSAMIM, DRENURBES, Matanza-Riachuelo, Reconquista y Tiete ofrece multitud de aspectos positivos y lecciones que aprender. Como ya se ha visto, el PROSAMIM cambió el paisaje de Manaus e impactó positivamente en la población afectada a través de intervenciones urbanas, proyectos de drenaje, agua y saneamiento, reasentamiento y contacto con la población ${ }^{24}$. Una de las solicitudes realizadas durante la confección del proyecto fue que, en las siguientes operaciones, se incluyera la preservación de las nacientes de los arroyos urbanos. Los proyectos de DRENURBES, Reconquista y Tiete incorporan esta acción. Por lo tanto, hay que repensar estos proyectos como intervenciones integrales a nivel de cuenca urbana.

23 Garzón, C. y Sturzenegger, G. (2015). "Los desafíos de la Agenda De Desarrollo post-2015 para el Sector de Agua Y Saneamiento en América Latina y el Caribe: conclusiones de la Semana Mundial del Agua 2015"

24 Informe de Terminación de Proyecto-PCR, 2013. 
Los PNRH necesitan estar ampliamente amparados por la legislación de recursos hídricos

Las Cuentas del Agua permiten establecer una evidencia cuantitativa y comparativa de los sectores económicos menos eficientes en el uso del agua

\section{Planes Nacionales de Recursos Hídricos (PNRH)}

Aunque sean instrumentos de la política de recursos hídricos de un país, los PNRH necesitan estar ampliamente amparados por la legislación de recursos hídricos. Por ejemplo, en Brasil, aunque existe un marco legal bien definido, aún no está reglamentado el inciso VII del artículo 7º de la ley 9.984 del 2000, que establece la competencia de los planes de recursos hídricos, para definir una regla general sobre prioridades para la otorgación de permisos de recursos hídricos. También es necesario que exista una estrecha coordinación entre el plan nacional y los planes de cuencas y, quizás lo más importante, debe haber garantía de recursos para financiar las acciones propuestas en los PNRH. En este caso, el plan de Perú presenta un cuadro optimista de financiación de las acciones programadas para el periodo 2021- 2035, que tiene como punto de partida los costos de la gestión de recursos hídricos en el 2011, los cuales representaron solo un 4,9\% de las inversiones totales del Estado. La cooperación técnica internacional fue designada como responsable para financiar una parte de las acciones identificadas. El análisis de varios planes demuestra la necesidad de una estandarización, principalmente con relación al contenido mínimo, los mecanismos legales para su debida implementación y la forma de presentar la necesidad de un compromiso financiero ligada a las responsabilidades de su implementación. Esto puede ser cubierto a través de un enfoque ampliado en planes nacionales de seguridad hídrica.

\section{Cuentas Económicas Ambientales del Agua (CEAA)}

Esta herramienta de reciente creación promete ser muy útil para la SH porque, a través de los conceptos de "agua virtual" y "huella hídrica", permite establecer una evidencia cuantitativa y comparativa de los sectores económicos menos eficientes en el uso del agua, facilitando así la definición de políticas para la gestión de los recursos hídricos en situaciones tanto rutinarias como de escasez. La utilización de las CEAA supone un punto de entrada importante para incluir el tema de la SH en las decisiones de desarrollo económico nacional a través de las cuentas nacionales.

\section{¿Qué factores y criterios deben guiar la acción del BID en material de SH?}

Sintetizando algunos mensajes clave acerca de la experiencia del BID en materia de $\mathrm{SH}$ se puede decir lo siguiente ${ }^{25}$.

- Visión integral. La falta de sinergia entre las diferentes acciones del Banco puede ser uno de los obstáculos para lograr impactos más significativos hacia la obtención de la SH en la región. En este sentido es necesario coordinar las acciones y proyectos de las divisiones involucradas desde la preparación de la Estrategia de País hasta la concepción de la operación. Las operaciones pasan a tener un carácter multisectorial y multipropósito. El Banco necesita incorporar la visión integral al apoyo que brinda a los países.

25 Las experiencias no necesariamente obedecen a diagnósticos profundos nacionales, sino que se basan en información limitada y resultan en intervenciones que pueden resultar difusas y poco coordinadas. 
Aunque el Banco ha financiado proyectos de tratamiento de aguas residuales en varias ciudades, es necesario hacer un esfuerzo más amplio y coordinado para recuperar la calidad del agua en las cuencas estratégicas de la región para componer el abanico de acciones que conducen a la SH. A este respecto, los proyectos de descontaminación por cuencas pueden ser más eficientes que trabajar a nivel de ciudades o cuencas urbanas y permite la visión global de la relación causas-impactos-soluciones.

- Minimizar los posibles conflictos. Se estima que para el 2050, el 68\% de la población mundial estará viviendo en áreas urbanas. Estas áreas dependerán, muy seguramente, de los recursos hídricos provenientes de microcuencas aledañas en zonas rurales para abastecer de agua a una población urbana creciente. Normalmente, estas microcuencas rurales tienen ya usos y usuarios del recurso bien definidos, lo que podría originar conflictos por demandas urbanas adicionales de agua. En este sentido, es de absoluta relevancia construir una estructura de gobernanza que permita minimizar posibles conflictos sociales por el uso del recurso, en particular en zonas áridas en las que la disponibilidad se verá significativamente afectada por cambio climático.

- EI BID como instrumentador y capacitador. El desarrollo de herramientas de gestión como HydroBID y el Nexo Agua-Energía-Alimentos ha tenido buena recepción en la región ${ }^{26}$, lo cual es indicativo del importante rol del BID como instrumentador y capacitador de los actores clave para implementar acciones de cara a la consecución de la SH.

- Crear la demanda. Para impulsar el movimiento hacia la SH en la región, en un contexto en el que los objetivos económicos y sociales son vistos como prioritarios, es importante crear en los países una demanda de proyectos y acciones afines. Una forma de impulsar la demanda es a través de demostraciones del valor económico de la SH y del vínculo entre esta y los objetivos económicos y sociales. Este es un campo abierto a la contribución del Banco, ya sea a través del desarrollo de las cuentas ambientales del agua o del desarrollo de modelos económicos que vinculan las cuentas nacionales con los insumos estratégicos como el agua, bajo diferentes escenarios factibles de cambio climático.

- Formación para actores estratégicos. Aún en relación con la creación de la demanda de proyectos y acciones vinculadas a la SH, el Banco debe elaborar programas de comunicación dirigidos a actores estratégicos tanto dentro del Banco (niveles de gerencia media hacia presidencia) como en los países clientes. Dichos programas podrían ser complementados con cursos y seminarios que ofrezcan capacitación e información sobre cómo insertar el tema de SH más efectivamente en cada país.

26 La comunidad de usuarios de HydroBID alcanza ya más de 15 países y tiende a crecer. 
- Buscar modelos de inversión. Es fundamental entender la importancia de invertir en la gestión de los recursos hídricos en la región. La falta de financiamiento de temas relacionados con la SH (p. ej., GIRH y temas similares) repercute en varios sectores como agua y saneamiento, agricultura, industria, energía, minería y turismo. Los Fondos de Agua representan una iniciativa que debe ser mejorada y expandida; pero persiste la necesidad de canalizar más recursos del sector privado y de identificar disposiciones a pagar por cuencas más limpias y mejor manejadas. Por ejemplo, en Brasil se han adoptado tasas vinculadas al consumo de electricidad (Fondo de Recursos Hídricos). En Estados Unidos, existen tasas, como la tasa de protección de Chesapeake Bay en el estado de Maryland, que está incluida en la tarifa de agua. Esta es un área en la que el Banco podría contribuir ampliamente a través de la investigación, del desarrollo de modelos específicos para cuencas específicas o del apoyo a universidades para crear foros e intercambio de experiencias a nivel mundial.

Recuadro 3.4. HYDROBID: cuando la sed se calma con tecnología

Ya hemos visto cómo la región de ALC se caracteriza por la abundancia de recursos hídricos que, no obstante, deben ser adecuadamente gestionados para poder lograr la SH y, con ella, el desarrollo sostenible de la región. También hemos visto cómo la adecuada gestión de los recursos hídricos pasa, entre otras cosas, por disponer de información sobre su dinámica, la cantidad y calidad del recurso y las relaciones entre oferta y demanda hídrica.

Para hacer frente a esos retos, la División de Agua y Saneamiento del BID ha creado HydroBID, una herramienta de simulación para la gestión y Planificación de los Recursos Hídricos para la región de América Latina y el Caribe (ALC). Así, el sistema permite trabajar bajo escenarios de cambio (clima, uso del suelo y población), que permiten evaluar la cantidad y calidad del agua, las necesidades de infraestructura y el diseño de estrategias y proyectos de adaptación en respuesta a estos cambios.

Es una herramienta sencilla compuesta por una base de datos, una plataforma simple, flexible y accesible para todos (no tiene coste), que permite la gestión eficiente de las cuencas hídricas en América Latina y el Caribe mediante el uso de tecnologías de la información, facilita la toma de decisiones y la planificación a corto, medio y largo plazo, y promueve el diálogo regional y la integración de los diferentes actores que tienen que ver con la gestión de los recursos hídricos en la región (tomadores de decisiones, personal técnico y comunidad científica).

Desde su puesta en marcha, HydroBID funciona ya en más de una docena de países, entre los que se incluyen Argentina, Perú, Ecuador, Guatemala, Bolivia, Brasil y Haití. También ha incorporado HydroBID Flood, una nueva herramienta para ayudar en proyectos de mitigación de inundaciones y en la mejora del drenaje urbano. 
Recuadro 3.5. Fondos de aguas: La inversión que se bebe

Durante mucho tiempo hemos infravalorado la capacidad de la naturaleza para ayudarnos a afrontar los retos que nos impone la SH. Hoy día sabemos que la esta es capaz de generar soluciones que, por ejemplo, favorezcan la infiltración de agua, nos ayuden a filtrarla mejorando su calidad o eviten inundaciones.

Los Fondos de Agua nacieron para reivindicar el papel de la naturaleza como componente clave de la SH. Son mecanismos financieros, de gobernanza y de gestión que integran a los actores relevantes de una cuenca (usuarios, empresas administradoras del agua, corporaciones, autoridades y sociedad civil) para promover la SH de una zona metropolitana a través de soluciones basadas en la naturaleza. Canalizan inversiones a largo plazo y apalancan recursos púbicos y privados destinando sus rendimientos a proyectos de conservación como reforestaciones, creación de áreas protegidas en zonas de alto valor ecosistémico, gestión de pagos por servicios ambientales o mejora de prácticas agrícola-ganaderas.

Con el objetivo de promover la creación y el fortalecimiento de fondos de agua en ALC, The Nature Conservancy (TNC), la Fundación FEMSA, el Banco Interamericano de Desarrollo (BID) y el Fondo Mundial para el Medio Ambiente (FMAM) formaron, en 2011, la Alianza Latinoamericana de Fondos de Agua. En sus ocho años de funcionamiento, la Alianza ha creado 24 Fondos de Agua y tiene 15 más en proceso de creación; ha impactado positivamente en 1,6 millones de hectáreas de ecosistemas; ha beneficiado a más de 70 millones de personas y ha apalancado más de 120 millones de dólares para inversiones en infraestructura verde. 


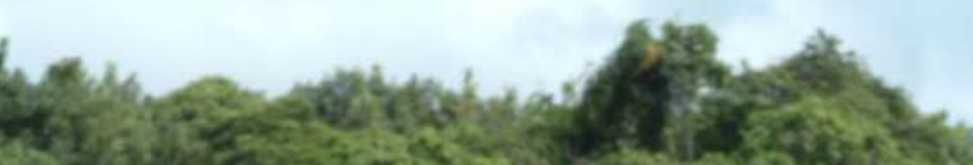

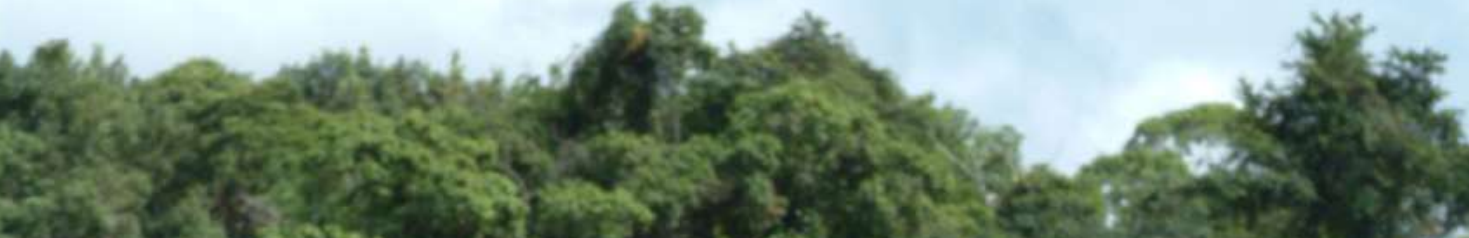
Q $x^{2}=2$

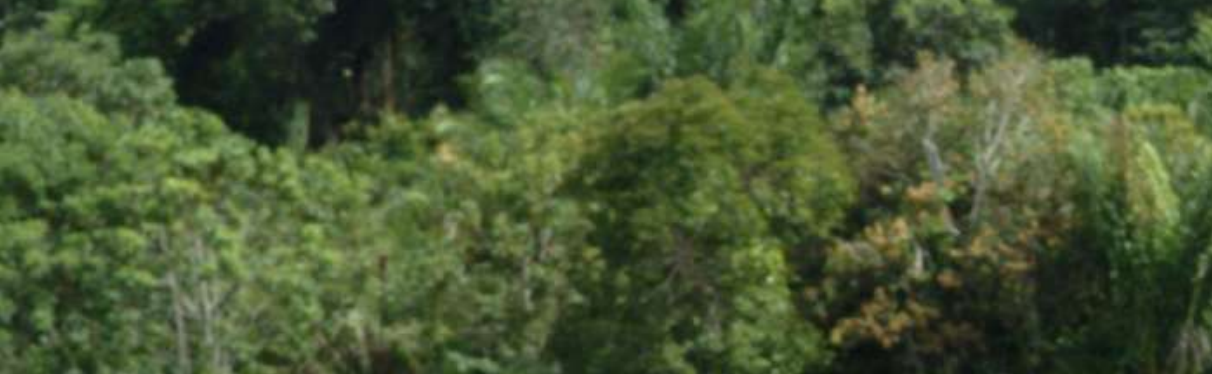

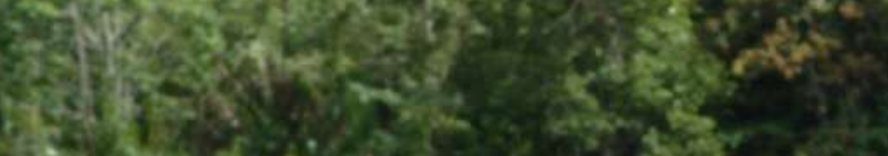

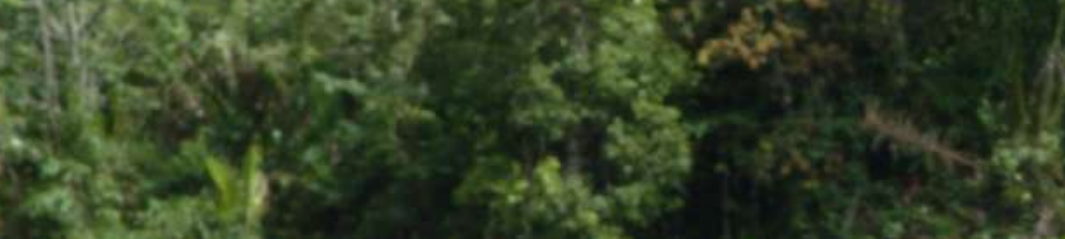
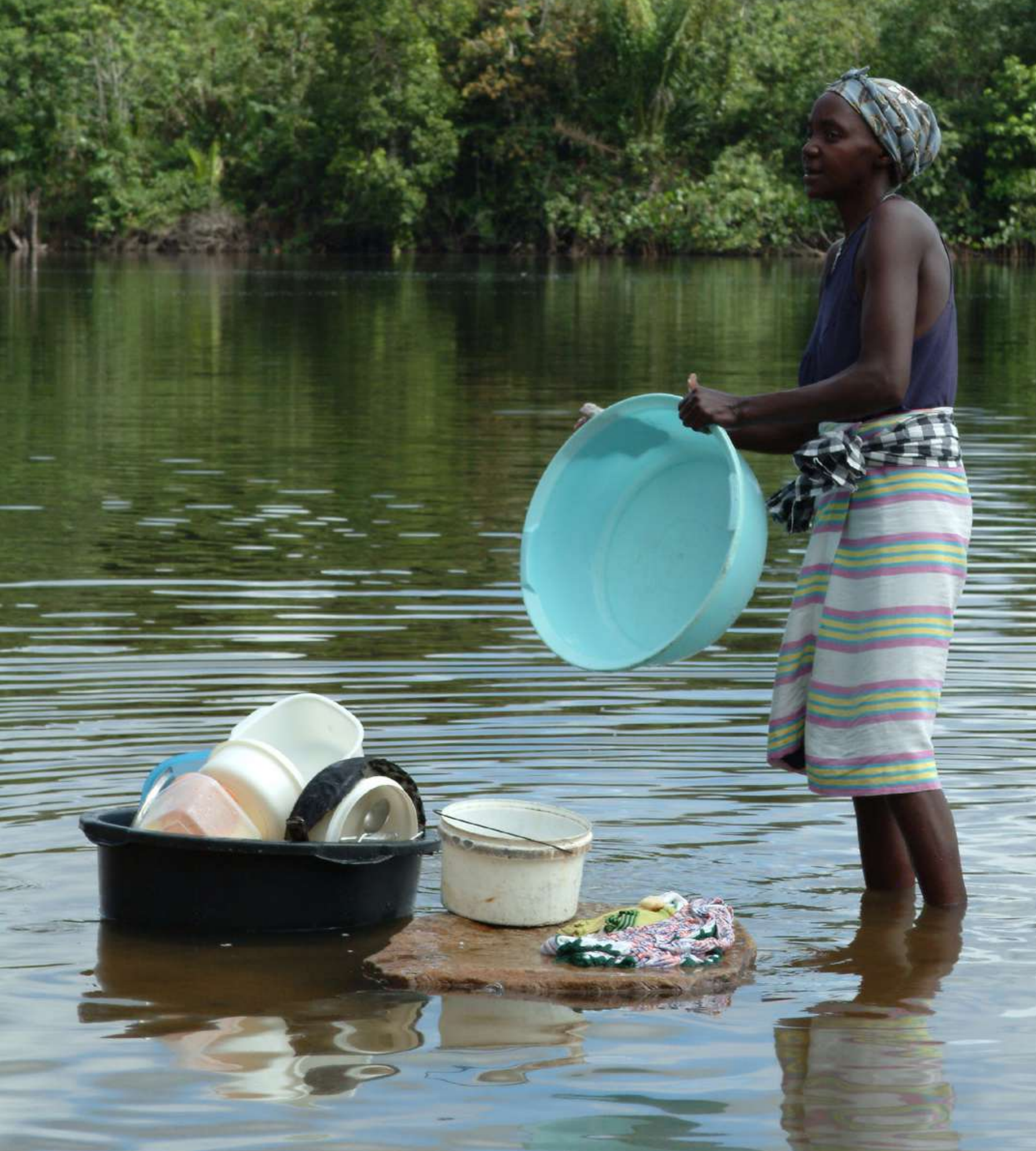
Las principales deficiencias en materia de SH en la región de Latinoamérica y el Caribe pueden ser resumidas con una sola palabra: fragmentación. Fragmentación en la concepción del problema; fragmentación en la consideración de las soluciones y fragmentación en el marco institucional y normativo.

El enfoque innovador aquí propuesto para resolver los problemas de SH se basan precisamente en la integralidad. Más concretamente en la gestión integral del ciclo del agua. Este enfoque implica cuatro áreas fundamentales de innovación: cambio climático y planificación multisectorial (enfoque de Nexo), infraestructura hídrica y SBN, marco institucional para la SH y avances en ciencia y tecnología.

En lo que se refiere a la planificación multisectorial, del nexo agua-energía-alimentos se derivan algunas innovaciones posibles como la consideración de los costos de suministro de agua en la planificación de la infraestructura energética o inversiones multisectoriales (como embalses multipropósito), que incorporen elementos de infraestructura natural (SBN) y proyecciones de cambio climático.

Por su parte, las Soluciones Basadas en la Naturaleza ofrecen múltiples oportunidades de innovación en diversos ámbitos como la gestión de las fuentes de agua ( $p$. ej., programas de reservas de agua o vinculación de ríos y planicies aluviales), servicios de agua y saneamiento (humedales artificiales, reutilización del agua o jardines de azotea), sistemas de riego y producción de alimentos (humedales para mitigar las consecuencias negativas de los sistemas de riego tradicionales y agricultura urbana), generación de electricidad (energías alternativas como la generación de corriente de marea, la energía de mareas o la energía azul) y prevención de sequías o inundaciones (planicies de inundación).

El marco normativo e institucional del agua en ALC se caracteriza por la heterogeneidad de escenarios y, por tanto, el gran desafío pasa por coordinar e integrar la actuación de los diferentes órganos administrativos competentes en materia de aguas con las demás autoridades con competencias implicadas en la consecución de objetivos de SH.

\section{Oportunidades de innovación en seguridad hídrica}

$D$ ara avanzar en la realización de mejoras significativas a la SH en la región de América Latina y Caribe, los países de la región deben explorar diferentes opciones para atacar las deficiencias que se han identificado en el Capítulo II y aprovechar la experiencia y lecciones aprendidas por el BID, expuestas en el Capítulo III. De manera prospectiva, en este informe se sintetizan una serie de oportunidades de innovación basadas en mejorar las deficiencias identificadas explotando el conocimiento adquirido por el BID en su trabajo de más de 50 años en la región.

Las principales deficiencias expuestas en la región en materia de SH descritas en el Capítulo II se pueden resumir en:

- Una sobresimplificación del problema de la disponibilidad hídrica, que se refleja en procesos de planificación y gestión de los recursos hídricos fragmentados y que no consideran fenómenos que afectan a la oferta y la demanda hídrica ni tienen en cuenta el cambio climático.

- Utilización excesiva de inversiones en infraestructura gris para intentar resolver los problemas relacionados con el acceso a los recursos hídricos, la calidad de agua y la reducción de riesgos ante eventos hidrometeorológicos extremos, abordando estos problemas de manera individual (e.g., presas, embalses, plantas de tratamiento, sistemas de bombeo y otros) y dando poca relevancia al uso de capital natural y a mecanismos de gestión adaptativos.

- La formulación de marcos institucionales y de normativas fragmentados, con poca consideración de la interrelación entre los sectores de uso del agua; necesitados de mayor planificación hidrológica y relativamente débiles en cuanto capacidad de implementación. 
(1) El enfoque de SH como tal debe concretarse en una política pública o ciclo de políticas públicas, que debe consignar sus objetivos, concretarlos en planificaciones, impulsar las modificaciones normativas necesarias e implementar los arreglos institucionales precisos. Esto debe hacerse a través de una planificación hídrica (transparente, informada y vinculante), una normativa (que contemple una ley de aguas, el ordenamiento territorial y la gestión de riesgos).

Los avances en ciencia y tecnología pueden jugar un gran papel al servicio de la SH en ALC, sobre todo en lo que se refiere a la disponibilidad de datos sobre la cantidad y la calidad del agua y, en un sentido más amplio, el monitoreo del ciclo del agua y el desarrollo de herramientas que transformen estos datos en información confiable de acceso público para apoyar la toma de decisiones y la planificación.

(1) La percepción remota o teledetección, que ya se usa en la medición de múltiples variables hidrometeorológicas y ambientales, ofrece una oportunidad significativa de innovación en material de SH, aunque es preciso capacitar a los responsables de la formulación de políticas en la operacionalización de estos avances.
El enfoque innovador propuesto para resolver los problemas de $\mathrm{SH}$ en ALC se basa en el concepto central de una gestión del ciclo del agua, en lugar de una gestión basada en la asignación de recursos hídricos disponibles entre varios sectores. El esquema de interacciones que conforman el ciclo del agua se ilustra en la Figura 4.1.

Este enfoque ampliado implica varias áreas de innovación que se tratan en este capítulo: (i) una gestión integrada de la oferta y la demanda, que incluya consideraciones ambientales y de cambio climático ( $y$ cómo este afecta a la oferta y la demanda hídrica), y reconozca interacciones múltiples en la demanda hídrica entre sectores (lo que se conoce como el "nexo"); (ii) la utilización de SBN con el fin de complementar y fortalecer los enfoques tradicionales de infraestructura gris, y al mismo tiempo aumentar la resiliencia natural de las fuentes de agua; y (iii) un marco institucional y normativo que enlace estos componentes y facilite su implementación en la práctica por los tomadores de decisiones en los países de la región. A estas áreas de innovación hay que agregar iv) los avances que se han producido en materia de ciencia y tecnología, aplicables a los diferentes componentes del ciclo del agua, para acelerar y facilitar mejoras significativas en la $\mathrm{SH}$ para la región.

La Figura 4.2 esboza una serie oportunidades específicas en las diferentes áreas de innovación propuestas. Estas oportunidades también pueden aprovechar la experiencia y el conocimiento adquirido por el BID y las lecciones aprendidas a lo largo de más de cinco décadas de trabajo en la región presentadas en el Capítulo III. La capacidad para facilitar la transición de innovaciones en diferentes ámbitos, al trabajo de campo en los países de la región requiere de conocimiento y capacidad para implementarlo. Esta combinación de reconocer áreas prospectivas para innovar y la capacidad de llevarlas al trabajo de campo es una ventaja competitiva del BID en el proceso de avanzar en el tema de la SH con sus clientes en la región. 
Figura 4.1. Esquema conceptual del ciclo del agua y los aspectos integrados que involucran su gestión en torno a mejorar la SH.

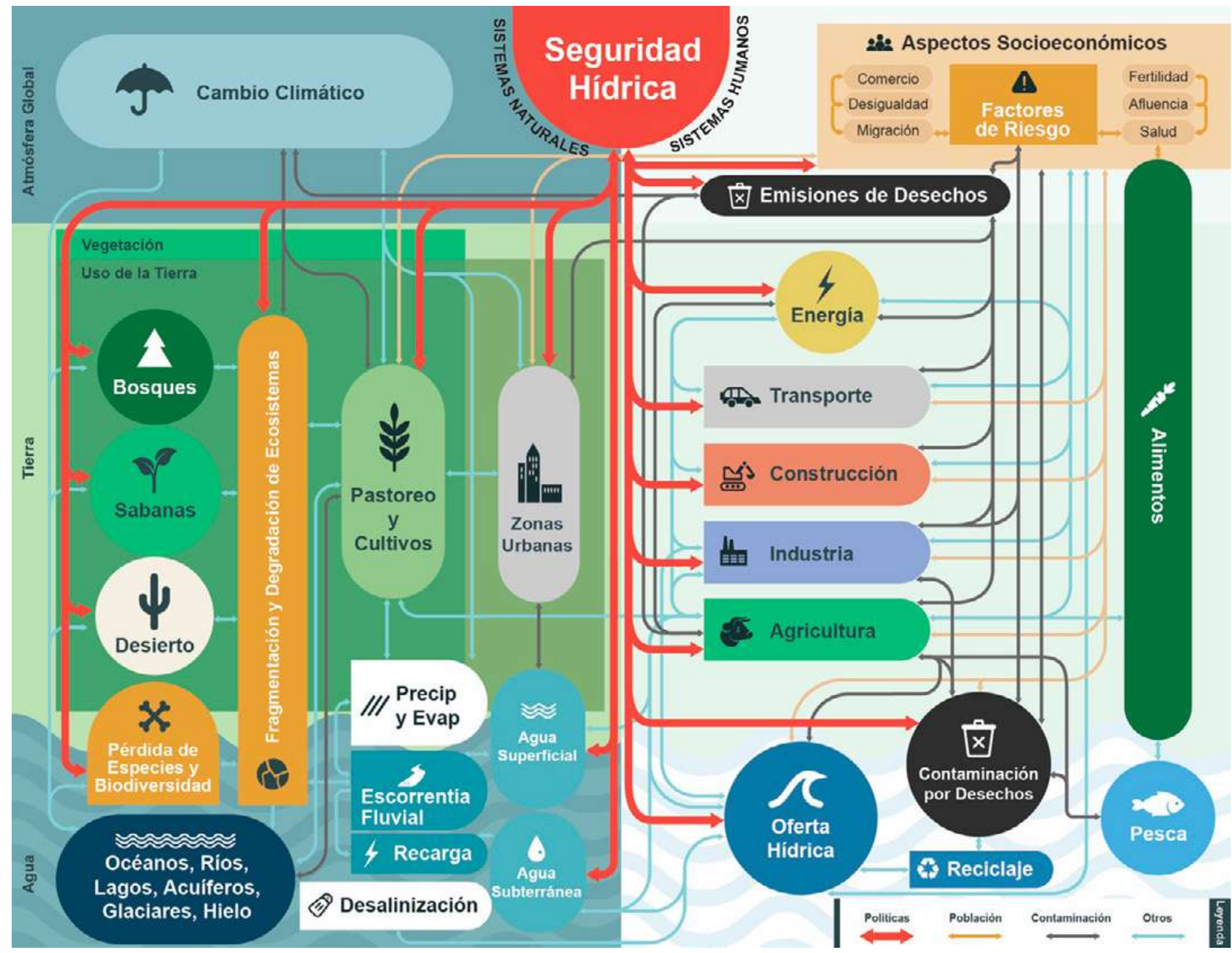

Fuente: Elaboración propia. 
Figura 4.2. Oportunidades de innovación en SH para la región de ALC. Se proponen cuatro categorías de oportunidades que son interdependientes y que involucran la participación de diferentes actores.

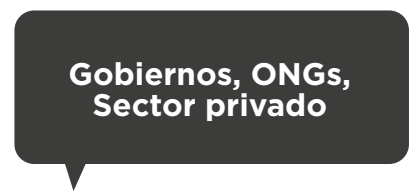

\section{INFRAESTRUCTURA HÍDRICA Y SBN}

- Combinación de infraestructura construida (gris) y natural (verde)

- Utilización de infraestructura para avanzar en el reuso del agua

- Infraestructura para la gestión del ciclo del agua

Académicos, Institutos de investigación, ONGs

AVANCES EN CIENCIA Y TECNOLOGÍA

- Avances necesarios en monitoreo del ciclo del agua

- Teledetección satelital de variables en cantidad y calidad del agua

- Uso de fuentes de adatos públicas y abiertas facilita la trasparencia
Gobiernos, Bancos Multilaterales

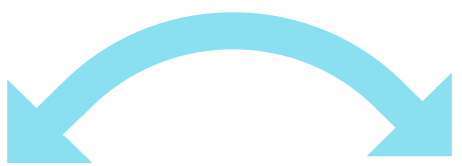

\section{CAMBIO CLIMÁTICO Y} PLANIFICACIÓN MULTISECTORIAL NEXO

- Gestión de la demanda hídrica considerando interacciones entre sectores

- Impactos en la demanda hídrica para los sectores por el cambio climático

- Crecimiento de la energía renovable en la región afecta la $\mathrm{SH}$
Gobiernos,

Organismos

internacionales
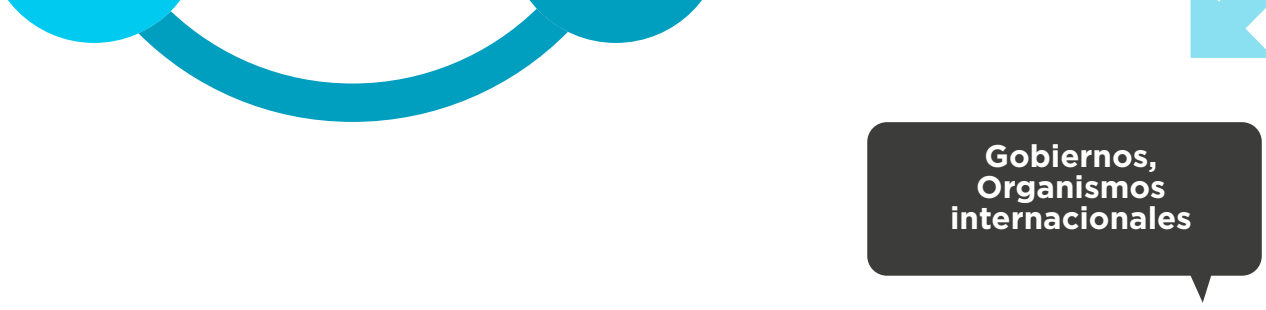

\section{MARCO INSTITUCIONAL PARA LA SH}

- Planificación; Normatividad; Institucionalidad,

Administración y Gestión

- Instrumentos económicos, fiscales y de mercado

- Cuencas internacionales

Fuente: Elaboración propia. 
Los componentes del nexo entre clima-tierra-energíaagua se afectan mutuamente de varias maneras
Las áreas de innovación propuestas son las siguientes:

- Cambio climático y planificación multisectorial (Nexo), incorporando específicamente la demanda hídrica integrada para diversos usos en la gestión efectiva de la SH.

- Infraestructura hídrica y SBN, para dar mayor espacio a combinaciones de infraestructura gris y verde que provean de mayor eficiencia, confiabilidad y costoefectividad en la prestación de servicios de SH.

- Marco institucional para la SH, para adaptar los espacios de política y de toma de decisiones a los principios de la $\mathrm{SH}$, e integrarlos con la gestión de otros recursos naturales (p. ej., nexo con energía, agricultura, biodiversidad y cambio climático, entre otros).

- Avances en ciencia y tecnología, para realizar, deliberadamente, inversiones en conocimiento e implementación de nuevos conceptos y avances en $\mathrm{SH}$.

Las oportunidades específicas de innovación en cada una de estas áreas se describen a continuación.

\section{IV.1 Cambio climático y planificación multisectorial (Nexo)}

El nexo de recursos hídricos, energéticos y terrestres, conocido también como nexo agua-energía-alimentos, resume una creciente preocupación sobre la disponibilidad de estos recursos vitales y de los sistemas interrelacionados que se utilizan para su gestión, particularmente en respuesta a los desafíos planteados por las demandas humanas y el cambio climático. En un sentido más amplio, los componentes del nexo entre clima-tierra-energía-agua (Muñoz-Castillo y Miralles-Wilhelm, 2018) se afectan mutuamente de varias maneras. El agua se encuentra frecuentemente bajo estrés por parte del sector agrícola, que es responsable de aproximadamente el $70 \%$ del total de extracciones de agua dulce en el mundo (FAO 2011a). En particular, la producción de alimentos representa aproximadamente el $30 \%$ del consumo total de energía del mundo (FAO 2011b). Por otro lado, la variabilidad y el cambio climático se reflejan en variaciones espaciales y temporales de la disponibilidad de agua, con fluctuaciones intensificadas del ciclo hidrológico que conducen a crecientes inundaciones y eventos de sequía. Es probable que esto incida en la SH en todos los sectores: agricultura (el mayor consumidor de agua del mundo), pero también generación de energía, suministro de agua potable y presiones sobre los ecosistemas.

En la región de ALC, la población y el ingreso per cápita continúan creciendo (Figura 4.3), lo que a su vez aumenta la demanda de agua, energía y alimentos, especialmente en países de rápido crecimiento. En ALC, el nexo se caracteriza por la abundancia de agua, pero con grandes heterogeneidades 
espaciales y temporales, una dependencia crítica de la agricultura en la producción económica y un sector energético diverso y en crecimiento con una matriz de generación más amplia. Todo esto aumenta la presión sobre la seguridad del agua. Según las estimaciones de la base de datos AquaStat de la FAO (que incorpora el flujo anual promedio de los ríos y la recarga de los acuíferos generados por las precipitaciones endógenas), alrededor del 32\% de los recursos hídricos renovables del mundo se pueden encontrar en ALC.

En este contexto, no solo la $\mathrm{SH}$, sino también la seguridad alimentaria y la seguridad energética, han sido reconocidas como consideraciones críticas para el crecimiento sostenible y la estabilidad social. Dadas las complejas interacciones entre estos sectores, es imperativo ir más allá de los enfoques tradicionales, en los que la toma de decisiones se produce como si estos fueran independientes entre sí, hacia un desarrollo de la planificación integrada (nexo). Además de promover la eficiencia económica y de recursos, este marco de planificación integrado es importante para evitar consecuencias no deseadas y posibles conflictos relacionados con la utilización de los recursos de EWL (Energy, Water, Land) en las próximas décadas (Da Silva et al., 2018; Miralles-Wilhelm y Muñoz- Castillo, 2018).

Un estudio reciente del BID analizó las proyecciones a futuro de la demanda de agua, energía y alimentos en la región (Miralles-Wilhem y Muñoz Castillo, 2018). El cuadro regional de la demanda de agua se ilustra en la Figura 4.4. La mayor demanda de agua en la región la ocasiona la producción de alimentos (alrededor del 65\% en promedio durante el período 2010-2100). Esta abarca los cultivos agrícolas, el ganado y la alimentación del ganado. Le sigue la demanda de agua para obtener energía (aproximadamente el 20\%), que incluye la generación de electricidad y las actividades extractivas (industria). El uso doméstico del agua (municipal y rural) representa el 15\% restante. La parte superior de la figura muestra la demanda hídrica bajo un escenario de referencia que extiende la tendencia actual (business as usual); la parte inferior muestra la misma proyección bajo un escenario en el que se implementan las políticas climáticas NDC (contribuciones nacionales voluntarias) para cada país de la región. Al comparar estas cifras, el escenario NDC, que realiza esfuerzos para mitigar y adaptarse al cambio climático, resulta en un aumento de la demanda de agua de más del 35 por ciento. Este aumento significativo en la demanda regional de agua, aunque puede parecer contrario a la intuición, se explica precisamente por razones derivadas del nexo existente, el cual no se capta en análisis sectoriales tradicionales.

Paralelamente, la energía primaria producida ALC se ilustra en la Figura 4.5. Estas cifras incluyen la demanda de energía no solo dentro de la región en sí; también incluyen la energía importada y/o exportada a/desde otras regiones del mundo. Estos resultados para la energía primaria reflejan el crecimiento de la demanda de energía debido al crecimiento de la población, así 
como el aumento de la demanda de energía per cápita a medida que crece la economía. El crecimiento se produce en todo el mundo. Estos resultados sugieren que la región de ALC continuará dependiendo de las industrias extractivas (por ejemplo, petróleo, gas natural y carbón), aunque con el tiempo, se producirá un rápido crecimiento de varias opciones de energía renovable (eólica, solar o biomasa), que tienen huellas relativamente pequeñas. Este crecimiento en energías renovables contribuirá al crecimiento de la energía primaria total producida, particularmente en países con escasos recursos extractivos (por ejemplo, América Central y el Caribe). Un mayor enfoque en el cambio climático, la mitigación en particular, pone énfasis en una reducción general de las demandas de energía proveniente de fuentes fósiles y una "descarbonización" de la economía. Esto mueve las fuentes de energía de la energía primaria tradicional (ver parte superior de la Figura 4.5) a una matriz energética que consiste en una combinación más amplia de tecnologías menos intensivas en carbono (ver parte inferior de la Figura 4.5), particularmente biomasa y CCS (captura y secuestro de carbono). Estas tecnologías, aunque son eficientes con el carbono, también requieren mayores cantidades de agua. Esta tendencia general de reducción de la demanda de energía y disminución de la demanda de fuentes de energía primarias tradicionales, acompañada por una mayor demanda de agua es otro resultado del análisis integrado (nexo).

Figura 4.3. Población y Producto Interno Bruto (PIB) proyectados para la región de ALC (2010-2100)

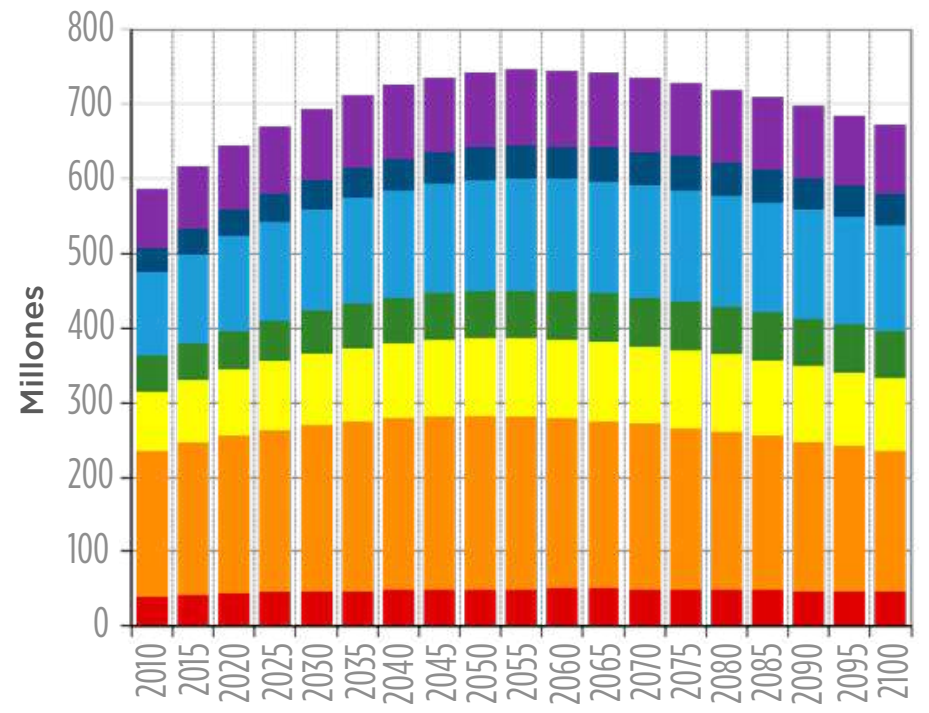

Argentina

Brasil
Centroamérica y El Caribe

Colombia

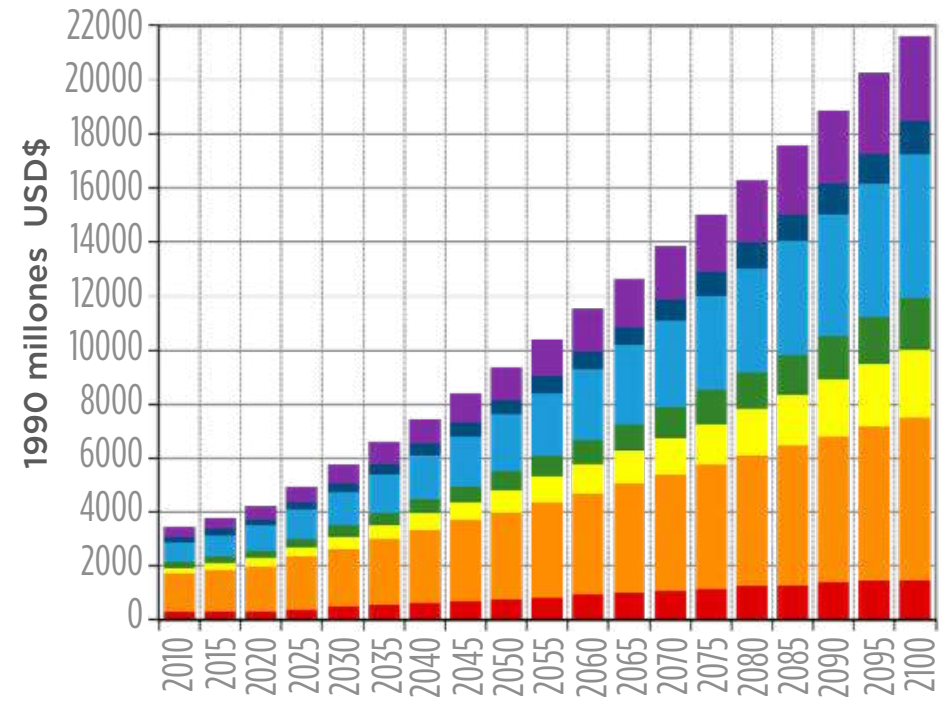

México

América del sur (Sur)

Fuente: Miralles-Wilhelm y Muñoz-Castillo, 2018. 
Figura 4.4. Proyecciones de la demanda hídrica $\left(\mathrm{km}^{3}\right)$ en la región de ALC (2010-2100). Izquierda: escenario de referencia. Derecha: escenario NDC.
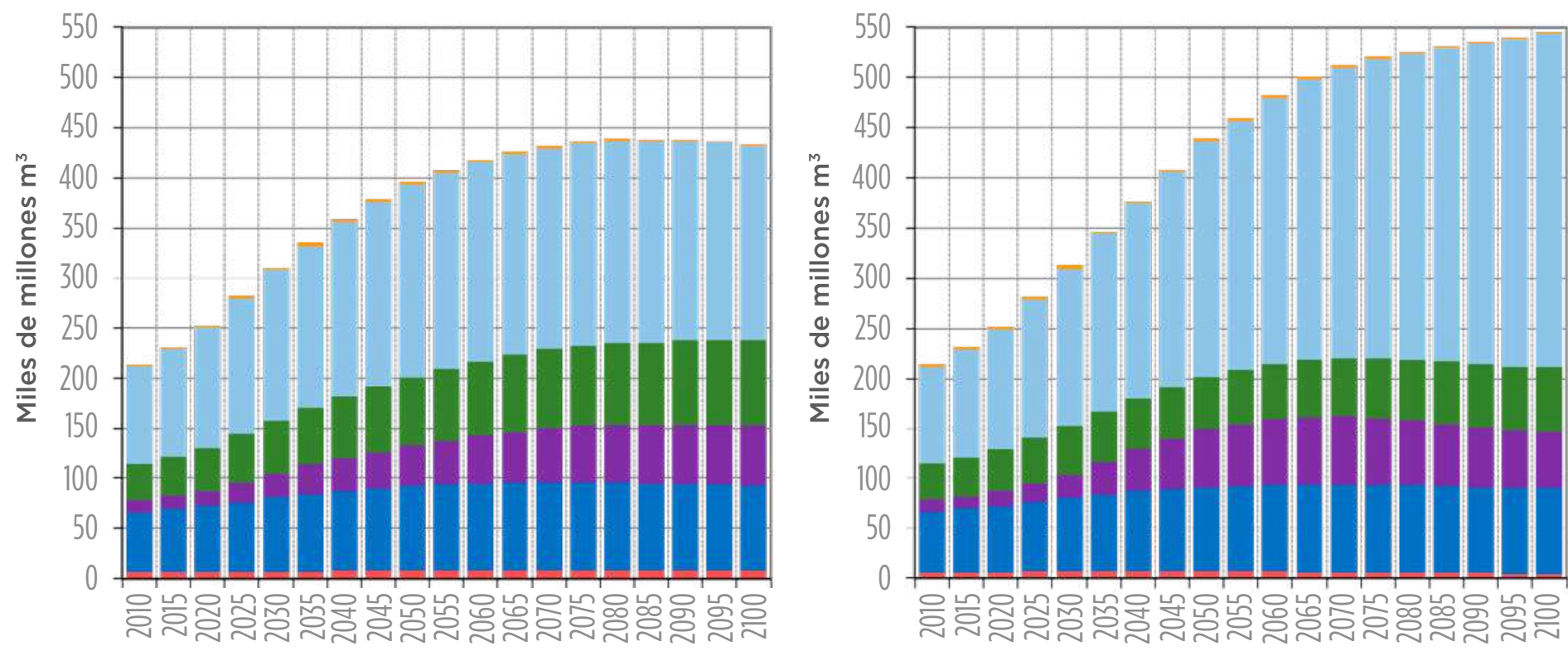

Energía primaria

Riego

Manufactura

Electricity

Municipal

Ganado

Fuente: Miralles-Wilhelm y Muñoz-Castillo, 2018.

Figura 4.5: Proyecciones de la demanda de energía primaria (EJ) en la región de ALC (2010-2100). Izquierda: escenario de referencia. Derecha: escenario NDC.
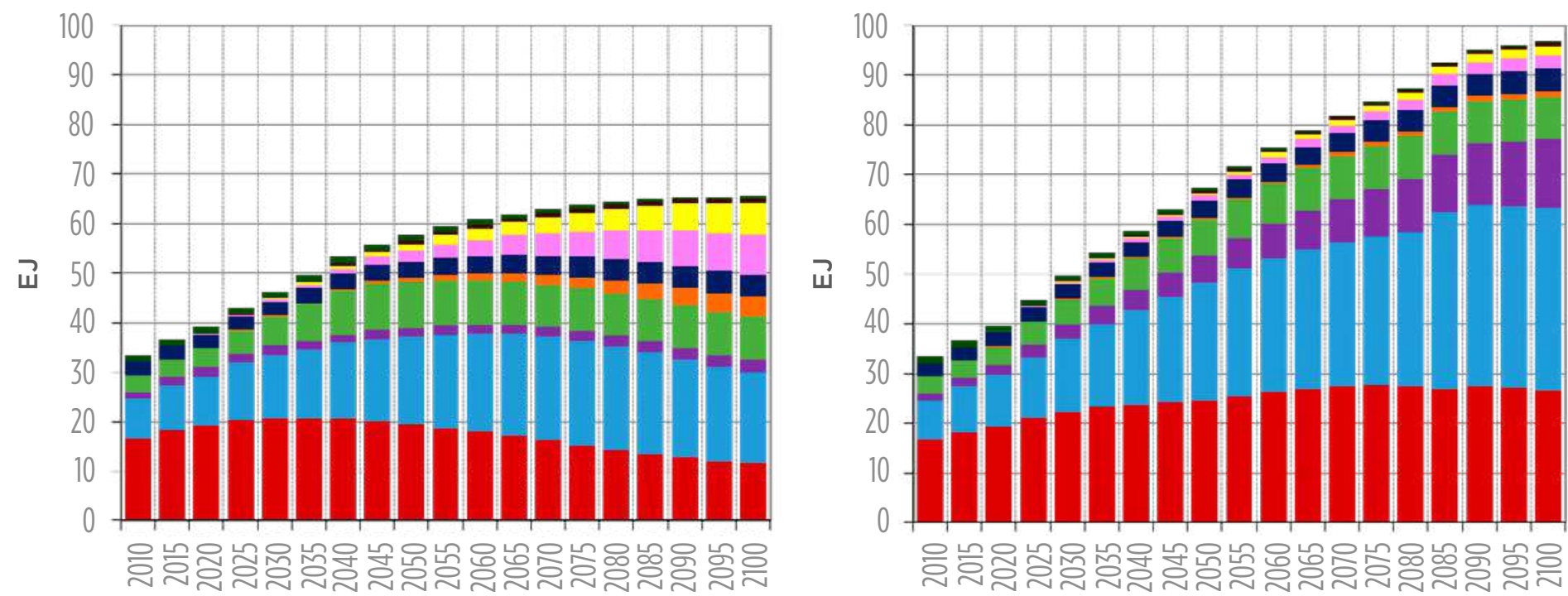
Biomass tradicional
Geotérmica
Solar
Eolica
Carbón
Gas Natural
Petróleo

Fuente: Miralles-Wilhelm y Muñoz-Castillo, 2018. 
Figura 4.6. Proyecciones de la producción agrícola (TM) en la región de ALC (2010-2100).

Izquierda: escenario de referencia. Derecha: escenario NDC.

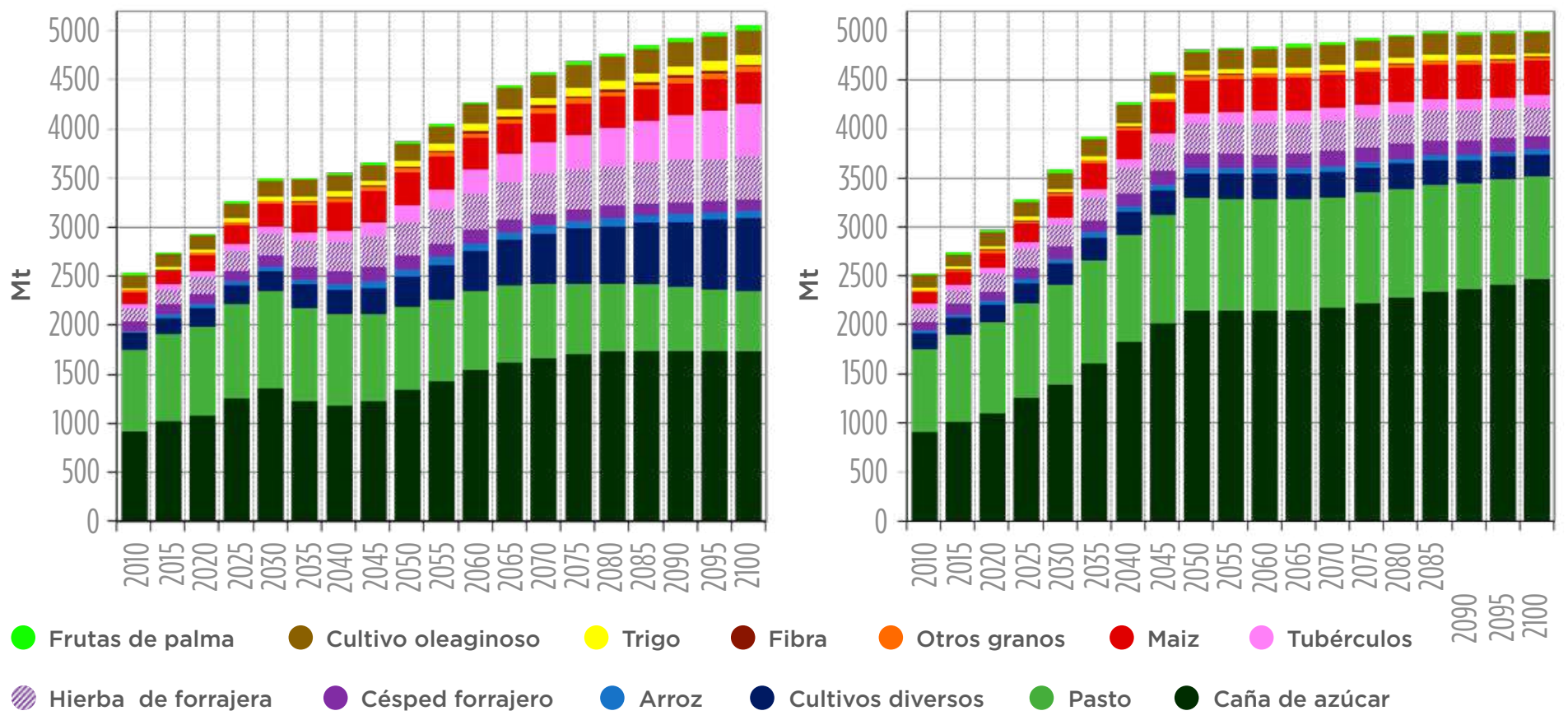

Fuente: Miralles-Wilhelm y Muñoz-Castillo, 2018.

Los resultados para las proyecciones de la producción agrícola en la región se muestran en la Figura 4.6. El panorama general es de crecimiento progresivo hasta el año 2050; a partir de ahí se produce una estabilización y, hacia el final del siglo, un crecimiento moderado. Esto está en consonancia con las tendencias de crecimiento de la población, tanto a nivel mundial como en la región, con una producción agrícola estrechamente vinculada al consumo per cápita de cultivos. Los resultados también sugieren que estas cadencias temporales se darán en todos los cultivos, con el azúcar y el maíz experimentando una mayor tasa de crecimiento que otros cultivos. El crecimiento del azúcar y el maíz está parcialmente impulsado por su uso en la producción de biocombustibles para mitigar el cambio climático. También en esta línea, los escenarios de demanda que se centran en aumentar la resiliencia y la sostenibilidad (como el NDC) dan como resultado un mayor uso de la tierra para actividades de conservación de bosques para la mitigación del clima. Esto se traduce en un aumento general de la tierra utilizada para el cultivo de bosques en lugar de la producción agrícola, que se reduce ligeramente como se muestra en la parte inferior de la Figura 4.6.

El aumento general de la demanda de agua en escenarios que se centran en la mitigación del cambio climático y la descarbonización es una clara compensación que surge como resultado del análisis de nexos de los sectores de agua, energía y alimentos. Este resultado también se ha documentado en otra investigación reciente centrada en la mitigación del cambio climático y el aumento del consumo de agua en los Estados Unidos (Hejazi et al., 2014). Debido a que el agua es un recurso relativamente económico para los 
La consideración del nexo en planificación multisectorial ofrece oportunidades de innovación que pueden traducirse, en inversiones multisectoriales como embalses multipropósito

La combinación de infraestructura construida y verde constituye un eje principal de innovación en materia de SH para la región usuarios de estos sectores (su suministro es relativamente abundante pero también está fuertemente subsidiado en la región) esta compensación tiene implicaciones importantes para las áreas de la región que tienen escasez de agua. En estas regiones, una consideración más realista de los costos de suministro de agua en un análisis como este puede ofrecer resultados muy diferentes en la asignación de recursos de inversión en infraestructura de agua, energía y alimentos. Estudios recientes en Sudáfrica (Rodríguez et al., 2017) y China (Rodríguez et al., 2018), países con escasez crónica de agua, muestran cómo considerar los costos de suministro de agua en la planificación de la infraestructura energética puede cambiar drásticamente las demandas resultantes de energía (matriz de energía primaria) y agua (demanda total y asignación) a través del tiempo. Esta es un área importante para el trabajo de nexos en el futuro en la región de ALC.

La consideración del nexo en planificación multisectorial ofrece oportunidades de innovación a la hora de vincular la SH con la seguridad energética y la seguridad alimentaria, dos áreas objeto de intensa actividad por parte del BID y los países de la región. En la práctica, esto puede traducirse, por ejemplo, en inversiones multisectoriales (como embalses multipropósito), que incorporen elementos de infraestructura natural (SBN) y proyecciones de cambio climático para robustecer los sistemas diseñados y facilitar su resiliencia y sostenibilidad. Bajo el proyecto de cooperación técnica RG-T2660, el BID ha empezado a realizar estudios piloto de la aplicación de esta planificación multisectorial nexo en Colombia (análisis de impactos de las políticas NDC en los sectores de agua, energía y agricultura), Argentina (SH a nivel de dos cuencas piloto) y Uruguay (análisis de impactos de políticas multisectoriales). Estos esfuerzos deben continuar y tienen la oportunidad de capitalizarse en programas de inversión en infraestructura y políticas como los que se exponen en el Plan de Trabajo del Capítulo VI.

\section{IV.2 Infraestructura hídrica y Soluciones Basadas en la Naturaleza (SBN)}

La definición de SH propuesta por ONU Agua (Capítulo I) implica claramente que los ecosistemas reciben los impactos de las acciones humanas y son un componente clave a la hora de alcanzar la SH. Por ello, un enfoque innovador de $\mathrm{SH}$ precisa soluciones que combinen infraestructura construida (gris) y natural (verde) que puedan reducir la vulnerabilidad y aumentar la resiliencia y confiabilidad de los sistemas de abastecimiento de agua para diversos usos. En estas soluciones, la cuestión de la infraestructura no puede disociarse del tema del medio ambiente a la hora de gestionar el ciclo del agua de una manera más eficiente y sostenible. Habida cuenta del gran "capital natural" que existe en toda ALC, esta combinación de infraestructura construida y verde constituye un eje principal de innovación en materia de SH para la región. El Cuadro 4.1 resume algunas de estas oportunidades que utilizan SBN para atacar problemas de $\mathrm{SH}$, por sí mismas o en combinación con infraestructura gris. 
Cuadro 4.1. Potencial de aplicación de SBN para resolver problemas de SH

\begin{tabular}{|c|c|c|c|c|c|c|c|c|c|c|}
\hline \multirow{2}{*}{$\begin{array}{r}\text { Problemas de Seguridad } \\
\text { Hídrica }(\mathrm{SH}) \rightarrow \\
\downarrow \text { Soluciones Basadas en } \\
\text { la Naturaleza (SBN) }\end{array}$} & \multicolumn{2}{|c|}{$\begin{array}{l}\text { Disponibilidad Hídri- } \\
\text { ca y Fuentes de Agua }\end{array}$} & \multicolumn{2}{|c|}{$\begin{array}{l}\text { Inundaciones } \\
\text { y Sequías }\end{array}$} & \multicolumn{4}{|c|}{$\begin{array}{l}\text { Calidad de Aguas } \\
\text { Superficiales }\end{array}$} & \multirow{2}{*}{$\begin{array}{c}\text { Calidad } \\
\text { de Aguas } \\
\text { Subter- } \\
\text { ráneas }\end{array}$} & \multirow{2}{*}{$\begin{array}{c}\text { Trata- } \\
\text { miento } \\
\text { de Aguas } \\
\text { Residuales }\end{array}$} \\
\hline & $\begin{array}{l}\text { Caudal } \\
\text { Fluvial }\end{array}$ & $\begin{array}{l}\text { Recarga de } \\
\text { Acuíferos }\end{array}$ & $\begin{array}{l}\text { Inunda- } \\
\text { ciones }\end{array}$ & Sequías & $\mathbf{N}, \mathbf{P}$ & $\begin{array}{l}\text { Sedimen- } \\
\text { tos }\end{array}$ & $\begin{array}{l}\text { Pestici- } \\
\text { das }\end{array}$ & $\begin{array}{l}\text { Micro } \\
\text { Poluentes }\end{array}$ & & \\
\hline \multicolumn{11}{|l|}{ Protección de Tierras } \\
\hline \multicolumn{11}{|l|}{$\begin{array}{l}\text { Reforestación y } \\
\text { Revegetación }\end{array}$} \\
\hline \multicolumn{11}{|l|}{$\begin{array}{l}\text { Restauración de } \\
\text { zonas buffers en } \\
\text { riberas de ríos }\end{array}$} \\
\hline \multicolumn{11}{|l|}{$\begin{array}{l}\text { Remoción de } \\
\text { especies invasivas }\end{array}$} \\
\hline \multicolumn{11}{|l|}{ Recarga de acuíferos } \\
\hline \multicolumn{11}{|l|}{$\begin{array}{l}\text { Reconexión de } \\
\text { ríos y planices de } \\
\text { inundación }\end{array}$} \\
\hline \multicolumn{11}{|l|}{$\begin{array}{l}\text { Conservación y } \\
\text { Restauración de } \\
\text { Humedales }\end{array}$} \\
\hline \multicolumn{11}{|l|}{$\begin{array}{l}\text { Construcción } \\
\text { de Humedales } \\
\text { Artificiales }\end{array}$} \\
\hline \multicolumn{11}{|l|}{$\begin{array}{l}\text { Espacios Verdes } \\
\text { (bioretención e } \\
\text { inffiltración) }\end{array}$} \\
\hline \multicolumn{11}{|l|}{$\begin{array}{l}\text { Pavimentos } \\
\text { Permeables }\end{array}$} \\
\hline \multicolumn{11}{|l|}{$\begin{array}{l}\text { Establishing flood } \\
\text { bypasses }\end{array}$} \\
\hline \multicolumn{11}{|l|}{$\begin{array}{l}\text { Mejores Prácticas } \\
\text { Agrícolas }\end{array}$} \\
\hline \multicolumn{11}{|l|}{$\begin{array}{l}\text { - Cobertura por } \\
\text { Cultivos }\end{array}$} \\
\hline \multicolumn{11}{|l|}{$\begin{array}{l}\text { - Cambio y/o rotación } \\
\text { de cultivos }\end{array}$} \\
\hline \multicolumn{11}{|l|}{$\begin{array}{l}\text { - Reducir uso de } \\
\text { agroquímicos }\end{array}$} \\
\hline \multicolumn{11}{|l|}{$\begin{array}{l}\text { - Cambios en uso de } \\
\text { pesticidas }\end{array}$} \\
\hline \multicolumn{11}{|l|}{$\begin{array}{l}\text { Mejores Prácticas } \\
\text { Forestales }\end{array}$} \\
\hline $\begin{array}{l}\text { Mejores Prácticas } \\
\text { Ganaderas }\end{array}$ & & & & & & & & & & \\
\hline
\end{tabular}

Fuente: adaptación de material contenido en Green Infrastructure, Guide for Water Management (UNEP/DHI, IUCN y TNC) ${ }^{27}$ y Beyond the Source $(\mathrm{TNC})^{28}$

27 http://wedocs.unep.org/handle/20.500.11822/9291

28 https://global.nature.org/content/beyond-the-source-report 
Figura 4.7. Mapa que muestra la factibilidad de utilizar SBN para la protección de fuentes de agua potable y la reducción de riesgos por inundación en Río de Janeiro
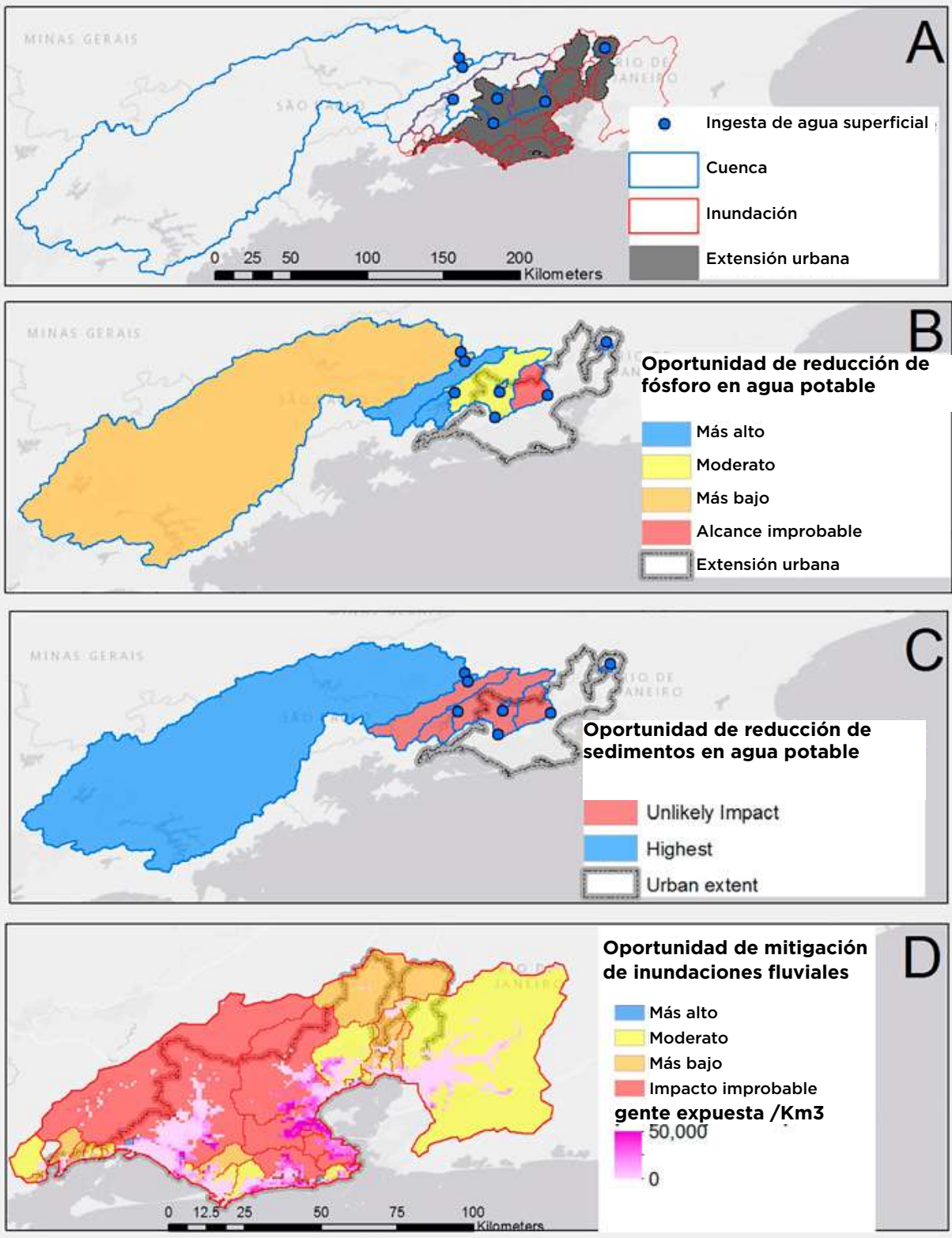

Oportunidad de mitigación de inundaciones fluviales

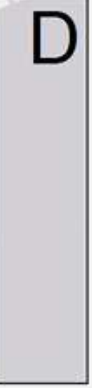

Fuente: Tellman et al., 2018.

Así mismo, las áreas metropolitanas importantes en ALC podrían considerarse como ecosistemas antropogénicos, que afectan el ciclo del agua particularmente en cuanto a la demanda hídrica. Junto con los ecosistemas naturales, existe una necesidad crítica de desarrollar e implementar estrategias de gestión adaptativa para tener en cuenta los cambios en el ciclo del agua 
asociados con los cambios en los parámetros funcionales de los ecosistemas debido al cambio climático.

Aquí se sintetizan los aspectos de infraestructura hídrica relacionados con los diferentes aspectos del ciclo del agua: (i) gestión de fuentes de agua; (ii) servicios de agua y saneamiento; (iii) sistemas de riego para la producción de alimentos; (iv) generación de hidroelectricidad; y (v) protección y prevención de riesgos de desastres de origen hídrico. Una revisión más detallada de estos aspectos se presenta en el Anexo C.

Oportunidades de innovación en la gestión de fuentes de agua

En términos generales, en lo que se refiere a la oferta del recurso, es necesario contar con una combinación de fuentes alternativas de abastecimiento, preferiblemente de agua superficial y subterránea con protección de fuentes de agua y reúso que se alternen entre diferentes zonas con microclimas complementarios. En Quito, por ejemplo, el sistema de abastecimiento de agua de la ciudad recibe agua de fuentes superficiales que se encuentran tanto en la zona montañosa como en la vertiente oriental, que posee otro tipo de clima y que se alterna con el de Occidente (montañoso).

Respecto a las aguas superficiales es conveniente combinar esquemas de infraestructura tradicionales de almacenamiento mediante embalses con SBN, con el fin de otorgar una robustez climática adicional al suministro, esencial en periodos de sequías. Las aguas subterráneas ofrecen la ventaja de que entrañan ya una regulación propia en la medida en que los acuíferos, si no están contaminados, constituyen embalses subterráneos que otorgan una gran robustez a la disponibilidad del recurso. En ambos casos, deben considerarse soluciones de protección de fuentes tales como los Fondos de Agua, implementados por el BID en la región, y cuyo funcionamiento efectivo ha sido probado en otras partes del mundo (TNC, 2018).

En cuanto a las demandas hídricas, deben gestionarse de una manera integrada, contabilizándolas de manera simultánea y en sintonía con el balance hídrico. Para ello pueden desarrollarse sistemas de datos detallados y modelos predictivos que consideren el tipo de población (urbana, rural o periurbana) y sus diferentes actividades. Al mismo tiempo, no se debe perder la perspectiva de la cuenca y de la calidad del ecosistema que la alimenta y mantiene. En este sentido, muchas legislaciones ya establecen objetivos de calidad que es preciso cumplir. En el caso de la Unión Europea, la Directiva Marco es aún más ambiciosa y plantea el concepto de "estado" de las masas de agua, que considera no sólo aspectos de calidad físico-química, sino también hidromorfológicos (riberas, bosque en galería, formas del lecho, etc) y biológicos. 


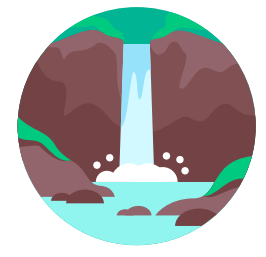

A continuación se enumeran algunas oportunidades de innovación relacionadas con una mejor gestión de las fuentes de agua en ALC:

- Programas de reservas de agua: el Programa Nacional de Reservas de Agua de México (http://awsassets.panda.org/downloads/wwf_mex_water_reserves_program.pdf), con la cooperación del BID, WWF, CONAGUA y la Fundación Gonzalo Río Arronte, ha implementado un ambicioso programa para desarrollar mapas y caracterizar cuencas hidrográficas dirigidos a la planificación y gestión integrada de las aguas subterráneas y superficiales. El objetivo final es alcanzar la SH mediante la planificación y el monitoreo a largo plazo de la cantidad y la calidad del agua, con énfasis en el mantenimiento de los caudales ecológicos y la diversidad biológica, al tiempo que se satisfacen las necesidades de abastecimiento. Los resultados iniciales de los caudales ambientales y la asignación de agua a los ecosistemas y los sectores humanos son positivos (Ordoñez et al., 2015). Este tipo de iniciativas pueden expandirse a otras partes de la región, mejorando la metodología a través de avances en ciencia y tecnología como los que se exponen en la Sección IV.4.

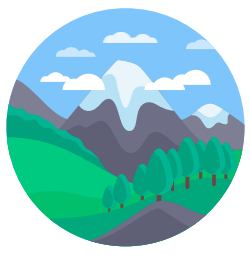

- Gestión de cabeceras de cuencas: en América Latina y Caribe, la mayoría de los ríos se originan en montañas altas (bioma montano). Los Andes contribuyen con el 50\% del caudal del río Amazonas, el 93\% de su carga de sedimentos y la mayor parte de la productividad fluvial que controla el nitrógeno y el fósforo (Anderson et al., 2018). Las fuentes de agua dominantes para los ríos andinos, los glaciares, se han estado derritiendo progresivamente durante los últimos 50 años, especialmente como reacción a los fenómenos del cambio climático (Rabatel et al., 2013), y los humedales de montaña (bofedales y páramos), que almacenan el agua glacial y la producción de alimentos emergentes a lo largo del año, se ven afectados por el sobrepastoreo, la conversión a la producción de quinua y la minería.

Frente a los glaciares en rápido descenso y al aumento en el número proyectado de presas planificadas, el BID ha reconocido la importancia de estas áreas altas de fuentes hídricas y su importancia para el suministro de agua potable en ciudades grandes como La Paz, Lima y Quito (Chevallier et al., 2011); el pastoreo de ganado; el riego y la minería. Así, se llevó a cabo un proyecto integral para suministrar agua de riego a las comunidades locales y agua potable a la ciudad boliviana de El Alto (BO-G1004). Este proyecto ponía en lugar primordial la regulación, almacenamiento y suministro de agua a corto plazo en los bofedales que alimentan los embalses pequeños, que satisfacen las demandas de los sectores hídricos rurales y urbanos. También abordó en detalle el tema de los caudales ambientales, proporcionando planes para el manejo de bofedales, que maximizan su valor para la biodiversidad y las comunidades indígenas de la zona. 

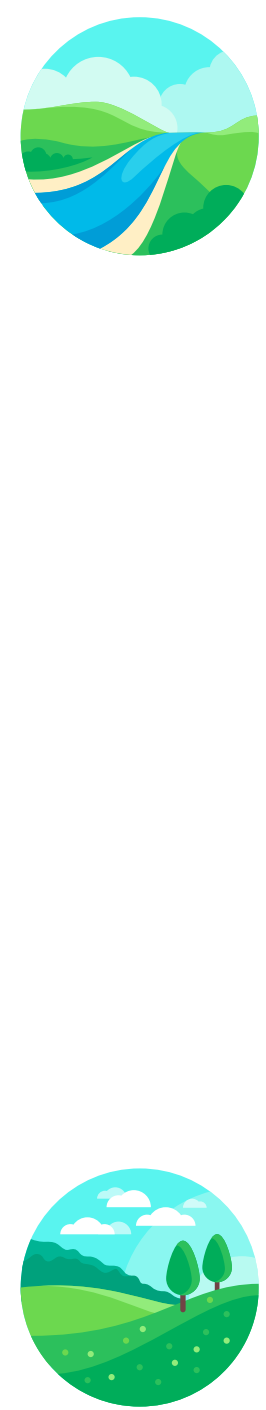

La recarga de acuíferos permite utilizar los acuíferos como reservorios naturales
- Vinculación de ríos y planicies aluviales: Si bien durante mucho tiempo se ha reconocido que la estructura y la función de los grandes ríos como el Amazonas están controladas de forma única por los vínculos estacionales con sus planicies de inundación (Junk et al., 1989), y que estas planicies pueden proporcionar servicios ecosistémicos valiosos que incluyen control de inundaciones, captura de sedimentos y hábitat para peces, su uso como SBN para mejorar la SH no ha sido explorada en gran medida. Las planicies aluviales tienen un potencial sin explotar, especialmente en las secciones superior y media de los ríos en ALC. En este sentido, algunos autores han sugerido que las planicies de inundación aguas arriba podrían reducir significativamente la carga de sedimentos y nutrientes en la parte baja del río Mississippi y el Golfo de México si se reconectaran periódicamente al canal principal del río (Mitsch y Day, 2006). Así, según señalan, las planicies de inundación, en los bofedales de aguas de cabecera, pueden almacenar cantidades significativas de agua mientras se producen las condiciones de inundación y liberarla lentamente aguas abajo, disminuyendo el riesgo de esta. Esta oportunidad de innovación en materia de SH incorpora las planicies de inundación como parte de la planificación para la SH en ALC. El Banco puede explorar la realización de proyectos piloto en cuencas aguas arriba de zonas urbanas con el fin de determinar la efectividad y los factores de factibilidad de esta SBN en la prevención de inundaciones y sus cobeneficios con otros servicios ecosistémicos.

- Recarga de acuíferos: la recarga de acuíferos (aquifer storage and recovery) permite utilizar los acuíferos como reservorios (embalses subterráneos) naturales. Esto permite almacenar agua en el subsuelo para mitigar inundaciones durante eventos de precipitación y tener la posibilidad de utilizarla durante períodos de escasez, ayudando a mitigar el impacto de sequías. La recarga de acuíferos requiere de un conocimiento detallado de la hidrogeología local con el fin de ubicar, dentro de los acuíferos, las zonas mejor capacitadas para almacenar y extraer el agua. La recarga de acuíferos se está explorando en muchas ciudades que dependen única y exclusivamente de agua subterránea (como Oruro en Bolivia y algunas zonas del norte de Chile).

\section{Oportunidades de innovación en servicios de agua y saneamiento}

En relación con los sistemas de agua y saneamiento, las tecnologías de tratamiento de aguas residuales están bien desarrolladas y en permanente innovación. Además, se han ido incorporando a la práctica, una serie de mejoras a los sistemas a través de SBN, particularmente la utilización de humedales para tratar las aguas. Noyola et al. (2012) evaluaron 2.734 plantas de tratamiento de aguas residuales municipales en seis países que representan las diversas subregiones de ALC (Brasil, Chile, Colombia, República Dominicana, Guatemala y México). Aproximadamente, el $67 \%$ de las plantas eran 
Los humedales artificiales se llevan utilizando más de un siglo para el tratamiento de aguas residuales municipales en Gran Bretaña y los Estados Unidos pequeñas (con un caudal de entrada menor a 25 litros por segundo) y muy pequeñas ( menor a $5 \mathrm{~L} / \mathrm{s}$ ), especialmente en México y Brasil. Sin embargo, la mayor parte de la infraestructura en estas plantas (80\%) están constituidas por equipos tradicionales: tanques de estabilización, lodos activados y reactores anaeróbicos.

Los humedales artificiales se llevan utilizando más de un siglo para el tratamiento de aguas residuales municipales en Gran Bretaña y los Estados Unidos (Vymazal, 2011). El sistema utilizado se basa en la captación de residuos por parte de las plantas y el almacenamiento final en sedimentos. Desde la década de los noventa del siglo pasado, los humedales artificiales se han utilizado cada vez más como unidades independientes o para complementar la infraestructura gris, anticuada y sobrecargada, para satisfacer las necesidades de tratamiento de los centros urbanos en rápida expansión. A diferencia de las plantas de tratamiento de aguas residuales convencionales, que tienen una esperanza de vida útil de 60-70 años para las estructuras de concreto y de 15-25 años para los componentes mecánicos y eléctricos (USEPA, 2002), los humedales artificiales no tienen una vida útil limitada; pero si cuentan con un monitoreo adecuado y una gestión adaptativa para mantener la máxima eficiencia operativa, pueden proporcionar servicios a largo plazo. Arias y Brown (2009) estimaron que el costo anual para operar un humedal artificial cerca de Bogotá, Colombia, es comparable al $20 \%$ del costo para operar un reactor convencional.

El primer humedal artificial documentado en la región de ALC fue en Brasil en la década de los ochenta (Salati y Rodrigues, 1982), pero su uso se ha expandido rápidamente desde principios de siglo, especialmente en Brasil y México (Zhi y Ji, 2012). La mayoría de los sistemas son pequeños pero existe la oportunidad de construir sistemas híbridos (infraestructura gris y verde) de mayor envergadura para satisfacer las necesidades de los centros urbanos. Aún no existe una compilación exhaustiva de datos sobre humedales artificiales en la región; la literatura es escasa y la mayoría de los proyectos no tienen protocolos de monitoreo adecuados o, simplemente, no informan de los resultados. Con un repositorio de datos completo y de fácil acceso, se pueden desarrollar principios de diseño y operación de estos sistemas, incluyendo cuándo y cómo aplicar una gestión adaptativa para mantener el humedal en operación con la máxima eficiencia. Los temas clave incluyen opciones para vincular componentes de diseño, desarrollar tecnologías híbridas y combinar infraestructura verde y gris para mejorar la eficiencia de tratamiento. Todavía hace falta más evidencia empírica acerca de cuándo los humedales construidos pueden servir como único sistema de tratamiento, especialmente en las comunidades rurales.

La utilización de humedales artificiales para el tratamiento de aguas residuales constituye una oportunidad de innovación para mejorar significativamente las metas de cobertura de los servicios de saneamiento en la región. 
En cuanto al potencial de aplicación a poblaciones rurales dispersas a lo largo de los países de ALC, ha habido un número creciente de estudios enfocados en el diseño de sistemas de tratamiento que incorporan varios tipos de humedales artificiales, vinculados a proyectos de infraestructura gris o independientes (WSP, 2008): proyectos piloto en pequeñas aldeas rurales (Whitney et al., 2003; Dallas et al., 2004; Ríos et al., 2009; Kaplan et al., 2011 y Zurita et al., 2012). Estos estudios se han ido expandiendo a través de universidades (Mitsch et al., 2008) e industrias, mejorando el diseño y la composición de las especies de vegetación en los humedales para abordar los desechos especializados de granjas y plantas lecheras, plantas de papel, vertederos de desechos sólidos (Nahlik y Mitsch, 2006), granjas porcinas (González et al., 2009) y mataderos (Rivera et al., 1997). Recientemente, se han producido avances en la eliminación de compuestos sintéticos (Belmont et al., 2006 y Toro-Velez et al., 2016) que se tratan parcialmente en plantas de aguas residuales convencionales.

Aunque Zhang et al. (2014) sugieren que los sistemas pequeños y descentralizados de tratamiento de aguas residuales son ideales para entornos urbanos, otros consideran que los paisajes multifuncionales que incorporan servicios

Aunque demuestran un gran potencial, los servicios ecosistémicos

urbanos son, en general, inexistentes en la región ecosistémicos urbanos tienen una mayor capacidad de recuperación para enfrentar las condiciones urbanas y el cambio climático en constante cambio (Anderson et al., 2014; Lovell y Taylor, 2013 y Gomez-Baggethun y Barton, 2013). El desarrollo de sistemas urbanos que maximicen, tanto el potencial de manejo adaptativo como la participación de las partes interesadas locales, es clave para alcanzar la SH en áreas urbanas (Luederitz et al., 2015; Haase et al., 2014; McPhearson et al., 2015). Aunque demuestran un gran potencial, los servicios ecosistémicos urbanos son, en general, inexistentes en la región (con la excepción de los sistemas templados del norte) y el conocimiento sobre ellos sigue siendo inadecuado (Dobbs et al., 2018 y McPhearson et al., 2015): en general, los datos no se han transferido a las partes interesadas locales y su potencial no se ha incorporado adecuadamente a la planificación urbana (Luederitz et al., 2015; McPhearson et al., 2015 y Haase et al., 2014).

El reúso o la reutilización del agua continúa siendo un reto pendiente en la región, incluso en zonas áridas y de escasez natural. Por ejemplo, la descarga de los humedales artificiales utilizados para tratar las aguas residuales en el centro de México está siendo reutilizada actualmente por las comunidades locales para aliviar las tensiones en el riego impuestas por las condiciones de sequía (Belmont et al., 2004). En Estados Unidos, un proyecto similar se está utilizando para pretratar agua proveniente de minas de carbón antes de convertirse en parte del suministro de agua potable para una pequeña ciudad. Si bien se ha observado el uso de SBN, como los humedales, para el tratamiento previo del agua potable en algunos lugares de la región, los datos sobre su funcionamiento son prácticamente inexistentes. Es preciso realizar una evaluación detallada de la reutilización y el tratamiento previo del agua en la región. Su potencial de aplicación para el suministro de riego y 
Para mejorar la eficiencia hídrica de los sistemas de riego, han empezado a implementarse innovaciones como la creación de pequeños embalses a lo largo del canal que facilitan la regulación hidráulica agua potable es grande, pero su aplicación amplia necesita del desarrollo de proyectos pilotos demostrativos que incluyan igualmente análisis detallados con cuantificación de beneficios económicos y sociales.

Los jardines de azotea (techos verdes o rooftop gardens), los jardines verticales y las paredes vivas son enfoques recientes que muestran un gran potencial para el tratamiento y reutilización del agua en las ciudades de América Latina y Caribe. Los techos verdes han demostrado ser eficaces, tanto para reducir la escorrentía de aguas pluviales (del 30\% a más del 40\%) por la absorción de la planta y el suelo y la evapotranspiración, como para mejorar la calidad del agua (Stovin, 2010; Hashemi y Mahmud, 2015 y Feng y Pomeroy, 2016). La Ciudad de México ha implementado proyectos altamente innovadores utilizando jardines de azotea y paredes vivas para capturar la escorrentía de aguas pluviales y reducir la contaminación del aire (Qiu et al., 2013 y Dieleman, 2017). Los datos sobre el potencial de aplicación para ALC aún son escasos, pero son tecnologías prometedoras para reducir la escorrentía y promover la reutilización del agua.

\section{Oportunidades de innovación en sistemas de riego y producción} de alimentos

Los sistemas de riego tradicionales, con decenas de miles de hectáreas en explotación, suelen constar de un gran canal conductor de varias decenas de kilómetros de longitud, que conducen las aguas desde su punto de toma, principalmente un río, con o sin embalse, hasta la zona de riego, desde la que se canaliza a través de la red de distribución que con todo un sistema de acequias lleva el agua a la parcela de riego. En estos sistemas los canales han sido tradicionalmente diseñados por gravedad y suelen carecer de regulación.

Las consecuencias negativas que ello tiene en el marco de los ODS y de lucha contra el cambio climático se pueden sintetizar en dos aspectos. Primero, falta de flexibilidad para adecuar la oferta a la demanda, lo que ocasiona pérdidas de importantes volúmenes de agua en el caso de la interrupción repentina del riego por un episodio de lluvia sobre la zona regable, en el que el agua almacenada en el canal acaba saliendo por el aliviadero del mismo. Segundo, lentitud en la respuesta a la demanda, debido a la baja velocidad con la que se propagan las ondas por el canal, con gran perjuicio para el agricultor.

Para mejorar la eficiencia hídrica de los sistemas de riego, han empezado a implementarse innovaciones como la creación de pequeños embalses a lo largo del canal que facilitan la regulación hidráulica. En canales nuevos es más fácil; en los ya existentes, obliga a nivelar con recrecidos y a sustituir los puentes de paso $^{29}$. Estas soluciones también pueden ser complementadas con

29 Una actuación relevante en esta materia se ha realizado en España con el Canal de Navarra, con la ventaja de que se concibió así desde el principio, hace unos 10 años. Tiene una longitud de 177 kilómetros y atiende a una zona regable de más de 53.000 hectáreas. 


\section{La Ciudad de México satisface aproximadamente \\ el \\ de su demanda \\ de alimentos a \\ través jardines de azotea}

infraestructura verde para proveer de cierta capacidad de almacenamiento en la vegetación, evitando así pérdidas de agua durante las lluvias y acelerar la respuesta a la demanda. Como ejemplo de esto, se puede mencionar la modernización que en 2013 acometió la empresa líder en renovables, EDP, en el canal Durance-Verdon en la Provenza francesa. Comenzado a construir en 1955, este canal produce 6.000 millones de $\mathrm{kWh}$ al año, es capaz de tener caudales de hasta $250 \mathrm{~m}^{3} / \mathrm{s}$ y ofrece agua potable a toda la cuenca. Además de generar electricidad, el canal también suministra agua de riego a toda la Provenza, una zona que abarca aproximadamente un tercio de todo el riego francés.

La infraestructura natural (SBN) también ha empezado a ser adoptada en la agricultura más allá de los sistemas de riego. Por ejemplo, en humedales construidos, puede haber desarrollo agrícola bien sea dentro o adyacente a sistemas de tratamiento de aguas residuales; esto facilita la reutilización del agua y otros componentes del efluente ( $p$. ej., nutrientes). Además de proporcionar una fuente sostenible de agua para el riego de cultivos (Belmont et al., 2004), incluido el arroz (Salati et al., 1999) y hortalizas selectas (Martinez-Cruz et al., 2006), pueden plantarse plantas de alto valor, especialmente flores, directamente en el sistema construido, especialmente en los humedales de flujo horizontal subsuperficial (Belmont et al., 2004; Zurita et al., 2009 y Zurita et al. 2011). Las plantas ornamentales pueden ser muy efectivas para eliminar nutrientes y surfactantes de las aguas residuales (Belmont y Metcalfe, 2003). Además, algunos flujos de residuos especializados siguen siendo tan concentrados y tóxicos después del tratamiento de los humedales que, si bien no pueden utilizarse para regar los cultivos, aún pueden proporcionar un suministro de agua para plantas ornamentales y tierras recreativas (Rivera et al., 1997).

Quizás una de las experiencias más notorias de innovación en materia de SH es la tendencia hacia una mayor agricultura urbana. Al menos 800 millones de personas en todo el mundo participan en la agricultura urbana que suministra aproximadamente el 15\% de los suministros de alimentos (Kisner, 2008). La producción local no solo reduce las pérdidas de alimentos posteriores a la cosecha por conservación y transporte inadecuados, sino que también proporciona beneficios adicionales que incluyen la reducción de la contaminación del aire y la temperatura (Qiu et al., 2013) y el almacenamiento de agua dentro de las áreas urbanas para reducir las inundaciones y proporcionar un suministro de agua suplementario durante los períodos de sequía (Rowe, 2010).

Los jardines de azotea se prefieren en núcleos urbanos densos con espacio limitado, mientras que los jardines hidropónicos (no necesitan suelo) son más utilizados en las zonas urbanas, con menos limitaciones de espacio y fuentes de agua gris fácilmente disponibles. Actualmente, la Ciudad de México satisface aproximadamente el $20 \%$ de su demanda de alimentos a través de los jardines de azotea y está trabajando para ampliar este esfuerzo a los aproximadamente $22.000 \mathrm{~km}^{2}$ de azoteas existentes en la ciudad (Dieleman, 
2014). Aunque menos desarrollados, los jardines hidropónicos han producido beneficios positivos para las comunidades empobrecidas en las áreas periurbanas de Lima, Perú, al disminuir la desnutrición y la pobreza a través de la producción de vegetales (Orsini et al., 2010). El potencial de producción de cultivos de alto valor es excelente siempre que se puedan establecer mercados (Schnitzler, 2012). Sin embargo, existe una necesidad de estudios que evalúen las eficiencias operativas de los jardines de azotea e hidropónicos en ALC. No hay duda de que estas operaciones pueden hacer que los componentes importantes de la gestión adaptativa puedan enfrentar tanto inundaciones como sequías en áreas urbanas con un rendimiento económico y social significativo.

\section{Oportunidades de innovación en generación de electricidad}

Aunque la infraestructura hidroeléctrica está muy desarrollada en ALC, hay algunos aspectos en los que existe potencial innovador de cara a potenciar su utilización más eficiente, junto con otras renovables como la eólica y la solar, para reducir las emisiones de gases de efecto invernadero que contribuyen al cambio climático. Primero, impulsar su rol de acumulador energético merced a las centrales de acumulación por bombeo, especialmente si se desarrollan la energía eólica y solar cuya producción puede no estar sincronizada con la demanda del mercado eléctrico: utilizando la energía sobrante en horas no punta se eleva agua a un depósito superior para después usarla en horas punta. Esta alternativa se ha utilizado en varios países del mundo: Estados Unidos, diversos países europeos, entre ellos España, Japón, China y Suráfrica. Sin embargo, en ALC se ha utilizado poco, excepto en grandes centrales. Por ejemplo, se ha reportado el caso del complejo hidroeléctrico de Rio Grande, en Argentina, con 1.000 Mw de potencia instalada. En el momento actual de desarrollo de energías renovables, esto puede generar oportunidades importantes de innovación.

Esto deriva en un aumento de la energía confiable. Se sabe que la potencia que diariamente demanda el mercado eléctrico es muy variable. La Figura 4.8 muestra la evolución de la demanda de potencia eléctrica típica en un día: durante la noche se produce una caída de la demanda de potencia que tiene su máxima expresión entre las 0,00 y las 8,00 horas (horas valle). En España, $y$, en general en el mundo occidental, se producen dos puntas de demanda, la primera hacia las 11 de la mañana y la segunda, hacia las 10 de la noche (horas punta); el resto son potencias intermedias (llano y valle). Estas variaciones de potencia son difíciles de satisfacer por la red eléctrica cuando se dispone únicamente de plantas nucleares, térmicas y renovables del tipo eólico o solar. Este papel regulador de la potencia ofertada al mercado suele estar reservado a la energía hidroeléctrica, ayudada por las centrales de gas o de ciclo combinado. 
Existe la oportunidad de realizar un análisis detallado del impacto de las presas existentes (y aquellas proyectadas) en toda la región de ALC
Figura 4.8. Ejemplo de la demanda diaria de energía en España

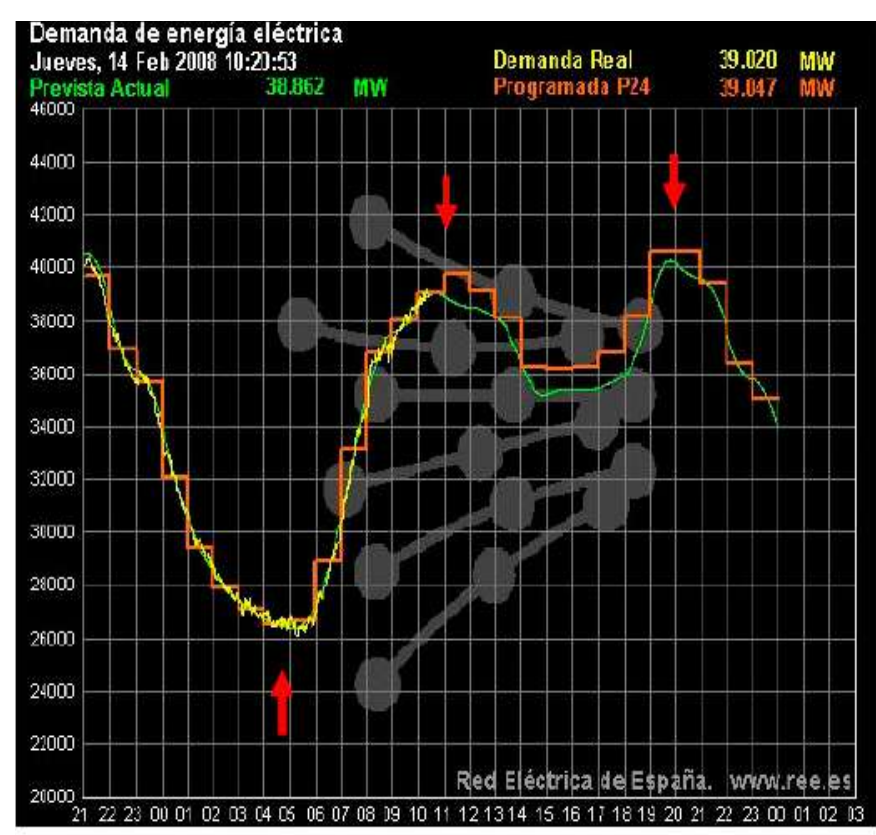

Fuente: Red Eléctrica Española.

Sin embargo, la generación de hidroelectricidad presenta deficiencias notorias en cuanto a aspectos de SH. Por ejemplo, las presas hidroeléctricas tienen un gran impacto en las cuencas hidrográficas a través del almacenamiento de agua y el flujo alterado aguas abajo. Su contribución a la pérdida de agua en la atmósfera a través de la evapotranspiración se ha ignorado en gran medida (Hogeboom et al., 2018). Además de esto, aunque la relación entre la disponibilidad de agua y los usos humanos se ha caracterizado en mayor detalle (huella hídrica), los embalses han sido ignorados en estudios previos (Hoekstra y Mekonnen, 2012; FAO, 2016) o su contribución a la pérdida de agua por evapotranspiración a la atmósfera no se ha considerado (EIA, 2016). En este sentido, para proporcionar una imagen realista de la influencia de los embalses en los presupuestos de las cuencas hidrográficas, Hogeboom et al. (2018) propusieron el concepto de huella hídrica azul, que calcula el consumo de agua de los recursos hídricos azules (aguas superficiales y subterráneas), incluida la evapotranspiración. Así, la necesidad topográfica de tener grandes embalses de superficie para la producción de energía puede tener un impacto significativo en la SH aguas abajo. Es el caso de Brasil, que tiene la mayor huella hídrica azul de en todo el mundo, debido a sus grandes embalses. En contraste, se puede esperar que las presas pequeñas y las ubicadas en áreas de montaña tengan un impacto mucho menor en la $\mathrm{SH}$. Si bien es un comienzo prometedor para abordar el impacto más amplio de los embalses en la SH, existe la oportunidad de realizar un análisis detallado del impacto de las presas existentes (y aquellas proyectadas) en toda la región de ALC. 
Dada los impactos negativos documentados de las presas, tanto aguas arriba como aguas abajo, es necesario incrementar el uso de tecnologías alternativas para la generación de energía que no impidan el flujo del río. Además de la energía solar y la energía eólica, deben ser consideradas dos tecnologías de desarrollo reciente: la generación de corriente de marea (ROR) y la energía de las mareas. La generación de corriente de marea genera energía al desviar el flujo de un río a través de un canal paralelo equipado con una turbina. Si bien los diseños ROR de estanque incluyen pequeñas presas en los ríos para garantizar una disponibilidad de agua estable, el diseño preferido está sujeto a la variación de flujo estacional por lo que es una fuente de energía intermitente. Los beneficios de este último incluyen un impacto limitado en los regímenes de flujo natural y en los movimientos de peces aguas arriba sin impedimentos (Jager y Bevelhimer, 2007). La gran mayoría de las operaciones de ROR en el mundo se realizan en Asia. En América Latina, Brasil es el país con más diseños ROR.

La generación de energía de las mareas se basa tanto en las magnitudes de las mareas como en las corrientes de la descarga de los ríos en las turbinas oceánicas. Si bien se considera una fuente importante de energía renovable, los impactos ambientales aún son poco conocidos (Frid et al., 2012). Otra innovación en generación de electricidad a través de SBN que vale la pena mencionar es la llamada "potencia osmótica" o "energía azul” (blue energy), energía obtenida por la diferencia en la concentración de sal entre el agua de mar y el agua de río, que ha mostrado su factibilidad en diversas investigaciones (Jia et al., 2014).

Estas tres fuentes de energía (ROR, generación de energía de las mareas y energía azul) tienen aplicaciones potenciales en ALC que implican la oportunidad de realizar un análisis detallado de las ubicaciones viables, la operacionalización de estas tecnologías y sus posibles impactos ambientales.

Recuadro 4.1. ¿Qué son las contribuciones nacionales voluntarias?

La utilización de SBN también ofrece oportunidades de innovación para la generación de electricidad y contribuir, al mismo tiempo, a la $\mathrm{SH}$ en ALC. Un ejemplo de ello es el impulso que está teniendo la utilización de fuentes de energía renovables debido al cambio climático y las políticas que se han empezado a implementar como resultado de este. Por ejemplo, en el Acuerdo de Paris (2015) de las Naciones Unidas, los países propusieron medidas para mantener el aumento de temperatura global por debajo de $2^{\circ} \mathrm{C}$, y a proseguir con estos esfuerzos para lograr un aumento máximo de $1,5^{\circ} \mathrm{C}$. Estas medidas se denominan NDC (siglas en inglés de "contribuciones nacionales voluntarias"). En el caso de ALC, las políticas 
NDC se han volcado fundamentalmente hacia la utilización de biocombustibles y a la reducción de emisiones atmosféricas por cambios en el uso de la tierra. La producción de biocombustibles, sin embargo, requiere de una mayor intensificación del riego, lo que puede incrementar los riesgos a la SH (Silva et al., 2018). Así mismo, los cambios en el uso de la tierra ofrecen oportunidades de utilizar SBN (p. ej., diferentes tipos de restauración, incluyendo la reforestación). En este sentido, algunos estudios recientes (Baruch-Mordo et al., 2019) apuntan hacia la factibilidad de incrementar la oferta de electricidad a nivel global, a través del mejor uso de tierras ya intervenidas, y proponen la realización de estudios locales más detallados y proyectos piloto para definir las oportunidades específicas y los aspectos operativos y de eficiencia.

\section{Protección y prevención de sequías e inundaciones}

Una tendencia reciente es la realización de un Plan de Sequías, cuya metodología está ya suficientemente desarrollada en otros países del mundo para que pueda ser de aplicación en ALC ${ }^{30}$. Por ejemplo, en lo que respecta al Plan de Sequía de Cuenca, en el período transcurrido en España desde la aprobación de los primeros planes de sequía, en marzo de 2007, se han producido cambios importantes en la consideración conceptual de las sequías. En la primera versión de los Planes de Sequía, la interpretación se orientó hacia la satisfacción de las demandas, es decir, a establecer indicadores que alertaran de la proximidad de una sequía y de su afectación a los distintos usos del agua. La Directiva Marco europea del Agua es ambigua a este respecto por lo que el Ministerio de Medio Ambiente español llegó a la conclusión de que resultaba necesario diagnosticar claramente y de forma diferenciada las situaciones de sequía prolongada y las de escasez, ya que las acciones y medidas a tomar y la capacidad de gestión en función de ese diagnóstico también podrían ser diferentes.

En esencia, el Plan de Sequías español dispone de:

- Un sistema de Indicadores de sequía prolongada y de escasez. El indicador de sequía prolongada se basa en registros de precipitaciones y aportaciones a embalses en régimen natural o cuasi natural. El de escasez coyuntural, en volúmenes almacenados en embalses, aportaciones en la red fluvial, volúmenes en acuíferos o combinaciones de los mismos. Se construyen adimensionales para facilitar su comparación, de forma que se puedan presentar mapas como el que se presenta en la Figura 4.9. (mensual).

- Umbrales para definir los diferentes estadios de sequía (normalidad, prealerta, alerta y emergencia) como el que aparece en la Figura 4.10, basado en el volumen almacenado en un embalse característico de la

30 Para consolidar la metodología, el Ministerio para la Transición Ecológica español está en vías de aprobar una Instrucción Técnica para la elaboración de los planes especiales de sequía y la definición del sistema global de indicadores de sequía prolongada y de escasez. 
subcuenca hidrográfica bajo análisis. En este caso el indicador no se ha hecho adimensional para mostrar mejor su realidad física (es decir, volumen almacenado en embalse). En el caso de la sequía prolongada, la definición de si se está o no en esa situación es más simple. Se ha optado por el siguiente criterio: si el indicador adimensional de sequía prolongada supera o iguala el valor 0,3 se está en sequía prolongada.

- Un programa de medidas para aplicar progresivamente con el avance de la sequía, de manera que se puedan ir atenuando sus efectos. En el caso de la sequía prolongada, se trata únicamente de dos tipos de medidas: i) aceptar un deterioro temporal de la masa de agua, ii) aceptar una reducción del caudal ecológico establecido para la masa de agua. En escasez, las medidas abarcan un mayor campo: reducción de las dotaciones nominales servidas a los distintos usos, puesta en marcha de nuevos recursos, puesta en servicio de infraestructuras de interconexión de sistemas... En estadio de emergencia, el organismo de cuenca puede solicitar al Gobierno de la Nación la promulgación de un Decreto para la adopción de medidas adicionales y excepcionales al amparo del artículo 58 de la Ley de Aguas Española.

Como es natural, las medidas se han adoptado desde siempre, antes incluso de disponer de los planes de sequía, tal como ocurrió en la sequía de los años 1994 y siguientes en España. Ante la gravedad con la que se estaba manifestando esta y ante el riesgo en el que se ponía el abastecimiento a Madrid capital, con más de seis millones de usuarios, el Ministerio de Medio Ambiente impulsó un programa de metasequía en el que se incluyó una conexión desde el sistema del río Alberche para transferir recursos al sistema de Madrid.

Figura 4.9. Indicadores de sequía de escasez coyuntural en España.

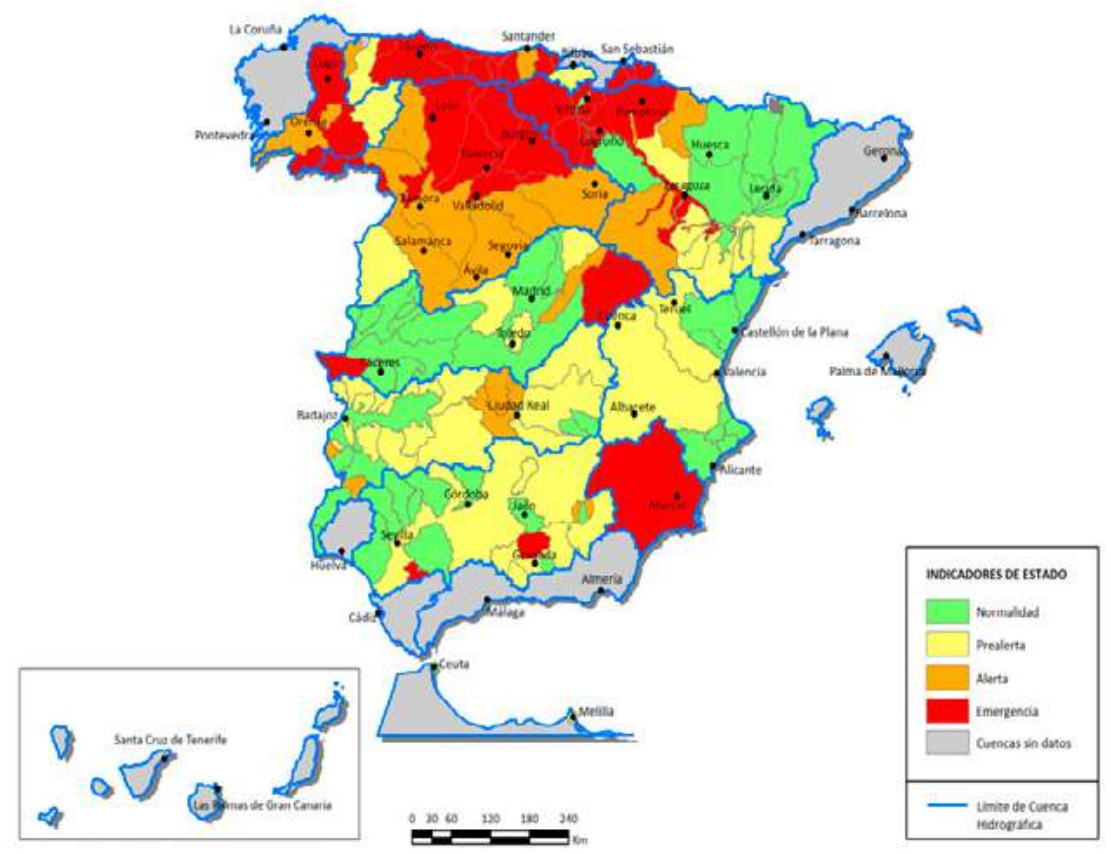

Fuente: Ministerio de Medio Ambiente. Mayo 2017. 
Figura 4.10. Indicador mensual de estadio de escasez coyuntural en una subcuenca española. En ordenadas, el volumen almacenado en un embalse significativo de la subcuenca, en $\mathrm{hm}^{3}$

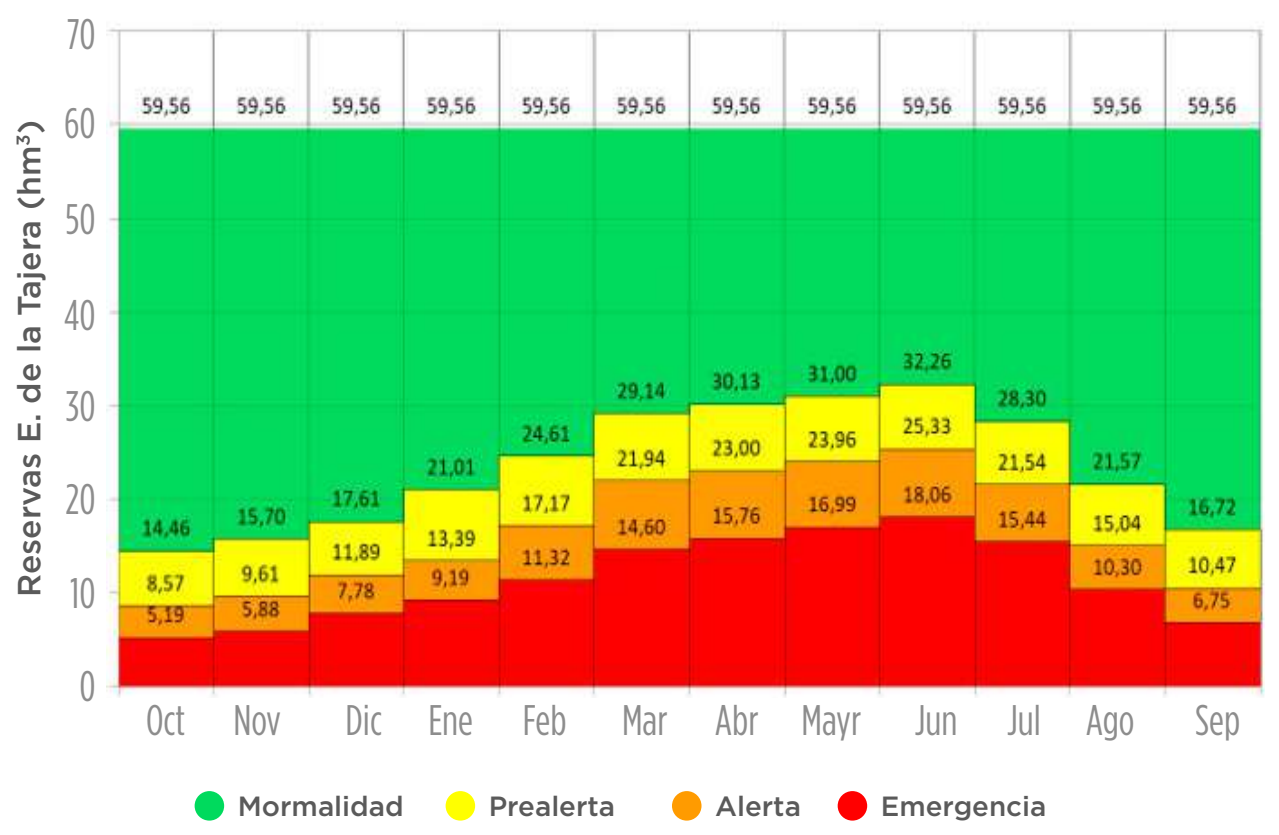

Fuente: Ministerio de Medio Ambiente. España

Tal como ocurre con las sequías, las inundaciones son causadas por una incidencia climatológica extrema, por la que las precipitaciones se incrementan muy por encima de los valores medios, aumentando los caudales que fluyen por los cauces de tal grado que producen su desbordamiento, anegando grandes extensiones del valle, con afectación a bienes económicos y poniendo en riesgo vidas humanas. Al igual que con las sequías, el cambio climático tiende a incrementar el grado extremo de las inundaciones.

En este sentido, la Directiva Marco Europea se refiere a las inundaciones como desastres naturales o de fuerza mayor. Las graves inundaciones que tuvieron lugar en Inglaterra y el centro de Europa, dieron lugar a la Directiva 2007/60/CE relativa a la Evaluación y Gestión de los Riesgos de Inundación. Esta señala una serie de observaciones clave sobre las inundaciones que, en lo sustancial, coinciden con lo que señala la UNESCO en el documento Flood Risk Management: A Strategic Approach. 2013. El BID, a través de su División de Agua y Saneamiento también considera estratégico el tema de prevención y mitigación de inundaciones y así lo refleja su Documento de Marco Sectorial (BID, 2017).

Estos enfoques estratégicos se pueden sintetizar de la siguiente manera: (i) Programación de las actuaciones enmarcadas en la planificación hidrológica de las cuencas hidrográficas; (ii) Gestión eficiente del riesgo, utilizando un 


\section{La prevención de inundaciones es un terreno fértil para la innovación en materia de infraestructura natural y SBN}

elenco amplio de medidas; (iii) Consideración de la especificidad de cada cuenca y reconocimiento de la imposibilidad para establecer estándares de protección de aplicación universal a todas las cuencas; (iv) necesidad de incorporar acciones de gobernanza que impidan que los planes urbanísticos agraven la situación actual, ya de por sí delicada debido a la naturaleza cambiante del problema originada por la propia dinámica natural y de la evolución humana; ( $v$ ) Establecimiento de mecanismos de colaboración en el ámbito de la protección civil (muy relevante a la hora de paliar de manera inmediata los efectos de las inundaciones) de los países de ALC, para aumentar la eficiencia de la intervención ante inundaciones, especialmente en las cuencas internacionales; (vi) resaltar la importancia de una información cada vez más precisa y sistemas predictivos de alerta temprana, así como una participación pública en la aceptación del programa de medidas. La respuesta al problema de las inundaciones se materializa en los Planes de Gestión del Riesgo de Inundación (PGRI) ${ }^{31}$.

La prevención de inundaciones es un terreno fértil para la innovación en materia de infraestructura natural y SBN. En este sentido, la repoblación forestal está siendo objeto de debate en Europa a raíz de la Estrategia de biodiversidad que la Comisión Europea estableció en 2011, con horizontes a 2020 y 2050, en la que ya se establecía una línea clara de "restauración de ecosistemas", entre otros objetivos. Algunos estudios recientes parecen estar demostrando el importante papel que pueden jugar los bosques en la lucha contra el cambio climático, por lo que parece previsible (Rodero, 2018) que los gobiernos de los países de la UE anuncien próximamente importantes proyectos de aforestación ${ }^{32}$.

Desde el punto de vista de la protección frente a las inundaciones, la vegetación en las SBN desempeñaría un doble rol: (i) disminuye el coeficiente de escorrentía instantáneo, de manera que se reducen significativamente los caudales punta de los hidrogramas; (ii) previene la erosión del suelo causada por las aguas, reduciendo también significativamente, los arrastres sólidos en la red fluvial. En ALC este segundo aspecto es muy destacable porque existen grandes cuencas que, ya sea por procesos naturales (geología con materiales blandos y muy erosionables) y/o por acciones antrópicas, presentan grandes arrastres sólidos que causan graves daños al ecosistema al alterar de manera acelerada las condiciones hidromorfológicas de los cauces y su hábitat biológico. Es el caso, por ejemplo, de la cuenca del río Pilcomayo, que con sus $270.000 \mathrm{~km}^{2}$ afecta a Argentina, Bolivia y Paraguay y que ha dado lugar al desarrollo del "Proyecto de gestión integrada y plan maestro

31 Plan de Gestión del Riesgo de Inundación de la Cuenca del Ebro. Gobierno de España. Ministerio de Agricultura, Alimentación y Medio Ambiente. Confederación Hidrográfica del Ebro. Septiembre 2015.

32 La aforestación (ampliación del territorio boscoso en zonas en las que no necesariamente existía bosque) puede tener un impacto en cuanto al consumo de agua y podría también aumentar el riesgo de introducir especies invasoras tales como el Eucalipto que ya es un problema en muchas cuencas en ALC. 
de la cuenca del Río Pilcomayo", parcialmente financiado por el BID, y uno de cuyos objetivos específicos es, precisamente, reducir la erosión y el aporte de sedimentos en la cuenca del río.

Las planicies de inundación pueden ser un componente efectivo para mitigar los desastres naturales, especialmente las inundaciones, al tiempo que desempeñan un papel importante en el almacenamiento de agua para contrarrestar las sequías. Las planicies aluviales juegan un papel importante tanto en entornos rurales como urbanos, aunque hasta hace poco se ignoraron en estos últimos. Si bien las planicies aluviales de ríos grandes como el Amazonas y el Orinoco brindan valiosos servicios ecosistémicos, que incluyen el control de inundaciones, la captura de sedimentos y el hábitat para la cría de peces durante los enlaces estacionales con el río (Junk et al., 1989), las corrientes urbanas y los ríos se consideran conductos para aguas residuales y las aguas pluviales y sus llanuras de inundación se clasifican como tierras de desecho ocupadas por el desarrollo urbanístico irregular.

Recuadro 4.2. La planicie de inundación de Curitiba

Sobre la base de la propuesta de que las planicies naturales de inundación y los humedales asociados pueden utilizarse para reducir los sedimentos del río y las concentraciones de nutrientes (Mitsch, 1992), la ciudad brasileña de Curitiba adoptó un enfoque multifuncional para integrar la planicie de inundación del río Iguazú en el plan maestro urbano (http://i2ud.org/2013/08/flood-management-in-curitiba-metoropolitan-area-brazil/). Así, una gran parte de la planicie aluvial se transformó en un parque lineal y en un área de conservación, capaz de reducir el riesgo de inundación aguas abajo; también se construyeron humedales para tratar el agua de los ríos y las aguas pluviales de los vecindarios circundantes. Los humedales atrapan nutrientes y sedimentos y pueden servir como tecnología de pretratamiento para reducir el costo y aumentar la calidad del tratamiento del agua doméstica (Varnell et al., 2009). La experiencia de Curitiba se considera un modelo de gestión ambiental que debería ser implementado en otras partes de ALC. Es un excelente ejemplo del enfoque de servicios ecosistémicos urbanos en los planes de SH con beneficios colaterales: suministro de agua, eliminación de contaminantes, producción de alimentos, control del microclima, secuestro de carbono, oportunidades de recreación y hábitat de biodiversidad (Lundy et al., 2011; Lovell y Taylor, 2013 y Anderson et al., 2014).

Finalmente, los enfoques innovadores en SBN en las áreas urbanas, tales como la reutilización del agua, los humedales construidos, los jardines de azotea y los jardines verticales (muros hidropónicos), retienen las aguas pluviales que normalmente se escurrirían y provocarían inundaciones río abajo. 
Estas prácticas pueden tener además muchos beneficios complementarios que incluyen la promoción de la seguridad alimentaria, el almacenamiento de agua para mitigar las sequías y la disminución del impacto de las islas de calor urbano.

En este sentido, hay que animar a las partes interesadas y a las comunidades locales a que se apropien de la infraestructura verde urbana que puede mejorar la SH. Aunque esto aún se encuentra en su desarrollo inicial, hay grandes oportunidades para que las comunidades locales se conviertan en administradores de proyectos ecológicos a través del desarrollo de actividades productivas que también contribuye a mantener dichos proyectos en funcionamiento con la máxima eficiencia. Además de proporcionar agua de riego para cultivos como el arroz (Salati et al., 1999) y hortalizas selectas (Martinez-Cruz et al., 2006), pueden plantarse plantas de alto valor, especialmente flores, directamente en el sistema construido, especialmente en el subsuelo y en humedales de flujo horizontal (Belmont et al., 2004; Zurita et al., 2009 y Zurita et al., 2011). Los humedales pueden apoyar considerablemente las economías locales, como se ha visto en Uganda, a través de la producción de pescado, vegetales, pastoreo de ganado y materiales de construcción para casas y muebles (Kakuru et al., 2013). Es necesario hacer mayor hincapié en la catalogación de las actividades económicas de los humedales, las planicies de inundación y los hábitats urbanos que pueden fomentarse para apoyar los programas de $\mathrm{SH}$.

\section{IV.3 Marco institucional para la seguridad hídrica}

Hay que evitar a toda costa las políticas fragmentadas
Conceptualmente, el enfoque de Seguridad Hídrica implica la consideración de múltiples aspectos y objetivos que integran competencias muy diferentes entre sí que habitualmente se gestionan por separado. Hay que evitar a toda costa las políticas fragmentadas. Para que este enfoque integral pueda producirse es necesario un reflejo institucional concreto.

Si tomamos como punto de partida los órganos administrativos competentes en materia de aguas en la región, puede advertirse que la situación se caracteriza por la heterogeneidad de escenarios, que se deriva de las múltiples condiciones geográficas, climáticas y de recursos naturales de los distintos Estados. Esto evidencia la falta de recetas o modelos únicos o exitosos, con independencia del contexto concreto de desempeño, pero no impiden advertir que, en la mayoría de los casos, el gran desafío pasa por coordinar e integrar la actuación de estas autoridades con las demás autoridades con competencias implicadas en la consecución de objetivos de SH.

Partiendo del diagnóstico efectuado en el Capítulo II, se identifican cinco dimensiones en el marco de las cuales se refieren en términos de mejores prácticas, algunos de los arreglos institucionales principales para la incorporación 
del enfoque de $\mathrm{SH}$ destacando algunos casos de estudio o experiencias tanto de la región como extranjeras.

Lo primero que cabe señalar en términos generales es que la $\mathrm{SH}$, como enfoque o paradigma en el marco del cual se desarrollan esas prácticas, no depende de la disponibilidad natural de recursos hídricos sino, sobre todo, de su nivel de demanda. Tampoco se encuentra escindida de la gobernanza en general y de su gestión en particular, sino que, por el contrario, en gran medida depende de ella.

De esta manera, la SH se encuentra especialmente vinculada a aquellos paradigmas que plantean una gestión integrada de los recursos hídricos por cuencas o que ponen énfasis en las relaciones entre distintos elementos (como el enfoque de nexo). En ese contexto, la gestión de los recursos hídricos aparece como el elemento prevalente, punto de contacto o ámbito central de actuación de todos los enfoques referidos, incluso desde la perspectiva del cambio climático, cuya principal vía de impacto se manifiesta, precisamente, a través de los recursos hídricos. Sin embargo, el enfoque de SH obliga a incluir una serie de elementos adicionales a la gestión de los recursos hídricos convencional que normalmente son considerados por separado.

El enfoque de SH como tal debe concretarse en un política pública o ciclo de políticas públicas, perspectiva que, de hecho, resulta más apropiada para un enfoque que, careciendo de un ámbito específico institucional de actuación gubernamental, lo que procura es incidir progresivamente en los distintos sectores organizados implicados en sus propios objetivos, marcos regulatorios y planes ya en marcha. Esa política de seguridad hídrica debe consignar sus objetivos, concretarlos en las distintas planificaciones implicadas, impulsar las modificaciones normativas necesarias e implementar los arreglos institucionales propicios para facilitar la gestión de riesgos cuyo signo distintivo será la transversalidad y coordinación de autoridades y sectores diversos. De esta manera, las condiciones, arreglos institucionales o mejores prácticas a incorporar en una política pública de SH pueden esquematizarse alrededor de cinco ejes concatenados: planificación, normatividad, institucionalidad, economía e instrumentos y cuencas internacionales. Más allá de los ejemplos expuestos en esta sección, algunas experiencias específicas de institucionalización de la SH se presentan en el Anexo D.

\section{Planificación hídrica}

La planificación aparece como la herramienta por excelencia y clave para el diseño de cualquier política pública inspirada en un enfoque o paradigma que postule cambiar la forma en que habitualmente se gestionan distintos sectores como el agua, el territorio o los recursos naturales. En el marco del enfoque de $\mathrm{SH}$, la planificación hidrológica aparece, naturalmente, en primer término; pero en línea con lo antedicho, otras planificaciones sectoriales 
pueden resultar incluso más importantes. Es el caso de la planificación territorial, la urbanística o la de uso del suelo, especialmente en una región que cuenta con un patrón de expansión urbana muy desordenado. También resultan muy relevantes, según el punto de convergencia, la planificación energética, ambiental, de cambio climático o aquella definida por la política agrícola (por ejemplo, dentro de un enfoque multisectorial nexo).

\section{La gran mayoría de las dimensiones de riesgo implicadas en la SH dependen directamente de la articulación de, al menos, la planificación hidrológica y la planificación territorial: inundaciones, abastecimiento de agua potable y saneamiento, contaminación, impactos de la sequía, etc. Aunque resulta cla- ro, sin embargo, que una planificación de este tipo se enmarca en procesos de planificación más amplios, como puede ser el de desarrollo económico, y debe articularse con el resto de las planificaciones sectoriales, como la ambi- ental, energética o agrícola, etc.}

Recuadro 4.3. Algunas experiencias normativas en la región

Costa Rica ha hecho avances significativos en ordenamiento territorial a partir de 2010, cuando se asume oficialmente como un desafío central para el desarrollo del país, formulando una Política Nacional de Ordenamiento Territorial 2012-2040, que incorpora como ejes transversales la gestión del riesgo y el cambio climático y el enfoque de género y de derechos; y, como ejes estructurales, la calidad del hábitat, la protección y manejo ambiental y la competitividad territorial, además de impulsar buenas prácticas territoriales a través de medidas fiscales y financieras (Ferrufino y Grande, 2013).

En algunos países de la región se han desarrollado planes bajo la denominación específica de seguridad hídrica. Es el caso de Panamá donde el Plan Nacional de Seguridad Hídrica 2015-2050 Agua para Todos (PNSH) parte de un diagnóstico participativo sobre la situación de los recursos hídricos y los desafíos a corto, mediano y largo plazo para garantizar la provisión de agua en cantidad y calidad aceptable para todos los usuarios ${ }^{33}$. EI PNSH responde a cinco metas alcanzables en un horizonte de 35 años: 1) acceso universal a agua de calidad y servicios de saneamiento; 2) agua para el crecimiento socioeconómico inclusivo; 3) gestión preventiva de los riesgos relacionados con el agua; 4) cuencas hidrográficas saludables y 5) sostenibilidad hídrica.

33 El PNSH fue elaborado con la participación de 19 instituciones, representantes de todos los niveles de la administración central y entidades descentralizadas, responsables del manejo, administración, protección y regulación de los recursos hídricos, presentados y validados en foros públicos de consulta abierta con representantes de todos los sectores que utilizan el agua. Fue aprobado por resolución del Consejo de Gabinete, que estableció el Consejo Nacional de Agua (CONAGUA) como la entidad encargada de impulsar, orientar, coordinar y garantizar su desarrollo e implementación, y la Secretaría Técnica de Seguridad Hídrica. 
Si bien este plan responde a varias de las características apuntadas como de mejor práctica con carácter general (referencia al ámbito de la cuenca hidrográfica, pluritemporalidad, derechos humanos, participación, etc.), carece de base normativa adecuada (Decreto Ley № 35 de 1966 por el que se reglamenta el Uso de las Aguas), no se enlaza con la planificación hidrológica anterior (Plan Nacional de Gestión Integrada de los Recursos Hídricos de la República de Panamá 2010-2030), ni se coordina con el resto de la planificación sectorial. Tampoco tiene aprobación legislativa ni imputación presupuestaria para su realización, aspectos que resultan cruciales prever para su implementación efectiva y supervivencia en el tiempo.

Sin alcanzar a delinear un plan como tal, sí pueden consignarse ejemplos de implementación de políticas específicas para la gestión de sequías en la región, desde enfoques de tipo preventivo con acento en la gestión de riesgos, que buscan superar el paradigma reactivo de la emergencia antes referido. Así, en 2013, México puso en marcha el Programa Nacional contra la Sequía (PRONACOSE), con el fin de atender la sequía de manera integral a partir de la identificación e implementación de acciones para su prevención y mitigación, acordando con autoridades locales los programas y acciones necesarios para atender las condiciones particulares en cada cuenca y usuario de agua nacional (Arreguín-Cortés et al., 2016).

Lo mismo ha ocurrido en Chile con la preparación de una serie de informes y estudios sobre la megasequía 2010-2015 (CR2, 2015) y la promoción del enfoque de gestión de riesgos por sequía (FAO, 2010), proporcionando el marco para futuras reformas institucionales y legales. El BID, por su parte, acaba de sintetizar en un documento las lecciones aprendidas de cinco casos de sequía que pueden ser tenidas en cuenta por los países a la hora de abordar el tipo de riesgos implicados en esta dimensión de la SH (Cathala et al., 2018).

\section{¿Cómo debe ser una buena planificación hídrica?}

En vista de estos ejemplos, las oportunidades de innovación en la planificación hídrica en ALC pasan por que esta se realice de una manera indicativa (no imperativa), flexible (no rígida) y adaptativa (con mecanismos periódicos de revisión e incluyendo el aspecto de cambio climático como un punto relevante de planificación a mediano y largo plazo), y debe considerar diversidad de escalas (interescalar), sectores (intersectorial) y plazos (pluritemporal). Una planificación hídrica debe reconocerse como un proceso y ser (como condición de su efectividad) transparente, participativa e informada34; detentar jerarquía normativa (con efectos previstos por la legislación) y revestir carácter vinculante tanto para el sector público (actual y futuro) como para

34 Véase, por ejemplo, las previsiones sobre información y consulta públicas contenidas en la Directiva Marco del Agua de la Unión Europea 2000/60/CE del Parlamento Europeo y del Consejo. 
el privado. Debe además ser realista, factible y contar con la correspondiente asignación presupuestaria que garantice su ejecución.

\section{Normatividad}

Hasta el momento, no existe un ámbito de normatividad propio de la SH como tal; más bien se trata, en todo caso, de un régimen que debe construirse y componerse a partir de distintos marcos regulatorios o legislaciones sectoriales que convergen en determinados aspectos (aguas, energía, medio ambiente, ordenamiento territorial, legislación civil, agua potable y saneamiento, riesgos, emergencia, defensa civil, etc). Normalmente, se trata de legislación de carácter nacional, pero también provincial o estatal en los casos de países federales (México, Brasil y Argentina) y, a veces, municipal. Un corpus que, en todo caso, opera dentro del marco del derecho internacional general, como puede ser el de los derechos humanos (al agua y al saneamiento, al ambiente sano, etc.) o particular como el que conforman los tratados internacionales para el uso de cursos de aguas o cuencas compartidas. En ese marco general hay al menos tres ámbitos de normatividad que resultan capitales para definir el entorno de $\mathrm{SH}$ y sobre las que se profundiza a continuación: la legislación de aguas, el ordenamiento territorial o urbanístico y la gestión de riesgos.

\section{A) Legislación de aguas}

El diagnóstico presentado en el Capítulo II da cuenta de los avances en la legislación de aguas reformada en la última década incorporando institutos clave no sólo para el enfoque de SH sino para la gestión de los recursos hídricos en general. Pero la gran mayoría de las legislaciones no han sido actualizadas y se evidencia, cada vez más, dificultades para hacerlo (Embid y Martín, 2015).

Una ley de aguas apta para propiciar o potenciar un enfoque de SH debería contemplar, equilibrada y simultáneamente, el agua como un bien ambiental, económico y social, y contener una serie de institutos e instrumentos entre los que se encuentran al menos: (i) una estructura institucional central adecuada, con autoridades u organismos de cuenca; (ii) un sistema de planificación hidrológica y especial (sequías, riesgos de inundación) flexible y adaptativa; (iii) un sistema de catastro y registro de usos y derechos de aguas efectivo; (iv) un sistema de catastro y registro de autorizaciones y permisos de vertido; (v) un régimen económico financiero racional y robusto; (vi) sistemas y herramientas de información, evaluación, participación y consulta públicas (Embid y Martín, 2018).

\section{B) Legislación de ordenamiento territorial}

El segundo ámbito relevante es el del ordenamiento territorial (y la legislación civil en la parte respectiva) que contemple, condicione y posibilite el uso del territorio y el suelo teniendo especialmente en cuenta aspectos como la disponibilidad de agua, el riesgo de inundación y la preservación de los re- 
La gestión del riesgo en relación con la SH es tal vez el aspecto menos desarrollado en la legislación regional cursos hídricos como uno de los ejes vertebradores de su diseño. Este aspecto resulta sumamente trascendente en una región que tiene como patrones de expansión urbana prevalentes el desorden o la rentabilidad inmobiliaria, al margen de los planes de ordenamiento territorial (allí donde existen), incrementando los riesgos para la SH. De ahí que, en muchos países, el principal desafío no sea la planificación de un territorio por desarrollar sino la regularización o urbanización de suelo ya ocupado de forma irregular, con todo lo que ello conlleva en términos sociales, de contaminación, relocalización, etc.

Un caso del que podrían extraerse algunas lecciones sobre esta materia es de la experiencia colombiana de ordenamiento territorial, en general, y la de Medellín, en particular, donde las normas y planes han comenzado a incorporar paulatinamente las unidades hidrológicas y el enfoque basado en derechos humanos. Sin embargo, todavía se trata de un proceso en transición, donde el recurso hídrico aún no da cuenta de acciones administrativas prioritarias y/o exclusivas de intervención o manejo de las cuencas y microcuencas, limitándose a cumplir un rol de criterio auxiliar que ayuda a efectivizar otros derechos, como sucede en el caso del criterio de seguridad para la ubicación de viviendas y el desarrollo de infraestructura para la movilidad (Vásquez Santamaría, 2014).

\section{C) Gestión de riesgos}

El ejemplo colombiano considerado también permite conectar la legislación del ordenamiento territorial con la de la gestión del riesgo, el tercer ámbito relevante de normatividad que aparece como el anverso de la seguridad propia del enfoque de $\mathrm{SH}$.

En Colombia, la Ley Orgánica de Ordenamiento Territorial (LOOT) 1454 del 28 de junio de 2011 sentó las bases para la formulación de otras políticas públicas como la contenida en la Ley 1523 del 24 de abril de 2012, donde se adopta y reestructura la política nacional de gestión del riesgo de desastres estableciendo el Sistema Nacional de Gestión del Riesgo (SNGRD). Este sistema permitió que los entes territoriales pudieran organizarse en una gestión conjunta al nivel central, bajo los principios de descentralización, coordinación, complementariedad y concurrencia, con el objetivo de fomentar acciones estratégicas coordinadas hacia el conocimiento, la reducción del riesgo y el manejo de la emergencia. Esa ley de ordenamiento permitió mejorar las competencias de los entes territoriales para la gestión del riesgo de desastres, confiriendo mayor autonomía desde el nivel nacional hacia los departamentos y municipios, así como el fortalecimiento de asociaciones municipales con casos de planes intermunicipales de gestión del riesgo (Calderón Ramírez y Frey, 2017).

La gestión del riesgo en relación con la SH es tal vez el aspecto menos desarrollado en la legislación regional que, en general, sigue considerando a los fenómenos extremos (sequías e inundaciones) como accidentes o catástro- 
La clave de cualquier buena práctica relacionada con la $\mathrm{SH}$ reside en la coordinación institucional fes naturales imprevisibles, que son enfrentadas como situaciones de crisis a través de declaraciones de emergencia y acciones ex post. Frente a ese paradigma reactivo de actuación, una buena práctica sugiere la incorporación, a los respectivos marcos legales, de un enfoque preventivo que considere que estos fenómenos son normales y recurrentes, e incorpore estos riesgos a la planificación general, arbitrando las medidas de mitigación y prevención que deben tomarse con carácter previo.

\section{Institucionalidad, administración y gestión}

Si el ámbito de la normatividad es difícil de componer en torno al enfoque de $\mathrm{SH}$, con mayor razón lo es el de la institucionalidad o, más precisamente, el de la coordinación interinstitucional, donde reside la clave de cualquier buena práctica que pueda considerarse. Esto es así porque, esencialmente, los problemas de SH no sólo abarcan una diversidad enorme de escalas territoriales (continente, región, zona, cuenca, ciudad, pueblo, país, etc.), sino diversas materias (factores naturales pero también, y sobre todo, culturales o humanos, sociales y económicos). De ahí, la relativa inconsistencia o utilidad que presentan los índices de SH elaborados sobre la base de la exclusiva jurisdicción nacional y la mayor o menor disponibilidad natural de precipitaciones, caudales o recursos hídricos.

La incorporación del enfoque de SH para la institucionalidad presenta, al menos, dos desafíos. El primero es identificar correctamente el riesgo para abordarlo en la escala espacial, territorial e institucional adecuada. Es decir, la necesidad de compatibilizar el ámbito espacial con la base jurisdiccional nacional (y/o provincial en el caso de los estados federales) y municipal, que la mayoría de las políticas y la legislación implicada tiene. También, en algunas ocasiones podría resultar internacional, no sólo por el tipo de cuenca sino por la clase de intercambios que estén implicados, por ejemplo. El segundo desafío pasa por articular los mecanismos de coordinación orgánica y funcional, vertical, horizontal y con el sector privado, adecuados para la gestión de esos riesgos. La característica de la institucionalidad en materia de SH va a ser la de la imprescindible transversalidad horizontal y vertical de su actuación.

De todos los arreglos institucionales y mecanismos de coordinación disponibles relevantes para el enfoque de SH resulta capital la institucionalización del ámbito de la cuenca hidrográfica. La variedad de esquemas disponibles, de acuerdo con las características particulares de cada caso, hace que estas deban tenerse muy en cuenta a la hora de su diseño, pues no cualquier arreglo resultará eficaz en cualquier cuenca (Martín, 2017).

La experiencia regional demuestra que la constitución, y sobre todo la consolidación, de estos organismos es un proceso largo y dificultoso, cuya necesidad se pone de manifiesto con el agravamiento de los problemas. El caso de la Autoridad de Cuenca Matanza-Riachuelo (ver detalle en el Anexo 
La adopción de instrumentos y mecanismos económicos y financieros adecuados es vital para la eficacia de las políticas de SH
D) puede ser un buen ejemplo de ello que, sin embargo, no reviste carácter aislado, pudiendo añadirse a este, otros casos de Argentina, el del río Bogotá y el río Atrato en Colombia o, incluso, el de la Amazonía donde se adoptan mecanismos regulatorios e institucionales novedosos (ver Anexo D), cuya efectividad, sin embargo, está todavía por comprobarse.

En este sentido, una de las tendencias observables en la región, que ya hemos mencionado, es la creciente judicialización de los conflictos ambientales o por el agua. Estos pueden tener origen en una simple reclamación por daño, contaminación o violación de derechos humanos al ambiente sano o al agua ${ }^{35}$. Al advertir las limitaciones de la solución individual, los tribunales han comenzado a transformarlos en auténticos procesos ambientales colectivos en el marco de los cuales se buscan soluciones integrales a partir del diálogo entre poderes, la implementación de mejores prácticas o la adopción de principios ya consolidados de gestión de recursos hídricos.

Este fenómeno reciente merece ser destacado puesto que es en el marco del poder judicial y de este tipo de procesos donde se están diseñando o condicionando muchas de las políticas, arreglos institucionales y programas innovadores que buscan realizar o efectivizar lo que la ley o los poderes legislativo y ejecutivo, por distintos motivos, no pudieron hacer o conseguir con antelación. De hecho, el rol del financiamiento de la banca multilateral ha sido clave para la ejecución y el desarrollo de muchas de estas soluciones (como ha sido el caso de la cuenca Matanza-Riachuelo).

\section{Economía: instrumentos económicos, fiscales y de mercado}

La eficacia de las anteriores dimensiones dependerá sin embargo y en buena medida de las condiciones macroeconómicas generales del país y de la adopción de instrumentos y mecanismos económicos y financieros adecuados para definir políticas, implementar planes, financiar obras y determinar conductas dirigidas a conseguir los objetivos planteados por la política de SH adoptada.

Los instrumentos y mecanismos económicos y financieros incluyen sistemas tarifarios y de cánones en al menos cuatro ámbitos tradicionales de la gestión de los recursos hídricos vinculados a: (i) usos del agua; (ii) vertidos o descargas; (iii) servicios de agua potable y saneamiento y (iv) uso de determinadas infraestructuras.

El ejemplo de la figura del canon de vertidos o por descargas puede servir para ejemplificar cómo una buena práctica, consistente con las necesidades urgentes, las carencias y posibilidades de los países de la región puede pasar por plantearse objetivos modestos en relación con la implementación o

35 La jurisprudencia producida sobre el Derecho Humano al Agua durante los últimos 15 años en la región americana es numerosísima y sirve para mostrar hasta qué punto está comprometida la $\mathrm{SH}$ en su aspecto más básico que es el de satisfacer las necesidades esenciales humanas en primer término. 
mejora de instrumentos económicos básicos para la gestión de los recursos hídricos pero fundamentales para la SH.

En este sentido, la figura del canon de vertidos debería contar con previsión legal que no constituye ni mucho menos, garantía alguna de aplicación efectiva. Su eficacia depende de una serie de factores entre los que pueden mencionarse: (i) la existencia de medios dispositivos de control, medios técnicos y policiales suficientes para su cobro y control, que puede además estar en cabeza de una entidad diferente de la administradora del recurso hídrico con incentivos y autoridad suficiente para favorecer su independencia; (ii) la cuantía del canon resulta capital para que pueda cumplir su cometido, pues muchas veces su irrelevancia o carácter meramente simbólico, no sólo lleva a una aplicación desvirtuada del principio de "quien contamina paga", sino que impide sufragar los costos mínimos que supone perseguir su cobro y control; (iii) la construcción de plantas depuradoras que se beneficien y a la vez justifiquen su cobro cumpliendo el cometido esencial de preservar la calidad de las aguas; (iv) su cobro, que puede tener además múltiples finalidades (comenzando por la disuasión o el incentivo para el tratamiento previo al vertido) puede estar destinado al financiamiento de las autoridades de aguas, de cuenca o el mejoramiento de las fuentes, entre otros.

La implementación adecuada de estas figuras constituye un requisito imprescindible para cualquier modelo de gestión de los recursos hídricos que procure incrementar los niveles de SH. No sólo porque son clave para aportar financiamiento genuino a la gestión del agua sino porque tienen un potencial muy difícil de reemplazar para inducir conductas y proveer señales contundentes al mercado en línea con los postulados de una política de SH.

Pero esto ocurre sólo cuando están bien diseñados y son efectivamente aplicados, cosa que no suele suceder en casi ninguno de los países de la región, donde los nulos o bajos precios pagados por los servicios del agua en general (incluyendo todos los usos) operan como subsidio indirecto de los usos o actividades económicas desarrolladas, al margen de la falta de control, cobro efectivo y la frecuente afectación de recursos públicos al sostenimiento de autoridades de aguas o la construcción de obras hidráulicas en forma directa o vía endeudamiento. Muy alejado, de hecho, de alcanzar cualquier realización del principio de repercusión de costos. Esto reenvía la cuestión a problemas vinculados, tanto a la institucionalidad específica del sector, como a la falta de coordinación con políticas e instrumentos de otros sectores con los que el agua tiene un nexo evidente: energía, agricultura y alimentación.

Sólo en el marco del diagnóstico realizado en el Capítulo II puede contemplarse la implementación de instrumentos económicos de mayor sofisticación como pueden ser los mercados de derechos o cuotas, los pagos por servicios ambientales, fondos verdes (p. ej., Fondos de Agua) o esquemas de contratación como los esquemas de asociación o participación público-privada. 
La OCDE, por ejemplo, en vez de centrar su enfoque de SH en una perspectiva de desarrollo (Hoekstra et al., 2018), lo ha hecho en una perspectiva de riesgos, recomendando la implementación de diferentes instrumentos de mercado, entre los que incluye, para la oferta y demanda de agua: mercados de aguas regionales e internacionales e incorporación en las tarifas del costo marginal que refleje el valor de la escasez; para la cantidad y calidad de agua: recompra de derechos de aguas, mercado de permisos de emisión y cargos por vertidos (OCDE, 2013).

Sin embargo y aunque esos instrumentos puedan resultar de buenas prácticas en determinados contextos, su correcto funcionamiento depende casi totalmente de una serie de condiciones y prerrequisitos de tipo legal e institucional que no se cumplen ni dan habitualmente en la región. Por ejemplo, implementar mercados de derechos de uso de aguas o de vertidos sin un adecuado catastro, información, registro de derechos, o capacidad institucional de control que garantice una mínima transparencia en las transacciones, puede conllevar riesgos muy serios para la sostenibilidad de su explotación, de acaparamiento o captura, que comprometan la garantía de usos comunes o prioritarios como el abastecimiento poblacional, entre otros, afectando consecuentemente la SH. Esta visión se corresponde con el enfoque planteado al comienzo, relativo a que las amenazas a la SH no provienen sólo de la naturaleza sino que también pueden venir de la implementación inconveniente o incorrecta de instrumentos o dispositivos legales. La asignación de derechos de agua en fuentes compartidas entre la población rural y urbana no es un tema menor en países con zonas que tienen clara tendencia a la sequia recurrente, situación que se verá acrecentada con cambio climático. Por este motivo es imperativo que se continúe trabajando en mecanismos de gestión comunitarios que permitan un acercamiento entre los diferentes usuarios para tomar decisiones consensuadas durante épocas de crisis, evitando así conflictos y tensiones sociales.

Por su parte, los mecanismos de recompra de derechos de aguas con fines ambientales como los practicados en Estados Unidos o Australia, parecen no solo fuera de las posibilidades económicas de la mayoría de los países de la región incluidos en la cartera del Banco, sino hasta, en cierta forma, innecesarios en sistemas que parten del carácter público de sus aguas, y en los que la preservación de sus fuentes o caudal ecológico no constituye un uso como tal, sino que debiera ser considerada una condición previa a cualquier utilización (y, por tanto, no indemnizable en principio), tal y como ocurre en España, cuya legislación de hecho es la fuente mediata de la mayoría de las leyes de aguas de la región (Embid y Martín, 2015). 


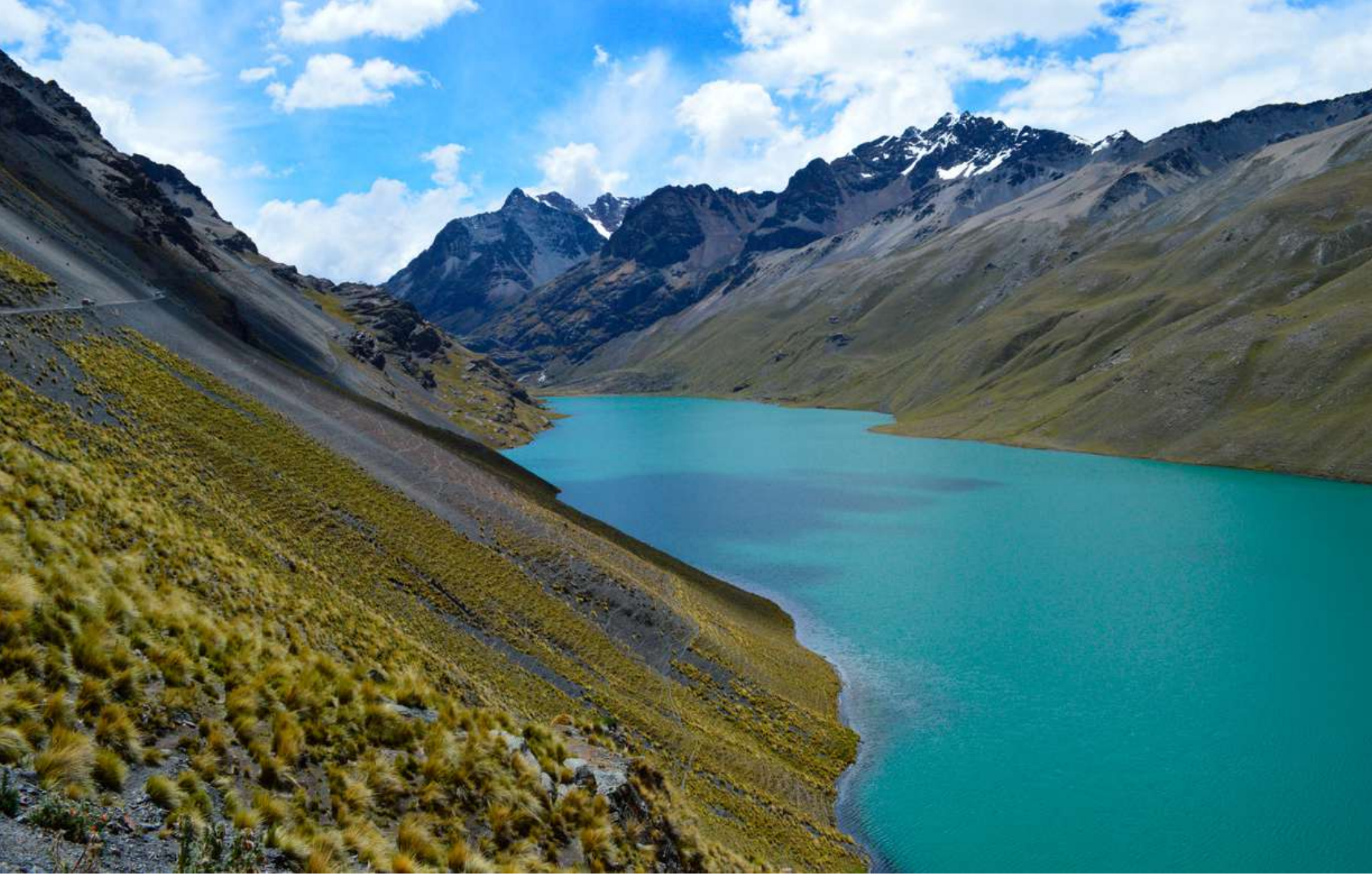

\section{Cuencas internacionales}

La creciente conflictividad por el uso del agua en la región hace escalar el conflicto que en un principio puede aparecer como meramente local o regional al nivel de cuenca, muchas de las cuales revisten carácter internacional. La experiencia enseña además que, una vez producido el conflicto, resulta mucho más difícil alcanzar acuerdos que permitan canalizarlos institucionalmente preservando la paz y el deber de cooperación que preside las relaciones entre estados que poseen cursos de agua o cuencas compartidas (Martín y Justo, 2015).

El reconocimiento del principio de unidad de cuenca aparece con todas las variantes de soluciones institucionales en la región americana, aunque debe destacarse la inexistencia de un convenio multilateral general para las aguas transfronterizas en la región. La Convención de Nueva York de 1997 sobre el Derecho de los Usos de los Cursos de Agua Internacionales para Fines Distintos a la Navegación no ha sido objeto de ratificaciones en ALC. Tampoco ha sido objeto de adhesiones hasta el momento el Convenio sobre la Protección y Utilización de los Cursos de Agua Transfronterizos y de los Lagos Internacionales (Convenio del Agua) de la UNECE ${ }^{36}$ de 1992, abierto a esa posibilidad desde 2013 (Martín y Pinto Salinas, 2013).

Esa ausencia de marco general multilateral, el derecho internacional de aguas latinoamericano se caracteriza por su particularismo, es decir, por la celebración de tratados internacionales específicos entre los estados implicados

36 Comisión Económica de las Naciones Unidas para Europa (por sus siglas en inglés). 
Es imprescindible contar con tratados multilaterales $\circ$ particulares e institucionalidad para las cuencas y acuíferos internacionales de la región sobre determinados ríos, cursos de aguas, lagos, cuencas o para determinados usos u obras de infraestructura. Aunque durante los últimos años no pueden mostrarse grandes avances en la gestión de las aguas internacionales de la región (donde en cambio si puede advertirse un incremento de la conflictividad), sí hay casos que merecen una mención por su sofisticación y avances recientes en el plano normativo. Es el caso del Tratado de la Cuenca del Plata o el novedoso Tratado sobre el Acuífero Guaraní de 2010.

Si bien la mayoría de los cursos de aguas superficiales relevantes para la región cuenta con algún tipo de tratado o arreglo institucional, no ocurre lo mismo con los acuíferos transfronterizos. Identificadas las aguas compartidas a futuro como potencial fuente de conflicto e inestabilidad política, ha sido la UNESCO, en el marco del Programa Hidrológico Internacional, y junto con otras organizaciones, la promotora del reconocimiento mutuo del carácter internacional de los acuíferos y de la promoción de acuerdos legales e institucionales para su monitoreo, gobierno y gestión ${ }^{37}$, ejemplo de lo cual resulta el Tratado sobre el Acuífero Guaraní (ver Anexo D). El programa publicó un inventario de los sistemas de acuíferos identificados y reconocidos por los estados de la región que, en 2006 eran sesenta y ocho: diecisiete en Norteamérica, cuatro en el Caribe, dieciocho en Centroamérica y veintinueve en Sudamérica (UNESCO, 2008).

Dado el carácter clave del ámbito de la cuenca para el abordaje de la mayoría de los riesgos implicados en el enfoque de SH, resulta ineludible contar con tratados multilaterales o particulares e institucionalidad para las cuencas y acuíferos internacionales de la región con carácter previo a la producción o escalada del conflicto. En caso de que existan, es conveniente el apoyo de acciones tendientes a perfeccionarlos, desarrollarlos o fortalecerlos a través de cooperación técnica, política, económica y diplomática.

Los Organismos de Cuenca como organización administrativa propia de un enfoque de $\mathrm{SH}$

En los Organismos de Cuenca (OO. CC.) se expresan de forma relevante las posibilidades de coordinación en cuanto que se pueden incorporar a ellos representantes institucionales y sociales de los distintos componentes de la $\mathrm{SH}$ (y otros). Esto permite configurar un órgano capacitado para debatir y también (depende de su configuración concreta) para adoptar decisiones que tengan efectos, entre otros, sobre todos los componentes de la SH (p. ej., disponibilidad hídrica, calidad de agua, SBN, riesgos de sequías e inundaciones, etc.). Hasta ahora, en ALC, lo más común es la existencia de órganos de cuenca (con el nombre que en cada caso reciban) con funciones de consulta y coordinación, pero no ejecutivas.

37 De hecho, la VIII fase 2014-2021 del Programa Hidrológico Internacional (PHI) de UNESCO está consagrada a Seguridad hídrica: respuestas a los desafíos locales, regionales y mundiales involucrando ocho áreas temáticas (UNESCO, 2013). 
Por otra parte, su ámbito territorial de competencia, la cuenca hidrográfica ${ }^{38}$, es un espacio natural no vinculado a una división histórica o política, lo que es un elemento valorable positivamente desde el punto de vista técnico o de la eficacia de su actuación, aun cuando ese hecho natural engendra las dificultades propias de la configuración de órganos que no tienen en cuenta estrictamente las divisiones (y exigencias) políticas.

Son bastantes los países la región que conocen la existencia de Organismos de Cuenca si bien no en todos ellos su composición y funciones responden al mismo esquema (al final de esta sección se ofrece como ejemplo el 00. CC. de Matanza Riachuelo en Argentina). Aun con todas las dificultades que su evolución ha tenido en la región, los OO. CC. tienen un rol crucial que desempeñar en la gestión de los recursos hídricos, con particular énfasis en el enfoque de nexo (Embid y Martín, 2017).

Por su ámbito de actuación y a pesar de su debilidad actual, los OO. CC. pueden jugar un papel más decisivo en el futuro al ir incorporando progresivamente el enfoque de SH al ámbito de la cuenca ${ }^{39}$. Por todo ello se recomienda como política pública la generalización de los Organismos de Cuenca con arreglo a una serie de pautas que se desarrollan a continuación.

1) Las posibilidades de correspondencia entre cuenca hidrográfica y 00. CC.: los 00. CC. Ilevan a cabo su función en el ámbito geográfico natural de la cuenca hidrográfica. Ello no quiere decir que cada cuenca deba ser necesariamente objeto de la labor de un OO. CC. ni que deba existir siempre una relación de igualdad o interdependencia entre cuenca hidrográfica y su correspondiente OO. CC. Esa decisión puede ser funcionalmente ineficaz y económicamente muy onerosa si se trata de pequeñas cuencas hidrográficas incapaces de sostener un aparato administrativo mínimamente eficaz (o de justificar las cargas económicas que ello lleva consigo). Por ello no hay inconveniente en que, cuando el tamaño de la cuenca sea suficiente haya un OO. CC. solo para ella pero, igualmente, puede ser aconsejable que un OO. CC. tenga una base territorial que se extienda a varias cuencas, con la condición básica de que sean vecinas desde el punto de vista territorial. Esto presupone que el ordenamiento jurídico

38 Las definiciones de cuenca hidrográfica son relativamente variadas en la normativa existente en los distintos países de ALC que, en ocasiones, se adapta a las necesidades del territorio concreto al que debe aplicarse. A veces se denominan cuencas hidrográficas a lo que no son sino subcuencas, pues la definición más correcta técnicamente de cuenca debe hacer referencia a un curso de agua que desemboca en el mar (o en un lago interior) y recoge los aportes de un determinado territorio que vierte hacia él. La cordillera de los Andes, hecho natural vinculado a varios países, determina que solo puedan responder de forma exacta al concepto de cuenca los cursos de agua que vierten hacia el Océano Pacífico, mientras que los territorios del otro lado, solo pueden dar lugar a subcuencas nacionales, integradas, a su vez, en cuencas internacionales a veces de inmenso tamaño, como sucede en el caso de la del Amazonas. En la práctica y dado el gran número de cuencas existentes en un país (de tamaño regular) normalmente se crean estos organismos para grupos de cuencas (o subcuencas) y/o en cuencas prioritarias (con mayores problemas y necesidades de coordinación.

39 Lo que se dice guarda relación, hasta ahora, solo con el ámbito del agua y no ambiental en general. La posibilidad de extender sus atribuciones al ámbito ambiental es controvertida y no siempre el nivel de cuenca puede ser el adecuado para ello (Dourojeanni et al, 2002). 
aplicable en cada caso debe contener una definición de cuenca hidrográfica en base a la cual se habrán determinado, por parte del órgano competente, tanto las cuencas existentes como los OO. CC. que deban existir.

Esta determinación previa debe realizarse rigurosamente para no prever la constitución de OO. CC. allí donde haya incapacidad económica de sostenimiento o donde por la escasa población o importancia económica de la gestión del agua no sea prioritario el establecimiento. Por otra parte, la existencia de OO. CC. presupone un convencimiento social previo de su utilidad, para lo que deben realizarse acciones que converjan en ese resultado. Desde la perspectiva de la $\mathrm{SH}$, los OOCC pueden jugar un papel importante en las interrelaciones entre sus componentes, por lo que deben potenciarse las actuaciones para su constitución aun con todos los inconvenientes que puedan señalarse para los pasos previos a ello.

2) Los 00. CC. como instrumentos de participación con posibilidad de gestión: los OO. CC. deben ser elementos de coordinación, participación y debate y también podrían ser instrumentos de gestión. Allí donde los OO. CC. no existan, lo más necesario es implantarlos aún cuando solo sea como instrumentos de participación social y de coordinación. La atribución de competencias para la gestión del recurso hídrico puede seguir a la existencia de OO. CC. con una cierta tradición de participación y de coordinación de criterios en torno al aprovechamiento del agua, a la constitución de agrupaciones de agricultores para la utilización en común de recursos hídricos en su actividad económica y a la generación de hidroelectricidad. Esta es una cuestión sumamente importante y en la que los planteamientos graduales, pausados pero progresivos, pueden tener una capacidad de resultados positivos mucho mayor que el apresuramiento o las actuaciones puramente formales.

Para el cumplimiento de la función participativa es esencial determinar su composición, lo que significa establecer la de los distintos órganos que puedan existir dentro de ellos. En OO. CC. plenamente consolidados es habitual distinguir la existencia de asambleas generales o comisiones de debate donde se agrupan todos los usuarios del agua o los de un determinado sector productivo y, por otra parte, estructuras propias de la gestión.

En esos términos la participación debe configurarse de una forma amplia, de tal manera que no pueda decirse que ningún interés social, político, técnico o económico de significación queda fuera del Organismo de Cuenca.

Por ello deben pertenecer al Organismo los representantes de los usuarios de agua, teniendo en cuenta los distintos usos existentes en cada cuenca (consumo urbano, producción de energía, agricultura, acuacul- 
tura, pesca, recreación...). Igualmente, es conveniente que se incorporen representaciones sociales (sindicatos, patronales, consumidores, organizaciones ambientalistas) y los poderes locales y regionales (municipios o ayuntamientos, regiones, provincias y estados), algo muy importante teniendo en cuenta que los OO. CC. son una división natural y no político-administrativa. En particular, las empresas públicas prestadoras de servicios del agua pueden tener una representación propia o, también, incorporarse a través de la instancia política de la que dependen (normalmente serán los municipios).

Desde luego la administración, autoridad o ministerio competente en materia de agua debería formar parte del Organismo, normalmente a través de sus organismos periféricos (los que ejercen sus competencias sobre territorio relativamente similar al de la cuenca). Y si el OO. CC. ejerce funciones ejecutivas (otorgamiento, modificación o revisión de concesiones, potestad de policía incluyendo la imposición de sanciones, percepción de tasas o cánones por el uso de agua etc.) la condición de no duplicación competencial consistirá en la conexión de estas estructuras ministeriales en el propio OO. C.

Este es un nivel de OO. CC. superior a los usualmente existentes en ALC y que se corresponde con modelos europeos consolidados de gestión de las aguas (confederaciones hidrográficas en España, agencias del agua en Francia) y al que se debería tender, como objetivo último, dada la eficacia alcanzada en la experiencia comparada. Precisamente es en torno a los OO. CC. (confederaciones hidrográficas) en España donde pueden ofrecerse ejemplos de organización administrativa en el ámbito del nexo entre agua-energía-alimentación, pues ejercen competencias en todos esos sectores, prácticamente exclusivas en el ámbito del agua, e importantes en energía (hidroeléctrica, refrigeración de centrales térmicas) y agricultura (otorgamiento de concesiones en materia de agricultura de regadío).

Los porcentajes de participación de los grupos enumerados (y de otros que pudieran existir en función de las peculiaridades de las distintas cuencas) es cuestión en la que se mezclan valoraciones políticas con consideraciones propias de las características sociales y económicas de cada cuenca y respecto de las que resulta prácticamente imposible hacer propuestas con voluntad de validez y de aplicación general. Puede señalarse la conveniencia de que los representantes de los usuarios del agua con destino al regadío puedan ser mayoritarios ente los grupos de representación por el mucho mayor volumen de agua que utilizan. Pero es posible encontrar también (como sucede en Europa) cuencas en las que los usos predominantes no sean los de regadío sino los industriales, por lo que pueden existir decisiones distintas. 
Agua, energía y agricultura en los OO. CC.: los sectores de energía y agricultura deben estar presentes en la actuación de los OO. CC., y lo pueden estar a través de los productores de energía hidroeléctrica o, en su caso, de los titulares de las centrales térmicas o nucleares en las que se utilice el agua como elemento de refrigeración (aunque existan muy pocos ejemplos de este último en la región). Lo mismo sucedería con la representación de los productores agrícolas, a través de organizaciones empresariales $u$ organizaciones de usuarios agrícolas de aguas (comunidades o asociaciones de usuarios). Por último, está la desalinización, todavía escasa aunque en crecimiento en la región. En este sentido, la representación de los titulares de las instalaciones que, en su caso, existan es, en sí misma, un elemento de SH por el importante peso que en la producción de agua desalinizada tiene la utilización de energía y los posteriores usos del agua desalada. También estos elementos del nexo pueden estar presentes a través de la representación de los sindicatos o de las organizaciones empresariales y de las representaciones político-administrativas (ministeriales y sus delegaciones locales) competentes en materia de energía y agricultura.

3) 00. CC. y planificación hidrológica: La relación de los OO. CC. con la elaboración de la planificación hidrológica es imprescindible. Y también con la elaboración de la planificación energética y agrícola. Esa participación operará normalmente a nivel consultivo siendo otras entidades u órganos administrativos quienes serán los responsables de la elaboración de los correspondientes planes; aunque en el ámbito de la planificación hidrológica la actuación de OO. CC. consolidados, con estructura y servicios administrativos competentes, puede alcanzar un nivel mayor de responsabilidad. Incluso puede atribuírseles la autoría (inicial) de los planes hidrológicos que podrán ser luego sometidos a procesos de información, consulta pública y aprobación final por órganos centrales de la administración (en la forma que luego se comentará).

Recuadro 4.4. Organismos de cuenca singulares: la Autoridad de Cuenca Matanza-Riachuelo

El caso Autoridad de Cuenca Matanza-Riachuelo (ACUMAR: http://www. acumar.gov.ar) puede ser considerado un caso de buenas prácticas en la región en tanto ensayo reciente de dotar de mayor intensidad a 00. CC. caracterizados por su debilidad, centralizando importantes competencias ejecutivas y de planificación que facilitan la implementación de enfoques como el de SH. Parte del atractivo del caso proviene además de haber sido adoptado en un contexto adverso de catástrofe ambiental (algo cada vez más frecuente en la región) y judicialización por violación 
de derechos humanos y conflictos de competencias entre autoridades responsables.

ACUMAR se instaura por la Sentencia Mendoza de $\mathbf{2 0 0 6}$ de la Corte Suprema de Justicia de la República Argentina y supone la colaboración de la Nación, la Provincia de Buenos Aires y la Ciudad de Buenos Aires. Varios elementos motivan la decisión de crear este OO. CC.: la planificación hidrológica, la lucha contra la contaminación y el enfoque basado en derechos humanos. Es el ejemplo de un OO. CC. creado a partir de una resolución judicial y constituye una muestra de activismo judicial muy presente en temas ambientales en distintos países de ALC.

De hecho, se produce a partir de una acción por daños y perjuicios interpuesta por varios vecinos afectados, contra el Estado y distintas empresas, por la contaminación en la Cuenca Matanza Riachuelo. La Corte Suprema de Justicia de la Nación Argentina propició una solución basada en los siguientes principios: (i) activismo judicial; (ii) exigibilidad y operatividad del derecho a un medio ambiente sano como derecho colectivo; (iii) integralidad de la solución/interdependencia de los derechos; (iv) diseño de un proceso colectivo ambiental; (v) la cuenca como unidad ambiental de gestión indivisible y fuente de potestades; (vi) enfoque basado en Derechos Humanos, legitimación amplia, publicidad y participación; (vii) la planificación en el centro de la solución; y (viii) control de ejecución de sentencia/dialogo con los otros poderes.

La ACUMAR cuenta así con facultades de regulación, control y fomento respecto de las actividades industriales, la prestación de servicios públicos y cualquier otra actividad con incidencia ambiental en la cuenca, pudiendo intervenir administrativamente en materia de prevención, saneamiento, recomposición y utilización racional de los recursos naturales. En particular, está facultada para: a) unificar el régimen de vertidos de efluentes a cuerpos receptores de agua y emisiones gaseosas; b) planificar el ordenamiento ambiental del territorio; c) establecer y percibir tasas por servicios; d) llevar a cabo cualquier tipo de acto jurídico o procedimiento administrativo necesario para ejecutar el Plan Integral de Control de la Contaminación y recomposición Ambiental; y e) gestionar y administrar fondos (Art. 5). Para evitar los conflictos entre autoridades competentes se establece la prevalencia de las facultades, poderes y competencias de la ACUMAR en materia ambiental sobre cualquier otra concurrente en el ámbito de la cuenca, debiendo establecerse su articulación y armonización con las competencias locales (Art. 6).

Se trata de facultades que en conjunto denotan una enorme delegación de facultades propias de otras jurisdicciones administrativas que se centralizan en el OO. CC., facilitando de esta forma la coordinación para la 
Además de la voluntad política, las mejoras en SH dependerán de avances en ciencia y tecnología que ayuden a llenar vacíos de información implementación de políticas con enfoque de SH que requieren de competencias de planificación y ejecutivas en sectores usualmente organizados por separado.

Otro ejemplo reciente es el de la Resolución de la Corte Suprema de Justicia de Argentina en la demanda de la Provincia de La Pampa contra la de Mendoza (1/12/2017) que ordena la revitalización del organismo de cuenca interprovincial existente pero sin actividad, el Comité Interprovincial del Atuel Inferior (CIAI) para la gestión del río Atuel, integrando el derecho humano de acceso al agua potable, la planificación hidrológica y ordenando el establecimiento acordado de un caudal ambiental o ecológico (mínimo) a transportar por el río Atuel. Se trata de decisiones importantes en el ámbito de la gestión del agua pero igualmente en los otros componentes del nexo, puesto que la relación de esta sentencia con la actividad agrícola a desarrollar en las provincias de La Pampa y Mendoza es innegable e, igualmente, puede afectar a la producción hidroeléctrica en ambas provincias.

\section{IV.4 Avances en ciencia y tecnología}

Además de la voluntad política, las mejoras en SH tanto a nivel mundial como en la región de ALC, dependerán, en buena medida, de avances en ciencia y tecnología que ayuden a llenar vacíos de información y puedan apoyar a la toma de decisiones en los diferentes ámbitos institucionales, técnicos y políticos del sector de agua y sectores relacionados. Aunque la revisión exhaustiva de este tema escapa del alcance de este informe, vale la pena detenerse en un aspecto en el que el BID y sus clientes han hecho hincapié de forma constante: la disponibilidad de datos sobre la cantidad y la calidad del agua y, en un sentido más amplio, el monitoreo del ciclo del agua y el desarrollo de herramientas que transformen estos datos en información confiable de acceso público para apoyar la toma de decisiones y la planificación.

Para gestionar adecuadamente el agua como recurso vital, son necesarios una buena comprensión física de la dinámica de los recursos hídricos a través del tiempo y el espacio y un buen monitoreo casi en tiempo real de los balances hidrológicos. Esta comprensión constituye la base para abordar los desafíos importantes de la SH, como la cantidad y calidad de agua, los caudales ecológico-ambientales, los servicios ecosistémicos, la asignación de usos del agua para la agricultura y la energía y la protección ante riesgos de desastres de naturaleza hídrica, entre otros.

Por ejemplo, hacer frente a la variabilidad del clima y sus impactos en el ciclo del agua requiere de herramientas de monitoreo confiables, que ayuden a los usuarios y tomadores de decisiones y planificadores a priorizar y gestionar la demanda con anticipación en años secos y consumir más racionalmente 
durante los años húmedos. Una mejor cuantificación de los caudales y almacenamientos hidrológicos ayudará a mejorar la SH y, por lo tanto, influirá positivamente en la salud y el bienestar de las poblaciones, al proporcionar información más confiable sobre la disponibilidad y el uso del agua. En este sentido, la percepción remota o teledetección, permite obtener observaciones terrestres de muchas variables hidrometeorológicas y ambientales, así como la identificación de muchos tipos diferentes de uso de la tierra y un número creciente de variables ecológicas. Algunas de las variables relevantes son la precipitación, la humedad del suelo, el cambio en el almacenamiento de agua terrestre (incluidas las aguas de la zona vadosa y las aguas subterráneas), la evapotranspiración, el Índice de Vegetación de Diferencia Normalizada (NDVI), la elevación del agua superficial y las variables de calidad del agua. Un buen monitoreo de los caudales hidrológicos y su distribución temporal y espacial permitirá obtener datos cuantitativos que facilitarán los enfoques de planificación, institucionales, económicos y de otro tipo para la gestión del agua.

\section{¿Cómo puede la teledetección ayudar a una mejor gestión de los recursos hídricos?}

La teledetección puede proporcionar observaciones distribuidas espacial y temporalmente que pueden permitir mejores capacidades de pronóstico y un uso más eficiente del agua, de las siguientes maneras:

- Las operaciones en áreas dominadas por glaciares y/o páramos pueden beneficiarse de las estimaciones de cobertura de hielo y equivalentes de agua correspondientes para saber cuánta agua hay almacenada y en qué cuencas hidrográficas se almacena.

- En cuencas grandes con tiempos de concentración de muchos días, las estimaciones satelitales en tiempo real de las precipitaciones y los pronósticos del caudal de escorrentía pueden ayudar a las empresas operadoras a distribuir el agua entre los usuarios y operar los embalses de manera más eficiente, teniendo en cuenta la cantidad de agua que se espera que traiga el río en los días siguientes.

- En los ríos caudalosos, los datos altimétricos de las superficies de los ríos se pueden usar para estimar el caudal en las partes superiores de la cuenca y hacer predicciones para los caudales aguas abajo, para emitir alertas de inundaciones y para la asignación y operaciones de agua (Hossain et al., 2014).

- Las mediciones satelitales de la humedad del suelo pueden proporcionar información sobre la cantidad de riego que se necesita, así como ayudar a corregir eventos perdidos o falsas detecciones de productos de precipitación satelital y ayudar a evaluar el riesgo de inundación. 
- Las estimaciones de evapotranspiración pueden ayudar a los operadores del sector a comprender mejor la dinámica del bombeo de agua subterránea en áreas agrícolas y el impacto de las políticas hídricas implementadas y los cambios en los subsidios de energía para el bombeo. De manera más general, la evapotranspiración se puede usar en combinación con datos medidos en el terreno para comprender las eficiencias en el uso del agua, con el objetivo de disminuir las pérdidas no beneficiosas y aumentar la productividad agrícola (Wu et al., 2013).

Figura 4.11. Datos para caudales de agua superficial a nivel global, actualizada cada tres horas en tiempo real
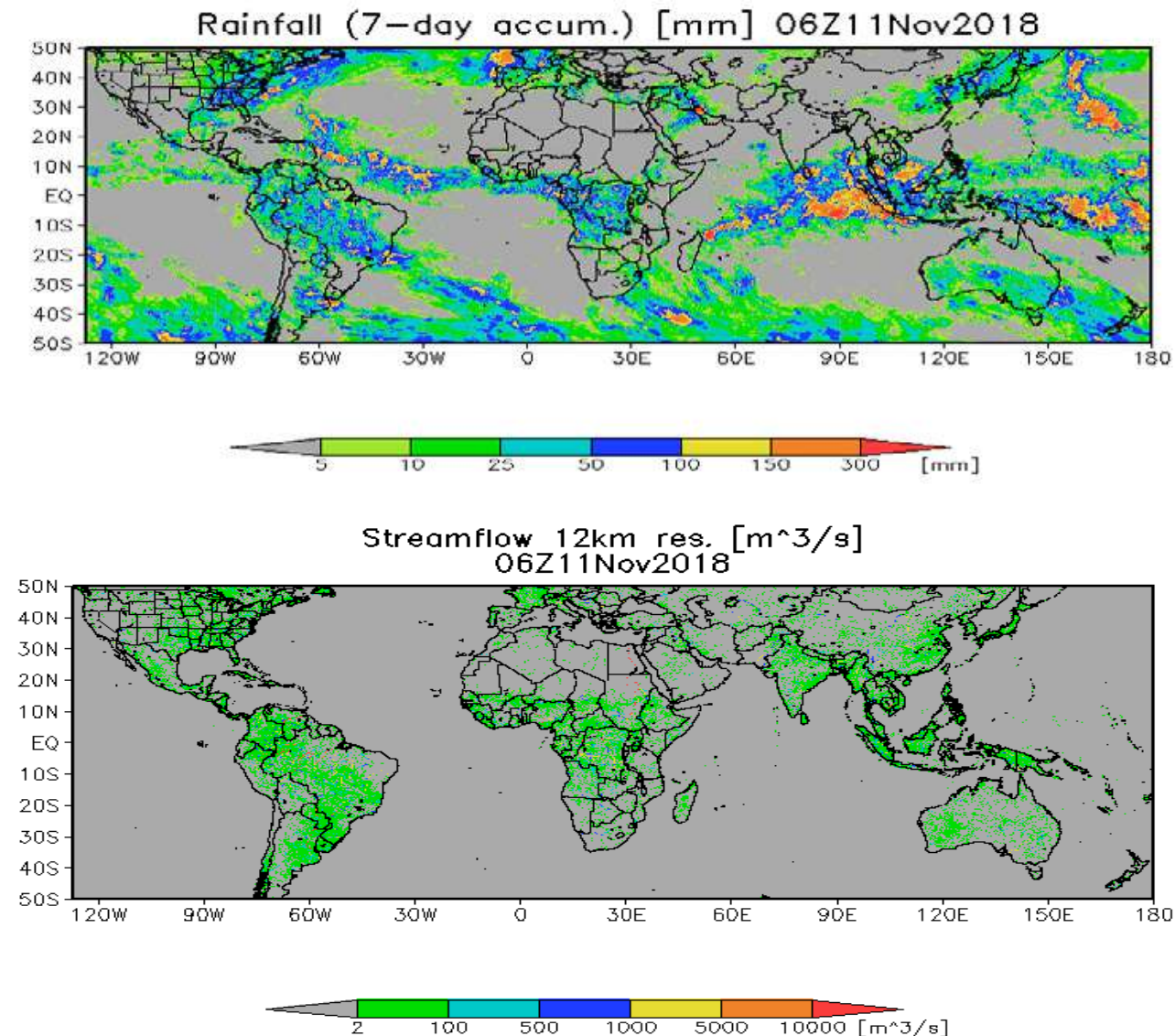

Fuente: $\underline{\text { http://flood.umd.edu. }}$

Existen varias fuentes públicas abiertas de datos de teledetección de aguas superficiales que cubren todo el mundo. Por ejemplo, el Global Flood Monitoring System (Figura 4.11) disponible a través de http://flood.umd.edu, que utiliza datos de precipitaciones de la NASA y modelos hidrológicos para crear mapas de detección e intensidad de inundaciones en tiempo real. O los datos 
del satélite Grace para conocer el estado de las aguas subterráneas (https:// nasagrace.unl.edu) que se muestra en la Figura 4.12. Estos datos se pueden utilizar para evaluar los balances hídricos, el almacenamiento de agua y los caudales hidrológicos que se necesitan en los programas nacionales, estatales o municipales, así como en iniciativas regionales.

Figura 4.12. Obtención de series históricas de la disponibilidad de agua subterránea de la misión GRACE de la NASA en la cuenca Amazónica

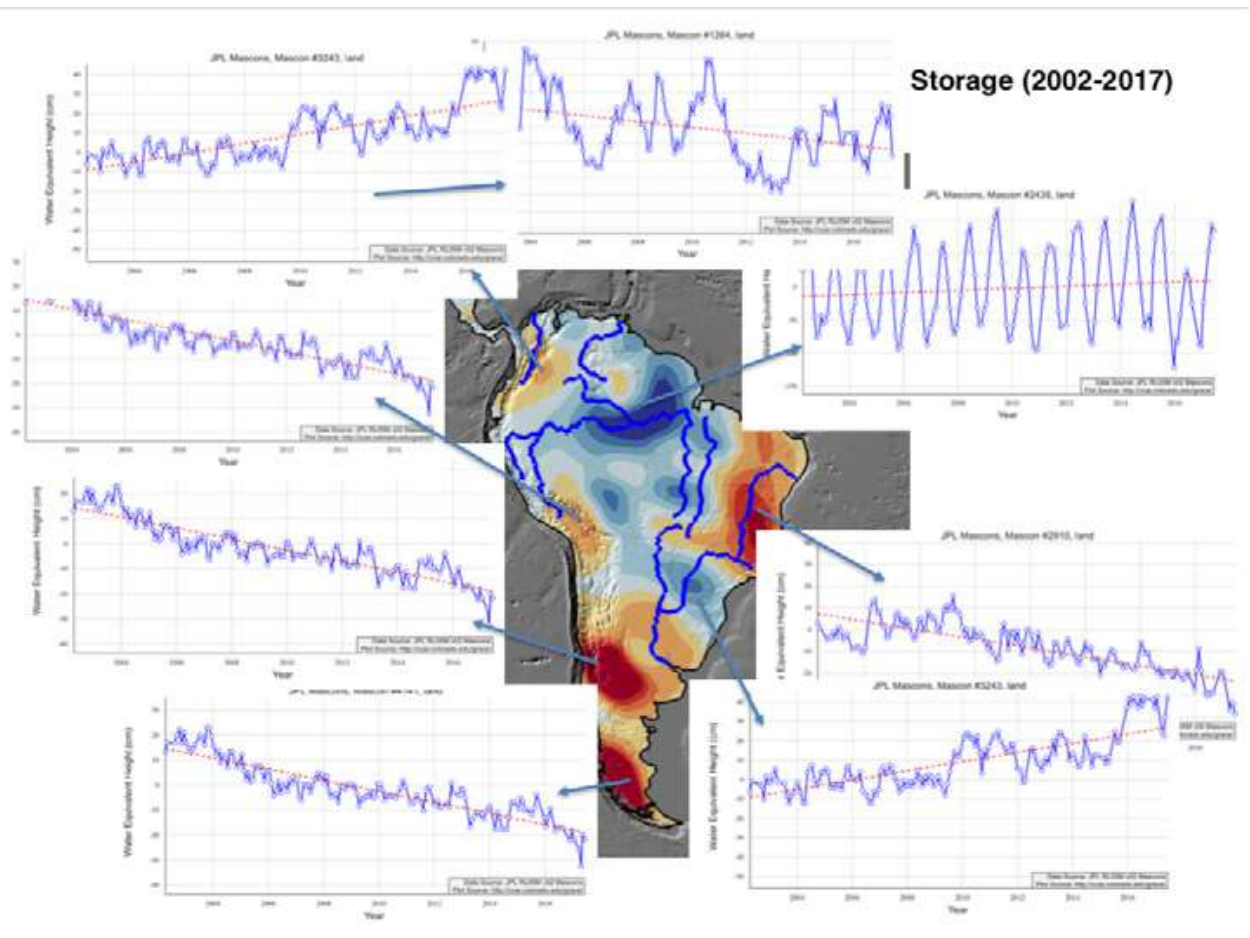

Fuente: https://photojournal.jpl.nasa.gov/archive/PIA13243 gracelenticular 07 web2.gif.

Figura 4.13. Base de datos de cobertura de nieve a nivel global( Satélite NASA TERRA-MODIS)

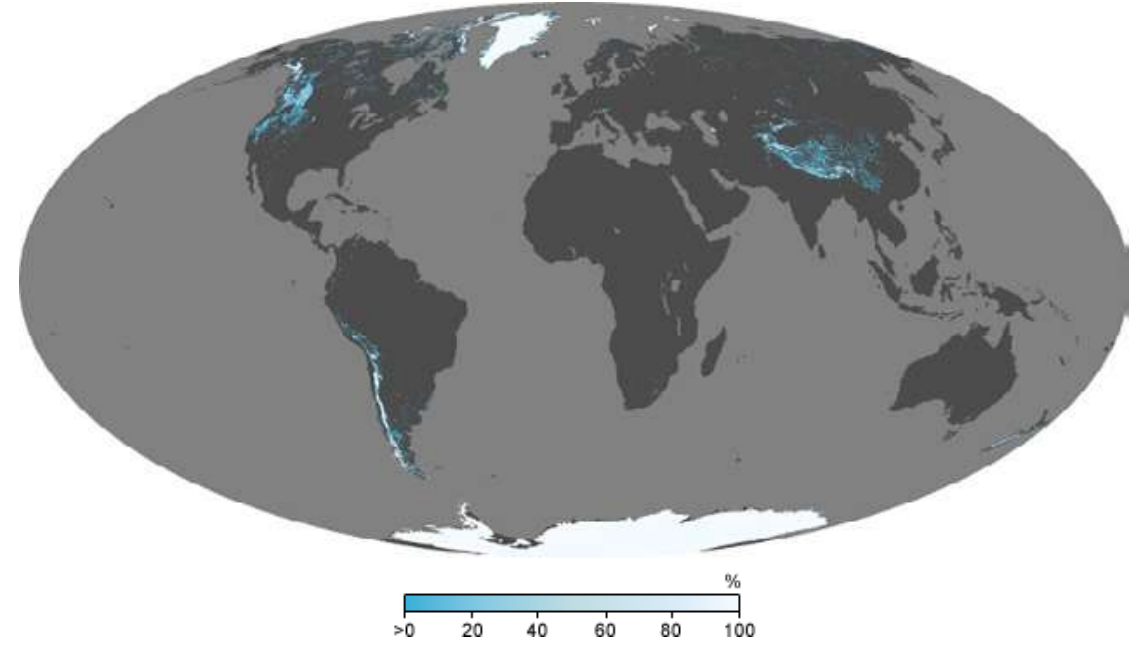

Fuente: https://earthobservatory.nasa.gov/global-maps/MOD10C1_M SNOW 
Para el monitoreo de glaciares y cobertura de hielo y nieve en general, existen bases de datos públicas a nivel global obtenidas de mediciones satelitales. Por ejemplo, el satélite TERRA de la NASA contiene el instrumento MODIS (Moderate Resolution Imaging Spectroradiometer) que puede medir cobertura porcentual de nieve. La Figura 4.13 ilustra un mapa de cobertura de nieve con estos datos, y el sitio web contiene los archivos de datos con todas las mediciones.

El monitoreo de agua en humedales reviste gran importancia en el balance hídrico y la $\mathrm{SH}$ en zonas costeras, dado que estos ecosistemas juegan un papel importante en la regulación de la conexión entre el agua dulce y el agua salada. Por otra parte, los humedales sirven como sistemas de almacenamiento y regulación de agua, ayudando a mitigar los impactos de sequías e inundaciones en zonas aledañas a los mismos. Existen fuentes de mediciones de volúmenes de agua contenidos en humedales a través de tecnologías de radar (SAR: Synthetic Aperture Radar) que se encuentran disponibles. La Figura 4.14 muestra la aplicación de esta tecnología en los humedales de Sian Ka’an en la península de Yucatán en México.

Para el monitoreo de condiciones de sequías e inundaciones, existen varias bases de datos existentes y en constante desarrollo. Aquí se ilustran dos ejemplos. El primero es una base de datos global del Índice de Precipitación Estándar (SPI) diario (Figura 4.15), que se utiliza, junto con una base de datos de lluvia como la que se presenta en la Figura 17, para la detección temprana de condiciones de sequías e inundaciones. El segundo ejemplo muestra el Índice de Estrés Evaporativo (ESI), un índice que mide la sequía aplicable a la agricultura y su impacto en la productividad agrícola (Figura 4.16).

Figura 4.14. Mediciones de volúmenes de agua en los humedales de la Reserva de la Biósfera de Sian Ka’an, en México. (a) Península de Yucatán (b) Sian Ka'an (polígono verde; (c) Volúmenes de agua entre las fechas (2006/10/262006/11/19; (d) Volúmenes de agua entre las fechas (2006/08/152006/09/08)
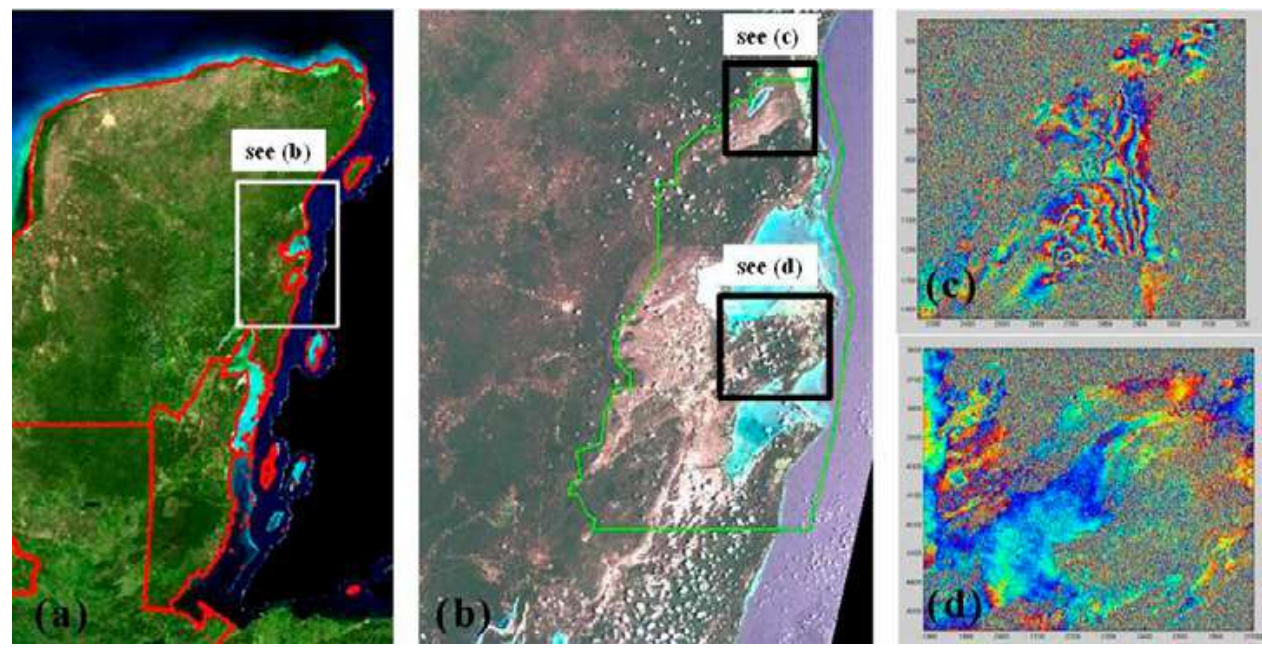

Fuente: Digital Chart of the World (http://www.maproom.psu.edu/dcw/) 
Figure 4.15. Base de datos del SPI a escala global y diaria Standardized Precipitation Index (Gamma distribution), 270-day scale

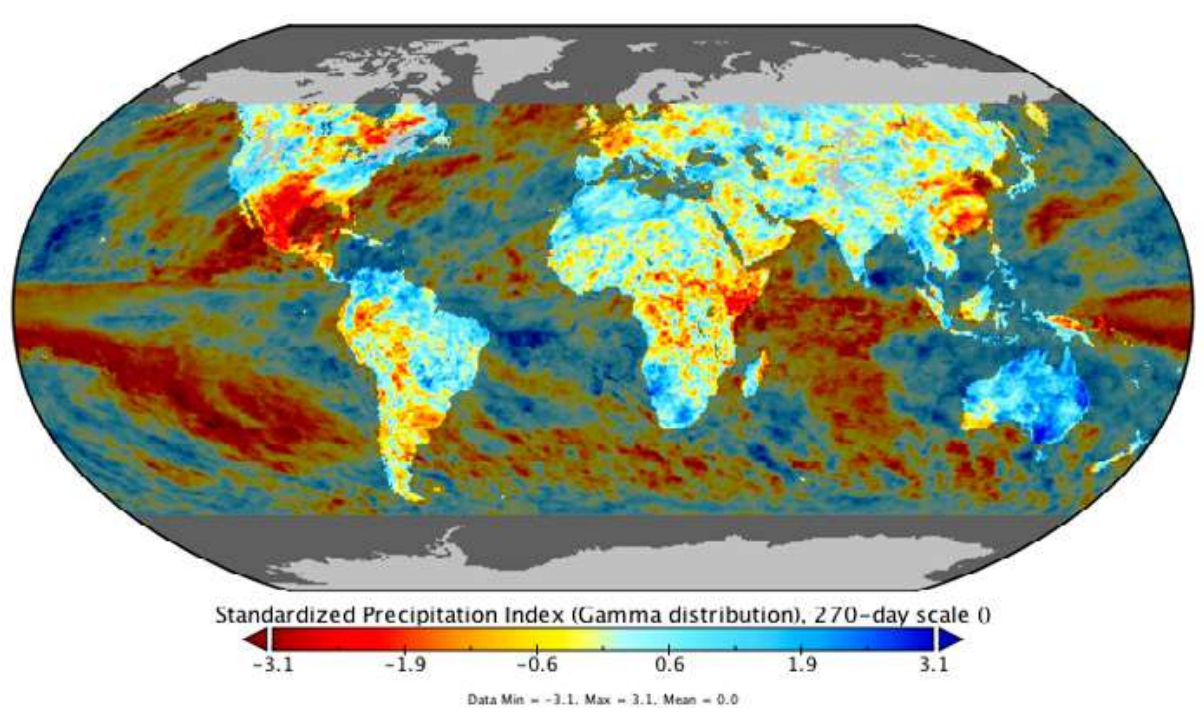

Fuente: https://www.cpc.ncep.noaa.gov/products/international/dm/daily/index.shtml

Figura 4.16. Valor del ESI (índice de estrés evaporativo) y su incidencia en la productividad agrícola anual en Brasil

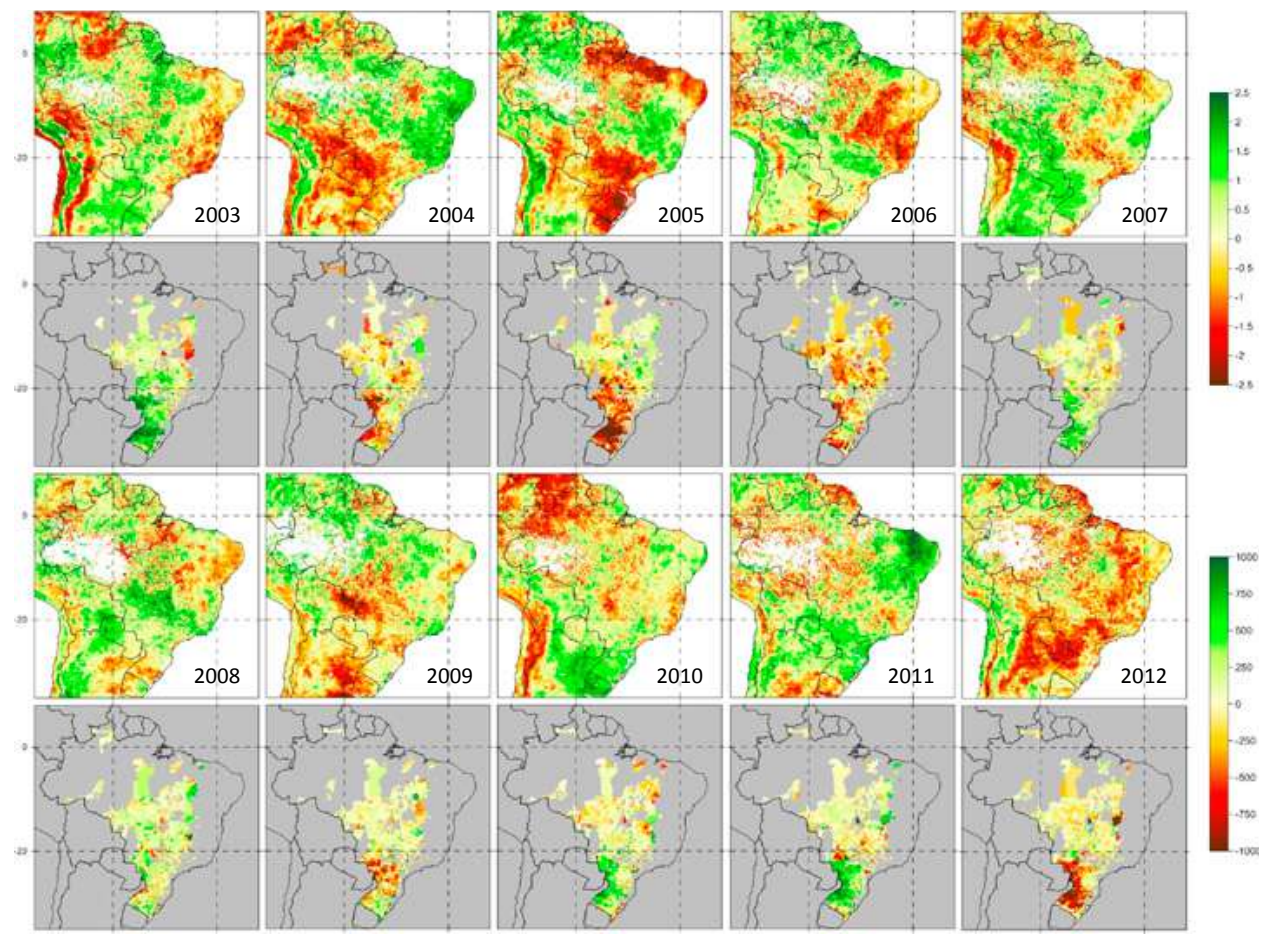

Fuente: http://catalogue.servirglobal.net/Product?product id=198 
Además de la cantidad de agua, algunas investigaciones recientes han logrado un progreso significativo en el monitoreo de muchos parámetros de calidad del agua (Gholizadeh et al., 2016; Chang et al., 2015). Esto hace posible seguir la dinámica de la calidad del agua en el tiempo y el espacio a través de vastas regiones, complementando significativamente las mediciones de puntos de muestreo en campo, que son costosas y limitadas. Las variables de calidad del agua que pueden evaluarse con teledetección son la temperatura; la clorofila (un indicador de biomasa de fitoplancton, estado trófico y de nutrientes) y el índice más utilizado de la calidad del agua y el estado de los nutrientes a nivel mundial; cianoficocianina y cianoferceritrina (indicadores de biomasa de cianobacterias, comunes en la proliferación de algas nocivas y tóxicas); materia orgánica disuelta (un componente medible ópticamente de la materia orgánica disuelta en la columna de agua que a veces se usa como un indicador de materia orgánica y carbono acuático); y materia total en suspensión y partículas no algales (importante para evaluar la calidad del agua potable y controlar el ambiente de luz en ambientes acuáticos).

Las aplicaciones directas para la gestión incluyen:

- Monitoreo de la calidad del agua para evaluar los impactos de las políticas de manejo de las cuencas hidrográficas y las prácticas de uso del suelo en el medio ambiente y las aguas superficiales. La dimensión espacial de esta capacidad de monitoreo es importante para esta aplicación.

- Monitorear la probabilidad de floraciones de algas y otras amenazas a la calidad del agua para los embalses y sistemas de suministro de agua.

Las técnicas de teledetección permiten tener una visión espacial y temporal de los parámetros de calidad del agua superficial y monitorear de manera más eficaz y eficiente los cuerpos de agua, cuantificando los problemas de calidad del agua. Hay muchos otros parámetros importantes de la calidad del agua, como el pH, el nitrógeno total (TN), el nitrógeno amoniaco (NH3-N), el nitrógeno nitrato (NO3-N) y el fósforo disuelto (DP), sobre los que hace falta obtener mayores conocimientos y experiencias. La razón principal se debe a sus características ópticas (para ser detectados por los satélites) débiles y baja relación señal-ruido. Sin embargo, estos parámetros son una parte importante de los índices de calidad del agua y su teledetección es un aspecto desafiante de la investigación en el campo de la evaluación de la calidad del agua.

Esta síntesis de los parámetros de calidad del agua medidos a través de teledetección resume los enfoques más comúnmente empleados para estimar la concentración de algunos indicadores clave asociados con la contaminación antropogénica de las masas de aguas continentales. La Figura 4.17 muestra la imagen de una investigación reciente (Banco Mundial, 2018) sobre el uso de sensores remotos para monitorear la cantidad de agua (lluvia, caudal y agua subterránea) y la calidad del agua (clorofila y turbidez) para un embalse 
importante de suministro de agua en México (el Valle de Bravo, que sirve a aproximadamente el $20 \%$ del suministro de agua de la Ciudad de México). También existen ya ejemplos del desarrollo de bases de datos globales para calidad de agua a partir de mediciones vía teledetección para el caso de indicadores como la clorofila (Figura 4.18) y la turbidez (Figura 4.19).

Figura 4.17: Mapa de calidad de agua en el embalse Valle de Braz (México): clorofila-a y turbidez

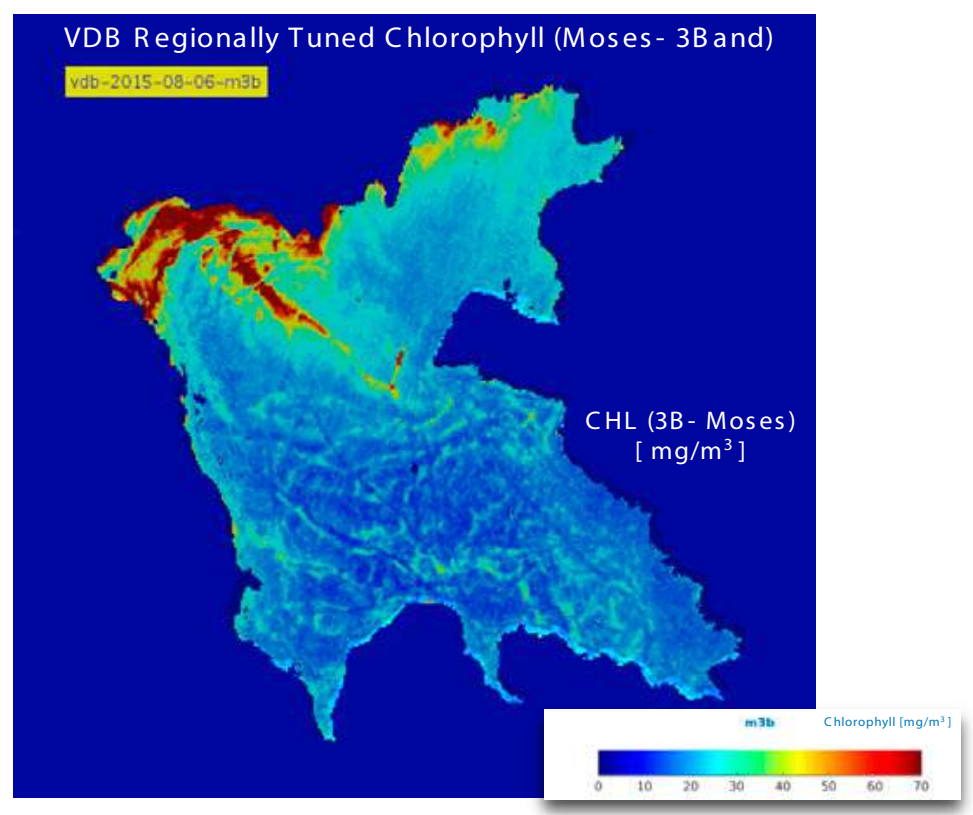

\section{VDB Regionally Tuned Turbidity $(835 \mathrm{~nm}$ Nechad)}

\section{vob-2015-06-06-ne8}

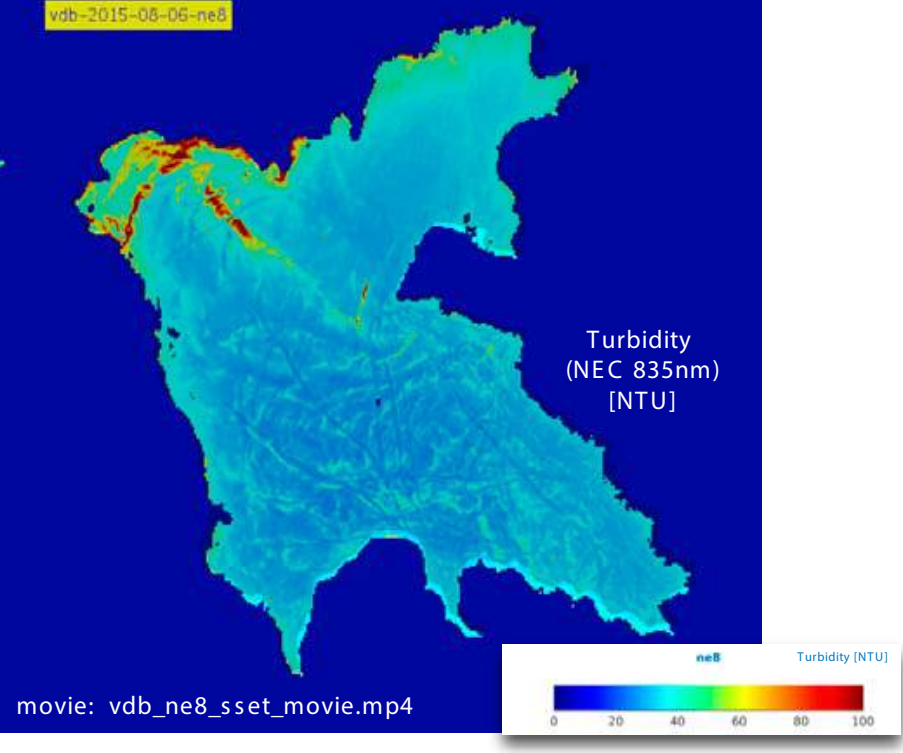

Fuente: Banco Mundial, 2018. 
Figura 4.18. Mapa de concentración de Clorofila-a a nivel regional para ALC sintetizado a partir de observaciones satelitales

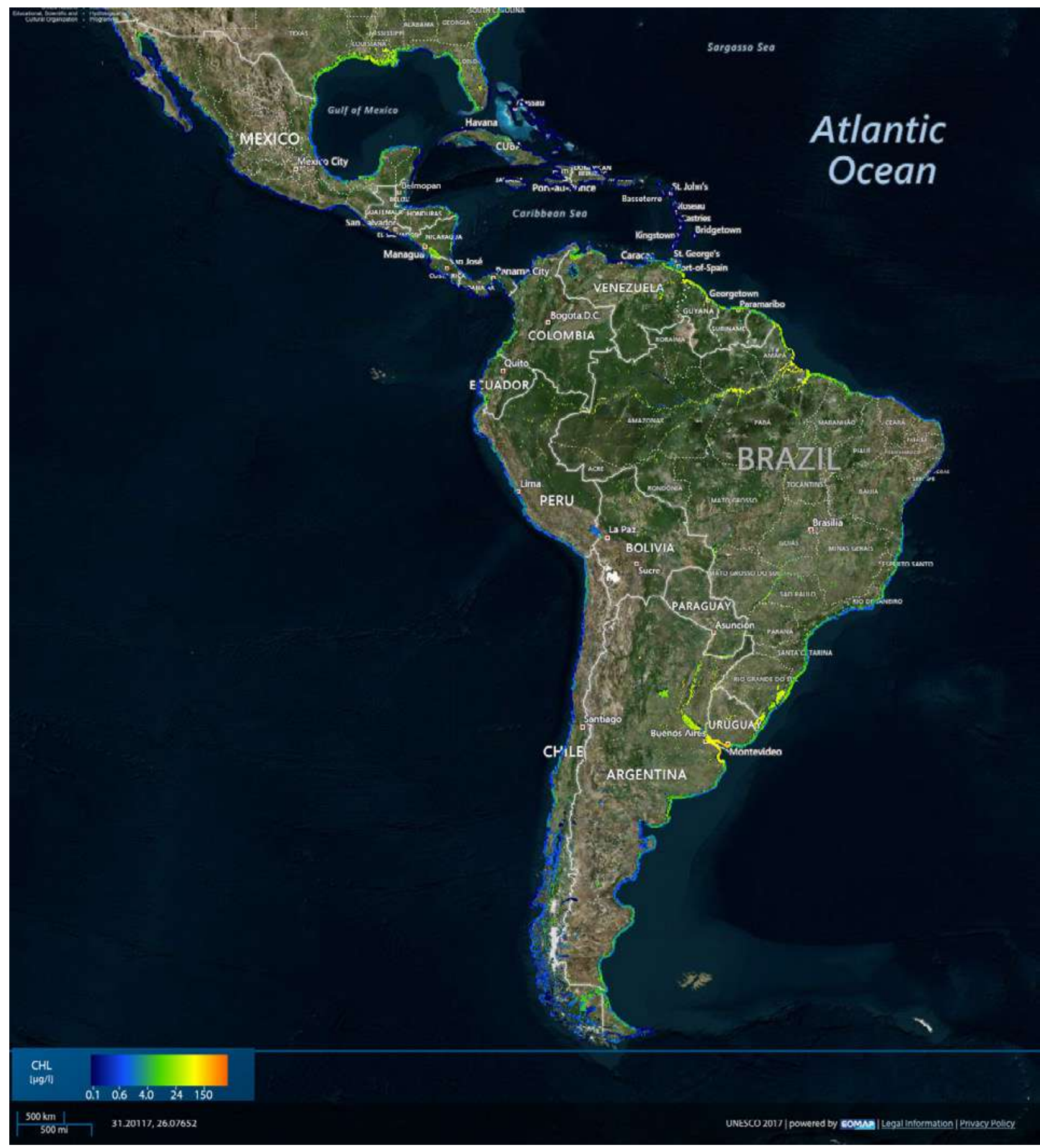

Fuente: UNESCO, https://www.eomap.com/world-water-quality/ 
Figura 4.19. Mapa de turbidez a nivel regional para ALC sintetizado a partir de observaciones satelitales

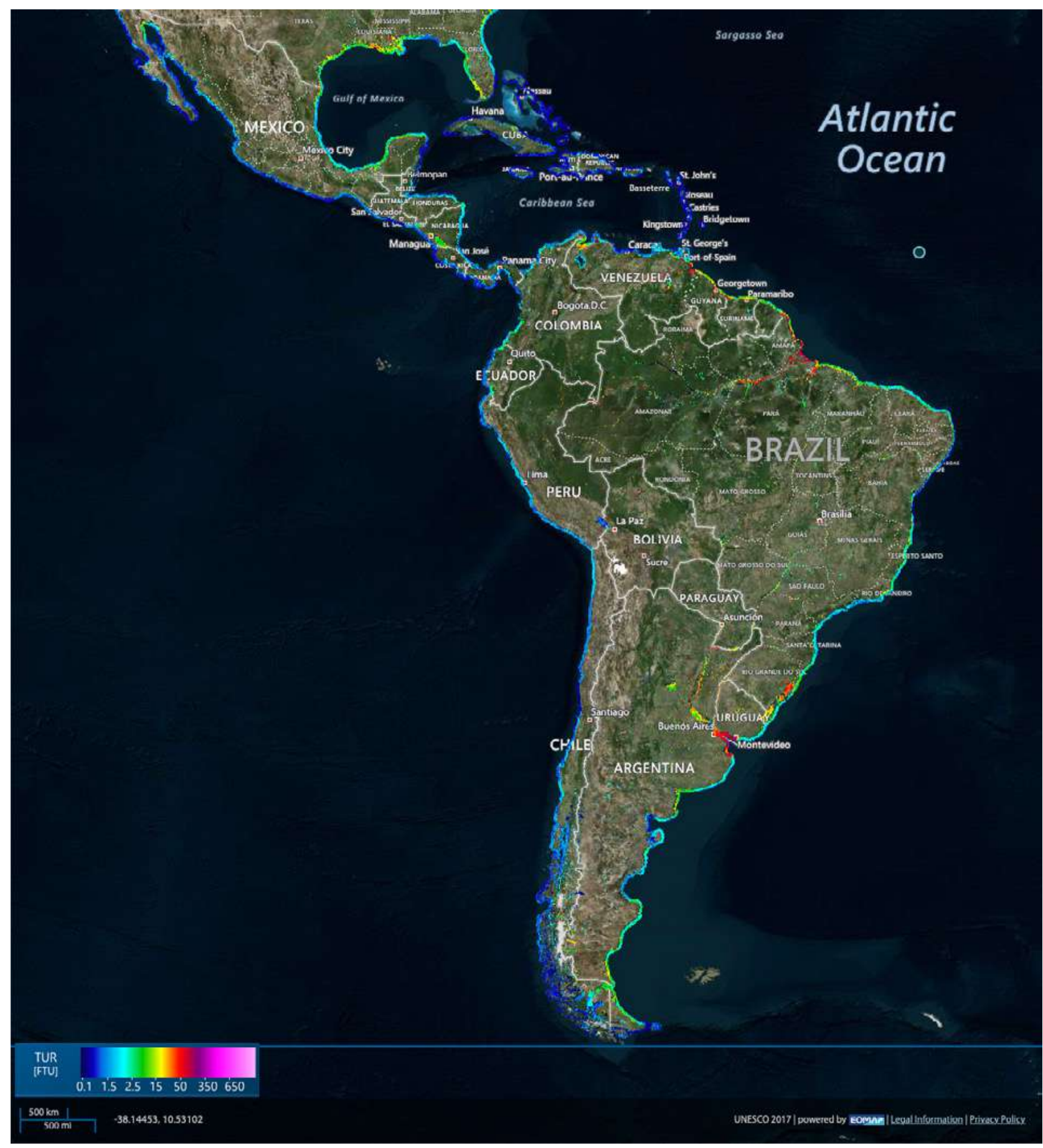

Fuente: UNESCO, https://www.eomap.com/world-water-quality/ 


\section{La teledetección, junto} con el muestreo de campo, los modelos de simulación y las técnicas de gestión de datos ofrecen una oportunidad significativa de innovación
En términos más generales, la teledetección como herramienta de medición de los diferentes componentes del ciclo del agua, unido a técnicas de SIG (Sistema de Información Geográfica), utilizadas en combinación con el muestreo de campo tradicional (in situ), modelos de simulación como los presentados en la Sección IV.1 y técnicas de gestión de bases de datos grandes (lo que se conoce como Big Data) ofrece una oportunidad significativa de innovación en material de SH. Actualmente, pocas decisiones de gestión del agua se basan en mediciones derivadas de la teledetección. En la mayoría de los casos, los tomadores de decisiones y los responsables de la formulación de políticas, sin experiencia técnica, suelen carecer de los conocimientos necesarios para comprender las descripciones técnicas, las capacidades y las limitaciones de las técnicas de teledetección. Por lo tanto, existe la necesidad de crear capacidad en la operacionalización de estos avances en la ciencia y tecnología de mediciones en el ciclo del agua. Esto debe ser una actividad fundamental en las actividades de producción de conocimiento que se describen en el Capítulo VI.

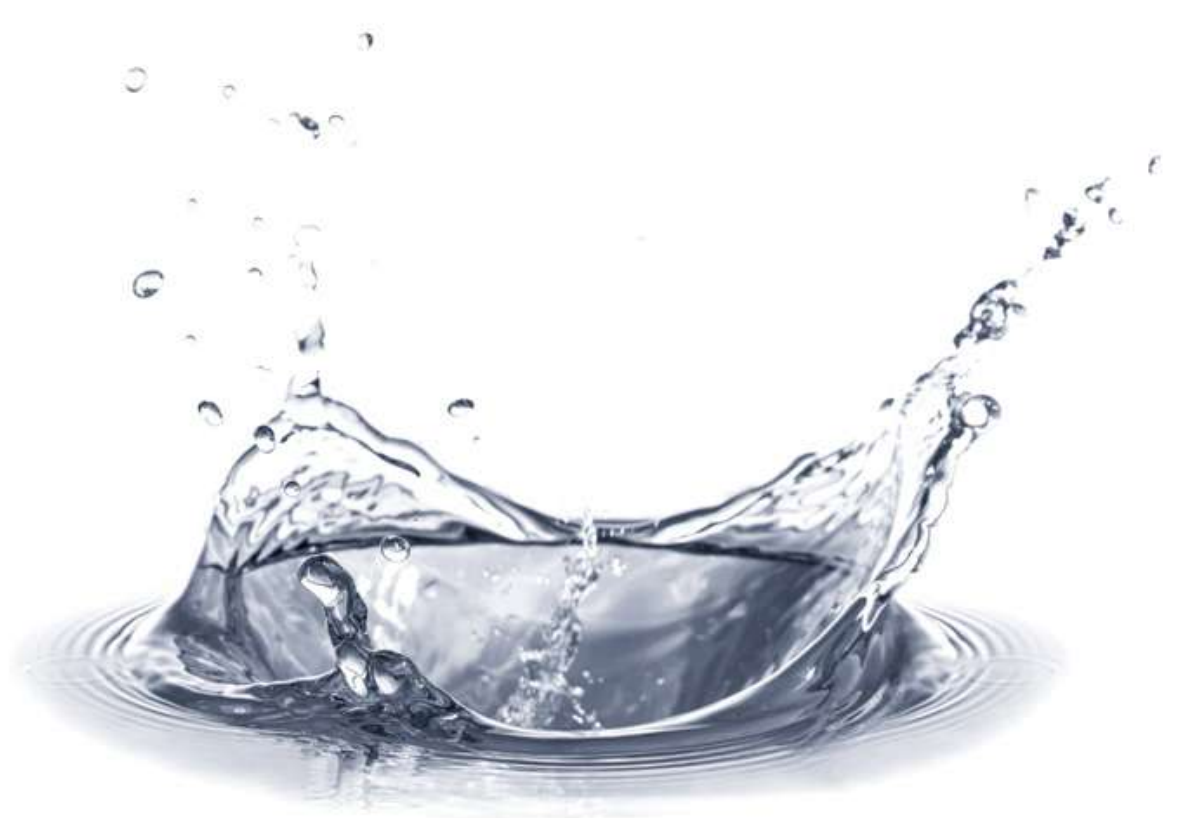





\section{EN CLAVE}

La gestión y el perfeccionamiento de los recursos hídricos son fundamentales para el desarrollo sostenible y la reducción de la pobreza. No pueden concebirse objetivos de desarrollo para los países sin que haya suficientes recursos hídricos para impulsarlos.

El grupo BID trabajará con los gobiernos nacionales, el sector privado, las ONG ambientales y de la sociedad civil, universidades y otros donantes y financiadores del desarrollo de la región, que harán un esfuerzo conjunto para avanzar en los objetivos estratégicos que permitirán la consecución de la SH en la región.

El objetivo estratégico principal es garantizar la disponibilidad de agua y su gestión sostenible y el saneamiento para todos. De este objetivo principal, se derivan seis objetivos estratégicos específicos.

Objetivo Estratégico 1: lograr y sostener el abastecimiento con agua potable y la provisión de servicios de recolección, tratamiento y disposición final de aguas servidas al $100 \%$ de la población.

Objetivo Estratégico 2: incentivar el desarrollo de marcos legales e institucionales adecuados para la gestión efectiva de los recursos hídricos teniendo como meta la SH, el manejo de los riesgos asociados y el desarrollo económico sostenible.

Objetivo Estratégico 3: en el marco de la SH, promover la seguridad alimentaria y la generación de energía renovable a partir de la planificación y el desarrollo de proyectos integrales multipropósito que contemplen necesidades de desarrollo, mejoras y seguridad de la infraestructura hídrica.

Objetivo Estratégico 4: incentivar la recuperación de la calidad y la creación de reservas estratégicas de agua para garantizar la SH.

Objetivo Estratégico 5: modernizar los mecanismos y métodos de obtención de información y de apoyo a la toma de decisiones para la SH.

Objetivo Estratégico 6: fomentar el desarrollo de conocimiento e innovación para garantizar la SH.

\section{Estrategia de Seguridad Hídrica para América Latina y el Caribe - Cuencas Sostenib/es}

L os recursos hídricos son fundamentales para el mantenimiento de la vida en el planeta y también será el principal medio a través del cual los seres humanos, los ecosistemas y las economías de los países sentirán los efectos del cambio climático (Sadfoff y Muller, 2010). Esta interrelación entre recursos hídricos, poblaciones, ecosistemas y economía hacen que la economía de los recursos hídricos sea extremamente compleja. No pueden concebirse objetivos de desarrollo para los países sin que haya suficientes recursos hídricos para impulsarlos. Crecimiento económico y disponibilidad de recursos hídricos están relacionados y los impactos de efectos hidroclimáticos son más pronunciados en países pobres, con baja disponibilidad hídrica y/o con economía dependiente de agricultura. Los países con mayor disponibilidad de agua o con la economía más diversificada son más resilientes (GWP/OECD, 2015). La estrategia de recursos hídricos del Banco Mundial del 2004 destaca que la gestión y desarrollo de los recursos hídricos son fundamentales para el desarrollo sostenible y reducción de la pobreza (Banco Mundial, 2004).

A este respecto, la Estrategia Institucional del BID para el periodo 2010-2015 y sus posteriores actualizaciones ${ }^{40}$ incluyen como objetivos estratégicos: (i) atender las necesidades de los países pequeños y vulnerables, en particular Haití, y (ii) promover el desarrollo a través del sector privado y los siguientes cinco ámbitos prioritarios: (1) política social favorable a la equidad y la productividad; (2) infraestructura para la competitividad y el bienestar social; (3) instituciones de promoción del crecimiento y el bienestar social; (4) integración competitiva internacional en los niveles regional y global, y (5) protección del medio ambiente, respuesta frente al cambio climático, promoción de la energía renovable y aumento de la seguridad alimentaria.

40 La última actualización de la Estrategia Institucional fue enviada al Directorio para aprobación en enero de 2019. 
Por lo tanto, podemos afirmar que el logro de dichos objetivos se interrelaciona con las necesidades de inversiones en una gestión eficiente de los recursos hídricos y, más específicamente en la $\mathrm{SH}$, tal y como quedó definida en el Capítulo I: "la capacidad de una población para salvaguardar el acceso sostenible a cantidades adecuadas de agua de calidad aceptable para el sostenimiento de los medios de vida, el bienestar humano y el desarrollo socioeconómico; para garantizar la protección contra la contaminación transmitida por el agua y los desastres relacionados con el agua, y para la conservación de los ecosistemas en un clima de paz y estabilidad política" (ONU Agua, 2013). También sabemos que invertir en seguridad hídrica incluye invertir en infraestructura y gobernanza y que no siempre las grandes inversiones representan la solución. Sin embargo, las inversiones en mejora de eficiencia, como se han realizado en Australia y Los Ángeles (EE. UU.), pueden representar un camino eficaz para lograr la Seguridad Hídrica. Australia optó por reducir pérdidas en los sistemas de distribución de agua, en vez de invertir en nuevas presas de almacenamiento bajando las expectativas de inversiones de US\$1.370/megalitro a US\$365/megalitro. Los Ángeles se ahorró US\$1.216/megalitro en la construcción de una planta desalinizadora al invertir solo US $\$ 41 /$ megalitro en programas de mejora de eficiencia y recuperación (Dickinson, 2018).

En este capítulo, se aborda el tema de SH para la región de ALC desde una perspectiva estratégica. Esta estrategia se ha denominado Agua para el Futuro. Se presenta una misión, una visión y unos objetivos estratégicos que pretenden avanzar en los retos de SH identificados en el diagnóstico discutido en el Capítulo II, capitalizar en la experiencia del BID en la región (Capítulo III) y aprovechar las oportunidades de innovación presentadas en el Capítulo IV.

\section{V.1 Misión y Visión}

Misión Institucional

Desde el 2012, el BID es el principal prestador multilateral para el sector público de América Latina y el Caribe ${ }^{41}$. Esta ventaja comparativa, junto con la mayor apropiación por los países prestatarios y su histórico de actuación, otorgan al BID un gran potencial para influir sobre el diseño de políticas y programas en la región.

La Estrategia Institucional del BID reconoce que, "para responder a una demanda cada vez mayor, asociada a un crecimiento más lento, una posición fiscal más ajustada en la región y la dificultad creciente de actuar de manera contra-cíclica, el BID necesitará concentrarse en las operaciones con mayor efectividad, aumentar su enfoque en la movilización de recursos y diseñar instrumentos que permitan el mayor apalancamiento posible de su capital existente. Se reconoce un déficit anual de inversiones en infraestructura del

41 Informes anuales del Banco Mundial, BID y CAF. 
Sólo para infraestructura, las necesidades anuales de financiamiento están alrededor de US\$170.000 millones orden de US $\$ 170.000$ millones y que la banca multilateral de desarrollo debe ir más allá de las actividades tradicionales, en particular si se considera la necesidad de invertir en medidas para crear resiliencia y una estructura institucional más robusta para gestionar el riesgo de desastres y los peligros relacionados con el cambio climático".

La Estrategia Institucional refuerza el objetivo de la resiliencia climática en el proceder del BID y ofrece las condiciones para el apoyo a los países con el cumplimiento de los acuerdos internacionales de cambio climático (Acuerdo de Paris) y planes nacionales específicos y/o generales de desarrollo. Los avances en esta área incluyen: el financiamiento de un 30\% de las aprobaciones combinadas del grupo BID para el 2020, la aprobación del Plan de Acción Conjunto para el Cambio Climático (PACCC) y la creación del NDC Invest. EI PACCC establece las conexiones con las directivas de la Estrategia Institucional identificando cómo hacerlas más efectivas, operativamente, con la perspectiva del cambio climático. Por su parte, el NDC Invest tiene como objetivo apoyar a los países de la región para que puedan transformar sus NDC en planes de inversión.

Este amplio marco de actuación del grupo BID crea oportunidades, pero no garantiza resultados, porque depende de la demanda de los países del apoyo propuesto y de la disponibilidad de recursos. Sólo para infraestructura, las necesidades anuales de financiamiento están alrededor de US $\$ 170.000$ millones, mientras que la cantidad total anual que el BID presta a los países es de US\$10.000 millones. Aunque la capacidad del BID de apalancar recursos privados sea del orden de dos a cinco veces su aportación, no es fácil visualizar resultados contundentes de acciones para lograr la SH. En estas circunstancias, es necesaria una nueva forma de focalizar las acciones del Banco para que sean más efectivas y eficientes. Como el agua (ya sea por exceso o defecto) refleja los impactos del cambio climático, y considerando que los países más pobres son los más afectados, trabajar desde la perspectiva de SH teniendo en cuenta el nexo agua-agricultura-energía-ciudades, puede optimizar las acciones de cambio climático, infraestructura sostenible, agua y saneamiento, agricultura y medio ambiente resaltando la función de ecosistemas estratégicos, energía y desarrollo urbano. Esta es una estrategia alineada con la Estrategia Institucional y existe soporte empírico que justifica su implementación ${ }^{42}$. Así, el Banco deberá incluir entre sus objetivos estratégicos el apoyo a los países para lograr la $\mathrm{SH}$, definiendo acciones basadas en una visión integral y a partir del conocimiento de los nexos pertinentes en cada caso.

\section{Visión}

Como se ha expuesto en el Capítulo II, la región de ALC dispone de fuentes de agua que, gestionadas de manera sostenible, permitirían alcanzar la SH

42 GWP/OECD. (2015). Securing Water Sustaining Growth, Informe de la Fuerza de Tarea para la Seguridad Hídrica y el Crecimiento Sostenible del GWP/OECD. 

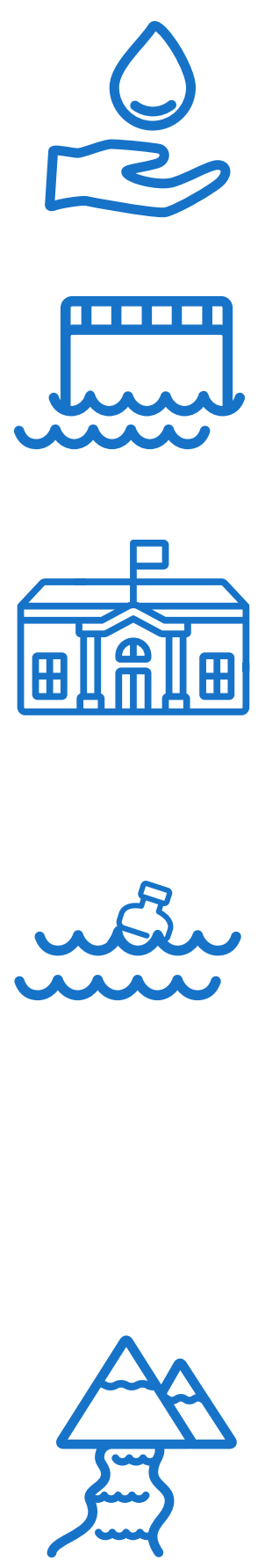

(atender las necesidades de su población, garantizar su desarrollo económico sostenible y con equidad y conservar las funciones de los ecosistemas de las cuencas, amparados por un marco legal e institucional que permita la gestión de riesgos asociados a extremos hidroclimáticos de sequías e inundaciones).

Para materializar esta visión es necesario:

- Invertir en abastecimiento de agua potable y saneamiento, con vistas a la cobertura universal de agua potable y recolección y el tratamiento y reúso de aguas servidas, utilizando soluciones tradicionales e innovadoras y teniendo en cuenta que invertir en mejorar la eficiencia y recuperación de sistemas existentes representa una alternativa factible a la construcción de nuevos sistemas.

- Invertir en infraestructura eficiente para garantizar las necesidades y/o controlar excesos de agua. Esta infraestructura debe ser diseñada teniendo en cuenta el nexo existente entre agua-agricultura-energía y sus consecuencias en los planes nacionales, subnacionales y de cuenca de desarrollo económico sostenible preparados, considerando aspectos de cambio climático.

- Modernización de la gestión de recursos hídricos que incluya un marco legal y la creación de instituciones eficientes y relevantes para insertar el tema como prioritario en la elaboración de los planes de desarrollo sostenible de los países, principalmente de los más vulnerables, y permitir la preparación, aprobación e implementación de estrategias de $\mathrm{SH}$ a nivel nacional, subnacional y de cuenca, incluyendo los planes de sequías y de control de inundaciones correspondientes.

- Elaborar una agenda de prevención de contaminación por ingreso de residuos sólidos a cuerpos de agua, con el fin de preservar calidad del recurso. Esto facilitaría la gestión hidráulica del recurso al minimizar riesgos de interrupción e interferencia en canales y drenaje. Esta agenda debe enfocarse en tres ejes fundamentales: (a) prevención de generación de residuos y componentes específicos (por ejemplo, microplásticos y macroplásticos), (b) manejo adecuado de residuos sólidos, que minimice el ingreso de residuos a los cursos de agua mediante una gestión adecuada que comprenda el reciclaje efectivo, el tratamiento y una disposición final adecuada; y (c) captación e intercepción de residuos sólidos en áreas de cuencas costeras, para prevenir contaminación de salida a cuencas y océanos.

- Generar el conocimiento necesario sobre el funcionamiento de las SBN, incluyendo las funciones de las planicies de inundaciones de los ríos, para aumentar el abanico de estrategias para la conservación de la cantidad y la calidad del agua.

- Desarrollar modelos de financiamiento de la gestión de recursos hídricos basados en un acuerdo nacional que garantice la sostenibilidad de las 


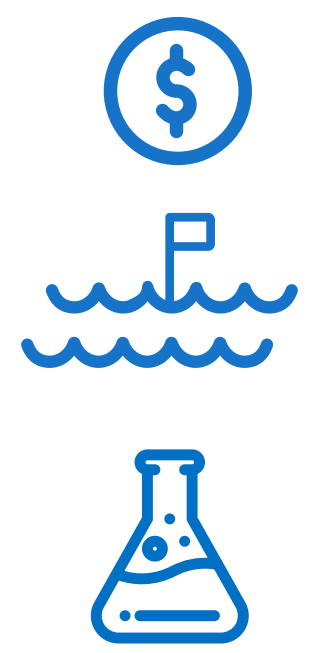

instituciones y los sistemas de gestión implementados.

- Creación de un marco adecuado para la discusión pacífica y el desarrollo de soluciones para el uso compartido de aguas internacionales, contribuyendo así a la SH y al desarrollo sostenible de los países involucrados.

- Apoyar el desarrollo de conocimiento en las áreas de ciencia y tecnología centradas en información, datos y modelos predictivos de mayor precisión y confiabilidad para apoyar la toma de decisiones en los sectores socioeconómicos involucrados y afectados por la SH (agua y saneamiento, agricultura, energía...).

\section{V.2 Objetivos estratégicos}

Para avanzar con la visión propuesta, el grupo BID trabajará con los gobiernos nacionales, el sector privado, las ONG ambientales y de la sociedad civil, universidades y otros donantes y financiadores del desarrollo de la región. Este esfuerzo conjunto impulsará la implementación de objetivos estratégicos que conformarán las bases y los soportes necesarios para lograr la SH a nivel nacional, regional y local.

Los objetivos estratégicos seleccionados están alineados con el ODS 6 (Agua limpia y Saneamiento).

Así, el objetivo estratégico principal es garantizar, para el año 2030, la disponibilidad de agua y su gestión sostenible y el saneamiento para todos. Más específicamente:

- Lograr el acceso universal y equitativo al agua potable, a un precio asequible para todos.

- Lograr el acceso equitativo a servicios de saneamiento e higiene adecuados para todos y poner fin a la defecación al aire libre, prestando especial atención a las necesidades de las mujeres y las niñas, así como de las personas en situación vulnerable.

- Mejorar la calidad del agua mediante la reducción de la contaminación, la eliminación del vertimiento y la reducción, al mínimo, de la descarga de materiales (macro y micro materiales) y productos químicos peligrosos. Esto incluye una estrategia de residuos sólidos que fomente la prevención (por ejemplo, eliminar los microplásticos en productos de consumo cotidiano), el manejo adecuado de residuos-reciclaje, el tratamiento y disposición final adecuada, así como la intercepción (captura de materiales en áreas costeras para impedir su traspaso a sistemas mayores), la reducción a la mitad del porcentaje de aguas residuales sin tratar y un aumento sustancial del reciclado y la reutilización en condiciones de seguridad a nivel mundial.

- Aumentar sustancialmente la utilización eficiente de los recursos hídricos en todos los sectores y asegurar la sostenibilidad de la extracción y el abas- 
tecimiento de agua dulce para hacer frente a la escasez, reduciendo de forma importante el número de personas que sufren de escasez de agua.

- Poner en práctica la gestión integrada de los recursos hídricos a todos los niveles, incluso mediante la cooperación transfronteriza, según proceda.

- Para 2022, proteger y restablecer los ecosistemas relacionados con el agua, incluidos los bosques, las montañas, los humedales, los ríos, los acuíferos y los lagos.

- Ampliar la cooperación internacional y el apoyo prestado a los países en desarrollo para la capacitación en actividades y programas relativos al agua y al saneamiento, incluidos el acopio y almacenamiento de agua, la desalinización, el aprovechamiento eficiente de los recursos hídricos, el tratamiento de aguas residuales y las tecnologías de reciclaje y reutilización.

- Apoyar y fortalecer la participación de las comunidades locales en la mejora de la gestión del agua y el saneamiento.

De este objetivo estratégico principal pueden derivarse una serie de objetivos estratégicos más específicos, expuestos a continuación.

\section{Objetivo estratégico 1}

Lograr y sostener el abastecimiento con agua potable y la provisión de servicios de recolección, tratamiento y disposición final de aguas servidas al $100 \%$ de la población.

En el Capítulo II se presenta una discusión extensiva sobre los niveles de cobertura de servicios de agua y saneamiento en la región de América Latina, que se resume en la Tabla 5.1.

Tabla 5.1. Niveles de cobertura de servicios de agua y saneamiento en ALC

\begin{tabular}{|c|c|c|c|}
\hline Tipo de cobertura ${ }^{43}$ & $\%$ & $\begin{array}{l}\text { Población no servida } \\
\text { (en millones) }\end{array}$ & $\begin{array}{l}\text { Objetivo Agenda } \\
2030 \text { (en \%) }\end{array}$ \\
\hline $\begin{array}{l}\text { Cobertura de agua } \\
\text { potable (promedio) }\end{array}$ & 95 & - & - \\
\hline $\begin{array}{l}\text { Cobertura de agua } \\
\text { segura }\end{array}$ & 68 & 198 & 100 \\
\hline $\begin{array}{l}\text { Cobertura de servicio } \\
\text { de saneamiento en } \\
\text { promedio }\end{array}$ & 68 & & \\
\hline $\begin{array}{l}\text { Cobertura real } \\
\text { de servicios de } \\
\text { saneamiento }\end{array}$ & 22 & 457 & 100 \\
\hline \multicolumn{4}{|c|}{$\begin{array}{l}\text { Los efectos y el impacto de la falta y/o deficiencia en el abastecimiento de } \\
\text { agua potable, así como de la no provisión de servicios de saneamiento ade- }\end{array}$} \\
\hline \multicolumn{4}{|c|}{ 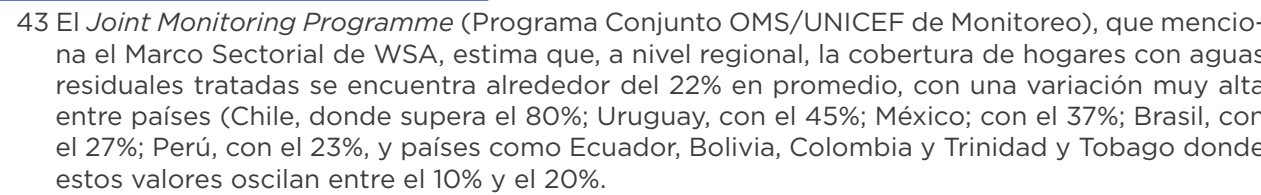 } \\
\hline
\end{tabular}


cuados, en la salud, la productividad, el PIB nacional y en la educación están bastante difundidos en la literatura. El Marco Sectorial de Agua y Saneamiento de la División de Agua y Saneamiento del BID provee una revisión extensiva de este tema ${ }^{44}$, que también ha sido objeto de una revisión conjunta realizada por la GWP y la OCDE ${ }^{45}$, donde se presentan resultados de estudios específicos para varios países. En estos documentos se destaca el impacto positivo de la provisión de servicios adecuados de agua y saneamiento a mujeres y niñas, que reafirma la dignidad, mejora el acceso a la educación y al mercado laboral y contribuye a la reducción de la violencia de género.

\section{Indicadores de resultados}

Algunos indicadores de resultados de la implementación adecuada de este objetivo podrían ser:

- 124 millones de personas conectados a sistemas de abastecimiento de agua segura y $\mathbf{1 9 6}$ millones de personas conectadas a sistemas adecuados de recolección y tratamiento de aguas servidas.

- 9.000 toneladas de DBO5 (Demanda Biológica de Oxígeno) no son descargadas diariamente a los cursos de agua de la región.

- $\mathbf{5 0} \%$ de incremento en la disponibilidad de recursos financieros públicos y privados para financiar la expansión de los servicios de agua y saneamiento.

\section{¿Qué acciones emprender para la consecución de este objetivo?}

Teniendo en cuenta la experiencia del BID en el sector de agua y saneamiento, se incluyen las siguientes acciones:

- En una primera instancia, priorizar los países de menor cobertura con servicios de agua y saneamiento y drenaje urbano: Bolivia, El Salvador, Guatemala, Haití, Nicaragua, Perú y República Dominicana. En un segundo momento, trabajar con ciudades pequeñas de países como Brasil, a través de préstamos a los Estados. En el Brasil, por ejemplo, el 32\% de la población vive en municipios con menos de 50.000 habitantes ${ }^{46}$, que no son priorizados por el gobierno para recibir préstamos del BID.

- Trabajar a nivel de cuencas prioritarias incorporando los planes maestros de agua, saneamiento y drenaje a los planes de gestión integrada de cuenca y/o de SH.

- Incentivar la recuperación, reducción de pérdidas, mejora de eficiencia y reúso frente a la construcción de nuevos sistemas de agua, saneamiento y drenaje.

- Incluir en los préstamos a las Empresas de Agua y Saneamiento (EAS) la preparación de planes de SH y de seguridad física de las instalaciones,

44 Banco Interamericano de Desarrollo (2017). Documento de Marco Sectorial de Agua y Saneamiento. División de Agua y Saneamiento.

45 GWP/OECD (2015). Securing Water Sustaining Growth. Informe de la Fuerza de Tarea para la Seguridad Hídrica y el Crecimiento Sostenible del GWP/OECD.

46 Agência Nacional de Águas-ANA. (2010). Atlas Brasil: Panorama Nacional-Volume 1, Abastecimento Urbano de Água. 
un asunto de gran relevancia en el momento actual de cambio climático y crecimiento de riesgos exógenos al sector (ASCE/AWWA, 2006). Asimismo, también es urgente apoyar a las EAS para que participen en el financiamiento de la protección de las cuencas productoras de agua y que incorporen el concepto industrial en su proceso de producir agua, protegiendo su insumo básico, optimizando su proceso, tratando sus residuos y reciclando lo máximo posible, teniendo siempre en cuenta las necesidades de los ecosistemas involucrados y de los servicios que estos proveen.

- Apoyo a las EAS para que desarrollen planes efectivos de comunicación que hagan que, tanto los actores implicados en el proceso como la población general, asuman e interioricen que el cambio climático es una realidad y que la seguridad hídrica se construye con la participación y la responsabilidad de todos.

- Apoyar a los países para que creen las condiciones que incentiven la participación del sector privado en la provisión de los servicios de agua y saneamiento. Este trabajo involucra al sector privado del Grupo BID y debe ser precedido por un esfuerzo de comunicación e intercambio de experiencias con otros países, patrocinado por varios organismos multilaterales además del BID, que difundan las lecciones aprendidas y la importancia de la implicación del sector privado, sin el cual no será posible alcanzar los objetivos deseados.

- Realizar alianzas con donantes (EI BID ya trabaja con fondos de varios países, pero hay que captar más recursos) y otros multilaterales para focalizar las acciones en las zonas críticas identificadas en este estudio $\mathrm{y}$, consecuentemente, maximizar los impactos positivos en los tiempos establecidos.

\section{Objetivo estratégico 2}

Incentivar el desarrollo de marcos legales e institucionales adecuados para la gestión efectiva de los recursos hídricos teniendo como meta la SH, el manejo de los riesgos asociados y el desarrollo económico sostenible.

Como se ha visto en el Capítulo II, la región carece de un ámbito de normatividad propio de la $\mathrm{SH}$ como tal. Actualmente es un régimen que debe construirse y componerse a partir de distintos marcos regulatorios o legislaciones sectoriales que convergen en determinados aspectos como los de aguas, energía, ambiente, ordenamiento territorial, agua potable y saneamiento, riesgos, emergencia, defensa, etc. También reconocemos que la $\mathrm{SH}$ depende de la demanda de agua y de la efectividad del modelo de gobernanza, lo que obliga a incluir una serie de elementos adicionales a la gestión convencional de los recursos hídricos que normalmente son considerados por separado. Las condiciones, arreglos institucionales o mejores prácticas a incorporar en una política pública de SH pueden esquematizarse alrededor de cinco ejes 
Según algunas estimaciones, los problemas derivados del agua podrían reducir las expectativas de crecimiento económico entre un $6 \%$ y un $15 \%$ que se encuentran concatenados en el diseño completo de esa política pública (planificación, normatividad, institucionalidad, economía e instrumentos y cuencas internacionales) y de los que ya se ha hablado en la Sección 3 del Capítulo IV de este informe (Oportunidades de Innovación dentro del Marco Institucional para la Seguridad Hídrica).

El crecimiento económico de los países de la región se beneficiará de un sistema robusto de gestión de los recursos hídricos que garantice la SH. Existen estimaciones del Banco Mundial para el 2050 que indican que la contaminación del agua, la creciente demanda y la escasez de manantiales podrían reducir la expectativa de crecimiento económico de algunas regiones en torno a un 6\% del PIB y que, en algunos países, esta reducción puede llegar hasta el $15 \%{ }^{47}$.

\section{Indicadores de resultados}

Posibles indicadores de resultados de la implementación adecuada de este objetivo, hasta el 2030, serían:

- Todos los países en la región cuentan con políticas, legislación y estructura institucional a nivel local y nacional para la gestión integrada de los recursos hídricos y la promoción de la Seguridad Hídrica.

- Todos los países en la región tienen desarrollados planes de SH nacionales, subnacionales y a nivel de cuenca amparados por una legislación específica y ejecutados con instituciones adecuadamente equipadas y con fuentes de recursos garantizadas.

- 15 cuencas y acuíferos transfronterizos de la región que cuentan con tratados multilaterales o específicos.

\section{¿Qué acciones se recomiendan para desarrollar los marcos legales e institucionales?}

Desde el punto de vista jurídico, las pautas para la implementación de este objetivo están desarrolladas en los capítulos II y el capítulo IV (Sección 3). Teniendo en cuenta algunas experiencias del BID con la modernización institucional en la región, se recomienda:

- Promover la adopción de una legislación de aguas en aquellos países que no la posean todavía y en aquéllos que, aun teniéndola, esta sea antigua y no recoja los elementos de planificación, participación social, régimen económico-financiero y otros de los contenidos recomendados en este informe.

- Promover un debate amplio con todos los niveles de gobierno para demostrar la relación entre el uso y la valoración del recurso del agua y los resultados de los planes de desarrollo económico del gobierno en un contexto de cambio climático. Esto podría hacerse a través de cursos y 
seminarios basados en resultados de estudios específicos para el país seleccionado. Se recomienda igualmente utilizar resultados y conclusiones de estudios como nexo agua-agricultura-energía y/o sistemas de cuentas ambientales para el agua, para apoyar el desarrollo de políticas de gestión apropiadas y para demostrar cómo los riesgos de origen hidroclimático pueden afectar las expectativas de crecimiento económico. Este debate debería comenzar en los países de áreas con mayor afectación prevista por los modelos hidroclimáticos (Figuras 2, 3 y 4): cuenca del Amazonas, norte de México, noroeste de Brasil, el Caribe y América Central.

- Desarrollar planes de comunicación específicos, dirigidos a actores claves y la población en general, para lograr su participación efectiva en los planes y programas que se refieren a la SH. Es importante que se entienda que la búsqueda de la SH es una nueva realidad que afecta a todos y que requiere el esfuerzo de todos para lograrla. Estos planes deben incorporar una visión integral de la situación que incluya variables culturales, tradiciones históricas, situaciones económicas y sociales específicas, perspectivas individuales y colectivas y el ambiente físico.

- Realizar experiencias piloto en al menos tres países de la lista de áreas más vulnerables a fenómenos hidroclimáticos.

- Incentivar la coordinación entre los países para planificar conjuntamente el uso de aguas transfronterizas, fortaleciendo las instituciones existentes, o creando nuevas, y los mecanismos necesarios para ello.

- Utilizar la SH como instrumento de aproximación y de fortalecimiento del diálogo entre los países.

\section{Objetivo estratégico 3}

En el marco de la SH, promover la seguridad alimentaria y la generación de energía renovable a partir de la planificación y el desarrollo de proyectos integrales multipropósito que contemplen necesidades de desarrollo, mejoras y seguridad de la infraestructura hídrica.

\section{Objetivos sectoriales vs. Perspectiva multipropósito}

Tradicionalmente, la construcción de presas para almacenar agua ha tenido objetivos sectoriales: controlar inundaciones estacionales, abastecer estructuras de riego para producir alimentos, abastecer de agua a ciudades y pueblos o generar energía para usos diversos. Algunos proyectos incluyen una perspectiva de multiuso o multipropósito almacenando agua para consumo humano y riego (Programa Multipropósito de agua potable y riego para los municipios de Batallas, Pucarani y El Alto) y otras incluyen generación de energía y otros usos como abastecimiento poblacional, riego, recreación y conservación ambiental (Hoover Dam en Estados Unidos).

Aspectos positivos vs. Aspectos negativos

La construcción de presas tiene impactos positivos para la SH como almace- 
En 2010, ALC aportó el $18 \%$ del comercio de materias primas agrarias y el $12 \%$ de productos alimentarios en el mundo nar agua para períodos de sequías y control de inundaciones, producir energía y mantener caudales mínimos en los cursos de agua; pero también pueden desplazar a personas de sus hogares, cambiar la ecología de los cursos de agua de ambientes lóticos a lénticos ${ }^{48}$, disminuir la extensión de importantes planicies de inundación, que en muchos casos abrigan lagunas marginales (las cuales contribuyen al repoblamiento de la fauna existente en los cursos de agua), y generar pérdidas por evaporación de sus lagos artificiales. No obstante, el crecimiento poblacional, a nivel regional y mundial, supone un aumento de la demanda de alimentos y de energía para impulsar y sostener la economía de los países. Estos aumentos apuntan a necesidades de incremento en las fuentes de agua (en aquellos casos en que las condiciones físico-climáticas lo permitan) o a una mayor regulación del agua, ya sea a través de la implantación de nuevos embalses, la rehabilitación de aquellos en uso o la utilización de SBN como las que se han descrito en el Capítulo IV.

En lo que se refiere a la agricultura y producción de alimentos, algunos estimados indican que, en 2010, ALC aportó el 18\% del comercio de materias primas agrarias y el $12 \%$ de productos alimentarios en el mundo. Entre los países a los que exporta, pueden destacarse China, Israel, Japón, la mayoría de los países de la Unión Europea y toda la región del Oriente Medio y Norte de África. Las estimaciones de la FAO indican que unos cuatro millones de hectáreas podrían ser incorporadas a nuevos sistemas de riego en Argentina Brasil, Chile, México, Perú, Colombia y Bolivia y que, por su antigüedad, entre ocho y diez millones de hectáreas necesitan de rehabilitación en Argentina Brasil, Chile, México y Perú. Estas tendencias sugieren un mayor consumo de agua que, en este sector, ya representa más del $70 \%$ de la demanda total.

El uso de la energía hidroeléctrica en América Latina es un componente importante de la matriz energética, llegando a representar casi el 100\% en Costa Rica, seguida de Brasil (donde ronda el $80 \%$ de la demanda) y de Ecuador, Perú y Colombia (donde supone más del 70\%) (Tundisi et al. 2014). Para atender la creciente demanda de energía se estima que, para el 2030, podrían rehabilitarse 26 grandes presas ubicadas en Brasil, Argentina, Colombia, México, Perú y Venezuela para generar $55.765 \mathrm{Mw}$ a un costo de US $\$ 70.000$ millones, así como otras presas menores, elevando el potencial rehabilitado a $60.684 \mathrm{Mw}$, a un costo de US $\$ 130.000$ millones. Adicionalmente, se estima que la construcción de nuevas presas podría agregar $35.640 \mathrm{Mw}$ a un costo de US $\$ 198.000$ millones. Por otro lado, de forma más ambiciosa, se han planificado para los próximos 20 años, más de 150 grandes presas en seis de los ocho principales afluentes del Amazonas, lo que produciría un aumento del $300 \%$ en la generación de electricidad (Finer y Jenkins, 2012 y Anderson et al., 2018). En el Brasil, la cuenca del Amazonas se ve como la "nueva frontera hidroeléctrica” donde 100 presas están operativas y se planean 137 adiciona-

48 Un ambiente lótico hace referencia al ecosistema de un río, arroyo o manantial, en los que las aguas fluyen hacia alguna dirección. Contrastan con los ecosistemas lénticos en el que las aguas se encuentran relativamente estancadas, como los lagos o estanques. 
A la par con la construcción y rehabilitación de presas, y teniendo en cuenta las consecuencias de una eventual rotura (especialmente de estructuras con años de funcionamiento ${ }^{49}$ ), es fundamental incluir dentro de este objetivo estratégico, la revisión y el análisis de la seguridad de las presas anexas al aprovechamiento hidroeléctrico. Asimismo, es necesario disponer de un marco legal sobre seguridad de presas y contar con unas normas de explotación que contemplen i) los protocolos de vigilancia y control, ii) los protocolos de conservación y mantenimiento, y iii) los protocolos de la propia explotación, en situación normal y en avenidas, con fijación de resguardos estacionales y protocolos de alerta. Ante el riesgo de rotura potencial, debería proponerse la redacción de un Plan de Emergencia que, activado desde las Normas de Explotación, estableciera los indicadores, umbrales y estados de emergencia, con todo un protocolo de alerta a las poblaciones que pudieran resultar afectadas y comunicación a las autoridades regionales y de protección civil.

\section{Indicadores de resultados}

Algunos posibles indicadores de resultados de la implementación adecuada de este objetivo serían:

- Basándose en estudios hidroclimatológicos que consideran el nexo agua-agricultura, la búsqueda de eficiencia y la $\mathrm{SH}$, se ha incorporado, para el 2030, un 30\% en la producción de alimentos a la cosecha de Brasil, Chile, México, Perú, Colombia y Bolivia, a través de la rehabilitación de diez millones de hectáreas de proyectos de riego. También se incorporan cuatro millones de nuevos proyectos de riego al sistema productivo de estos países, teniendo en cuenta impactos de cambio climático sobre los ciclos hidrológicos locales.

- Para el 2030, se han incorporado 154.089 Mw de energía al potencial producido en América Latina, a través de la rehabilitación de 26 presas hidroeléctricas de grande porte; varias de menor porte (con potencial recuperable de $60.684 \mathrm{Mw}$ ) y la construcción de nuevas unidades (con un potencial de $35.640 \mathrm{Mw}$ ).

- Para el 2030, todos los países de América Latina cuentan con legislación y protocolos específicos para la gestión de sus presas.

49 Por ejemplo, el impacto del rompimiento de dos presas de la compañía Vale do Río Doce (Mariana, en el 2015 y Brumadinho, en enero de 2019) provocó el fallecimiento de más de 100 personas y ocasionó pérdidas de millones de dólares. Quedó contaminada toda la extensión del río Doce y un área importante de playas en el Estado de Espirito Santo, en el 2015 y unos 40 kilómetros del río Paraopeba, en el 2019. 
Con pocas excepciones, la mayoría de los ríos urbanos de la región están extremamente contaminados
Objetivo estratégico 4

Incentivar la recuperación de la calidad y la creación de reservas estratégicas de agua para garantizar la SH.

\section{Ríos urbanos extremadamente contaminados}

La contaminación de aguas superficiales y acuíferos, principalmente en los ambientes urbanos y periurbanos, es parte de la realidad de la población de ALC. Con pocas excepciones, la mayoría de los ríos urbanos de la región están extremamente contaminados. Los ejemplos son constantes y pueden encontrarse cada día en la literatura y medios de comunicación: Tiete, en Sao Paulo; Bogotá, en Bogotá; Matanza-Riachuelo y Reconquista, en Buenos Aires; Guaire, en Caracas; Capibaribe, en Recife o Rimac, en Lima. En México, según CONAGUA, seis de sus diez ríos están contaminados ${ }^{50}$. Entre ellos se incluyen: el Balsas, Santiago, Pánuco, Grijalva, Papaloapan, Coatzacoalcos y Tonabá. Se añaden las siguientes cuencas con cursos de agua contaminados: en Chile, las de los ríos Maipo, Biobío, Elqui y Loa; en Colombia, las cuencas del Cauca y el Magdalena; en Paraguay, el lago Ypacarai y los ríos Paraná y Paraguay; en Venezuela, el río Murillo; en Perú, el río Ucayali y, en Costa Rica, las cuencas de los ríos Tarcoles y Virilla. Asimismo, el Ministerios de Medio Ambiente y Recursos Naturales en El Salvador, tiene catalogados al 20\% de sus cauces como de mala condición ambiental, con indicadores de contaminación por descargas orgánicas y de organismos patógenos ${ }^{51}$. Informaciones similares están disponibles para otros países y/o regiones. Por ejemplo, el $A t-$ las de Esgotos de la Agencia Nacional del Agua de Brasil indica que 110.000 km de ríos brasileños están contaminados por materia orgánica proveniente mayoritariamente de subproductos de la actividad urbana (www.ana.gov.br).

A la contaminación de origen doméstica hay que añadir: i) las descargas industriales que, además de materia orgánica, incluyen en sus efluentes sustancias tóxicas y metales pesados; ii) los flujos de retorno de los proyectos de riego, con sus cargas elevadas de sales y la contaminación proveniente de la actividad minera, que incluye los pasivos ambientales mineros ${ }^{52}$ y son muy comunes en Perú, Brasil, Chile y Bolivia. Por ejemplo, la mencionada rotura de las presas brasileñas en Mariana (2015) y en Brumadinho (2019) involucran pasivos antiguos una vez que los efluentes del proceso de minería son almacenados en presas específicas y muchas veces no existen planes para su recuperación.

50 CONAGUA, "Atlas de Agua”, 2016.

51 MARN. (2014). Informe de la calidad de las aguas de los ríos de El Salvador 2012-2013. Ministerio de Medio Ambiente y Recursos Naturales (MARN), El Salvador.

52 La legislación peruana define pasivo ambiental minero como aquellas instalaciones, efluentes, emisiones, restos o depósitos de residuos producidos por operaciones mineras en la actualidad abandonadas o inactivas, y que constituyen un riesgo permanente y potencial para la salud de la población, el ecosistema circundante y la propiedad. http://www.legislacionambientalspda.org.pe/index.php?option=com_content\&view=article\&id=387\&ltemid=3724 
Una estrategia prometedora para controlar los efluentes industriales es la coordinación con el sector privado del BID y con los programas de los gobiernos

\section{Trabajar con el sector privado}

El BID, a través de su ventanilla del sector público, ha concedido préstamos para la descontaminación de cursos de aguas, fundamentalmente urbanos, con ejecutores diversos y niveles de éxito variados. Así se han ejecutado proyectos junto a empresas de saneamiento (Proyecto Tiete, ejecutado por SABESP en Sao Paulo, Brasil), organismos provinciales (Reconquista en Buenos Aires, Argentina) y gobiernos centrales (PROSAMIM en Manaus, Brasil). También se ejecutan las obras de saneamiento (redes de alcantarillado, plantas depuradoras...) de control de inundaciones, y se implementa el fortalecimiento de las instituciones. Pero en lo que se refiere al control de la contaminación industrial se implementa poco. Las unidades ejecutoras públicas no tienen jurisdicción sobre las industrias del sector privado y los sistemas nacionales y locales de aplicación de la legislación específica son débiles. Como consecuencia de esto, el componente de control de la contaminación industrial queda sin ejecutar o se ejecuta, solo en parte (es el caso del Proyecto Rio Reconquista en Argentina, que está en su segunda fase y se desconoce el número total de industrias contaminantes en la cuenca). La descontaminación de los ríos urbanos no se logra sin el control de los efluentes industriales, de los flujos del drenaje urbano y los vuelcos de residuos sólidos clandestinos. Por lo tanto, para lograr dicho objetivo, hay que repensar el diseño de las operaciones y, quizás, trabajar junto con el sector privado del grupo BID. Además, para controlar la contaminación industrial, son necesarios recursos financieros que no siempre están disponibles y que no pueden ser asignados a partir del sector público del BID. Una estrategia prometedora, en este sentido, incluye el trabajo por cuencas y el control simultaneo de todas las fuentes de efluentes relacionadas con la administración pública (cloacas, drenaje urbano y residuos sólidos), así como la coordinación con el sector privado del BID y con los programas de los gobiernos para controlar los efluentes industriales. La ejecución de los componentes del sector público puede transformarse en una forma de "presión" y/o motivación para que los industriales se incorporen a los objetivos del proyecto.

Invertir en monitoreo y modelos de simulación

Efectivamente, cualquier estrategia de seguridad hídrica debe empezar por proteger las cuencas productoras de agua en buen estado y recuperar la calidad de los ríos y/o cuencas contaminadas. Garantizar la SH es absolutamente incompatible con el hecho de tener ríos o cuencas contaminadas. Son esfuerzos opuestos. Para recuperar la calidad del agua es necesario invertir en monitoreo 53 , modelos de simulación de calidad del agua bajo distintos escenarios, incluyendo los efectos del cambio climático, y en estructura de soporte como laboratorios e instrumental para procesar la información generada y divulgarla a través de un sistema de información de libre acceso. Resulta especialmente destacable el monitoreo del exceso de nutrientes en el agua, que intensifica los fenómenos de eutroficación y el riesgo de apa-

53 Este tema será discutido en un objetivo estratégico específico para monitoreo y generación de información para toma de decisión. 
rición de cianobacterias (aún más en contexto de cambio climático). Dado que los costos de extracción de estos nutrientes son más altos que los asociados a prevenir su vertido a los cuerpos de agua, se recomienda que, junto al monitoreo, se lleven a cabo inversiones para mejorar la tecnología de uso del fosforo y el nitrógeno en la agricultura, minimizando su presencia en la escorrentía superficial. Un ejemplo de esto puede ser la inyección directa en las raíces de las plantas (Daverede et al., 2004; Jarvis et al., 1996).

\section{Fondos y reservas estratégicas de agua}

Las experiencias con la creación de reservas estratégicas de agua, bien sea a través de los Fondos de Agua o programas como el mexicano (Reservas Estratégicas de Agua) o el brasileño (Productores de Agua), se describen en los capítulos II, III y IV. Concretamente, en el capítulo III se presenta una evaluación de los fondos de agua donde se resaltan sus fortalezas, su importancia $\mathrm{y}$ algunas necesidades de fortalecimiento.

\section{¿Qué hacer para recuperar la calidad del agua?}

Se concluye que este es un programa que debe de ser perfeccionado y expandido complementariamente a un programa de reserva estratégica de agua con una clara sostenibilidad financiera. En este sentido se propone:

- Continuar el apoyo a la creación de los Fondos de Agua e incentivar el desarrollo de estudios y modelos que demuestren su eficacia, con indicadores robustos que reflejen las mejoras planteadas, así como la atracción de nuevos recursos para consolidar su sostenibilidad financiera.

- Animar a los países a crear programas nacionales de reservas estratégicas de agua teniendo en cuenta la consecución de la SH y el cambio climático.

- Facilitar la difusión horizontal y norte-sur de las experiencias con creación de reservas estratégicas de agua con el enfoque de seguridad hídrica en el contexto del cambio climático.

- Incentivar programas integrales de descontaminación de cuencas estratégicas, que incluyan oportunidades de participación a la iniciativa privada ( $p$. ej. incentivos para que las industrias traten sus efluentes con negociación de metas realistas para implantar acciones de control).

- Apoyar la inclusión de programas integrales de descontaminación de cuencas en los planes nacionales, regionales y locales de SH.

- Apoyar la incorporación de las cuencas urbanas en la planificación del territorio teniendo en cuenta las funciones de los ecosistemas en el control de inundaciones y mantenimiento de la calidad del agua.

- Crear un sistema de premiación para los ríos urbanos más limpios de ALC que incluya la participación ciudadana.

- Fomentar el desarrollo de programas de comunicación que relacionen la descontaminación de las cuencas con el logro de la SH. 
- Fomentar la ampliación de las redes de monitoreo de calidad del agua incluyendo el uso de sistemas de teledetección vinculados a sistemas de información geográfica y a técnicas de gestión de bases de datos.

- Apoyar la implantación de laboratorios capacitados y certificados para realizar análisis de calidad del agua en los países y cuencas estratégicas.

- Desarrollar y difundir tecnología de modelos de calidad del agua, monitoreo en tiempo real, planes de control de la calidad del agua de la fuente a la canilla y gestión de información.

Indicadores de resultados

Algunos posibles indicadores de resultados de la implementación adecuada de este objetivo serían:

- Para el 2030, se ha incrementado la recuperación de cuencas productoras de agua en un área de 30.000 hectáreas a través de la creación de reservas estratégicas de agua en 10 países en el marco de los planes nacionales de $\mathrm{SH}$.

- Para el 2030, se ha recuperado la calidad del agua de cien mil kilómetros de ríos en cuencas estratégicas de los países, a niveles compatibles con el tratamiento convencional.

- Para el 2030, se ha premiado a 10 ciudades por recuperar la calidad de sus ríos a los niveles de calidad sin contaminación.

La gestión efectiva de los recursos hídricos requiere de información y datos confiables, modelos matemáticos de soporte y recursos humanos y financieros

\section{Objetivo estratégico 5}

Modernizar los mecanismos y métodos de obtención de información y de apoyo a la toma de decisiones para la SH.

Necesidad de información confiable

La gestión efectiva de los recursos hídricos requiere de información y datos confiables, modelos matemáticos de soporte y recursos humanos y financieros. Esta demanda de información confiable es aún más crítica bajo el enfoque de SH y la influencia del cambio climático, cuando los riesgos asociados a eventos extremos son mayores.

Varios países de la región (Argentina, Brasil, Colombia, Perú y otros) han avanzado en la expansión y modernización de sus redes de información de datos, principalmente aquellas relacionadas con la cantidad del agua. No obstante, en los diálogos BID-países, son comunes las solicitudes de apoyo para expandir la red y operar estaciones hidroclimáticas (Programa de modernización de los recursos hídricos de Perú) y no son raras las solicitudes de apoyo para la implementación de equipos de procesamiento de datos y realización de previsiones de corto, mediano y largo plazo (Apoyo al Centro Internacional para la Investigación del Fenómeno El Niño-CIIFEN ubicado en 
Guayaquil, Ecuador). Sin embargo, el mantenimiento de las estaciones fijas es financiado por los gobiernos que, en función de sus prioridades cambiantes, dejan a menudo que estas se deterioren comprometiendo la calidad de la información generada.

En este contexto, agregando las responsabilidades inherentes a un compromiso con la $\mathrm{SH}$, es necesario desarrollar instrumentos para el monitoreo, in situ y vía teledetección, de la cuenca, los acuíferos y los ecosistemas acuáticos. Aunque, como ya se ha mencionado, se han producido avances, sobre todo en redes de pluviometría, de aforos y de piezometría ${ }^{54}$, la densidad de la red de estaciones de medición de la calidad del agua está por debajo de lo deseable. También existe una brecha de conocimiento muy importante que hay que cubrir. Por eso es imprescindible promover la utilización de técnicas de análisis y fusión de datos para que además de detectar las deficiencias, permita priorizar proyectos de mejora y ampliación de las redes existentes, incluyendo variables como su valoración, forma de financiación, etc. Así se podrá, en el mediano plazo, contar con estaciones y datos confiables.

Todo esto implica hacer inversiones de conocimiento, no solo en monitoreo sino en análisis de datos, y el apoyo para implantar: (i) una red de estaciones de aforo en aguas superficiales; (ii) una red de piezometría en acuíferos; (iii) una red de estaciones de control de la calidad de aguas superficiales; (iv) una red de control de la calidad de las aguas subterráneas; (v) una red climatológica (pluviómetros, temperatura, evaporación y viento); (vi) una red de control de vertidos. Todas estas redes deben incluir bases de datos de medidas in situ y medidas vía teledetección. También, es necesario disponer de una cartografía digitalizada de la red fluvial que permita los estudios sobre inundaciones y sobre la que se pueda plasmar la cartografía digitalizada de zonas inundables. Finalmente, es importante contar con productos geoespaciales de información socioeconómica y ecológica, a fin de complementar las bases de datos para estas redes de monitoreo.

Como soporte a la toma de decisiones se utilizan modelos hidrológicos, climatológicos, de calidad del agua (autodepuración de cursos de agua, transporte de nutrientes y contaminantes en el agua y en el suelo), de gestión de cuencas y de optimización para la selección de alternativas adecuadas de proyectos específicos. Bajo el enfoque de $\mathrm{SH}$, crece significativamente la demanda de modelos que simulen eventos extremos y que puedan ser validados o calibrados con relativa facilidad y de forma práctica. También aumenta la necesidad de crear interfaces entre los sistemas de obtención de información y los modelos correspondientes. El BID tiene una gran oportunidad de innovación en el ámbito de modelos de simulación que apoyen los procesos de toma de decisiones en problemas y proyectos relacionados con la SH en la región.

54 La piezometría es la parte de la hidrología que estudia los métodos para determinar la cantidad de agua (subterránea) existente en un lugar sobre una capa impermeable de un terreno. 
De hecho, la experiencia exitosa con el desarrollo del HydroBID a partir del 2011 y su aplicación a partir del $2014^{55}$, ha motivado la expansión de la experiencia y se ha desarrollado el HydroBID-Flood para el apoyo en proyectos de drenaje urbano, inundaciones y diseño de infraestructura hidráulica. HydroBID simula el balance hídrico superficial y subterráneo e incluye un modelo de "downscaling" climático, sin embargo, todavía no incluye otros componentes de la SH como la calidad de agua, los servicios ecosistémicos, la hidráulica de acuíferos (en desarrollo), las sequías, las inundaciones (HydroBID Flood), los programas de riego, las demandas del sector energético y otros componentes.

Debido a su extensa experiencia y penetración en la ALC, el BID puede apoyar sus clientes con el desarrollo de herramientas punta para apoyar la toma de decisiones a nivel nacional, regional, estatal y municipal/local. Asimismo, los diferentes aspectos de la SH podrían ser cubiertos complementariamente por una serie de modelos integrados. De esta manera, se puede estructurar una línea de apoyo en la parte hidrológica (HydroBID), con modelos de planificación multisectorial nexo (GCAM-LAC), modelos de servicios ecosistémicos, modelos urbanísticos, demográficos, socioeconómicos o cualquier otro componente necesario (utilizando modelos existentes o desarrollando herramientas propias del BID); todo ellos desarrollado de manera evolutiva y con una interacción permanente con los usuarios potenciales de estos modelos (organismos de los gobiernos, universidades, institutos de investigación, ONG y otros).

Para impulsar el movimiento hacia la SH en la región es importante crear una demanda de proyectos y acciones afines
Crear la demanda a través de las "cuentas ambientales del agua"

Para impulsar el movimiento hacia la SH en la región, en un contexto en el que los objetivos económicos y sociales son vistos como prioritarios, es importante crear, en los países de ALC una demanda de proyectos y acciones afines. Dicha demanda se puede impulsar a través de demostraciones del valor económico de la $\mathrm{SH}$ y su vínculo con los objetivos económicos y sociales. Este es un campo abierto a la contribución del Banco, bien sea a través del desarrollo de las "cuentas ambientales del agua" o del desarrollo de modelos económicos que vinculan las cuentas nacionales con los insumos estratégicos como el agua, bajo múltiples escenarios plausibles de cambio climático.

\section{Indicadores de resultados}

Algunos indicadores posibles de resultados de la implementación adecuada de este objetivo serían:

- Para el 2030, se toman decisiones relacionadas con aspectos de SH basadas en información confiable y en el uso de modelos específicos desarrollados con el apoyo del BID (especialmente en las cuencas estratégicas de los países con mayor vulnerabilidad al cambio climático). 
- Para el 2030, 20 países de la región toman decisiones relacionados con la SH utilizando modelos desarrollados con apoyo del BID.

- Para el 2030, la información hidroclimatológica generada por todos los países de ALC cumple con los requisitos de la Organización Meteorológica Mundial (OMM) y son difundidas para uso público.

- Para el 2030, todos los países de ALC dispone de informaciones adecuadas de calidad del agua (superficial y subterránea) y las utilizan en acciones de descontaminación de ríos y conservación de fuentes de agua.

El desarrollo de modelos para la toma de decisiones relacionadas con la $\mathrm{SH}$ obedece a demandas específicas de los países y/o a la percepción de su necesidad por parte de los equipos del BID (caso de HydroBID) y de las constantes interacciones con las contrapartes. Para modernizar los sistemas de monitoreo y de procesamiento de la información generada es necesario una operación de préstamo del BID (debido a los montos de recursos necesarios). Estos recursos son incluidos en préstamos al sector de saneamiento o para la gestión de cuencas. Cuando se incluyen en los préstamos a las empresas de saneamiento, la implantación de sistemas de monitoreo es ejecutada por el sector correspondiente y es necesario un traspaso de recursos, lo cual no siempre es fácil. Por otro lado, los financiamientos para gestión de cuencas son de bajo monto y de ejecución compleja, por lo tanto, no son muy atractivos para el BID. Una posible solución pasaría por desarrollar proyectos integrales de descontaminación de cuencas, los cuales permiten incluir varias ciudades con varias obras de infraestructura con sinergias importantes que permitirían implantar sistemas de monitoreo y desarrollar sistemas de gestión, planes de SH, planes de sequía y planes de control de inundación. Los ejecutores podrían ser los estados o el organismo rector del sector de recursos hídricos y/o medio ambiente.

\section{Objetivo estratégico 6}

Fomentar el desarrollo de conocimiento e innovación para garantizar la SH.

Para enfrentar el desafío que representa la $\mathrm{SH}$ es necesario estar abiertos a nuevas áreas del conocimiento y emprender una constante innovación que involucre aspectos técnicos, éticos, conceptuales y de comunicación. Las necesidades de conocimiento se manifiestan en toda la cadena de la gestión de los recursos hídricos, que incluye la protección de reservas estratégicas, la provisión de agua potable, la obtención de información y el desarrollo de instrumentos para la toma de decisiones y de planes de acción para enfrentar situaciones críticas de sequía e inundación.

El Marco Sectorial de la División de Agua y Saneamiento incluye algunos temas de innovación seleccionados como importantes para el sector de agua y saneamiento, como tecnologías SWIFT (Sustainable Water Initiative For Tomorrow) para reducir agua no contabilizada y en el aspecto social y de género. 
El enfoque innovador de la Gestión Integral del ciclo del agua

En esta estrategia, el enfoque innovador propuesto para resolver los problemas de SH en la región se basa en el concepto central de gestión del ciclo del agua (frente a una gestión basada en la asignación de recursos hídricos disponibles entre varios sectores).

A este concepto de gestión contribuye i) la incorporación de la demanda hídrica integrada para diversos usos de manera explícita en la gestión efectiva de la $\mathrm{SH}$, en el marco de cambio climático y planificación multisectorial (nexo); ii) combinaciones de infraestructura gris y verde que provean mayor eficiencia, confiabilidad y costo-efectividad a la prestación de servicios de agua y saneamiento enfatizando las SBN; iii) la modernización del marco institucional para abrigar el enfoque de $\mathrm{SH}$ adaptando los espacios de política y de toma de decisiones y su integración con la gestión de otros recursos naturales ( $p$. ej. nexo con energía, agricultura, biodiversidad o cambio climático, entre otros); y iv) realizar inversiones en conocimiento e implementación de nuevos conceptos y avances en $\mathrm{SH}$.

El uso del concepto nexo en la planificación multisectorial ofrece oportunidades de innovación al vincular la SH con la seguridad energética y la seguridad alimentaria, dos áreas objeto de intensa actividad por parte del BID y los países de la región. En la práctica, esto se traduce, por ejemplo, en inversiones multisectoriales (como embalses multipropósito, que incorporan elementos de infraestructura natural -SBN- y proyecciones de cambio climático para robustecer los sistemas diseñados y facilitar su resiliencia climática y su sostenibilidad). La experiencia demuestra que al considerar el nexo agua-energía-alimentos en estudios de demanda de agua pueden detectarse demandas no cuantificadas en estudios sectoriales; estas diferencias pueden llegar al 35\% en algunos casos (Miralles-Willhem y Muñoz Castillo, 2018). Estos esfuerzos deben continuar y ser perfeccionados debido al potencial que tienen para optimizar los programas y proyectos que incluyen infraestructura y desarrollo de políticas específicas.

\section{Combinar infraestructura gris e infraestructura verde}

Un enfoque innovador de SH necesita de soluciones que combinen infraestructura construida (gris) y natural (verde) que puedan reducir la vulnerabilidad y aumentar la resiliencia y confiabilidad de los sistemas de abastecimiento de agua para diversos usos. El tema de la infraestructura no puede disociarse de la cuestión ambiental si la meta es la gestión eficiente y sostenible del ciclo del agua. Dado el gran "capital natural" que existe en toda la región de ALC, esta combinación de infraestructura construida y verde constituye un eje principal de innovación en materia de SH para la región. Por lo tanto, se propone un enfoque de gestión del ciclo del agua que combine la infraestructura hídrica tradicional con capital natural (SBN). Para ello es necesario evaluar las experiencias del uso de SBN en lo que se refiere a i)gestión y protección de nacientes; ii) provisión de agua y saneamiento; iii) sistemas de riego para la producción de alimentos; iv) generación de hidroelectricidad; y v) protección y prevención de riesgos de desastres de origen hídrico. 
La creación de reservas estratégicas de agua y los fondos de agua (www. waterfunds.org) son ejemplos de protección de nacientes y/o fuentes de agua con bastante aceptación en la región. El uso de las veredas (planicies de inundación) de ríos urbanos como parques lineales, no solo ha incorporado dichos ríos a la planificación urbana sino que ha contribuido a controlar inundaciones (es el caso del ya mencionado proyecto PROSAMIM en Manaus). El abanico de oportunidades que ofrece trabajar con los ecosistemas para lograr objetivos de SH es amplio y se extiende i) al manejo de bofedales en la Puna andina, ii) al uso de planicies de inundación para el control de inundaciones que contribuyan, también, al mantenimiento de la productividad del ecosistema rivereño, iii) el mantenimiento de caudales ecológicos y del flujo de agua que aportan a embalses, que contribuyen a la generación de hidroelectricidad y/o al riego. En este sentido, es importante evaluar las experiencias existentes y evaluar su escalabilidad para reproducción en otras regiones. Asimismo, es primordial recorrer las lecciones aprendidas con el uso de las SBN en el tratamiento de agua para abastecimiento y de aguas servidas para remoción de contaminantes y posible reúso.

\section{Promover conocimiento sobre SBN}

Considerando que las SBN son específicas para cada ecosistema, hay mucho trabajo de identificación de áreas con potencial para desarrollar soluciones basadas en la naturaleza y su correlación con necesidades reales de control de sequía, control de inundaciones y protección de reservas de agua en el marco de la SH. En un esfuerzo importante para proveer a los países de soluciones e instrumentos para atender las metas del Acuerdo de Paris, ya existe literatura con orientaciones para iniciar la utilización de SBN ${ }^{56}$. El perfeccionamiento de estos instrumentos y su uso, en el marco de la expansión del conocimiento sobre el impacto del funcionamiento de ecosistemas específicos en el cambio climático, forma parte de esta estrategia de $\mathrm{SH}$ y de las actuaciones futuras del grupo BID.

\section{Fomentar un cambio institucional}

Frente a este desafío surge otro mayor, representado por la necesidad de un cambio institucional que incluya políticas, leyes y administración de los recursos hídricos. Los análisis del BID y del Banco Mundial reconocen que, en la región, aún se utilizan políticas y un marco institucional característico de una era de excedentes hídricos cuando estamos entrando en una era de escasez. En este contexto, acciones como primar soluciones ingenieriles, el tratamiento del agua como un bien sin costo y la asignación y el manejo burocrático del agua son inconsistentes con la realidad actual. Además, debido a los importantes vínculos que tiene el agua con el resto de la economía, el análisis de los problemas relacionados con esta ya no puede estar confinado a un sector específico (Saleth y Dinar, 2004). Como identificamos en el

56 Banco Mundial. (2019). Integrating Green and Gray: Creating Next Generation Infrastructure y Banco Mundial. (2017). Implementing Nature Based Flood Protection: Principles and Implementation Guidance. 
capítulo IV, este cambio incluye temas institucionales cruciales relacionados con aspectos legales, políticos y administrativos del desarrollo y la gestión de los recursos hídricos. Es conocido en economía institucional que el cambio ocurre solo cuando el costo transaccional de la reforma es menor que el costo de oportunidad de no hacer nada (Saleth y Dinar, 2004).

En un contexto donde diferentes actores se van incorporando a la gestión del agua (ONG, sociedad civil, poblaciones originarias...), es en el ámbito institucional donde se requiere de una mayor creatividad e innovación para lograr la SH. Para realizar cambios efectivos y armónicos con la nueva realidad en la gestión del agua será necesario un proceder "quirúrgico" de diagnóstico situacional y el convencimiento e involucramiento de los actores para transformarse en conductores de los mecanismos que representan este nuevo conocimiento colectivo. $Y$ todo ello a través de un potente proceso de participación pública. Es importante entender los vínculos institucionales de cada país y cómo se encuentran movilizados frente a necesidades de cambio en la gestión del agua. Este es un desafío que requiere un convencimiento de la necesidad del cambio en los más altos niveles de la administración del país, así como la participación de técnicos altamente especializados en cambio institucional.

Se propone priorizar los países y cuencas más vulnerables al cambio climático (Brasil, México, Perú, Chile y algunas áreas de América Central y el Caribe) ${ }^{57}$ para implantar proyectos piloto y probar soluciones innovadoras que utilicen SBN para: i) el control de inundaciones, ii) el establecimiento de caudales ecológicos, iii) la protección de fuentes de agua y iv) la realización de análisis de las instituciones responsables por la gestión del agua para proponer estrategias de transformación.

\section{Indicadores de resultados}

Algunos posibles indicadores de resultados de la implementación adecuada de este objetivo serían:

- Para el 2023, el BID habrá desarrollado guías específicas para la evaluación de los ecosistemas que podrían ser utilizados como infraestructura verde en cuencas estratégicas, en relación con la SH y el cambio climático.

- Para el 2030, tres países tendrán implementadas SBN en algunas de las áreas mencionadas; estas SBN estarán fundamentadas en las guías desarrolladas por el BID y su metodología estará ampliamente divulgada en la región.

- Para el 2023, el BID habrá desarrollado una metodología específica para el cambio institucional que evalúe a las instituciones involucradas en la gestión del agua. Esta metodología propiciará la generación de información cuantitativa para los tomadores de decisiones y tendrá en cuenta los vínculos con otras instituciones del país.

- Para el 2030, la metodología para la promoción del cambio institucional estará implantada en tres países y ampliamente divulgada en la región. 


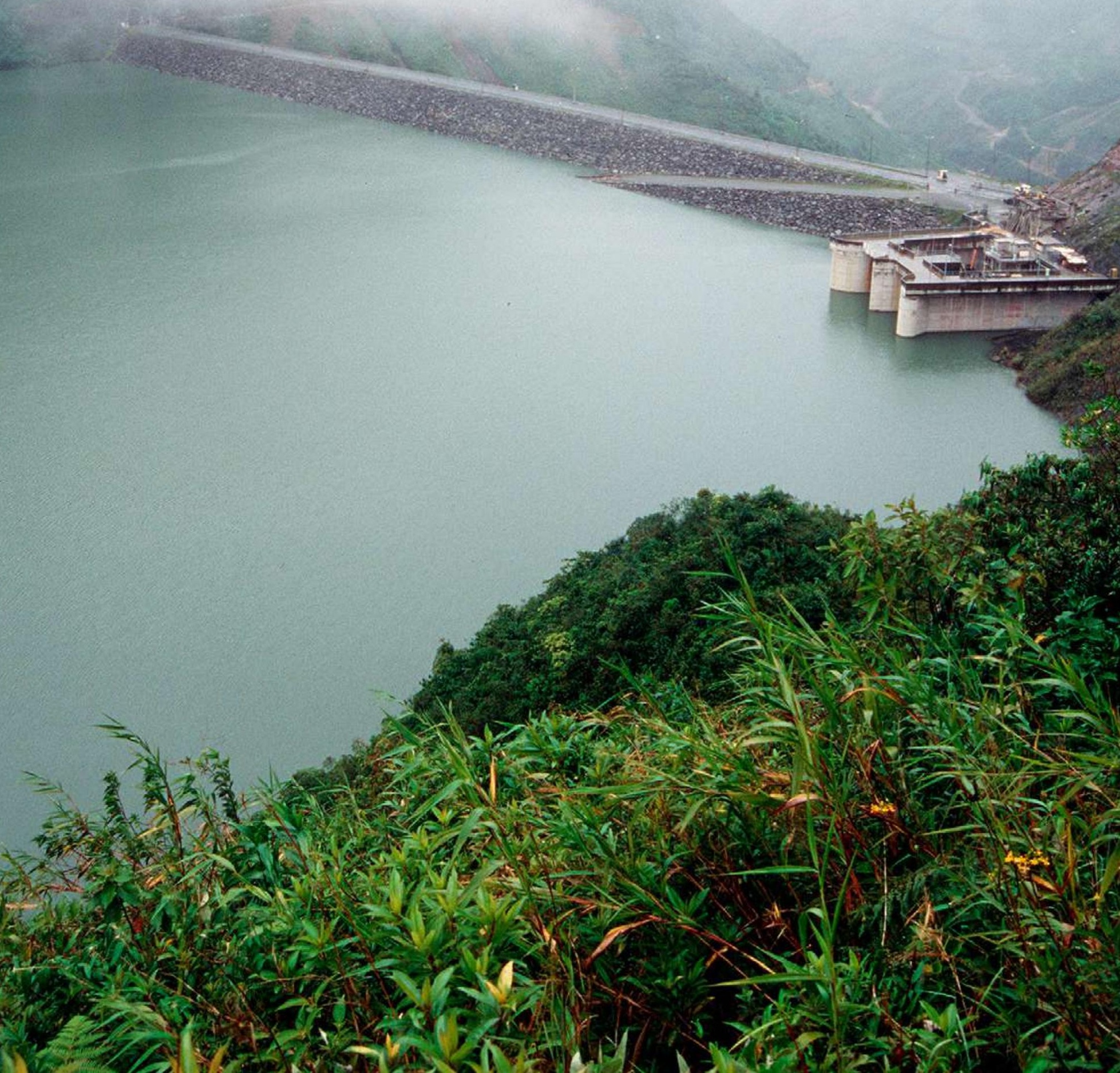




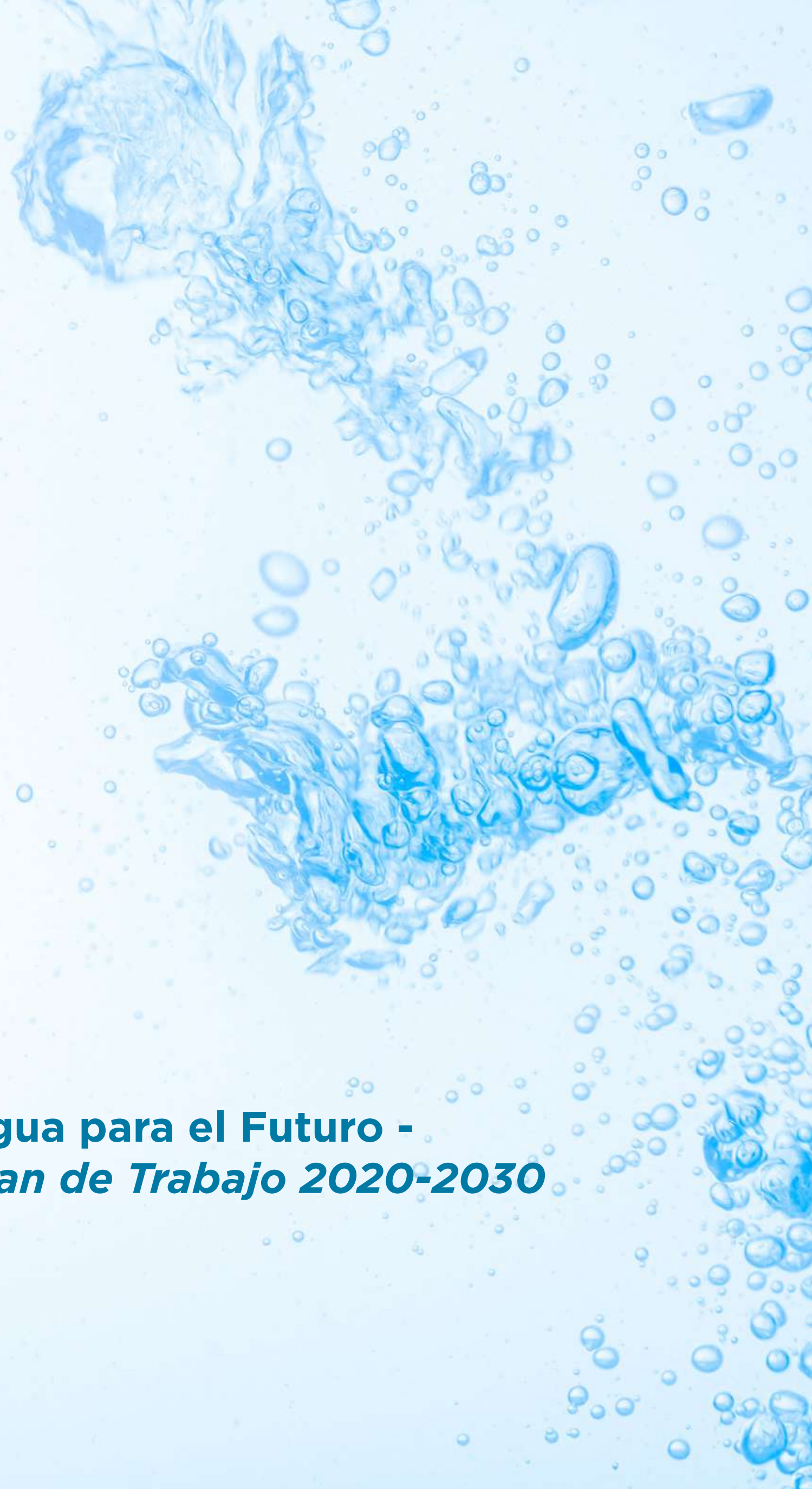


Para responder a los objetivos estratégicos propuestos, se ha diseñado un plan de trabajo, Agua para el Futuro, que puede iniciarse y empezar a ejecutarse desde el BID en los próximos 10 años.

$\triangle$ Este plan ha sido concebido para operacionalizar un programa de inversiones en materia de SH y proponer un portafolio de actividades de cooperación técnica para donantes del BID. Consiste en una serie de programas multisectoriales de inversión que integran actividades de políticas, infraestructura (gris y verde), conocimiento y creación de capacidades para "sembrar" el concepto de SH en los países de la región.

Los programas integrados de inversión se centran en la elaboración de planes nacionales de SH (Programa 1), planes urbanos de SH (Programa 2), plan para el subsector de riego (Programa 3), la consolidación y mejora de la generación hidroeléctrica (Programa 4) y las cuencas transfronterizas (Programa 5).

Los programas de conocimiento están focalizados en las Soluciones Basadas en la Naturaleza (Programa 6), los estudios sobre sequías (Programa 7) y las inundaciones (Programa 8), la definición del régimen de caudales ecológicos (Programa 9), la consolidación y mejora de las redes de monitoreo en campo y teledetección (Programa 10) y el desarrollo de modelos de simulación y apoyo a la toma de decisiones (Programa 11).

Los programas de inversión propuestos en este plan de trabajo para la SH tendrán impactos positivos medibles en la región en lo que respecta al desarrollo sostenible, con beneficios visibles a corto plazo.

Este plan debe considerar el grado de incertidumbre existente en torno a la SH (debido a la variabilidad hidrológica, el cambio climático y los cambios sociales y políticos). Por eso la formulación de políticas púbicas, planes y programas de inversión deben ser fuertes y adaptables.

\section{Agua para el Futuro - Plan de Trabajo 2020- 2030}

L n este capítulo se esboza un plan de trabajo que puede iniciarse y empezar a ejecutarse en los próximos 10 años (2020-2030). Este plan, que responde a los objetivos estratégicos expuestos en el capítulo anterior, toma en consideración el diagnóstico de la situación actual presentada en el Capítulo II, la experiencia del BID resumida en el Capítulo III y las oportunidades de innovación discutidas en el Capítulo IV.

El plan de trabajo de Agua para el Futuro consiste en una serie de programas multisectoriales de inversión que integran actividades de políticas, infraestructura (gris y verde), conocimiento y creación de capacidades para "sembrar" el concepto de SH en los países de la región. Este plan ha sido concebido para operacionalizar un programa de inversiones en materia de $\mathrm{SH}$ y proponer un portafolio de actividades de cooperación técnica para donantes del BID. Los programas de inversión propuestos en este plan también tienen en cuenta las consultas realizadas durante la preparación de este documento a través de dos talleres sucesivos: uno, desarrollado en Washington, con funcionarios del BID (24-25 de septiembre de 2018) y otro celebrado en Quito, con varios clientes del Banco en la región (2223 de octubre de 2018). La agenda de estos talleres se incluye en el Anexo E.

En el Anexo $\mathbf{F}$ se ha desarrollado una metodología para el cálculo de las inversiones en infraestructura hídrica a grandes niveles territoriales, así como una evaluación de los costos de operación y mantenimiento necesarios para que los programas propuestos dentro de este plan mantengan su funcionalidad y contribuyan a la mejora de la SH y a la adaptación frente el cambio climático. Esta cartera de inversiones propuestas se ha estimado para que la región alcance los objetivos de la Agenda 2030 de Desarrollo Sostenible de las Naciones Unidas (https://sustainabledevelopment.un.org/post2015/ 


\section{EN CLAVE}

Los indicadores de progreso en materia de SH no están aún suficientemente desarrollados a nivel mundial por lo que es material pendiente en la implementación de este plan de trabajo. Avanzar en el tema de SH requiere de la definición de indicadores de servicio y de riesgo aceptables y factibles de alcanzar para la región, así como también del establecimiento de una línea base comparativa entre países y con otras regiones del mundo.

La implementación de este plan requerirá de apoyo a los países del BID en materia de gestión del cambio. El mundo entero se encuentra en un proceso de aprendizaje sobre cómo poner en práctica, medir y gestionar la SH. Esto va a requerir de una serie de actividades de apoyo, tales como generación de estudios de caso concretos, intercambios sur-sur para compartir lecciones aprendidas, y mecanismos para incentivar los cambios en marcos legales e institucionales necesarios para la transformación que propone la SH. transformingourworld). El Cuadro 6.1 resume un estimado de las necesidades de inversión para este programa. Estas cifras se han comparado con cifras obtenidas por entidades como la CEPAL en términos de porcentaje del PIB de la región, observándose que están en el orden de magnitud, lo que les confiere cierta credibilidad y factibilidad.

Del análisis realizado se desprenden las siguientes prioridades interdependientes en materia de $\mathrm{SH}$ :

- Abastecimiento urbano: las mayores inversiones serán necesarias en el sector del abastecimiento urbano, especialmente en saneamiento y tratamiento de aguas residuales. Teniendo en cuenta la tendencia al aumento del porcentaje de población urbana en la región y el importante problema de contaminación al que están sometidas una buena parte de sus cuencas, para avanzar en materia de $\mathrm{SH}$ se necesita vincular los planes maestros sectoriales de agua y saneamiento urbanos a planes de gestión de cuenca. Habitualmente, estos planes se encuentran desvinculados.

- Agua segura: es imprescindible extender la cobertura de agua segura a toda la población, tema que sigue pendiente debido, fundamentalmente, al alto volumen de inversión que requiere. Esto debe abordarse corrigiendo las deficiencias que se observan en las redes existentes y ampliando la red para que el agua pueda alcanzar al 100\% de la población. Este tema ya está siendo trabajado desde el BID, y ha empezado a ser complementado con temas asociados a cambio climático y resiliencia para robustecer la cobertura de los servicios.

- Subsector riego: dado su rol como principal usuario de los recursos hídricos, es indispensable contar con un programa proactivo de actuación del Banco en el subsector de riego. Este programa debe abordar la eficiencia en el uso de los recursos al mismo tiempo que garantice la seguridad alimentaria, y debe incluir la modernización de la infraestructura de riego existente y el desarrollo de nuevos sistemas de riego, con énfasis en acciones encaminadas a reducir la contaminación que provocan y potenciando los programas de ayuda y formación del agricultor. 
- Sector hidroeléctrico: garantizar la capacidad de producción de energía de la región, y que esta se produce de forma sostenible, a través de inversiones en el sector hídrico y energético (enfoque nexo), conectadas con las metas de mitigación y de adaptación al cambio climático, que combinen diversas formas de energía renovable: hidroeléctrica, eólica, solar, biomasa y otras. Los ejes de intervención se dirigen tanto a la rehabilitación de la infraestructura existente, como al diseño de nuevos aprovechamientos.

- Gestión de riesgos: implementar mejoras en la prevención, preparación y mitigación de los impactos de fenómenos extremos, específicamente de sequías e inundaciones, mediante el lanzamiento de dos subprogramas: a) planes de sequía de cuenca y de los sistemas de abastecimiento urbano significativos y b) elaboración de los Planes de Gestión del Riesgo de Inundación, también por cuenca, con atención a los programas de Protección Civil.

- Mejora del conocimiento y desarrollo de redes de captura y diseminación de la información hídrica, su almacenamiento estructurado en bases de datos y desarrollo de herramientas para el apoyo a la toma de decisiones en el sector, partiendo de lo que ya se ha logrado en este campo en el BID y trabajando más de cerca con otros sectores: innovación, agricultura, energía, urbano, extractivas y otros.

- Marco institucional y legal: todo esto ha de estar acompañado por un paquete de actividades dirigido al establecimiento de un marco institucional y legal que garantice que las acciones que se emprendan para hacer frente a los retos enunciados sean operativas y se puedan llevar a término.

Cuadro 6.1. Resumen de Necesidades de Inversión en Seguridad Hídrica en ALC (en miles de millones US\$)

\begin{tabular}{|c|c|c|c|}
\hline Subsector & 2010-2025 & $2025-2030$ & $\begin{array}{l}\text { Acumulado } \\
2020-2030\end{array}$ \\
\hline Abastecimiento urbano & 228 & 163 & 391 \\
\hline Saneamiento & 415 & 297 & 712 \\
\hline Tratamiento de aguas residuales & 36 & 26 & 62 \\
\hline Total Subsector abastecimiento urbano & 679 & 486 & 1.165 \\
\hline Modernización de sistemas de riego existentes & 38 & 27 & 65 \\
\hline Nuevos sistemas de riego & 23 & 43 & 66 \\
\hline Total Subsector de riego & 61 & 70 & 131 \\
\hline Rehabilitación de grandes centrales & 67 & 4 & 71 \\
\hline Rehabilitación resto de centrales existentes & 105 & 25 & 130 \\
\hline Implantación de nuevas centrales & 115 & 82 & 197 \\
\hline Total subsector hidroeléctrico & 287 & 111 & 398 \\
\hline Conocimiento (investigación, estudios, planes...) & 50 & 50 & 100 \\
\hline
\end{tabular}


El interés despertado en ALC por la Agenda 2030 de la ONU, particularmente la utilización de SBN y la adaptación al cambio climático, constituye una ventana de oportunidad para impulsar las acciones propuestas en este plan. Los esfuerzos organizativos, legales y financieros que han de emprender los países de la región son de enorme complejidad e intensidad, por lo que no se debe demorar su inicio. Los programas propuestos en este plan son de largo alcance temporal y pretenden formular una estrategia a ser ejecutada más allá de su duración. La aplicación particularizada en varias escalas de acción (cuenca, ciudad, país) dará lugar a proyectos específicos de inversión y/o cooperación técnica en los diferentes temas contenidos en el plan de trabajo propuesto.

\section{VI.1 Programas integrados de inversión: políticas e infraestructura}

\section{PROGRAMA 1: Programa de planes nacionales de SH a nivel de cuenca y acuíferos: disponibilidad hídrica, calidad de agua, protección de fuentes de agua y servicios ecosistémicos.}

Este primer programa está enfocado a robustecer la cantidad y la calidad de agua de las cuencas y los acuíferos, así como la protección de los ecosistemas que sirven como fuentes de agua y que prestan otros servicios ecosistémicos. El alcance de este programa es fomentar la realización de planes nacionales de SH enfocados en cuencas y acuíferos como unidades de gestión y acción.

EI BID ya interviene en este ámbito, particularmente en lo que se refiere a gestión de cuencas y cuenta en su cartera con actuaciones sobre la cuenca del lago Titicaca y del río Reconquista, entre otras.

Con este programa se pretende:

i) Dar importancia a la innovación en la cartera relacionada con la contaminación de las cuencas y acuíferos del BID y sus clientes, particularmente en lo que se refiere a la vinculación de los planes maestros sectoriales de agua y saneamiento urbanos con los planes de gestión en los que se tiene en cuenta el cambio climático de forma sistemática.

ii) Poner énfasis en la orientación multipropósito considerando la gestión integrada del ciclo del agua y todos sus usos, siendo preciso incluir en este programa todos los usos del agua que puedan coexistir en la cuenca o acuífero (servicios de agua y saneamiento, usos industriales y extractivos y los procedentes del sector agrario), pues sólo interviniendo en todos ellos se podrá aspirar al objetivo ${ }^{58}$.

58 No hay que olvidar que los antiguos vertidos mineros o industriales, con metales pesados y otros compuestos tóxicos, han podido contaminar los lechos de los ríos y los lagos, lo que obligaría, aunque en una fase posterior, dada su complejidad y coste, a tener que tratarlos para impedir que sigan contaminando las aguas y deteriorando el hábitat fluvial. 
iii) Avanzar en el establecimiento de redes de monitoreo (red de vertidos, red de estaciones de calidad, extensión de redes de aforo), en el registro de la información en bases de datos, y en la asimilación de estos datos en modelos predictivos y herramientas de apoyo a la toma de decisiones en un ámbito operativo, de forma que se cree una estructura que soporte el seguimiento del programa y las futuras intervenciones.

En los casos en que ya estén en curso acciones de este tipo ${ }^{59}$, el programa se podría reconvertir en una auditoría sobre el seguimiento del plan de descontaminación y su revisión, evaluando la eficiencia en la mejora de la calidad del ecosistema y revisando las medidas previstas, en el caso de que se revelen insuficientes.

Teniendo en cuenta que los estados son los primeros interesados en la protección de los ecosistemas, no habría que descartar el establecimiento de fondos de ayuda a las pequeñas instalaciones (agrícolas, industriales y extractivas) para que acometieran sus tratamientos.

Los criterios a seguir, tanto en la versión original como en la alternativa de auditoría, serían los siguientes:

- Selección de las cuencas y/o acuíferos sobre los cuales actuar. En el Capítulo II se ha ofrecido una relación de posibles cuencas contaminadas, que pueden servir de guía en la aproximación a los departamentos gubernamentales con competencia en materia ambiental de los países de ALC. Así mismo, este programa debe incluir un componente de identificación y priorización de acuíferos contaminados para acciones similares en sistemas de agua subterránea.

- Cada plan nacional de SH complementaría los componentes de un plan hidrológico tradicional (de cuenca y/o acuífero) con su vinculación a los planes maestros de servicios de agua y saneamiento para la población correspondiente. También deben incluirse en estos planes consideraciones de cambio climático, protección de los ecosistemas en las cuencas y acuíferos y e inclusión de SBN en la selección de la infraestructura a utilizar. El contenido técnico de estos planes se ha detallado en el Capítulo IV.

- Con esta visión integral se llevaría a cabo una acción multipropósito: a) extender la red de alcantarillado al 100 \% de la población de la cuenca; b) tratar los vertidos, sea cual sea su origen, no sólo los urbanos sino también los industriales y agrarios; c) alcanzar un estado del ecosistema con unas características físicoquímicas aceptables que permitieran su recuperación a niveles consonantes con los estándares internacionales. Deben incluirse medidas tendentes a la protección de estos ecosistemas,

59 Es el caso de la cuenca del río Bogotá, que pese a la sentencia del Tribunal de Cundimarca de 2004, todavía en 2018 se encuentra lejos de los objetivos perseguidos. 
a la espera de que futuras legislaciones más exigentes (por ejemplo, en la línea de la Directiva Europea) aborden un enfoque más integral del ecosistema, no sólo físicoquímico, sino también hidromorfológico y biológico.

- Se sugiere ampliar la utilización de herramientas de datos y simulación de calidad de agua y modelos ecológicos en la concepción y el diseño de este programa, de la misma forma que las herramientas de cantidad de agua (p. ej. HydroBID) se utilizan actualmente para los estudios de recursos hídricos y el establecimiento de balances hídricos. En el Capítulo IV y los anexos a este documento se han señalado algunos de los modelos de simulación de calidad de agua más utilizados en el mundo.

Los impactos esperados del cambio climático sobre el aumento en la temperatura promedio, así como en la frecuencia y amplitud de eventos extremos y la alta variabilidad de los ciclos hidrológicos constituyen un incentivo para que los países y las entidades regionales y locales se aboquen a mejorar significativamente la resiliencia climática en las cuencas y acuíferos, y se aproximen a un nivel deseable de SH. En la terminología de la Directiva Marco Europea, el tema más urgente en este sentido es "prevenir el deterioro de los ecosistemas acuáticos", es decir, que no empeore la calidad actual de sus servicios en tanto se van ejecutando las acciones para la recuperación. Ya algunos clientes del Banco en la región (p. ej., Perú) han empezado a crear demanda de planes de $\mathrm{SH}$ con un enfoque ecosistémico como elemento central.

\section{PROGRAMA 2: Programa de planes urbanos de Seguridad Hídrica}

Bajo este programa de inversión, las acciones deben orientarse a "lotes de ciudades" para aumentar la eficiencia del programa y su velocidad de aplicación. Hay que señalar que el BID ya tiene en su cartera actividades similares combinadas con otras actividades (p. ej. refuerzo institucional y marco legal-normativo, protección frente a sequías, etc.). Es el caso del Programa de ampliación y mejora para abastecimiento sostenible y resiliente de agua en ciudades principales de Bolivia y de otros similares que se han incluido en la revisión de la cartera del BID.

La prioridad de este programa sería la cobertura de agua al 100\% de la población, con consideración del suministro del recurso en calidad y cantidad y con el nivel de garantía exigible para el abastecimiento urbano. Esto implica la consideración explícita de la resiliencia de los servicios a través de la protección de fuentes, la compatibilización de planes maestros con los planes de cuenca y acuíferos correspondientes y el desarrollo de planes locales de protección frente a eventos extremos de sequías e inundaciones, con una clara consideración de cambio climático dentro de los ejercicios de planificación. 
Para lograr sus objetivos de total cobertura y abastecimiento, este programa debe abordar los siguientes aspectos:

i) Análisis del estado de la red y la necesidad de reposición de determinados tramos.

ii) Revisión del grado de implantación de contadores a los usuarios (micromedición).

iii) Análisis de porcentaje de agua no facturada con identificación de eventuales fugas o de fraudes de agua.

iv) Grado de implantación de la sectorización de la red.

v) Ampliación de la red en los asentamientos periféricos.

vi) Revisión de la red de depósitos, de su estado y, en su caso, necesidad de reparación o ampliación.

vii) Estudio de las tarifas con análisis de su influencia sobre los consumos.

viii) Evaluación de las demandas actuales y futuras.

Con respecto al suministro del recurso en cantidad y calidad, es necesario:

i) Desarrollar procesos y metodologías actualizadas de planificación hidrológica que acometan el análisis de la suficiencia y sostenibilidad de los recursos actualmente disponibles, para lo cual se ha de proceder al estudio de los recursos en las fuentes actuales de suministro (cuencas y acuíferos), con conocimiento de los caudales y de los parámetros de calidad.

ii) Determinar si las aguas en las tomas reúnen características de prepotabilidad y si las estaciones de tratamiento dispuestas antes de su ingreso en la red son suficientes para producir agua potable, así como los riesgos a los que están sometidas ante eventuales vertidos tóxicos de plantas industriales o extractivas situadas aguas arriba.

Con esta evaluación preliminar de la calidad, se procederá al estudio de la cantidad con la modelación del sistema hidrológico, que contemple los otros usos que compitan con el abastecimiento.

Como resultado de estos análisis se estará en condiciones de evaluar si las fuentes disponibles en la actualidad proporcionan recursos con la garantía adecuada en cantidad y calidad o si, por el contrario, es preciso acudir a la búsqueda de nuevas fuentes (en la misma cuenca o en otra próxima) y si se accede a fuentes de agua subterránea. Esto ha de ir precedido de un análisis de su disponibilidad y calidad y de los riesgos a que pueden estar sometidas estas fuentes. Seguidamente habría que abordar el análisis hidrológico de 
constituye un incentivo para superar los problemas organizativos y económicos que presenta el subsector.

\section{El programa de inversión propuesto debe estructurarse en tres grandes ejes:}

(i) Modernización de sistemas de riego: como señalamos en el Capítulo II, según FAO, entre 8 y 10 millones de hectáreas tienen suficiente antigüedad para ser objeto de modernización, tecnificando tanto sus sistemas hidráulicos en alta como la tecnología del riego y sus efectos sobre la red de distribución. Los países más susceptibles de acogerse a este programa de modernización son Argentina Brasil, Chile, México y Perú.

(ii) Desarrollo de nuevos sistemas de riego: es previsible que, en las próximas décadas, unos 4 millones de hectáreas hayan de ponerse en riego. Los países más susceptibles de demandar estos sistemas serían los citados en el párrafo anterior, a los que habría que añadir Colombia y Bolivia. Estos nuevos sistemas pasarían a ser parte de la cartera del BID, y deben ser coordinados con los programas de SH a nivel de cuenca (Programa 1) y los planes urbanos (Programa 2).

(iii) Refuerzo de los programas de ayuda al agricultor en materia de SH: El programa debe ir unido al refuerzo de la red de asesoramiento y apoyo al agricultor por parte de las instituciones de los departamentos de agricultura de los gobiernos, con especial impulso a las organizaciones rurales que, en definitiva, son las que están más cerca del agricultor. Esta medida es fundamental para reducir la contaminación del sector agrario debido a la gestión del uso de agroquímicos, dado que actualmente no es posible por razones económicas (falta de capacidad de pago del sector) para tratar las descargas agrícolas.

Sobre la financiación de este programa

Llegados a este punto, es preciso hacer algunas consideraciones que influyen en la financiación de este programa. Los sistemas de riego dedicados a la exportación son fundamentalmente de iniciativa privada y son los más rentables. Los destinados al consumo nacional son generalmente de iniciativa pública, aunque existe una tendencia bien marcada para transferir a los regantes la competencia y responsabilidad de su explotación y mantenimiento. Esta transferencia se ha completado en Chile, casi lo está en México y Perú y se encuentra en plena transferencia en Ecuador, Colombia y Guatemala. En Brasil, Venezuela y Panamá está en curso ${ }^{61}$. Cuando esta transferencia se complete podrán iniciarse contactos con las autoridades con competencia en la materia para identificar y priorizar las zonas regables sobre las que intervenir.

61 Proyecto FODEPAL, FAO 
Por otro lado, la escasa capacidad de pago de los agricultores complica el financiamiento de estas actividades, especialmente los de las zonas públicas (actuales o ya transferidas). Sin embargo, los países suelen ser los mayores interesados en los beneficios ambientales de la modernización de los sistemas de riego: de ahí la práctica de establecer ayudas con fondos públicos. Esto mismo ha ocurrido en España, donde en los últimos 20 años se han modernizado más de 1,5 millones de hectáreas destinadas al riego, y donde los agricultores han participado en el financiamiento de los proyectos y obras con porcentajes del orden del $50 \%$ en muy buenas condiciones financieras. El agricultor ha entendido que, si bien el ahorro del recurso y la menor carga contaminante no eran relevantes para él, sí lo era la mejora de su calidad de vida, al liberarlo de la esclavitud de los turnos de riego, noche o día, fines de semana y días festivos. Esa dualidad ha favorecido un consenso para que el Estado aportara una parte importante y el resto lo financiara el propio agricultor, con una gran flexibilidad por parte de las entidades financieras a la hora de facilitar los créditos a las comunidades de regantes.

El subprograma de modernización de sistemas de riego junto con el refuerzo institucional local de asesoramiento y apoyo al agricultor es combinable con el Programa 1 de lucha contra la contaminación por su influencia en la calidad de los ecosistemas. El subprograma de nuevos sistemas de riego se podría combinar con el Programa 2 para contemplar la incidencia de este uso competidor con el abastecimiento urbano en una visión más global de las cuencas y acuíferos como fuentes de agua. Por último, como en algunos casos, los sistemas de riego disponen de presas de regulación, también hay que remitirse a lo señalado en el programa siguiente (Programa 4) sobre la seguridad de presas.

\section{PROGRAMA 4: Programa de consolidación y mejora del rol de la generación hidroeléctrica con atención a la seguridad de presas multipropósito}

Actualmente, una de las funciones más apreciadas de la energía hidroeléctrica en la SH está relacionada con la mitigación del cambio climático, al ser una energía renovable, que permite contener la emisión de gases de efecto invernadero.

Las presas ofrecen tres vectores que las vinculan con la $\mathrm{SH}$ :

- Su valioso rol en el control de inundaciones, mediante la capacidad de almacenamiento.

- La posibilidad de establecer reservas para atender los abastecimientos urbanos durante períodos de sequía.

- El peligro de su potencial rotura, generando inundaciones de intensidades muy superiores a las naturales. Por ello este programa dedicado a las presas multipropósito ha de ir complementado con un subprograma de seguridad de presas. 
En relación con la hidroelectricidad, este documento ha establecido tres tipos de acciones: (i) la rehabilitación (por antigüedad) de grandes centrales existentes; (ii) la rehabilitación (por antigüedad) del resto de centrales existentes; y (iii) la implantación de un nuevo potencial hidroeléctrico, considerando las necesidades de electricidad, otras fuentes de generación y los impactos sociales y ambientales de las nuevas presas.

(i) Rehabilitación de grandes centrales existentes: se han identificado 26 grandes centrales susceptibles de ser modificadas para el año 2030 con una potencia global de $55.765 \mathrm{Mw}$. Las centrales se encuentran en Brasil, Argentina, Colombia, México, Perú y Venezuela. A efectos meramente orientativos, se puede indicar que la inversión estimada se eleva a unos 70.000 millones \$US.

(ii) Rehabilitación del resto de centrales existentes: el potencial identificado susceptible de ser rehabilitado para 2030 se eleva $60.684 \mathrm{Mw}$. En este caso, las presas no están identificadas individualmente (aunque sí ha sido distribuido el potencial rehabilitable por subregiones), por lo que se trata de un paquete de rehabilitación pendiente de ser personalizado con las autoridades competentes de cada país y con las organizaciones que operan los aprovechamientos. La inversión necesaria se ha estimado en unos 130.000 millones $\$$ US.

(iii) Implantación de nuevo potencial: el potencial estimado de nueva implantación hasta 2030 se eleva a 35.640 Mw, y sus emplazamientos no están identificados, aunque sí se encuentran ubicados territorialmente por países. Al igual que en el caso anterior, habría que concretarlo en aproximaciones sucesivas con las autoridades de cada país y con las organizaciones de las compañías eléctricas. En este caso, podrían lanzarse estudios de selección de emplazamientos, partiendo de los trabajos que sobre esta materia se han llevado a cabo en los países con ocasión de determinados planes maestros. La inversión estimada se eleva a 198.000 millones \$US.

En el Capítulo IV se han destacado dos ejes adicionales de intervención sobre el sector hidroeléctrico: (i) centrales de acumulación de bombeo como acumuladores de energía; (ii) aumento de la potencia instalada en centrales existentes con el fin de incrementar el rol de la hidroelectricidad en la regulación de la demanda del mercado eléctrico. La inversión para estas acciones no ha sido incluida en este programa.

Este programa de inversión incluye también determinadas actuaciones sobre las presas en materia de seguridad. Así, en este subprograma deberían incluirse la revisión y el análisis de la seguridad de las presas anexas al aprovechamiento hidroeléctrico (una vez más, se hace necesario disponer de un 
marco legal sobre seguridad de presas, para lo que nos remitimos al apartado correspondiente del presente documento). Se pueden incluir los componentes básicos siguientes que tienen que ver con la seguridad de las presas:

- Contar con unas normas de explotación que contemplen los protocolos de vigilancia y control, los protocolos de conservación y mantenimiento y los protocolos de la propia explotación, en situación normal y en avenidas, con fijación de resguardos estacionales y protocolos de alerta.

- Ante el riesgo de rotura potencial, debe proponerse la redacción de un Plan de Emergencia que, activado desde las normas de explotación, estableciera los indicadores, sus umbrales y los estados de emergencia, junto con un protocolo de alerta a las poblaciones que pudieran resultar afectadas y comunicación a las autoridades regionales y de protección civil.

\section{PROGRAMA 5: Programa de SH en cuencas transfronterizas}

La SH debe ser propiciada también en el ámbito de las cuencas internacionales o transfronterizas, ámbito de particular relevancia en Latinoamérica (cuencas del Orinoco, Amazonas, Paraná-La Plata, Acuífero Guaraní, entre otros), aunque a veces postergado por la dificultad que encierra cualquier actuación en el ámbito internacional. Eso, identificado como un ámbito apropiado para la innovación, será facilitado por el BID a través de varios subprogramas.

\section{Subprograma 1. Institucional}

Mediante las acciones que se incluyan en este subprograma, el BID prestará asistencia técnica y económica a las actuaciones tendientes a suscribir acuerdos o tratados internacionales sobre aguas transfronterizas (tanto superficiales como subterráneas) o a modificar los acuerdos ya existentes en línea con los postulados de $\mathrm{SH}$, para adecuarlos a la evolución en las relaciones que muestran las buenas prácticas comparadas (como la observada en Europa con la aplicación de la Directiva Marco de Aguas de 2000).

Igualmente se incluirán en este subprograma actuaciones relativas a la mejora institucional entendiendo por tales la instauración de órganos de colaboración o mejora en el funcionamiento de los ya existentes. Se prestará especial atención (de forma coherente con otros programas de este Plan de Trabajo), a las actuaciones dirigidas a la consecución de planes hidrológicos de ámbito supranacional. En particular se procurará que estos incorporen disposiciones para el tratamiento conjunto, desde el punto de vista de la prevención de las sequías e inundaciones en un contexto de cambio climático, para evitar conflictos y cooperar en la búsqueda conjunta de la SH. 


\section{Subprograma 2. Infraestructuras}

En muchas ocasiones los acuerdos sobre aguas transfronterizas precisan de la realización de obras hidráulicas (embalses y canales) que suelen presentar dificultades específicas relacionadas con su condición internacional y con los distintos problemas que lleva consigo su proyección, aprobación y ejecución. Este subprograma prestará atención especial a las actuaciones tendentes a mejorar los procesos de realización de las evaluaciones de impacto ambiental de tales obras.

Este subprograma cubre la dimensión internacional del Programa 1 sobre programas integrados de inversión en infraestructuras que incluye no solo el financiamiento de las mismas sino la promoción de acuerdos, tratados o anexos que garanticen además de su funcionamiento, la conformación procedimientos e instituciones capaces de trabajar de manera programática en objetivos conjuntos de SH. También conecta con el Programa 4 junto al que adquiere gran potencial de desarrollo en la región, al promover aprovechamientos hidroeléctricos binacionales o conjuntos, con objetivos simultáneos de seguridad hídrica y energética, control de inundaciones y mitigación de sequías.

\section{Subprograma 3. Otras actuaciones}

En los ámbitos transfronterizos, la implementación efectiva del derecho al agua, tanto en su variedad de suministro como de depuración y saneamiento básico, puede entrañar dificultades especiales. En este subprograma se incluirán las actuaciones tendentes a la implementación específica de este derecho fundamental y básico. También se incluirán aquí las obras y actuaciones tendentes a la compensación a las poblaciones transfronterizas que en muchas ocasiones lleva aparejada la gestión de sus aguas. El programa "Cultivando Agua Bona" vinculado a la gestión de la presa de Iguazú (acuerdo entre Brasil y Paraguay) puede ser una muestra de buenas prácticas a tener en cuenta.

Este tipo de actuaciones pueden incluir también el desarrollo de estudios (escasos en materia de acuíferos transfronterizos) y sistemas de monitoreo conjunto e intercambio de información y alerta temprana de eventos que puedan afectar la SH (Programas 7 y 8), pero también debe ir más allá en el apoyo y financiamiento para la concreción de protocolos internacionales de actuación que promuevan la cooperación en caso de sequías, inundaciones o contaminación, con el objetivo de afianzar la SH en cuencas de este tipo.

\section{VI.2 Programas de conocimiento}

PROGRAMA 6: Soluciones Basadas en la Naturaleza para la Seguridad Hídrica Uno de los aspectos centrales de cualquier programa innovador en materia de SH es la utilización de SBN. La aplicabilidad y ventajas de las SBN han sido suficientemente expuestas en los Capítulos II y IV. Sin embargo, aún existen 
brechas de conocimiento importantes que deben ser abordadas antes de que las SBN puedan aplicarse efectivamente a una escala significativa en la región.

En primer lugar, debe reconocerse que no existe una solución única para aplicar SBN en general y que cada proyecto debe considerar cómo las condiciones locales (cambios en las condiciones hidroclimáticas, tipo de suelo, población y uso de la tierra) afectarán a la eficiencia de las SBN, así como las estrategias apropiadas de gestión adaptativa para prolongar la vida efectiva de los sistemas de infraestructura hídrica híbrida en cada programa del plan propuesto.

El conocimiento sobre SBN para la SH debe responder preguntas como si estas pueden implementarse independiente de la infraestructura gris o ser parte de una solución híbrida gris-verde y, actualmente, este conocimiento se encuentra en un estado incipiente. Incluso los datos más básicos para aplicaciones de SBN individuales hacen falta en ALC. Las áreas importantes de SBN que necesitan financiamiento del BID para hacer investigación, estudios piloto y generar conocimiento a corto y largo plazo incluyen:

Los requisitos de monitoreo deben estar estandarizados para proyectos individuales y la compilación de datos de todos los proyectos con SBN debe realizarse y colocarse en una base de datos fácil de usar para su planificación subsiguiente. Debe prestarse especial atención a los humedales construidos y a las aplicaciones urbanas para el tratamiento del agua, la reutilización y la agricultura.

En la mayoría de los proyectos con SBN existentes en ALC, es necesario desarrollar proyectos piloto de demostración para definir escalas temporales y espaciales de aplicación efectivas y establecer cuándo las SBN pueden ser independientes o deben desarrollarse en sistemas híbridos con infraestructura gris. Un estudio ya citado en el Capítulo IV (Tellman et al., 2018) presenta una evaluación a nivel regional de SBN destinadas a mejoras en la calidad de fuentes de agua potable y mitigación de inundaciones. Esta evaluación recoge algunas ciudades y cuencas prioritarias para realizar estudios piloto más detallados (Figura 6.1). Hay otros aspectos por explorar en relación con otros campos de la SH: tratamiento de aguas residuales, mejoramiento de la calidad de agua, prevención de sequías, almacenaje de agua en planicies de inundación y protección de acuíferos. Además de esto, algunas SBN se han empezado a implementar progresivamente en otras partes del mundo, y el BID debería alentar el diálogo sur-sur para comprender las lecciones aprendidas en otros lugares y ampliar la cartera de soluciones potenciales para su aplicación en LAC. 
Algunas áreas prometedoras para la utilización de SBN a mayor escala en ALC ya han sido destacadas en la sección IV.2 de este informe (Cuadro 4.1). Una exposición más detallada de este programa y sus actividades se presenta en el Anexo G.

Figura 6.1. Priorización de localidades en la región de ALC en cuanto a factibilidad de utilizar SBN para aspectos de SH (A: mejoras en la calidad de agua para uso potable; $\mathrm{B}$ : mitigación de impactos de inundaciones fluviales; C: mitigación de inundaciones pluviales)

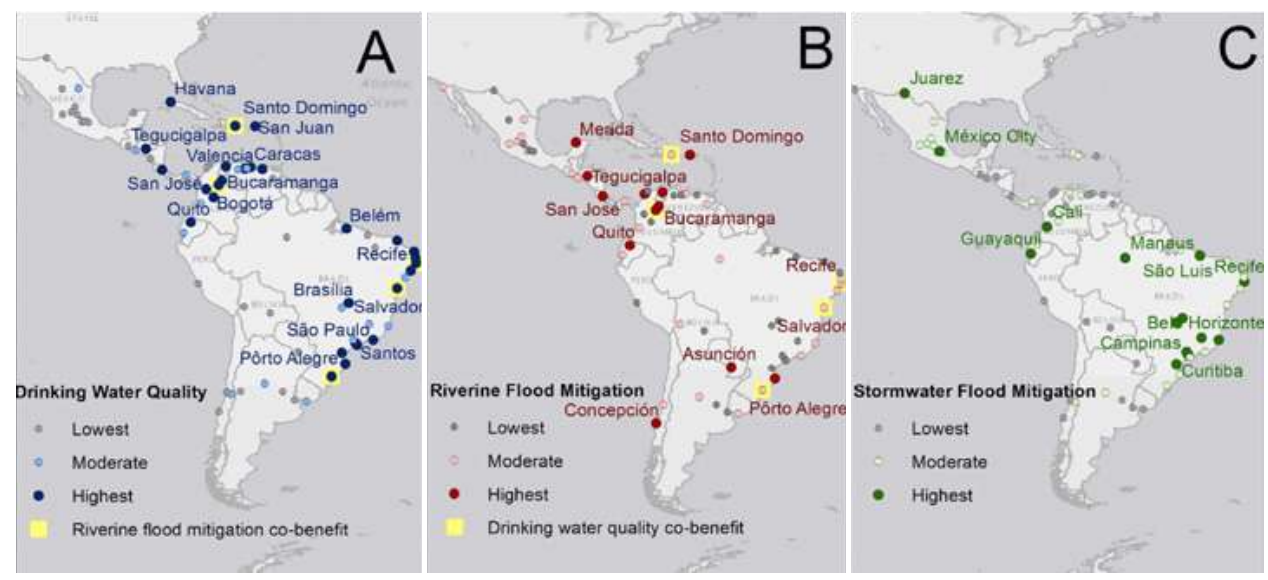

Fuente: Tellman et al., 2018.

\section{PROGRAMA 7: Estudios sobre fenómenos extremos en ALC: Sequías}

Este es un programa de conocimiento para ser desarrollado como complemento a lo señalado en el Programa 2 (que incluye la propuesta de los planes de sequía para los abastecimientos urbanos). En este caso, el programa se dirige al estudio de las condiciones de sequía a nivel de cuencas y acuíferos que debe alimentar a los planes maestros de abastecimiento urbano, a los planes de desarrollo agrícola (p. ej. planes de riego) y a los planes del sector energético, considerando aspectos de cambio climático y de protección de ecosistemas. Por ello, este programa ha de contemplar todos los usos del agua y el uso de la tierra en la cuenca o acuífero, de manera que pueda servir de insumo y apoyo a los programas de inversión en infraestructura y política (Programas 1-4). El alcance de los planes de sequía ya ha sido explicado en el Capítulo IV y en este mismo capítulo se ha referido la necesidad de contar con una Guía o Instrucción Técnica que armonice la metodología para todos los países de ALC.

Algunos ejemplos de tipos de productos de conocimiento son el desarrollo de mapas dinámicos de condiciones de sequía meteorológica, agrícola e hidrológica derivados de productos de información globales como el Global 
Drought Information System (https://www.drought.gov/gdm/current-conditions), el sistema GIDMAPS (http://drought.eng.uci.edu) y el sistema Global Forecast Drought Tool (https://iridl.Ideo.columbia.edu/maproom/Global/ World Bank/Drought Monitor/index3.html?gmap=\%5B10\%2C5\%2C2\%5D), entre otros.

\section{PROGRAMA 8: Estudios sobre fenómenos extremos en ALC: inundaciones}

Este programa consiste en elaborar el Plan de Gestión del Riesgo de Inundación (PGRI), cuyo alcance ha sido descrito en el Capítulo IV y que ha de emprenderse teniendo en consideración las fases que allí se describen. Con el objetivo de armonizar su alcance para todos los países de ALC, es valioso desarrollar y aplicar productos analíticos (como HydroBID Flood) que apoyen a los países en la metodología a seguir. Este programa debe impulsarse independientemente a todos los demás y, en su día, integrarse en el plan hidrológico de la cuenca.

Algunos ejemplos de productos de conocimiento relacionados con este programa son el desarrollo de mapas dinámicos de condiciones de inundaciones tales como el Global Flood Monitoring System (http://flood.umd.edu), el Global Flood Monitor (https://www.globalfloodmonitor.org), el Global Flood Detection System (http://www.gdacs.org/flooddetection/), y el sistema GLOFFIS (https://www.globalfloodforecast.com), entre otros.

\section{PROGRAMA 9: Definición del Régimen de Caudales Ecológicos}

La definición de un régimen de caudales ecológicos es un instrumento importante para minimizar los efectos de caudales extremadamente bajos sobre los ecosistemas que sirven de fuentes de agua y proveen otros servicios ecosistémicos y ambientales. En el ejemplo descrito en el Capítulo IV, la idea de los caudales ecológicos se introdujo en la Unión Europea precisamente por la cantidad de presas necesarias para alcanzar un nivel de regulación que los ríos europeos ya tenían sin necesidad de infraestructura alguna, debido al régimen relativamente regular de lluvias. En el caso de ALC, la situación es similar. Este programa se enfoca en la definición de un régimen de caudales ecológicos que debe tener en cuenta:

- El caudal mínimo: diferente según la estación del año para considerar el ciclo natural de la vida piscícola y demás especies que habitan el ecosistema. Han de utilizarse modelos ecológicos que requieren de considerables estudios de campo y, por tanto, exigen capacidad, tiempo y recursos económicos.

- Limitación del caudal máximo: en los embalses, por ejemplo, si no existe un canal de transporte y se utiliza el propio cauce del río para conducir los caudales hasta las tomas de las zonas regables (situación bastante 
usual en ALC), se produce una inversión del flujo hidrológico: en verano (las zonas tropicales son más singulares) circula un alto caudal cuando la naturaleza estaría en estiaje y en invierno los embalses cortan el flujo cuando las lluvias darían un importante caudal en el cauce. Para evitar que se deteriore el hábitat fluvial hace falta limitar el caudal máximo de la cuenca.

- Tasa de cambio: es otro parámetro importante que trata de impedir gradientes fuertes de caudal en el río que no se producen de forma natural (salvo en el caso de crecidas, de menor gradiente, por lo general). Esto, que es aplicable a cualquier embalse, es especialmente importante en las centrales hidroeléctricas con vocación de energía de puntas. La solución ideal para controlar la situación y que no se vea afectada la explotación es disponer de un contraembalse (o embalse paralelo de alivio) al pie de la presa para almacenar el agua descargada durante las puntas e irlas posteriormente devolviendo al río con un régimen que respete la tasa de cambio establecida.

- Caudal de reposición: este cuarto parámetro parte del hecho de que anualmente se produce en los ríos de forma natural una inundación que remodela el lecho del cauce. Esta remodelación, a la que la vida acuática está acostumbrada y que demanda para su hábitat, supone un problema adicional porque obliga a hacer descargas que tienen un costo importante por la utilización del recurso que suponen.

En definitiva, el régimen de caudales ecológicos es un proceso complejo al que hay que ir aproximándose progresivamente, comenzando con la implantación del caudal mínimo, deseablemente obtenido por modelos de hábitat. Será también condición imprescindible que se elaboren productos analíticos (p. ej., guías técnicas, mapas dinámicos) que establezcan una metodología armonizada, así como estudios de caso piloto para cuencas y acuíferos que operan bajo diferentes condiciones (tamaño, bioma, nivel de urbanización, uso del agua). Por sus características especiales, se trata de un programa que se puede ir implementando por conjuntos de cuencas y/o acuíferos, donde haya una mayor densidad de presas de embalse. Para minimizar el costo del programa es recomendable seleccionar puntos estratégicos en cada sistema, procediendo después a técnicas de regionalización para extender el régimen de caudales a otros puntos donde no se hayan practicado estudios.

\section{PROGRAMA 10: Consolidación y mejora de las redes de monitoreo en campo y teledetección}

Este programa consiste en el desarrollo de instrumentos fundamentales para el monitoreo in situ y vía teledetección de la cuenca, acuíferos y de los ecosistemas acuáticos. Sobre el monitoreo de campo se han producido avances en la región, sobre todo en redes de pluviometría, de aforos y de piezometría. 
Sin embargo, en estaciones para la medición de la calidad aún existe una laguna de conocimiento muy importante que hay que cubrir. Además, el uso de la teledetección como herramienta operativa de monitoreo del ciclo del agua y de la SH (descrito en el Capítulo IV) se encuentra en un estado prácticamente inexistente.

Las inversiones en la cartera del BID suelen incluir propuestas para monitoreo. Es conveniente mantener y apalancar esta estrategia, para poder identificar y corregir las carencias en las redes existentes y complementarlas con instrumentación de campo y métodos de teledetección, según sea necesario. Los programas 1 y 2 permitirían aportar información sobre el particular.

Este programa debe impulsarse de manera que permita utilizar técnicas de análisis y fusión de datos (big data o macrodatos) para que no sólo detecte las deficiencias, sino que también permita priorizar proyectos de mejora y ampliación de las redes existentes (incluyendo su valoración, forma de financiación, etc.), de forma que se pueda acometer en el medio plazo una acción de envergadura que ponga a la red de monitoreo en el estado que le corresponde, dada su importante condición para el seguimiento y control de las cuencas, los acuíferos y sus ecosistemas correspondientes. Esto implicaría inversiones de conocimiento no solo en monitoreo sino en análisis de datos.

Los paquetes de datos y análisis que debe contener este programa son: (i) red de estaciones de aforo en aguas superficiales; (ii) red de piezometría en acuíferos; (iii) red de estaciones de control de la calidad de aguas superficiales; (iv) red de control de la calidad de las aguas subterráneas; (v) red climatológica (pluviómetros, temperatura, evaporación, viento) y (vi) red de control de vertidos. $Y$ todas deben incluir bases de datos medidas in situ y medidas vía teledetección.

También es necesario disponer de una cartografía digitalizada de la red fluvial, que permita estudios sobre inundaciones y sobre la que se pueda plasmar la cartografía digitalizada de zonas inundables. Así mismo, es importante contar con productos geoespaciales de información socioeconómica y ecológica que complementen las bases de datos para estas redes de monitoreo.

\section{PROGRAMA 11: Modelos de simulación y apoyo a la toma de decisiones}

La experiencia del Banco con el desarrollo de HydroBID en los últimos años ${ }^{62}$ es indicativa de la necesidad de herramientas cuantitativas para apoyar los procesos de toma de decisión en el sector hídrico en la región. HydroBID ha tenido una recepción muy positiva, pasando de ser un modesto estudio de caso en la cuenca del Bermejo en Argentina, en 2014, a ser utilizado, cinco años después, en más de una docena de países en la región, incluido Perú, donde se está llevando a cabo una aplicación del modelo a nivel de todas las cuencas del país.

62 El desarrollo del modelo se inició en el 2011 y comenzó a aplicarse en el 2014 
Sin embargo, para atacar una problemática más compleja como la SH, HydroBID es solo una parte del rompecabezas, ya que aunque simula el balance hídrico aún no simula otros componentes de la $\mathrm{SH}$ como la calidad de agua, los servicios ecosistémicos, la hidráulica de acuíferos (en desarrollo), las sequías, las inundaciones (se ha empezado a hacer recientemente con la aplicación HydroBID Flood), los programas de riego, las demandas del sector energético y otros componentes detallados en la Figura 2.7.

El BID tiene una gran oportunidad de innovación en el ámbito de modelos de simulación que apoyen los procesos de toma de decisiones en problemas y proyectos relacionados con la SH en la región. Su rol como entidad regional de financiamiento y su conocimiento de la realidad de la región le permite abarcar problemas de SH a varias escalas (municipal, estadal, nacional y regional) y proveer a sus clientes de herramientas punta y modernas para apoyar la toma de decisiones a todos estos niveles. Además del ejemplo de HydroBID, existe el ejemplo reciente del modelo GCAM-LAC para simular el nexo agua-energía-alimentos, que en estos momentos se está aplicando en estudios piloto en Colombia, Argentina, Uruguay y Brasil con un buen nivel de recepción.

Este programa puede concebirse como una serie de modelos de simulación integrados que abarquen de manera complementaria los diferentes aspectos de SH que hemos desarrollado en este informe. Así, el programa puede estructurarse en el desarrollo y aplicación de modelos que integren la parte hidrológica (p. ej. HydroBID) con la planificación multisectorial nexo (p. ej., GCAM-LAC), con modelos de servicios ecosistémicos, modelos urbanísticos, demográficos, socioeconómicos y otros componentes necesarios (utilizando modelos existentes o desarrollando herramientas propias del BID) de manera evolutiva y con una interacción permanente con los usuarios potenciales de estos modelos (organismos de los gobiernos, universidades, institutos de investigación, ONGs y otros).

Como un ejemplo de esta manera de desarrollar modelos integrados, se puede mencionar la llamada Dinámica de Sistemas (System Dynamics), que ha sido utilizada durante varias décadas para desarrollar modelos de simulación interdisciplinarios y multisectoriales y ha tenido una amplia aplicación en el sector hídrico (Saysel et al., 2002; Winz et al., 2009 y Simonovic, 2002). En la Figura 6.2 se muestra una ilustración conceptual de esta metodología de simulación integrada. En esta figura, cada bloque de color puede referirse a un modelo de simulación para esa variable en particular (p. ej., cuencas, acuíferos, población...). 
Figura 6.2. Esquema de un modelo de sistemas dinámicos que incluye un componente socioeconómico de manera acoplada

Flujos externos Variables de estado de COWA impulsados por políticas

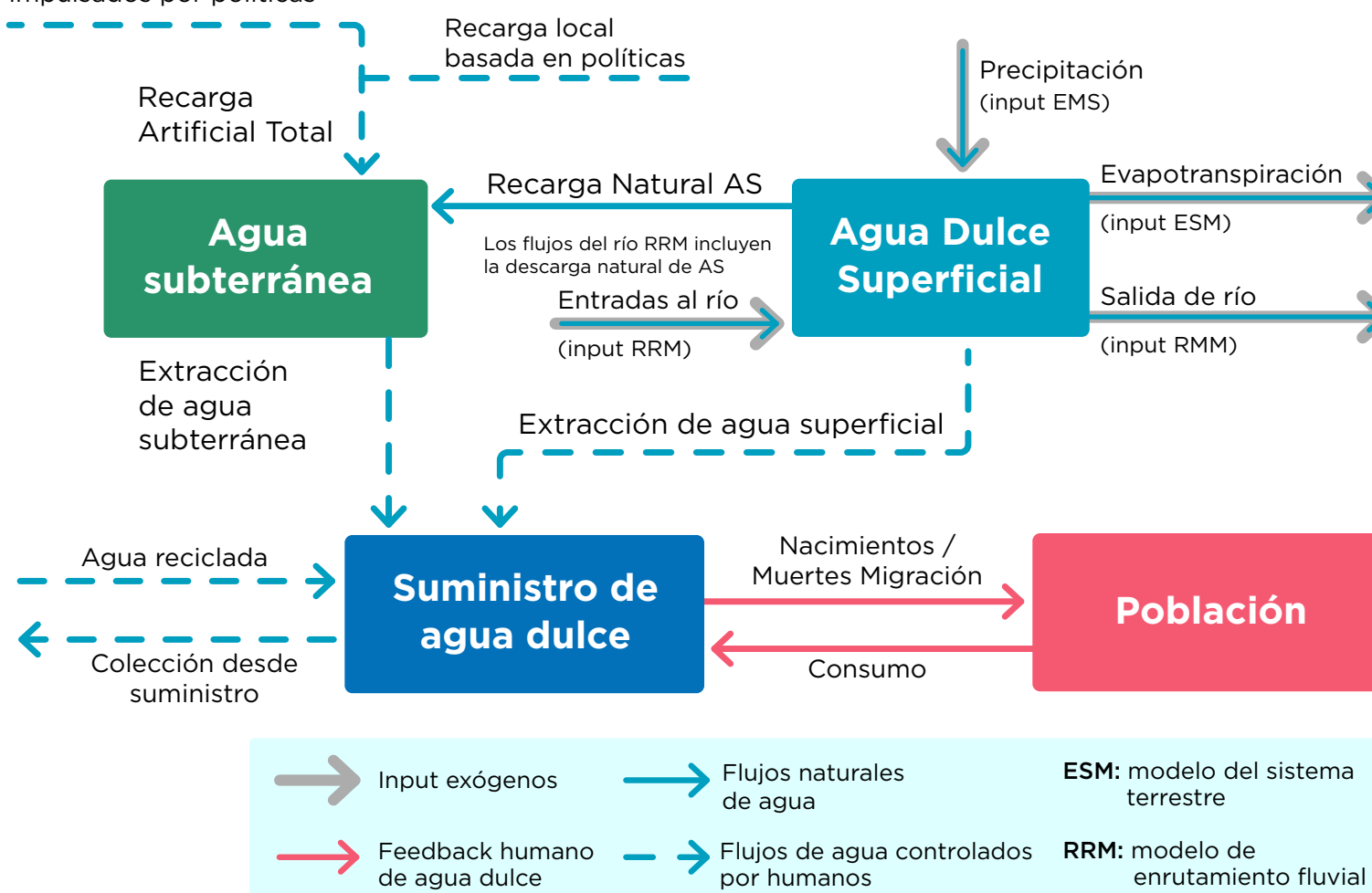

Un esquema de la variable de estado de COWA, incluidos los flujos entre ellos, así como los vínculos con el Modelo del Sistema Terrestre (ESM) y el Modelo de Ruta del Río (RRM). Leyenda: las flechas rojas muestran retroalimentaciones, mientras que las flechas azules muestran el flujo de agua.

Fuente: Motesharrei et al., 2016.

Debido al carácter progresivamente más multisectorial de la cartera del BID y del interés de sus clientes en la región, este programa, ejemplo concreto de innovación en materia de SH para el BID, puede ser muy fructífero.

\section{VI.3 Algunas consideraciones para la implementación}

En el Cuadro 6.2 se resume la correspondencia de cada uno de los programas propuestos en este plan de trabajo con los objetivos estratégicos de $\mathrm{SH}$ descritos en el Capítulo V. Con el fin de facilitar su implementación, en este cuadro se separan los programas de inversión y los préstamos basados en políticas (PBLs); también se separan los estudios de conocimiento, en cooperaciones técnicas y estudios económicos sectoriales (ESWs), haciendo referencia específica, dentro de cada objetivo estratégico, a cada programa del plan de trabajo. El Plan implica también el desarrollo de un proceso de priorización con los países para desarrollar presupuestos y etapas o fases (anuales o multianuales) para su implementación. 
Cuadro 6.2. Plan de Trabajo de Agua para el Futuro: Objetivos Estratégicos y Programas Propuestos

\begin{tabular}{|c|c|c|c|c|c|}
\hline \multirow{3}{*}{$\begin{array}{l}\text { Prioridades } \\
\text { estratégicas } \\
\text { para la Seguridad } \\
\text { Hídrica }\end{array}$} & \multicolumn{5}{|c|}{ Propuesta de Acción para el BID } \\
\hline & \multirow{2}{*}{$\begin{array}{l}\text { Proyectos } \\
\text { de inversión }\end{array}$} & \multirow{2}{*}{$\begin{array}{l}\text { Préstamos } \\
\text { basados en } \\
\text { Políticas (PBLs) }\end{array}$} & \multicolumn{2}{|c|}{$\begin{array}{c}\text { Estudios y Desarrollo } \\
\text { de Conocimiento }\end{array}$} & \multirow{2}{*}{ Comentarios } \\
\hline & & & $\begin{array}{l}\text { Cooperaciones } \\
\text { Técnicas }\end{array}$ & ESWs & \\
\hline $\begin{array}{l}\text { Objetivo } \\
\text { Estratégico 1: } \\
\text { Lograr y sostener } \\
\text { el abastecimiento } \\
\text { con agua potable } \\
\text { y la provisión } \\
\text { de servicios de } \\
\text { recolección, } \\
\text { tratamiento y } \\
\text { disposición final } \\
\text { de aguas servidas } \\
\text { al 100\% de la } \\
\text { población. }\end{array}$ & $\begin{array}{l}\text { Proyectos de agua } \\
\text { y saneamiento } \\
\text { por cuencas con } \\
\text { incorporación } \\
\text { de planes de SH } \\
\text { armónicos con los } \\
\text { planes maestros } \\
\text { sectoriales, } \\
\text { reducción de } \\
\text { pérdidas, reúso } \\
\text { e innovación. } \\
\text { (Programa } 1 \text { a } \\
\text { nivel nacional y } \\
\text { Subprograma } 5.2 \\
\text { para proyectos } \\
\text { transfronterizos). } \\
\text { Proyectos de agua } \\
\text { y saneamiento } \\
\text { urbanos con } \\
\text { incorporación } \\
\text { de planes de SH } \\
\text { armónicos con los } \\
\text { planes maestros } \\
\text { sectoriales, } \\
\text { reducción de } \\
\text { pérdidas, reúso } \\
\text { e innovación } \\
\text { (Programa } 2 \text { ). }\end{array}$ & $\begin{array}{l}\text { Apoyar a los } \\
\text { países para } \\
\text { crear las } \\
\text { condiciones } \\
\text { que atraigan la } \\
\text { participación del } \\
\text { sector privado } \\
\text { en la SH } \\
\text { (Programa } 1 \\
\text { para planes } \\
\text { nacionales y } \\
\text { Programa } 2 \text { para } \\
\text { planes urbanos). }\end{array}$ & $\begin{array}{l}\text { Modelos de } \\
\text { planes de SH } \\
\text { para EAS. } \\
\text { Modelos de } \\
\text { Estrategia de } \\
\text { comunicación } \\
\text { para la SH. } \\
\text { Nota: estas } \\
\text { cooperaciones } \\
\text { técnicas } \\
\text { apoyarían la } \\
\text { preparación de } \\
\text { operaciones } \\
\text { de préstamo } \\
\text { dentro del } \\
\text { Programa } 1 \\
\text { (nivel nacional) } \\
\text { y/o Programa } \\
2 \text { (nivel } \\
\text { urbano). }\end{array}$ & $\begin{array}{l}\text { Modelos } \\
\text { económicos } \\
\text { para el } \\
\text { financiamiento } \\
\text { de la SH. } \\
\text { Nota: estos } \\
\text { estudios ESW } \\
\text { apoyarían } \\
\text { la base de } \\
\text { conocimiento } \\
\text { para la } \\
\text { preparación } \\
\text { de préstamos } \\
\text { dentro de los } \\
\text { Programas de } \\
\text { inversión 1-5. }\end{array}$ & $\begin{array}{l}\text { Concentrar los } \\
\text { esfuerzos en } \\
\text { Bolivia, El Salvador, } \\
\text { Guatemala, Haití, } \\
\text { Nicaragua, Perú } \\
\text { y República } \\
\text { Dominicana, así } \\
\text { como en ciudades } \\
\text { con menos de } \\
50.000 \text { habitantes } \\
\text { del Brasil. }\end{array}$ \\
\hline
\end{tabular}




\begin{tabular}{|c|c|c|c|c|c|}
\hline \multirow{3}{*}{$\begin{array}{l}\text { Prioridades } \\
\text { Estratégicas } \\
\text { para la Seguridad } \\
\text { Hídrica }\end{array}$} & \multicolumn{5}{|c|}{ Propuesta de Acción para el BID } \\
\hline & \multirow{2}{*}{$\begin{array}{l}\text { Proyectos de } \\
\text { inversión }\end{array}$} & \multirow{2}{*}{$\begin{array}{l}\text { Préstamos } \\
\text { basados en } \\
\text { Políticas (PBLs) }\end{array}$} & \multicolumn{2}{|c|}{$\begin{array}{c}\text { Estudios y Desarrollo de } \\
\text { Conocimiento }\end{array}$} & \multirow{2}{*}{ Comentarios } \\
\hline & & & $\begin{array}{l}\text { Cooperaciones } \\
\text { Técnicas }\end{array}$ & ESWs & \\
\hline $\begin{array}{l}\text { Objetivo } \\
\text { Estratégico 2: } \\
\text { Incentivar el } \\
\text { Desarrollo de } \\
\text { Marcos Legales } \\
\text { Adecuados para } \\
\text { la Gestión Efectiva } \\
\text { de los Recursos } \\
\text { Hídricos teniendo } \\
\text { como foco la } \\
\text { Seguridad Hídrica, } \\
\text { el manejo de los } \\
\text { riesgos asociados } \\
\text { y el desarrollo } \\
\text { económico } \\
\text { sostenible }\end{array}$ & & $\begin{array}{l}\text { Modernización } \\
\text { del marco legal e } \\
\text { institucional para } \\
\text { la SH. } \\
\text { (Programa } 1 \text { a } \\
\text { nivel nacional y } \\
\text { Subprograma 5-1 } \\
\text { para proyectos } \\
\text { transfronterizos). }\end{array}$ & $\begin{array}{l}\text { Promoción de la } \\
\text { discusión sobre } \\
\text { la urgencia de } \\
\text { lograr la SH en } \\
\text { la región. } \\
\text { Términos de } \\
\text { Referencia para } \\
\text { desarrollar } \\
\text { marco legal e } \\
\text { institucional } \\
\text { bajo el enfoque } \\
\text { de SH. } \\
\text { Modelos } \\
\text { de planes } \\
\text { nacionales de } \\
\text { SH con soporte } \\
\text { legal. } \\
\text { Promoción de } \\
\text { la necesidad } \\
\text { de contar } \\
\text { con tratados } \\
\text { multilaterales } \\
\text { en las cuencas } \\
\text { transfronterizas. } \\
\text { (5-3). } \\
\text { Nota: estas } \\
\text { cooperaciones } \\
\text { técnicas } \\
\text { apoyarian la } \\
\text { preparación de } \\
\text { operaciones } \\
\text { de préstamo } \\
\text { dentro del } \\
\text { Programa } 1 \\
\text { (nivel nacional), } \\
\text { Programa } 2 \\
\text { (nivel urbano) } \\
\text { y Subprograma } \\
\text { transfronterizo). }\end{array}$ & $\begin{array}{l}\text { Estudio de } \\
\text { economía } \\
\text { institucional } \\
\text { para } \\
\text { determinar el } \\
\text { momento de } \\
\text { cada país con } \\
\text { relación a la } \\
\text { motivación } \\
\text { para el cambio } \\
\text { institucional y } \\
\text { legal para la } \\
\text { SH. } \\
\text { Nota: estos } \\
\text { estudios ESW } \\
\text { apoyarían } \\
\text { la base de } \\
\text { conocimiento } \\
\text { para la } \\
\text { preparación } \\
\text { de préstamos } \\
\text { dentro de los } \\
\text { Programas de } \\
\text { inversión 1-5. }\end{array}$ & $\begin{array}{l}\text { Todos los países } \\
\text { carecen, quizás en } \\
\text { niveles distintos, } \\
\text { de modernización } \\
\text { de sus marcos } \\
\text { legal, institucional } \\
\text { y administrativo } \\
\text { de los recursos } \\
\text { hídricos. }\end{array}$ \\
\hline
\end{tabular}




\begin{tabular}{|c|c|c|c|c|c|}
\hline \multirow{3}{*}{$\begin{array}{l}\text { Prioridades } \\
\text { Estratégicas } \\
\text { para la Seguridad } \\
\text { Hídrica }\end{array}$} & \multicolumn{5}{|c|}{ Propuesta de Acción para el BID } \\
\hline & \multirow{2}{*}{$\begin{array}{l}\text { Proyectos de } \\
\text { inversión }\end{array}$} & \multirow{2}{*}{$\begin{array}{l}\text { Préstamos } \\
\text { basados en } \\
\text { Políticas (PBLs) }\end{array}$} & \multicolumn{2}{|c|}{$\begin{array}{l}\text { Estudios y Desarrollo de } \\
\text { Conocimiento }\end{array}$} & \multirow{2}{*}{ Comentarios } \\
\hline & & & $\begin{array}{l}\text { Cooperaciones } \\
\text { Técnicas }\end{array}$ & ESWs & \\
\hline $\begin{array}{l}\text { Objetivo } \\
\text { Estratégico 3: } \\
\text { En el marco } \\
\text { de seguridad } \\
\text { hídrica, promover } \\
\text { la seguridad } \\
\text { alimentaria y la } \\
\text { generación de } \\
\text { energía renovable } \\
\text { a partir de la } \\
\text { planificación } \\
\text { y desarrollo } \\
\text { de proyectos } \\
\text { integrales que } \\
\text { contemplen } \\
\text { necesidades } \\
\text { de desarrollo o } \\
\text { mejoras en la } \\
\text { infraestructura y } \\
\text { la seguridad de } \\
\text { presas. }\end{array}$ & $\begin{array}{l}\text { Rehabilitación } \\
\text { y expansión del } \\
\text { área de riego para } \\
\text { la SA }{ }^{63} \text { bajo el } \\
\text { enfoque de SH } \\
\text { (Programa 3). } \\
\text { Rehabilitación } \\
\text { de presas } \\
\text { hidroeléctricas } \\
\text { bajo el } \\
\text { enfoque de SH } \\
\text { (multipropósito) y } \\
\text { sostenibilidad } \\
\text { (Programa 4). } \\
\text { Construcción de } \\
\text { nuevas presas } \\
\text { multipropósito } \\
\text { para atender } \\
\text { el aumento de } \\
\text { consumo bajo el } \\
\text { enfoque de SH y } \\
\text { sostenibilidad } \\
\text { (Programa 4). }\end{array}$ & & $\begin{array}{l}\text { Modelo de } \\
\text { protocolos y } \\
\text { legislación para } \\
\text { la seguridad de } \\
\text { presas. } \\
\text { Modelos de } \\
\text { planificación } \\
\text { hidrológica } \\
\text { utilizando el nexo } \\
\text { agua, energía, } \\
\text { alimentos en un } \\
\text { contexto de SH. } \\
\text { Nota: estas } \\
\text { cooperaciones } \\
\text { técnicas apoyarían } \\
\text { la preparación de } \\
\text { operaciones de } \\
\text { préstamo dentro } \\
\text { de los Programas } \\
3 \text { y } 4 \text {. }\end{array}$ & & $\begin{array}{l}\text { Países con potencial } \\
\text { para rehabilitar } \\
\text { sistemas de riego: } \\
\text { Brasil, Chile, México, } \\
\text { Perú, Colombia y } \\
\text { Bolivia. }\end{array}$ \\
\hline
\end{tabular}




\begin{tabular}{|c|c|c|c|c|c|}
\hline \multirow{3}{*}{$\begin{array}{l}\text { Prioridades } \\
\text { Estratégicas } \\
\text { para la Seguridad } \\
\text { Hídrica }\end{array}$} & \multicolumn{5}{|c|}{ Propuesta de Acción para el BID } \\
\hline & \multirow[t]{2}{*}{$\begin{array}{l}\text { Proyectos de } \\
\text { inversión }\end{array}$} & \multirow{2}{*}{$\begin{array}{l}\text { Préstamos } \\
\text { basados en } \\
\text { Políticas (PBLs) }\end{array}$} & \multicolumn{2}{|c|}{$\begin{array}{l}\text { Estudios y Desarrollo de } \\
\text { Conocimiento }\end{array}$} & \multirow[t]{2}{*}{ Comentarios } \\
\hline & & & $\begin{array}{l}\text { Cooperaciones } \\
\text { Técnicas }\end{array}$ & ESWs & \\
\hline $\begin{array}{l}\text { Objetivo } \\
\text { Estratégico 4: } \\
\text { Incentivar la } \\
\text { recuperación } \\
\text { de la calidad } \\
\text { y la creación } \\
\text { de reservas } \\
\text { estratégicas de } \\
\text { agua. }\end{array}$ & $\begin{array}{l}\text { Descontaminación } \\
\text { de cuencas con un } \\
\text { concepto integral en } \\
\text { el contexto de SH } \\
\text { (Programa 1). } \\
\text { Creación de reservas } \\
\text { estratégicas de agua } \\
\text { bajo el enfoque de } \\
\text { SH y de SBN } \\
\text { (Programa } 6 \text { ). }\end{array}$ & & $\begin{array}{l}\text { Fórum para cambio } \\
\text { de experiencias con } \\
\text { descontaminación } \\
\text { de cuencas y } \\
\text { creación del premio } \\
\text { ciudad con cuencas } \\
\text { más limpias de } \\
\text { ALC. } \\
\text { Nota: estas } \\
\text { cooperaciones } \\
\text { técnicas apoyarían } \\
\text { la preparación de } \\
\text { operaciones de } \\
\text { préstamo dentro } \\
\text { del Programa } 1 \\
\text { (nivel nacional) y } \\
\text { Programa } 2 \text { (nivel } \\
\text { urbano). }\end{array}$ & & $\begin{array}{l}\text { Seleccionar } \\
\text { cuencas } \\
\text { prioritarias en } \\
\text { el diálogo con } \\
\text { los países. Se } \\
\text { puede empezar } \\
\text { por Brasil, Perú, } \\
\text { México, Chile, } \\
\text { Colombia y } \\
\text { Venezuela }\end{array}$ \\
\hline
\end{tabular}




\begin{tabular}{|c|c|c|c|c|c|}
\hline \multirow{3}{*}{$\begin{array}{l}\text { Prioridades } \\
\text { Estratégicas } \\
\text { para la Seguridad } \\
\text { Hídrica }\end{array}$} & \multicolumn{5}{|c|}{ Propuesta de Acción para el BID } \\
\hline & \multirow{2}{*}{$\begin{array}{l}\text { Proyectos de } \\
\text { inversión }\end{array}$} & \multirow{2}{*}{$\begin{array}{l}\text { Préstamos } \\
\text { basados en } \\
\text { Políticas (PBLs) }\end{array}$} & \multicolumn{2}{|c|}{$\begin{array}{c}\text { Estudios y Desarrollo de } \\
\text { Conocimiento }\end{array}$} & \multirow{2}{*}{ Comentarios } \\
\hline & & & $\begin{array}{l}\text { Cooperaciones } \\
\text { Técnicas }\end{array}$ & ESWs & \\
\hline $\begin{array}{l}\text { Objetivo } \\
\text { Estratégico 5: } \\
\text { Modernizar los } \\
\text { mecanismos } \\
\text { y métodos de } \\
\text { obtención de } \\
\text { información y de } \\
\text { soporte a la toma } \\
\text { de decisiones }\end{array}$ & & & $\begin{array}{l}\text { Necesidades } \\
\text { regionales de } \\
\text { los sistemas de } \\
\text { monitoreo hidro } \\
\text { climatológicos de } \\
\text { ALC } \\
\text { (Programa 10). } \\
\text { Modelos hidro } \\
\text { climatológicos en } \\
\text { una plataforma } \\
\text { dinámica } \\
\text { complementaria a } \\
\text { HydroBID } \\
\text { (Programa 11). }\end{array}$ & $\begin{array}{l}\text { Desarrollo } \\
\text { de mapas } \\
\text { dinámicos de } \\
\text { condiciones } \\
\text { de sequía } \\
\text { meteorológica, } \\
\text { agrícola e } \\
\text { hidrológica } \\
\text { derivados de } \\
\text { productos de } \\
\text { información } \\
\text { globales como } \\
\text { el Global } \\
\text { Drought } \\
\text { Information } \\
\text { System } \\
\text { (Programa 7). } \\
\text { Desarrollo de } \\
\text { mapas dinámi- } \\
\text { cos de condi- } \\
\text { ciones de inun- } \\
\text { daciones tales } \\
\text { como el Global } \\
\text { Flood Monitor- } \\
\text { ing System } \\
\text { (http://flood. } \\
\text { umd.edu), } \\
\text { el Global } \\
\text { Flood Monitor } \\
\text { (https://www. } \\
\text { globalflood- } \\
\text { monitor.org), } \\
\text { el Global Flood } \\
\text { Detection } \\
\text { System } \\
\text { (http://www. } \\
\text { gdacs.org/ } \\
\text { flooddetec- } \\
\text { tion/), y el } \\
\text { sistema GL- } \\
\text { OFFIS } \\
\text { (https://www. } \\
\text { globalflood- } \\
\text { forecast.com) } \\
\text { (Programa 8) }\end{array}$ & $\begin{array}{l}\text { La implementación } \\
\text { de sistemas de } \\
\text { monitoreo in situ } \\
\text { no se puede incluir } \\
\text { como componente } \\
\text { de un préstamo } \\
\text { sectorial. }\end{array}$ \\
\hline
\end{tabular}




\begin{tabular}{l|l|l|}
\multicolumn{2}{|l}{} & \multicolumn{2}{|l}{} \\
\cline { 2 - 3 } $\begin{array}{l}\text { Prioridades } \\
\text { Estratégicas }\end{array}$ & \multicolumn{2}{|l}{ Préstamos } \\
para la Seguridad & $\begin{array}{l}\text { Proyectos de } \\
\text { basados en } \\
\text { inversión }\end{array}$ & $\begin{array}{l}\text { Políticas } \\
\text { (PBLs) }\end{array}$ \\
\hline
\end{tabular}

Objetivo Estratégico 6:

Fomentar el desarrollo

de conocimiento

e innovación para

garantizar la SH

\section{Propuesta de Acción para el BID}

Estudios y Desarrollo de Conocimiento

\section{Cooperaciones}

Técnicas

ESWs

Metodología para

identificar ecosistemas

estratégicos e

implantar SBN en

cuencas prioritarias

de ALC, de forma

independiente o en

combinación con

infraestructura gris

(Programa 6).

Metodología para

desarrollar planes de

sequía e de planes de

controle de inundación

incluyendo SBN

(Programas 7 y 8 ).

Metodología para el desarrollo de caudales ecológicos en el contexto de $\mathrm{SH}$ Identificación y desarrollo de modelos que impactan la $\mathrm{SH}$ por ejemplo: dinámica de agua subterránea y niveles óptimos de explotación

(Programa 9).

Creación de un fórum regional de $\mathrm{SH}$ para seguimiento de la implantación de acciones acordadas y cambio de experiencias.

Nota: estas cooperaciones técnicas apoyarían la preparación de operaciones de préstamo dentro del Programa 1 (nivel nacional) y Programa 2 (nivel urbano). 
Este plan de trabajo pasa del concepto tradicional de la gestión de recursos hídricos, basado en la disponibilidad de recursos hídricos naturales y la asignación de dichos recursos a usos diversos, a uno centrado en la SH sobre la base de una gestión del ciclo del agua con la integración de aspectos de cambio climático, la combinación de infraestructura gris y SBN, aspectos institucionales de normativa y la asimilación de hallazgos recientes en el campo de la ciencia y la tecnología. También es un plan de trabajo deliberadamente multisectorial (nexo), enfocado en el acceso y el uso eficiente del agua en cantidad y calidad adecuadas y para varios sectores (p. ej., la producción agrícola, el suministro de agua potable y la generación de energía). Esta distinción es particularmente importante para la región de ALC, ya que los resultados del diagnóstico realizado en este documento (así como de muchos otros estudios) muestran que la región está relativamente bien dotada de recursos hídricos, por lo que la SH dependerá de la habilidad para gestionar el ciclo del agua de forma sostenible, y adaptable a un conjunto amplio y variado de condiciones físicas (p. ej., el cambio climático), sociales (p. ej., la población y el cambio de uso de la tierra) y económicas (p. ej., el desarrollo y las políticas públicas).

Como hemos visto, la SH encapsula desafíos complejos e interconectados. Este trabajo destaca la importancia del agua para avanzar regionalmente en materia de seguridad (hídrica, energética, alimentaria), sostenibilidad, desarrollo y bienestar humano. Son muchos los factores que contribuyen a la SH: desde los biofísicos a los infraestructurales, pasando por los institucionales, políticos, sociales y financieros, muchos de los cuales están fuera del espacio del sector hídrico. En este sentido, la SH se encuentra en la intersección de muchas otras áreas de importancia para el desarrollo. Por ejemplo, la energía, los alimentos o el medio ambiente, cada una de las cuales está intrínsecamente vinculada al agua. Los enfoques de gestión y de inversión deben incorporar objetivos y metas relacionadas para alcanzar la $\mathrm{SH}$, y esto va a involucrar múltiples áreas de desarrollo prioritarias de interés apremiante: conflicto y fragilidad; la sostenibilidad ambiental, el crecimiento económico y el empleo, la salud, el hambre, los alimentos y la nutrición; inequidades; la energía, entre otros.

Los programas de inversión propuestos en este plan de trabajo para la SH tendrán impactos positivos medibles en la región en lo que respecta al desarrollo sostenible, con beneficios visibles a corto plazo. Este plan pretende hacer una contribución al trabajo analítico detrás de estas inversiones para los próximos años (tanto para el Banco como para sus clientes en la región de ALC).

Del mismo modo, para avanzar a niveles de SH consistentes con diferentes objetivos de desarrollo (p. ej. Agenda 2030), es necesario que este plan considere el grado de incertidumbre existente, derivado tanto de la variabilidad hidrológica y el cambio climático, como de los cambios socioeconómicos y 
políticos que se vislumbran en la región. Esto exige priorizar la formulación de políticas públicas, planes y programas de inversión robustos y adaptables, de manera que representen un avance efectivo en la $\mathrm{SH}$ considerando una amplia gama de escenarios futuros posibles.

Un aspecto importante que debe desarrollarse en más detalle para la implementación adecuada de este plan tiene que ver con los indicadores de progreso de la $\mathrm{SH}$ en la región. Una revisión de la literatura reciente en materia de indicadores de SH muestra que es un campo del conocimiento que se encuentra en estado incipiente a nivel mundial, y no está establecido aún a nivel regional, de país o de cuenca o acuífero. En los últimos años se han producido algunos esfuerzos sintetizadores en este sentido (Garrick y Hall, 2014; GWP, 2014 y, más recientemente, Hoekstra et al., 2018. En estos trabajos, los indicadores de $\mathrm{SH}$ se conciben desde la perspectiva de la gestión del riesgo, lo cual ha facilitado la definición de indicadores de seguimiento de riesgo por desastres, exposición y vulnerabilidad a eventos extremos. En este sentido, los indicadores de SH deben capturar la secuencia de inversiones en aspectos institucionales e infraestructura para reducir los riesgos relacionados con la $\mathrm{SH}$.

El desarrollo de indicadores de SH para actividades del BID y sus clientes debe compatibilizarse con otras iniciativas del Banco, regionales y nacionales, como el marco de infraestructura sostenible recientemente publicado por el BID (BID, 2018). Por ello, avanzar en el tema de SH requiere de la definición de indicadores de servicio y de riesgo aceptables y factibles para la región, así como también del establecimiento de una línea base comparativa (benchmark) entre países y con otras regiones del mundo, para cada una de las áreas geográficas y sectores de demanda del recurso hídrico, tomando en consideración que dichos niveles y riesgos variarán en función del desarrollo socioeconómico de los países y fenómenos como el cambio climático. También debe tenerse en cuenta que la SH tiene beneficios y costos asociados a estos niveles y riesgos y que, entre los diferentes requerimientos de $\mathrm{SH}$ en la región, existen diversas opciones de proyectos de inversión en el desarrollo de políticas e infraestructura, particularmente en un marco de recursos limitados. El desarrollo de tales indicadores es materia pendiente en la implementación de este plan de trabajo.

La implementación de este plan requerirá de apoyo a los países del BID en materia de gestión de cambio. Dado que la SH desafía los modos de gestión practicados en el sector hídrico tanto en la región como en otras partes del mundo, es importante entender que el mundo entero se encuentra en un proceso de aprendizaje sobre cómo poner en práctica, medir y gestionar la SH. Esto va a requerir de una serie de actividades de apoyo, como la generación de estudios de caso concretos, intercambios sur-sur para compartir lecciones aprendidas y mecanismos para incentivar los cambios necesarios en los marcos legales e institucionales. 
Este plan y el análisis que lo justifica pueden servir de insumo y contribuir al diálogo sobre SH entre el BID y los países en la región de América Latina y Caribe; también pueden contribuir a otros esfuerzos (por ejemplo, los relacionados con las NDC o los ODS) centrados en la sostenibilidad entre las múltiples actividades humanas y sus trayectorias hacia vías de desarrollo regional y global. A través de esta investigación y análisis, este plan de trabajo proporciona un conjunto integrado de programas de $\mathrm{SH}$ que incluyen consideraciones de cambio climático (mitigación y adaptación), desarrollos socioeconómicos y tecnológicos y la demanda hídrica para los sectores principales de demanda a nivel de país y dentro de un contexto regional y global.

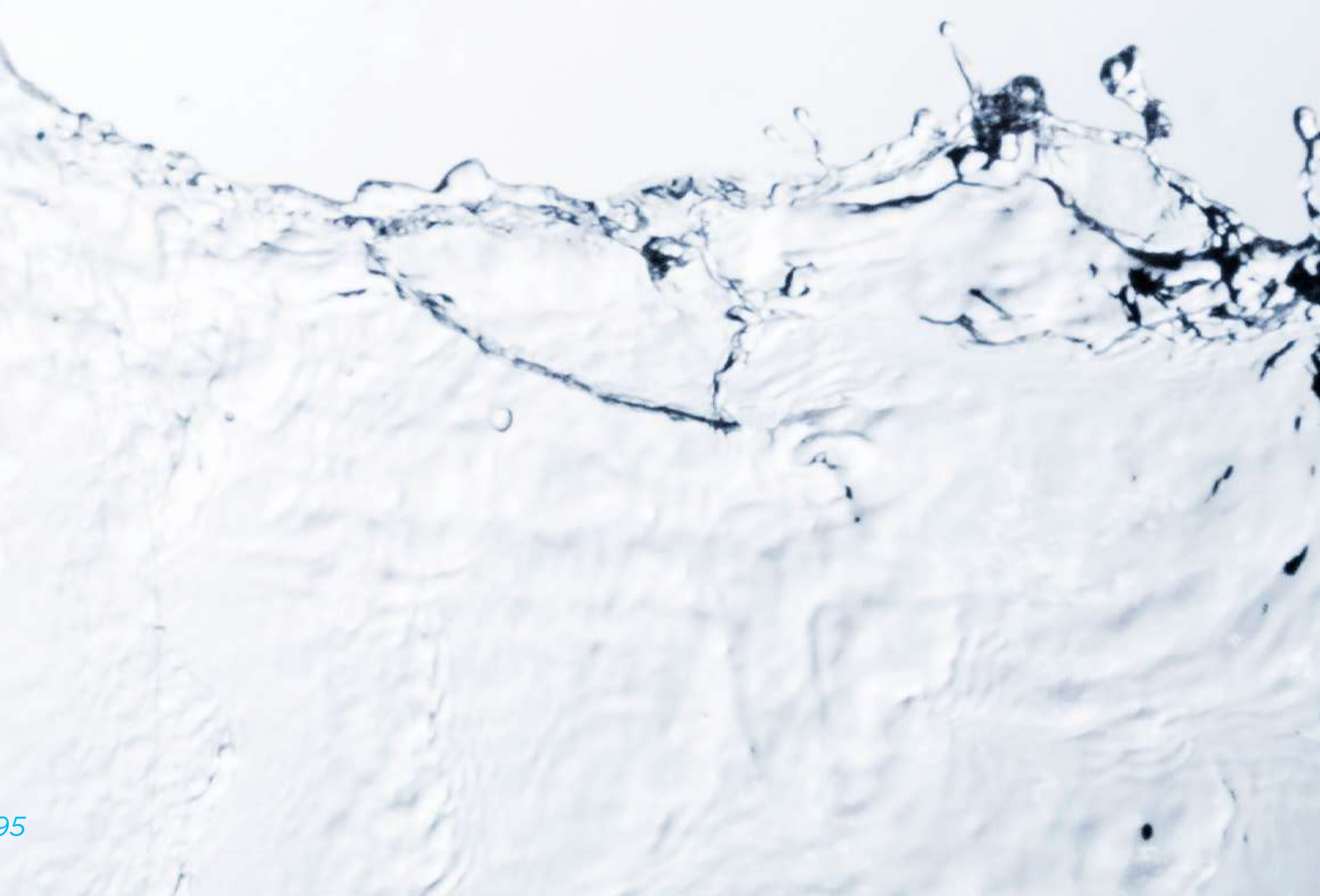




\section{Referencias Bibliográficas}

AAVV. (2018). Proceso regional de las Américas. Foro Mundial del Agua 2018. América Latina y el Caribe. Resumen ejecutivo, 18 pp.

AAVV. (2018). Proceso regional de las Américas. Foro Mundial del Agua 2018. América del Sur. Resumen ejecutivo, 19 pp.

AAVV. (2018). Proceso regional de las Américas. Foro Mundial del Agua 2018. Centroamérica. Resumen ejecutivo, $10 \mathrm{pp}$.

AAVV. (2018). Proceso regional de las Américas. Foro Mundial del Agua 2018. México. Resumen ejecutivo, 14 pp.

ACUMAR (Autoridad de la Cuenca Matanza Riachuelo). (2018). Buenos Aires, Argentina (http://www.acumar.gob.ar/).

Altomonte, H. y Sánchez R. J. (2016). Hacia una nueva gobernanza de los recursos naturales en América Latina y el Caribe, CEPAL, Santiago de Chile.

Andersson, E.P, S. Barthel, S. Borgstrom, J. Colding, T. Elmqvist, C. Folke y A. Gren. (2014). "Reconnecting Cities to the Biosphere: Stewardship of Green Infrastructure and Urban Ecosystem Services". Ambio, 43: 445-453.

Andersson, E.P., C.N. Jenkins, S. Heilpern, J.A. Maldonado-Ocampo, F.M. Carvajal-Vallejos, A.C. Encalada, J.F. Rivadeneira, M. Hidalgo, C.M. Canas, H. Ortega, N. Salcedo, M. Maldonado y P.A. Tedesco. (2018). "Fragmentation of Andes-to-Amazon Connectivity by Hydropower Dams". Science Advances, 4: eaao1642.

Arias, M.E. y M.T. Brown. (2009). "Feasibility of Using Constructed Treatment Wetlands for Municipal Wastewater Treatment in the Bogota Savannah, Columbia”. Ecological Engineering, 35:1070-1078.

Arreguín, F., López M., Ortega-Gaucín D., Ibáñez-Hernández O. (2016), "La política pública contra la sequía en México: avances, necesidades y perspectivas", Tecnología y Ciencias del Agua, vol. VII, núm. 5, septiembre-octubre, 2016, pp. 63-76.

Arroyo A. y Perdriel A., 2015, Gobernanza del gas natural no convencional para el desarrollo sostenible de América Latina y el Caribe. Experiencias generales y tendencias en la Argentina, el Brasil, Colombia y México. CEPAL, Santiago de Chile.

ASCE/AWWA. (2006). Guidelines for the Physical Security of Water Utilities. American Society of Civil Engineers y American Water Works Association. 
Banco Mundial. (2016). Water Security and Infrastructure for Development in Latin American and the Caribbean 2050. White Paper on Research Performed for the World Bank, $101 \mathrm{pp}$.

Banco Mundial. (1994). La ordenación de los recursos hídricos. Documento de política del Banco Mundial, Banco Mundial, Washington, 158 pp.

Banco Mundial. (2004). Water Resources Sector Strategy, Strategic Directions For World Bank Engagement.

Barberis, J., Armas, F. y Querol, M. (2002). Aplicación de los principios de Derecho Internacional en la administración de los ríos compartidos. Argentina con Paraguay y Uruguay, en A. Embid (ed.), El derecho de aguas en Iberoamérica y España: cambio y modernización en el inicio del tercer milenio, Civitas, Madrid.

Baruch-Mordo, S., J. Kiesecker, C. Kennedy, J. Oakleaf y J. Opperman, (2019). "From Paris to practice: sustainable implementation of renewable energy goals". Environmental research Letters, 14.

Bazilian, M., Rogner, H., Howells, M., Hermann, S., Arent, D., Gielen, D., Steduto, P., Mueller, A., Komor, P., Tol, R. S. J. y Yumkella, K. K., (2011). "Considering the Energy, Water and Food Nexus: Towards an Integrated Modelling Approach". Energy Policy 39(12): 7896-7906. doi: 10.1016/j.enpol.2011.09.039.

Bebbington, A. y M. Williams. (2008). "Water and Mining Conflicts in Peru". Mountain Research and Development 28 (3/4):190-195.

Bellfield, H. (2015). Water, Energy and Food Security Nexus in Latin America and the Caribbean. Trade-offs, Strategic Priorities and Entry Points, Global Canopy Programme.

Belmont, M. A., Ikonomou M. y Metcalfe, C. D. (2006). "Presence of Nonylphenol Ethoxylate Surfactants in a Watershed in Central Mexico and Removal from Domestic Sewage in a Treatment Plant". Environmental Toxicology and Chemistry 25(1):29-35.

Belmont, M. A., Cantellano E., Thompson, S., Williamson M., Sanchez A. y Metcalfe C. D. (2004). "Treatment of Domestic Wastewater in a Pilot-Scale Natural Treatment System in Central Mexico”. Ecological Engineering 23:299-311.

Benavides Vanegas, F. S y Ruiz López, C. E. (2016), "La minería ilegal y la reacción jurídica del Estado colombiano para su control”, en J. C. Henao y M. P. García Pachón (eds.), Minería y Desarrollo. Medio ambiente y Desarrollo sostenible en la actividad minera (pp. 437 y ss). Universidad Externado de Colombia, Bogotá. 
BID. (2012). Recursos hídricos y adaptación al cambio climático en América Latina y el Caribe: directrices estratégicas y líneas de acción propuestas, Nota Técnica № 478, Banco Interamericano de Desarrollo.

BID. (2018). What is Sustainable Infrastructure? A Framework to Guide Sustainability Across the Project Cycle, Nota Técnica №. IDB-TN-1388, Banco Interamericano de Desarrollo.

Bohoslavsky, J. P. (2010). Tratados de protección de las inversiones e implicaciones para la formulación de políticas públicas (especial referencia a los servicios de agua potable y saneamiento), CEPAL, Santiago de Chile.

Bustos Niño, V., García Pachón, M. P., Ortiz Rodríguez, C. (2016). Derecho de aguas y minería en Colombia, en J. C. Henao y M. P. García Pachón (eds.), Minería y Desarrollo. Medio ambiente y Desarrollo sostenible en la actividad minera (pp. 107 y ss.), Universidad Externado de Colombia, Bogotá.

Buytaert, W., Celleri R., De Bievre, B., Cisneros, F., Wyseure, G., Deckers J. y Hofstede, R. (2006). "Human Impact on the Hydrology of the Andean Paramos”. Earth-Science Reviews 79:53-72.

CADIS (Centro De Análisis de Ciclo de Vida y Diseño Sustentable). (2016). Huella de agua (ISO 14046) en América Latina, análisis y recomendaciones para una coherencia regional. CADIS.

Calderón, D. R. y Frey, K. (2017). "El ordenamiento territorial para la gestión del riesgo de desastres en Colombia”. Territorios, pp. 239-264. Doi: http:// dx.doi.org/10.12804/revistas.urosario.edu.co/territorios/a.4795

Cathala, C. Núñez A. M. y Ríos A. R. (2018). El agua en tiempos de sequía. Lecciones de cinco sequías alrededor del mundo, Resumen de políticas del BID: 295, Banco Interamericano de Desarrollo.

Centro de Ciencia del Clima y la Resiliencia (CR)2. (2015). La megasequía 2010-2015: una lección para el futuro, Informe a la Nación. Santiago de Chile. Recuperado de http://www.cr2.cl/megasequia/

CEPAL. (2017). Informe anual sobre el progreso y los desafíos regionales de la Agenda 2030 para el desarrollo sostenible en América Latina y el Caribe, Santiago de Chile.

CEPAL. (2018). Plan de Acción Regional para la implementación de la Nueva Agenda Urbana en América Latina y el Caribe. 2016-2036, Santiago de Chile.

CEPAL. (2018b). Segundo informe anual sobre el progreso y los desafíos regionales de la Agenda 2030 para el Desarrollo Sostenible en América Latina y el Caribe, Santiago de Chile. 
Chapaign A. K. y Hoekstra A. Y. (2004), Water Footprint and Nations, Value of Water Research Report, № 16, UNESCO-IHE.

Charveriat, C. (2000). Natural Disasters in Latin America and the Caribbean: an Overview of Risk. Banco Interamericano de Desarrollo. Washington, D.C.

Chevallier, P., Pouyaud, B. Suarez, W. y Condom, T. "Climate Change Threats to Environment in the Tropical Andes: Glaciers and Water Resources". Regional Environmental Change 11 (Suppl 1): S179-S187.

Comisión Europea. (2013), Infraestructura verde: mejora del capital natural de Europa, Bruselas 6.5.2013 COM (2013) 249 final.

COMIT. (1992). Aprovechamiento energético del Río Paraná. Documentos y tratados, Buenos Aires.

Crisman, T. L. (2014). Estimating Ecological Flow within the Kara Khota and Kullu Cachi Watersheds, La Paz, Bolivia. Banco Interamericano de Desarrollo, Washington, DC.

Daniels, A. E. y G. S. Cumming. (2008). "Conversion or Conservation? Understanding Wetland Change in Northwest Costa Rica". Ecological Applications 18 (1):49-63.

Dallas, S. Scheffe B. y Ho G. (2004). "Reedbeds for Greywater Treatment - A Case History in Santa Elena-Monteverde, Costa Rica, Central America”. Ecological Engineering, 23:55-61.

Da Silva, S., McJeon H., Miralles-Wilhelm F., Muñoz-Castillo, R., Clarke L., Delgado, A., Edmonds, J., Hejazi, M., Horing, J., Horowitz, R., Kyle, P., Link, R., Patel,P., y Turner, S. (2018). Energy-Water-Land Nexus in Latin America and the Caribbean, IDB Working Paper Series № IDB-WP-901.

Da Silva, J. L. y M.A. Vasconcelos, M. A. (2011). "Amazon and the Expansion of Hydropower in Brazil: Vulnerability, Impacts, and Possibilities for Adaptation to Global Climate Change". Renewable and Sustainable Energy Reviews 15:3165-3177.

Del Castillo, L. (2005). El régimen jurídico del Río de la Plata y su frente marítimo, Consejo Argentino para las Relaciones Internacionales, Buenos Aires.

Denny, P. (1997). "Implementation of Constructed Wetlands in Developing Countries”. Water Science and Technology 35 (5):27-34.

De Szoeke, S. M., Crisman, T. L. y Thurman, P. E. (2016). “Comparison of Macroinvertebrate Communities of Intermittent and Perennial Streams in the Dry Forest of Guanacaste, Costa Rica”. Ecohydrology, 9:659-672. 
Dickinson, M. A. (2018). "Why Efficiency Programmes are the Best Strategy for Water Security". International Water Association. Recuperado de https:// www.thesourcemagazine.org/efficiency-programmes-best-strategy-water-security/

Dieleman, H. (2014). "Urban Agriculture in Mexico City; Balancing Between Ecological, Economic, Social and Symbolic Value”. Journal of Cleaner Production, 83:1-4.

Dinerstein, E., Olson, D. M. Graham, D. J., Webster, A. L., Primm, S. A., Bookbinder, M. P., Ledec G. y World Wildlife Fund. (1995). A Conservation Assessment of the Terrestrial Ecoregions of Latin America and the Caribbean. World Bank, Washington D.C.

Dobbs, C., Escobedo, F. J., Clerici, N., De la Barrera, F., Eleuterio, A. A., MacGregor-Fors, I., Reyes-Paecke, S., Vásquez, A., Camaño J. D. Z. y Hernández H. J. (2018). "Urban Ecosystem Services in Latin America: Mismatch between Global Concepts and Regional Realities?” Urban Ecosystems. Recuperado en https://doi.org/10.1007/s11252-018-0805-3

Dourojeanni, A., Jouravlev, A. y Chávez, G. (2002), Gestión del agua a nivel de cuencas: teoría y práctica, Comisión Económica para América Latina y el Caribe (CEPAL), Santiago de Chile.

Ducci J. (2017). Temas críticos de la prestación de servicios de agua y saneamientos urbanos en América Latina: visión del BID”, en G. Delacámara, F. Lombardo Y J.C. Diez (coordinadores) Libro Blanco de la Economía del Agua (pp. 29 y ss.), McGraw-Hill/Interamericana de España S.L, Madrid.

Embid Irujo, A. (1991), La planificación hidrológica. Régimen Jurídico, Tecnos, Madrid.

Embid Irujo, A. (2013). El acuerdo sobre el sistema del acuífero Guaraní de dos de agosto de 2010 en el marco de la incipiente regulación general de las aguas subterráneas transfronterizas”, RADA 24, 2013, pp. 31-54 y también en las pp. 179-210, de Derecho de Aguas V, Universidad Externado de Colombia, Bogotá, 2013.

Embid Irujo, A., 2017, "Aproximación a una teoría general de las sequías e inundaciones como fenómenos hidrológicos extremos", RADA 37, 2017, ISSN 1695-2588.

Embid Irujo, A. y Embid Tello, A. E. (2017). "Fracturación hidráulica: entre la prohibición y la exigencia de evaluación ambiental. Evaluación de riesgos y moratoria aconsejable”, RADA 35, 2016. 
Embid Irujo, A. y Martín L. (2017a). La experiencia legislativa del decenio 2005-2015 en materia de aguas en América Latina, CEPAL, Santiago de Chile.

Embid Irujo, A. y Martín L. (2017b). El nexo entre el agua, la energía y la alimentación en América Latina y el Caribe. Planificación, marco normativo e identificación de interconexiones prioritarias, CEPAL, Santiago de Chile.

Embid Irujo, A. y Martín L. (2018). Lineamientos de políticas públicas. Un mejor manejo de las interrelaciones del Nexo entre el agua, la energía y la alimentación, CEPAL, Santiago de Chile.

FAO. (2010). Gestión del riesgo de sequía y otros eventos climáticos extremos en Chile, Santigo de Chile.

FAO. (2016). AQUASTAT Online Database. Food and Agriculture Organization, Rome.

FAO. (2011a). The State of the World's Land and Water Resources for FoodaAnd Agriculture (SOLAW) - ManagingSsystems at Risk. Food and Agriculture Organization of the United Nations, Rome and Earthscan, London. Recuperado en: http://www.fao.org/docrep/017/i1688e/i1688e.pdf

FAO (2011b). "Energy-Smart” Food for People and Climate - Issue paper. Food and Agriculture Organization of the United Nations, Rome. Recuperado en: http://www.fao.org/3/a-i2454e.pdf

FAO/UNESCO (2005): Groundwater in International Law. Compilation of Treaties and Other Legal Instruments, Roma.

Feng, Y., Burian S. y Pomeroy C. (2016). "Potential of Green Infrastructure to Restore Predevelopment Water Budget af a Semi-Arid Urban Catchment". Journal of Hydrology 542:744-755.

Ferrufino, C. y Grande, C. (2013). Tendencias del ordenamiento territorial en América Central y República Dominicana (2009-2012). San Salvador: Cooperación Alemana para el Desarrollo (GIZ).

Finer, M. y Jenkins C.N. (2012). "Proliferation of Hydroelectric Dams in the Andean Amazon and Implications for Andes-Amazon Connectivity", PloS One 7 (4): e35126.

Frid, C., Andonegi, E., Depestele, J., Judd, A., Rihan, D., Rogers S. I. y Kenchington, E. (2012). "The Environmental Interactions of Tidal and Wave Energy Generation Devices”. Enviromental Impact Assessment Review 32:133-139. 
Fundación Botín, (2014). Seguridad hídrica y alimentaria en América Latina y el Caribe. Implicaciones regionales y globales.

Garrick, D. y Hall, J. (2018). "Water Security and Society: Risks, Metrics and Pathways”. Annual Review Environmental Resources, 39:611-639.

Garzón, C., Sturzenegger, G. (2015). Los desafíos de la agenda de desarrollo post-2015 para el sector de agua y saneamiento en América Latina y el Caribe: conclusiones de la Semana Mundial del Agua 2015. Banco Interamericano de Desarrollo.

Garzón-López, C. (2017). Regional Platform for Water Resource Management-Final Evaluation. Banco Mundial.

Gause, M. (2008). Constructed Wetlands: a Promising Wastewater Treatment System for Small Localities. Experiences from Latin America. Water and Sanitation Program (WSP-LAC).

Génez Báez F. F. (2017). Sector eléctrico en Paraguay. Régimen jurídico. Tesis doctoral leída en la Universidad de Zaragoza el 20 de septiembre de 2017.

Gholizadeh M., Melesse A. y Reddi, L. (2016). "A comprehensive Review on Water Quality Parameters Estimation Using Remote Sensing Techniques”, Sensors 16, 1298; doi:10.3390/s16081298

Gobierno de Colombia. (2018). Plan Director Agua y Saneamiento Básico. Visión Estratégica 2018-2030, Bogotá D.C.

Gómez, C. M. (2017). La seguridad hídrica como envolvente, en G. Delacámara, F. Lombardo Y J.C. Diez (coordinadores) Libro Blanco de la Economía del Agua (pp. 5 y ss.), McGraw-Hill/Interamericana de España S.L, Madrid.

Gomez-Baggethun, E. y Barton D.N. (2013). "Classifying and Valuing Ecosystem Services for Urban Planning”. Ecological Economics 86:235-245.

Gonzales, F. T., Vallejos, G. G., Siveira, J. H., Franco, C. Q. Garia J. y Puigagut J. (2009). "Treatment of Swine Wastewater with Subsurface-Flow Constructed Wetlands in Yucatan, Mexico: Influence of Plant Species and Contact Time". Water SA 35(3):335-342.

Grau, H.R. y Aide M. (2008). "Globalization and Land-Use Transitions in Latin America”. Ecology and Society 13 (2) 16.

Grimm, A. M. y Saboia, J. P. (2015). "Interdecadal Variability of the South American Precipitation in the Monsoon Season". Journal of Climate 28: 755775. doi:10.1175/JCLI-D-14-00046.1 
Grimm, A. M. y Zilli, M. T. (2009). "Interannual Variability and Seasonal Evolution of Summer Monsoon Rainfall in South America". Journal of Climate 22: 2257-2275. doi:10.1175/2008JCLI2345.1

Guido, Z., McIntosh, J. C., Papuga S. A. y Meixner T. (2016). "Seasonal Glacial Meltwater Contributions to Surface Water in the Bolivian Andes: a Case Study Using Environmental Tracers". Journal of Hydrology: Regional Studies 8:260-273.

GWP. (2014). Assessing Water Security with Appropriate Indicators, Global Water Partnership.

GWP. (2013). La estrategia de GWP hacia el 2020: un mundo con seguridad hídrica, Global Water Partnership.

GWP/OECD. (2015). Securing Water Sustaining Growth. Informe del Grupo de Trabajo en Seguridad Hídrica y Desarrollo Sostenible. GWP/OECD.

Haberl, R. (1999). "Constructed Wetlands: a Chance to Solve Wastewater Problems in Developing Countries". Water Science and Technology 40 (3):11-17.

Harden, C.P. (2006). "Human Impacts on Headwater Fluvial Systems in The Northern and Central Andes". Geomorpholog 79:249-263.

Hasse, D., Larondelle, N., Andersson, E., Artmann, M., Borgstrom, S., Breuste, J., Gómez-Baggethun, J., Gren, A., Hamstead, Z., Hansen, R., Kabisch, N., Kremer, P., Langemeyer, J., Rall, E. L., McPhearson, T., Pauleit, S., Qureshi, S., Schwarz, N., Voigt, A., Wurster D. y Elmqvist, T. (2014). "A Quantitative Review of Urban Ecosystem Service Assessments: Concepts, Models and Implementation". Ambio 43:413-433.

Hashemi, S. S. G., Mahmud, H. B. y Ashraf, M. A. (2015). "Performance of Green Roofs with Respect to Water Quality and Reduction of Energy Consumption in Tropics: a Review". Renewable and Sustainable Energy Reviews 52:669-679.

Hoekstra, A. y Mekonnen M. (2011), "The Water Footpringt of Humanity", Proc. Nat. Acad. Sci. 109(9), 3232-3237.

Hoekstra, A., Buurman, J. y Van Ginkel, K. (2018), "Urban Water Security: a Review", Environ. Res. Lett. 13053002.

Hogeboom, R.J., Knook L. y Hoekstra A. Y. (2018). "The Blue Water Footprint of the World's Artificial Reservoirs for Hydroelectricity, Irrigation, Residential and Industrial Water Supply, Flood Protection, Fishing and Recreation". Advances in Water Resources 113:285-294. 
Hossain, F., Siddique-E-Akbor A. H., Mazumder, L. C., ShahNewaz S. M., Biancamaria, S., Lee, H. y Shum C. K. (2014). "Proof of Concept of an Altimeter-Based River Forecasting System for Transboundary Flow Inside Bangladesh". IEEE Journal of Selected Topics in Applied Earth Observations and Remote Sensing, 7, 587-601.

IEA. (2016). World Energy Outlook 2016. OECD/International Energy Agency, Paris.

IPCC (2014): Cambio Climático 2014. Impactos, adaptación y vulnerabilidad. Resumen para responsables de políticas. Contribución del Grupo de Trabajo II al Quinto Informe de Evaluación del Grupo Intergubernamental de Expertos sobre el Cambio Climático, Suiza.

IRENA (2015): Renewable Energy in the Water, Energy \& Food Nexus.

Jager, H. I. y Bevelhimer M. S. (2007). "How Run-Of-River Operation Affects Hydropower Generation”. Environmental Management 40:1004-1015.

Jia, Z., Wang, B., Song S. y Fan Y. (2014). "Blue Energy: Current Technologies for Sustainable Power Generation from Water Salinity Gradient”, Renewable and Sustainable Energy Reviews 31, 91-100.

Jiménez-Cisneros B. y Galizia Tundisi J. (coordinadores). (2012). Diagnóstico del agua en las américas, Foro Consultivo Científico y Tecnológico, AC, México.

Jiménez-Cisneros B. (2015). "Seguridad hídrica. Retos y respuestas, la fase VIII del Programa Hidrológico Internacional de la Unesco (2014-2021)”. AquaLAC, vol 7, nำ 1 .

Jiménez Cisneros, B. E., Oki, T., Arnell, N. W., Benito, G., Cogley, J. G., Döll, P., Jiang, T. y Mwakalila S. S. (2014). Freshwater resources. In: Climate Change 2014: Impacts, Adaptation, and Vulnerability. Part A: Global and Sectoral Aspects. Contribution of Working Group I/ to the Fifth Assessment Report of the Intergovernmental Panel on Climate Change [Field, C.B., V.R. Barros, D.J. Dokken, K.J. Mach, M.D. Mastrandrea, T.E. Bilir, M. Chatterjee, K.L. Ebi, Y.O. Estrada, R.C. Genova, B. Girma, E.S. Kissel, A.N. Levy, S. MacCracken, P.R. Mastrandrea, and L.L. White (eds.)]. Cambridge University Press, Cambridge, United Kingdom and New York, NY, USA, pp. 229-269.

Junk, W.J. Da Cunha, C. N. (2018). The Pantanal: a Brief Review of its Ecology, Biodiversity and Protection Status. En C.M. Finlayson, G.R. Milton, R.C. Prentice y N.C. Davidson (eds.). The Wetland Book (pp 798-811). Springer, New York. 
Junk, W. J., Bayley, P. B. y Sparks, R.E. (1989). The Flood Pulse Concept in River-Floodplain Systems. En D.P. Dodge (ed). Proceedings of the Large River Symposium (pp 110-127). Canadian Special Publication Fish and Aquatic Sciences 106.

Jouravlev, A. (2014). Los servicios de agua potable y saneamiento en el umbral del siglo XXI. CEPAL, Chile.

Kakuru, W., Turyahabwe, N. y Mugisha, J.. (2013). "Total Economic Value of Wetlands Products and Services in Uganda". The Scientific World Journal. Article ID 192656, 13 pages. http://dx.doi.org/10.1155/2013/192656.

Kaplan, D., Bachelin, M., Munoz-Carpena, R. y Chacon W. R. (2011). “Hydrological Importance and Water Quality Treatment Potential of a Small Freshwater Wetland in The Humid Tropics of Costa Rica". Wetlands 31:1117-1130.

Kisner, C. (2008). Green Roofs for Urban Food Security and Environmental Sustainability. Climate Institute http://climate.org/topics/international-action/urban-agriculture.htm

Kivaisi, A. K. (2001). "The Potential for Constructed Wetlands for Wastewater Treatment and Reuse in Developing Countries: a Review". Ecological Engineering 16:545-560.

Konar, D., Dalin, C., Suweis, S., Hanasaki, N., Rinaldo A. y Rodriguez-Iturbe, I. (2011). "Water for Food: the Global Virtual Water Trade Network", Water Resources Research 47, doi:10.1029/2010WR010307.

Leese M. y Meisch S. (2015). "Securitising Sustainability? Questioning the 'Water, Energy and Food-Security nexus'”, Water Alternatives 8 (1), pp. 695709.

Leopold, L. B., Wolman M. G. y Miller, J. P. (1964). Fluvial Processes in Geomorphology. Dover Press. New York

Lo, M. H., Famiglietti, J., Reager, J. T., Rodell, M., Swenson, S. y Wu, W. Y. (2016), "GRACE- Based Estimates of Global Groundwater Depletion, in Terrestrial Water Cycle and Climate Change: Natural and Human-Induced Impacts”, Geophysical Monograph 221, AGU Geophysical Monograph Series, 252 pages.

Lovell, S. T. y Taylor, J. R. (2013). "Supplying Urban Ecosystem Services Through Multifunctional Green Infrastructure in the United States". Landscape Ecology 28:1447-1463. 
Luederitz, C., Brink, E., Gralla, F., Hermelingmeier, V., Meyer, M., Niven, L., Panzer, L., Partelow, S., Rau, A. L, Sasaki, R., Abson, D. J., Lang, D. J., Wamsler C. y Von Wherden H. (2015). "A Review of Urban Ecosystem Services: Six Key Challenges for Future Research". Ecosystem Services 14:98-112.

Lundy, L. y Wade, R. (2011). "Integrating Sciences to Sustain Urban Ecosystem Services”. Progress in Physical Geography 35 (5):653-669.

Machado, I. F. y De M. Figueiroa, S. F. (2001). "500 years of mining in Brazil: a brief review". Resources Policy 27:9-24.

Magrin, G. O., Marengo, J. A., Boulanger, J. P., Buckeridge, M. S., Castellanos, E., Poveda, G., Scarano F. R. y Vicuña, S. (2014): Central and South America. En Climate Change 2014: Impacts, Adaptation, and Vulnerability. Part B: Regional Aspects. Contribution of Working Group II to the Fifth Assessment Report of the Intergovernmental Panel on Climate Change [Barros, V. R., C. B. Field, D. J. Dokken, M. D. Mastrandrea, K. J. Mach, T. E. Bilir, M. Chatterjee, K. L. Ebi, Y. O. Estrada, R. C. Genova, B. Girma, E. S. Kissel, A. N. Levy, S. MacCracken, P. R. Mastrandrea y L. L. White (eds.)]. Cambridge University Press, Cambridge, United Kingdom y Nueva York, NY, USA, pp. 1499-1566.

Malm, O., Pfeiffer, W. C. Souza C. M. M. y Reuther R. (1990). "Mercury Pollution Due to Gold Mining in the Madeira River Basin, Brazil”. Ambo 19 (1):11-20.

Manyari, W. V. y De Carvalho Jr., O. A. (2007). "Environmental Considerations in Energy Planning for the Amazon Region: Downstream Effects of Dams". Energy Policy: 6526-6534.

Martin, L. (2017). El futuro de los organismos de cuenca en Latinoamérica, en Antonio Embid (Ed.), El futuro de los organismos de cuenca, Cizur Menor.

Martin, L. y Justo, J. B. (2015). Análisis, prevención y resolución de conflictos por el agua en América Latina y el Caribe, CEPAL, Santiago de Chile.

Martínez, R. (2017). "With Melting Glaciers and Mining, Bolivia's Water is Running Dangerously Low". GlobalPost. Recuperado en https://www.pri.org/ stories/2017-01-04/la-paz-short-water-bolivia-s-suffers-its-worst-drought25-years

Martinez-Cruz, P., Hernandez-Martinez, A., Soto-Castor, R., Esquivel Herrera A. y Rangel Levario, J. (2006). "Use of Constructed Wetlands for the Treatment of Water From an Experimental Channel at Xochimilco, Mexico". Hydrobiologica 16(3):211-219.

McPhearson, T., Andersson, E., Elmqvist T. y Frantzeskaki, N. (2015). "Resilience of and Through Urban Ecosystem Services". Ecosystem Services 12:152156. 
Milanez, B. y Puppim de Oliveira, J. A. (2013). Innovation for Sustainable Development in Artisanal Mining: Advances in a Cluster of Opal Mining in Brazil.

Millones, J. O. (1982). "Patterns of Land Use and Associated Environmental Problems of The Central Andes: An Integrated Summary”. Mountain Research and Development 2(1):49-61.

Ministerio de Agricultura y Riego de Perú. (2015). Plan Nacional de Recursos Hídricos.

Ministerio de Medio Ambiente y Agua de Bolivia. (2018). La sequía 2016-2017 en Bolivia y su repercusión en las ciudades capitales de La Paz-El Alto-Sucre-Oruro-Potosí. Evaluación de capacidades de gestión; impacto socioeconómico en las empresas prestadoras de servicio.

Miralles-Wilhelm, F. (2014). "Desarrollo y aplicación de herramientas analíticas a la planificación trinómica agua-alimentos-energía en América Latina y el Caribe", Water Monographies, número 2.

Miralles-Wilhelm, F., (2016). "Development and Application of Integrative Modeling Tools in Support of Food-Energy-Water Nexus Planning-A Research Agenda”. J. Environ. Stud. Sci. 6(1): 3-10. doi:10.1007/s13412-016-0361-1

Miralles-Wilhelm, F. y Muñoz-Castillo, R. (2018). "An Analysis of the Water-Energy-Food Nexus in Latin America and the Caribbean Region: Identifying Synergies and Tradeoffs Through Integrated Assessment Modeling", Int. Jour. Eng. Sci. 7(1), 8-24.

Miralles-Wilhelm, F., Clarke L., Hejazi, M., Kim, S., Gustafson, K., Muñoz-Castillo, R. y Graham N. (2017). Physical Impacts of Climate Change on Water Resources, Banco Mundial, https://openknowledge.worldbank.org/handle/10986/26028.

Mitsch, W. J., Tejada, J., Nahlik, A., Kohlmann, B., Bernal B. y Hernández, C. E. (2008). "Tropical Wetlands for Climate Change Research, Water Quality Management and Conservation Education on a University Campus in Costa Rica". Ecological Engineering 34:276-288.

Mitsch, W. J. y Day Jr., J. W. (2006). "Restoration of wetlands in the Mississippi-Ohio-Missouri (MOM) River Basin: Experience and Needed Research". Ecological Engineering 26:55-69.

Mo, K. C. y Schemm, J. E. (2008). "Droughts and Persistent Wet Spells over the United States and Mexico". Journal of Climate 21: 980994. doi:10.1175/2007JCLI1616.1 
Motesharrei, S., Rivas, J., Kalnay, E., Asrar, G., Busalacchi, A., Cahalan, R., Cane, M., Colwell, R., Feng, K., Franklin, R., Hubacek, K., Miralles-Wilhelm, F., Miyoshi, T., Ruth, M., Sagdeev, R., Shirmohammadi, A., Shukla, J., Srebric, J., Yakovenko, V. y Zeng, N. (2016). "Modeling Sustainability: Population, Inequality, Consumption, and Bidirectional Coupling of the Earth and Human Systems", National Science Review, 3(4), 470-494.

Muñoz-Castillo, R. y Miralles-Wilhelm F. (2018). A CLEWS Nexus Modeling Approach to Assess Water Security Trajectories and Infrastructure Needs in Latin America and the Caribbean, Working Paper, BID.

Nadeau, T. L. y Rains, M. C. (2007). “Hydrological Connectivity Between Headwater Streams and Downstream Waters: How Science Can Inform Policy". Journal of the American Water Resources Association 43(1):118-133.

Nahlik, A. M. y Mitsch, W. J. (2006). "Tropical Treatment Wetlands Dominated by Free-Floating Macrophytes for Water Quality Improvements in Costa Rica”. Ecological Engineering 28:246-257.

Noyola, A., Padilla-Rivera, A., Morgan-Sagastume, J. M., Guereca L. P. y Hernandez-Padilla F. (2012). "Typology of Municipal Wastewater Treatment in Latin America”. Clean- Soil, Air, Water 40 (9):926-932.

OCDE. (2013). Water security for better lives: a summary for policy makers.

Olson, D. M., Dinerstein, E., Wikramanayake, E. D., Burgess, N. D., Powell, G. V. N., Underwood, E. C., D’Amico, J. A., Itoua, I., Strand, H. E., Morrison, J. C., Loucks, C. J., Allnut, T. F., Ricketts, T. H., Kura, Y., Lamoreux, J. F., Wettengel, W. W, Hedao P. y Kassem K. R. (2001). "Terrestrial Ecoregions of the World: a New Map of Life on Earth”. BioScience 51(11):933-938.

ONU (2017). Informe Mundial de las Naciones Unidas sobre el Desarrollo de los Recursos Hídricos, 2017. Aguas Residuales. El Recurso desaprovechado.

ONU-Agua. (2013). Analytical Brief on Water Security and the Global Water Agenda.

Ordóñez, J. E. B., Rodríguez, S. A. S., Pérez, M. L. Bracamonte, R. A. V., Angeles, F. R., Gilbert, A. G. y R. S. Navarro. (2015). National Water Reserves Program in Mexico: Experiences with Environmental Flows and the Allocation of Water for the Environment. Nota Técnica BID-TN-864. Water and Sanitation Division. Banco Interamericano de Desarrollo.

Orsini, F., Morbello, M., Fecondini M. y Gianquinto, G. (2010). Hydroponic Gardens: Undertaking Malnutrition and Poverty Through Vegetable Production in the Suburbs of Lima, Peru. En G. Prosdocimi Gianquinto y F. Orsini (eds.). Proceedings $2^{\text {nd }}$ International Conference on Landscape and Urban Horticulture (pp 173-178). Acta Hort 881 ISHS2010. 
Oyarzun, J., Maturana, H., Paulo A. y Pasieczna, A. (2003). "Heavy Metals in Stream Sediments from the Coquimo Region (Chile): Effects of Sustained Mining and Natural Processes in a Semi-Arid Andean Basin". Mine Water and Environment 22 (3):155-161.

Oyarzun, R., Guevara, S., Oyarzun, J., Lillo, J., Maturana H. e Higueras P. (2006). "The As-Contaminated Elqui River Basin: a Long-Lasting Perspective (1975-1995) Covering the Initiation and Development of Au-Cu-As Mining in the High Andes of Northern Chile". Environmental Geochemistry and Health 28 (5):431-443.

Passos Gomes, V. y Delgado Piqueras, F. (2016), "The role of the Amazon Cooperation Treaty for Shared Water Management”, Actualidad Jurídica Ambiental, 53.

Pedersen, S. F. (2015). Introduction to the Quinoa Dilemma. $8^{\text {th }}$ Nordic Latin American Research Network Conference. Helsinki, Finland.

Peña, H. (2016). Desafíos de la seguridad hídrica en América Latina y el Caribe. Serie Recursos Naturales e Infraestructura, CEPAL.

Pérez-Carrera, A. y Fernández, A. (2010). Arsenic and Water Quality Challenges in South America, en G. Schneier-Madanes y M.-F. Courel (eds.), Water and Sustainability in Arid Regions, DOI 10.1007/978-90-481-2776-4_1, Springer Science+Business Media B.V.

Perrone, D. y Hornberger, G. (2014). "Water, Food, And Energy Security: Scrambling for Resources or Solutions?” WIRES Water, 1: 49-68. doi:10.1002/ wat2.1004.

Pfeiffer, W. C., Drude de Lacerda, L., Malm, O., Souza, C. M. M., Gloria da Silveira E. y W. R. Bastos. (1989). "Mercury concentrations in inland waters of gold-mining areas in Rondonia, Brazil". The Science of the Total Environment 87/88:233-240.

Phillips, O. L. et al. (2009). Drought Sensitivity of the Amazon Rainforest. Science 323:1344-1347.

Poff, N. L. y Matthews, J. H. (2013). "Environmental Flows in the Anthropocene: Past Progress and Future Prospects". Current Opinion in Environmental Sustainability 5:1-9.

Poff, N. L., Allan, J. D., Bain, M. B., Karr, J. R., Prestegaard, K. L., Richter, B., Sparks R. y Stromberg, J. (1997). "The Natural Flow Regime: A New Paradigm for Riverine Conservation and Restoration”. BioScience 47:769-784. 
Qiu, G-Y., Li, H-Y., Zhang, Q-T., Chen, W., Liang, X-J. y Li X-Z. (2013). “Effects of Evapotranspiration on Mitigation of Urban Temperature by Vegetation and Urban Agriculture". Journal of Integrative Agriculture 12 (8):1307-1315.

Rabatel, A., Francou, B., Soruco, A., Gomez, J., Cáceres, B., Ceballow, J. L., Basantes, R., Vuille, M., Sicart, J. E., Hugel, C., Scheel, M., Lejeune, Y., Arnaud, Y., Collet, M., Condom, T., Consoli, G., Favier, V., Jomelli, V., Galarraga, R., Ginot, P., Maisincho, L., Mendoza, J., Menegoz, M., Ramirez, E., Ribstein, P., Suarez, W., Villacís M. y Wagnon, P. (2013). "Current State of Glaciers in the Tropical Andes: A Multi-Century Perspective on Glacier Evolution and Climate Change". The Cryosphere 7:81-102.

República Argentina. (2017ª). Plan Nacional de Agua Potable y Saneamiento. Cobertura Universal y Sostenibilidad de los Servicios. Lineamientos y Principales acciones.

República Argentina. (2017b). Plan Nacional del Agua.

República de Panamá, Resolución de Gabinete nํ114, de 23 de agosto de 2016 que aprueba el Plan Nacional de Seguridad Hídrica y establece el Consejo Nacional de Agua y la Secretaría Técnica (y documento técnico como Plan Nacional de Seguridad Hídrica 2015-2050. Agua para todos, 2016, Ciudad de Panamá).

República Oriental del Uruguay. (2017). Decreto de 31 de julio de 2017 por el que se aprueba el Plan Nacional de Aguas.

Reynolds, K. (2002). "El tratamiento de las aguas residuales en Latinoamérica. Identificación del problema”. Agua Latinoamericana. Recuperado de http://www.agualatinoamerica.com/docs/PDF/DeLaLaveSepOct02.pdf.

Richter, B. D., Warner, A. T., Meyer J. L. y Lutz., K. (2006). "A Collaborative and Adaptive Process for Developing Environmental Flow Recommendations". River Research and Applications 22:297-318.

Ringler, C., Rosgrant, M. W. y Paisner, M. S. (2000). "Irrigation and Water Strategies in Latin America and the Caribbean: Challenges and Strategies". International Food Policy Research Institute, Washington, DC.

Ríos, D. A., Vélez, A .F. T., Pena, M. R. y Parra, C. A. M. (2009). "Changes of Flow Patterns in a Horizontal Subsurface Flow Constructed Wetland Treating Domestic Wastewater in Tropical Regions”. Ecological Engineering 35:274-280.

Rivera, F., Warren, A., Curds, C. R., Robles, E., Gutiérrez, A., Gallegos E. y Calderón, A. (1997). "The Application of the Root Zone Method for the Treatment and Reuse of High-Strength Abattoir Waste in Mexico". Water Science Technology 35(5)271-278. 
Rodell, M., Famiglietti, J. S., Wiese, D. N., Reager, J. T., Beaudoing, H. K., Landerer, F. W., y Lo., M.H. (2018). "Emerging Trends in Global Freshwater Availability”. Nature https://doi.org/10.1038/d41586-018-0123-1

Rodgher, S., De Azevedo, H., Ferrari, C. R., Roque, C. V., Ronqui, L. B., Burato de Campos B. y Nacimento, M. R. L. (2012). "Evaluation of Surface Water Quality in Aquatic Bodies under Influence of Uranium Mining (MG, Brazil)". Environmental Monitoring and Assessment. DOI 10.1007/s10661-012-2719-5.

Rodríguez, D., Bazilian, M., Delgado, A., Liden, R., Miralles-Wilhelm, F., Toman M. y Sohns, A. (2017). Modeling the Water-Energy Nexus: How Do Water Constraints Affect Energy Planning in South Africa? Banco Mundial, https:// openknowledge.worldbank.org/handle/10986/26255.

Rodríguez, D., Bazilian, M., Delgado, A. y Miralles-Wilhelm, F. (2018). Thirsty Energy: Modeling the Water-Energy Nexus in China (English). Washington, D.C. World Bank Group. http://documents.worldbank.org/curated/ en/817631521818240201/Thirsty-energy-modeling-the-water-energy-nexus-in-China.

Rosa, L. P., Dos Santos, M. A., Matvienko, B., Sikar, E., Lourenco, R. S. M. y Menezes, C. F. (2003). "Biogenic Gas Production from Major Amazon Reservoirs, Brazil”. Hydrological Processes 17:1443-1450.

Rowe, D. B. (2011). "Green Roofs as a Means of Pollution Abatement". Environmental Pollution 159 (8-9):2100-2110.

Russell, A. M., Gnanadesikan A. y Zaitchik, B. (2017). "Are the Central Andes Mountains a Warming Hot Spot?”. Journal of Climate 30:3589-3608.

Sadoff, C. y Muller, M. (2010). La gestión del agua, la seguridad hídrica y la adaptación al cambio climático: efectos anticipados y respuestas esenciales, Global Water Partnership.

Salati, E. y Rodrigues, N. S. (1982). "De Poluente a Nutriente, a Descoberta do Aguape”. Revista Brasileira da Tecnologia 13(3):37-42.

Salati, E., Salati, E. Jr. y Salati, E. (1999). "Wetland Projects Developed in Brazil”. Water Science Technology 40(3):19-25.

Salazar, L. F., Nobre, C. A. y Oyama, M. D. (2007). "Climate Change Consequences on the Biome Distribution in Tropical South America". Geophysical Research Letters 34: https://doi.org/10.1029/2007GL029695

Saleth, R. M.; Dinar, A. (2004). The Institutional Economics of Water, a Cross Country Analysis of Institutions and Performance, Banco Mundial. 
Saysel, A. K., Barlas, Y., Yenign, O. (2002). "Environmental Sustainability in an Agricultural Development Project: A System Dynamics Approach". Journal of Environmental Management 64 (2002), Nr. 3, S. 247-260. - URL http://www. sciencedirect.com/science/article/pii/S0301479701904888.

Schnitzler, W. H. (2012). "Urban Hydroponics for Green and Clean Cities and for Food Security”. International Symposium on Soilless Cultivation. ISHAS Acta Horticulturae 1004. 10.17660/ActaHortic.2013.1004.1.

Simonovic, S. P. (2002). "World Water Dynamics: Global Modeling of Water Resources”. Journal of Environmental Management 66 (2002), Nr. 3, S. 249-267.

Solanes, M. (2015). Gobernanza y finanzas para la sostenibilidad del agua en América del Sur. Corporación Andina de Fomento.

Solanes, M. (2017), Institutional Arrangements, Efficiency, Equity and Sustainable Water Resources Management in Selected Countries of Latin American. No publicado, comunicación personal del autor.

Sosa, M. y Zwarteveen, M. (2012). "Exploring the Politics of Water Grabbing: the Case of Large Mining Operations in the Peruvian Andes". Water Alternatives 5 (2):360-375.

Stillwell, H. D. (1992). "Natural Hazards and Disasters in Latin America”. Natural Hazards 6:131-159.

Stovin, V. (2010). "The Potential of Green Roofs to Manage Urban Stormwater”. Water and Environment Journal 24:192-199.

Tellman, B., McDOnald, R., Goldstein, J., Vogl, A., Fiorke, M., Shemie, D., Dudley, R., Dryden, R., Petry, P., Karres, N., Vigerstol, K., Lehner, B. y Veiga, F. (2018). "Opportunities for Natural Infrastructure to Improve Urban Water Security in Latin America", PLoS ONE, 13(12): e0209470. https://doi.org/10.1371/ journal. pone.0209470.

TNC. (2018). Water Funds Field Guide. The Nature Conservancy.

Toro-Vélez, A. F., Madera-Parra, C. A., Pena-Varn, M. R., Lee, W. Y., Bezares-Cruz, J. C., Walker, W. S., Cárdenas-Henao, H., Quesada-Calderón, S., García-Hernández H. y Lens, P. N. L. (2016). "BPA and NP Removal from Municipal Wastewater by Tropical Horizontal Subsurface Constructed Wetlands". Science of the Total Environment 542:93-101. 
Tundisi, J. G., Goldemberg, J., Matsumura-Tundisi T. y Saraiva, A. C. F. (2014). “How Many More Dams in The Amazon?” Energy Policy 75:703-708.

Tundisi, J. G., Rocha, O., Matsumura-Tundisi T. Y Braga, B. (1998). "Reservoir Management in South America”. Water Resources Development 14 (2):141-155.

UNESCO. (2010). Atlas de Zonas Áridas de América Latina y el Caribe, dentro del marco del proyecto "Elaboración del Mapa de Zonas Áridas, Semiáridas y Subhúmedas de América Latina y el Caribe”. CAZALAC. Documentos Técnicos del PHI-LAC, N²5.

UNESCO. (2008). Marco legal e institucional en la gestión de los sistemas acuiferos transfronterizos en las Américas, Serie ISARM Américas No 2.

UNESCO. (2012). Managing Water under Uncertainty and Risk, Paris.

UNESCO. (2013). International Hydrological Programme (IHP) Eighth Phase: Water Security: Responses to Local, Regional and Global Challenges, (20142021).

United Nations. (2013). Water Security and the Global Water Agenda. United Nations University.

Van Beek, E. y Wouter Lincklaen, A. (2014). Water Security: Putting the Concept into Practice, Global Water Partnerschip, Elanders.

Vannote, R. L., Minshall, G. W., Cummins, K. W., Sedell, J. R. y Cushing, C. E. (1980). "The River Continuum Concept". Canadian Journal of Fisheries and Aquatic Sciences 37(1):130-137.

Varnell, C. J., Thawaba, S. y Brahana, J. V. (2009). Constructed Wetlands for Pre-Treatment of Drinking Water from Coal Mines. The Open Environmental Engineering Journal 2:1-3.

Vasallo Magro, J. M. (2015). Asociación Público Privada en América Latina. Aprendiendo de la experiencia. Bogotá: CAF.

Vásquez, J. E. (2014). "Transición del ordenamiento territorial y tratamiento del recurso hídrico: algunos determinantes desde el caso de Medellín”. CES Derecho, 5 (1), pp. 165-180.

Verzijl, A. y Quispe, S. G. (2013). "The System Nobody Sees: Irrigated Wetland Management and Alpaca Herding in the Peruvian Andes". Mountain Research and Development 33 (3)280-293. 
Vymazal, J. (2011). "Constructed Wetlands for Wastewater Treatment: Five Decades of Experience”. Environmental Science and Technology 45:61-69.

Ward, J. V. y Stanford, J. A. (1983). The Serial Discontinuity Concept of Lotic Ecosystems. En T.D. Fontaine y S.M. Bartell (eds.). Dynamics of Lotic Ecosystems (pp 29-42). Ann Arbor Scientific Publishers, Ann Arbor, MI.

Whitney, D., Rossman, A. y Hayden, N. (2003). "Evaluating an Existing Subsurface Flow Constructed Wetland in Akumal, Mexico". Ecological Engineering 20:105-111.

Wilk, D. y Altafin, I. (2018). Innovaciones en el desarrollo e implementación de humedales construídos para el tratamiento de aguas residuales. Parte II: análisis de la implantación de humedales construidos para el tratamiento de aguas residuales en Latinoamérica y el Caribe. Banco Interamericano de Desarrollo.

Willaarts, B., Garrido, A. y Llamas, R. (eds). (2014). Water for Food Security and Well-Being in Latin American and the Caribbean, Earthscan Studies y Water Resource Management, Routledge.

Winz, I., Brierley, G., Trowsdale, S. (2009). "The Use of System Dynamics Simulation in Water Resources Management". Water Resources Management 23 (2009), Mai, Nr. 7, S. 1301-1323. - URL https://link.springer.com/ article/10.1007/s11269-008-9328-7

World Economic Forum. (2011). Water security. The water-food-energy-climate nexus, Island Press, Washington.

World Economic Forum. (2018). The Global Risks Report 2018, 13th edition, Geneva.

Wu, H., Adler, R. F., Tian, Y., Huffman, G. J., Li, H y Wang, J. (2014). "Real-Time Global Flood Estimation Using Satellite-Based Precipitation and a Coupled Land Surface and Routing Model", Water Resources. Res., 50, 2693.2717, doi:10.1002/2013WR014710.

WWAP (Programa Mundial de Evaluación de los Recursos Hídricos de las Naciones Unidas)/ONU-Agua. (2017). Informe Mundial de las Naciones Unidas sobre el Desarrollo de los Recursos Hídricos 2017. Aguas residuales: el recurso desaprovechado, Paris, Unesco.

WWAP (Programa mundial de evaluación de los recursos hídricos de las Naciones Unidas)/ONU-Agua 2018: Informe Mundial de las Naciones Unidas sobre el Desarrollo de los Recursos Hídricos 2018: soluciones basadas en la naturaleza para la gestión del agua, París, Unesco. 
Yánez, L., Franco, P., Bastidas, W., Córdova, V. (2017). "Resumen del Plan Nacional de Gestión Integrada e integral de los Recursos Hídricos y de las cuencas y microcuencas hidrográficas de Ecuador", Aqua-LAC, vol. 9, ํㅜㄹ, pp. 124 y ss.

Zhang, D. Q., Jinadasa, K. B. S. N., Gersberg, R. M. y Liu, Y. (2014). “Application of Constructed Wetlands for Wastewater Treatment in Developing Countries - A Review of Recent Developments". Journal of Environmental Management 141:116-131.

Zi, W. y Ji, G. (2012). "Constructed Wetlands, 1991-2011: A Review of Research Development, Current Trends and Future Directions". Science of the Total Environment 441:19-27.

Zurita, F., DeAnda J. y Belmont, M. A. (2009). "Treatment of Domestic Wastewater and Production of Commercial Flowers in Vertical and Horizontal Subsurface-Flow Constructed Wetlands”. Ecological Engineering 35. 861-869.

Zurita, F., Roy, E. D. y White, J. R. (2012). "Municipal Wastewater Treatment in Mexico: Current Status and Opportunities for Employing Treatment Systems". Environmental Technology 33 (10):1151-1158.

Zurita, F., Belmont, M. A., DeAnda, J. y White, J. R. (2011). "Seeking a Way to Promote the Use of Constructed Wetlands for Domestic Wastewater Treatment in Developing Countries". Water Science and Technology 63(4):654-666. 


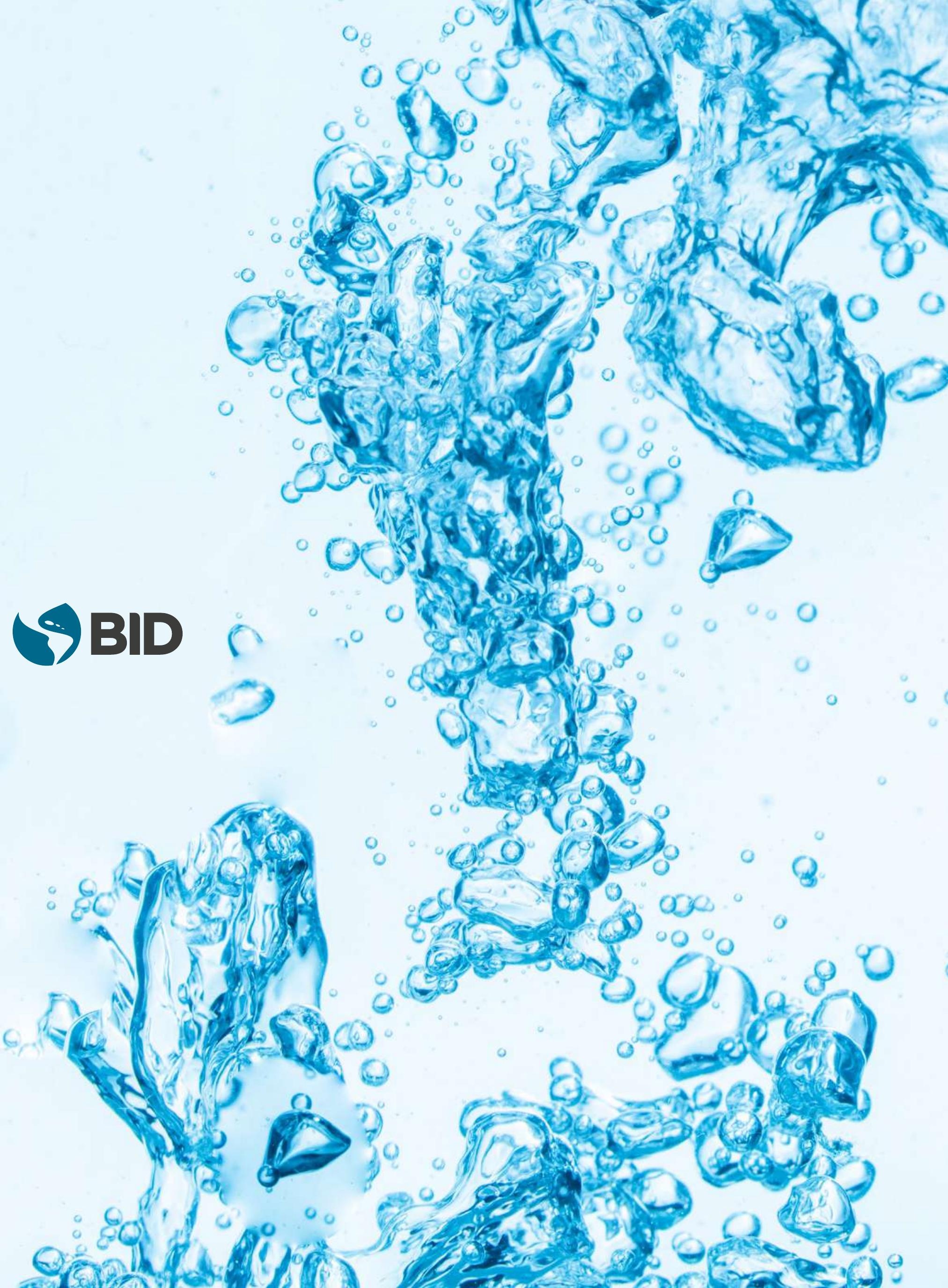

